\title{
Simulation Modeling of Prehospital Trauma Care
}

Robert L. Wears

University of North Florida

Follow this and additional works at: https://digitalcommons.unf.edu/etd

Part of the Computer Sciences Commons

\section{Suggested Citation}

Wears, Robert L., "Simulation Modeling of Prehospital Trauma Care" (1993). UNF Graduate Theses and Dissertations. 156.

https://digitalcommons.unf.edu/etd/156

This Master's Thesis is brought to you for free and open access by the Student Scholarship at UNF Digital Commons. It has been accepted for inclusion in UNF Graduate Theses and Dissertations by an authorized administrator of UNF Digital Commons. For more information, please contact Digital Projects.

(C) 1993 All Rights Reserved

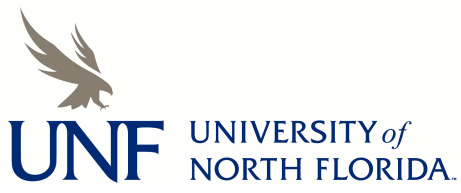


SIMULATION MODELING OF PREHOSPITAL TRAUMA CARE by

Robert L. Wears, MD

A thesis submitted to the Department of Computer and Information sciences in partial fulfillment of the requirements for the degree of

Master of Science in Computer and Information Sciences

UNIVERSITY OF NORTH FLORIDA

DEPARTMENT OF COMPUTER AND INFORMATION SCIENCES

April 30, 1993 
The thesis "Simulation Modeling of Prehospital Trauma Care" submitted by Robert L. Wears in partial fulfillment of the requirements for the degree of Master of Science in Computer and Information Sciences has been

Approved by the thesis committee: Date

Signature Deleted

Charles N. Winton

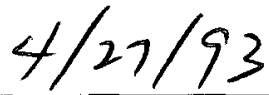

Thesis Adviser and Committee Chairperson

Signature Deleted

F. Layne wallace

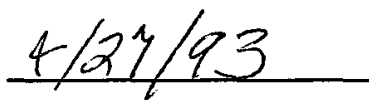

Signature Deleted

Susan R. Wallace

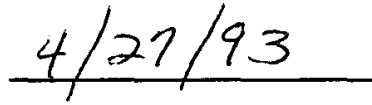

Accepted for the Department of Computer and Information Sciences :

Signature Deleted

Robert F. Roggio

Chairperson of the Department

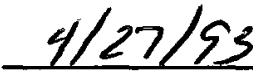

Accepted for the college of Computing Sciences and Engineering :

Signature Deleted

Robert F. Roggio

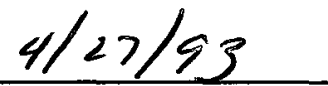

Dean of the College

Accepted for the University:

Signature Deleted
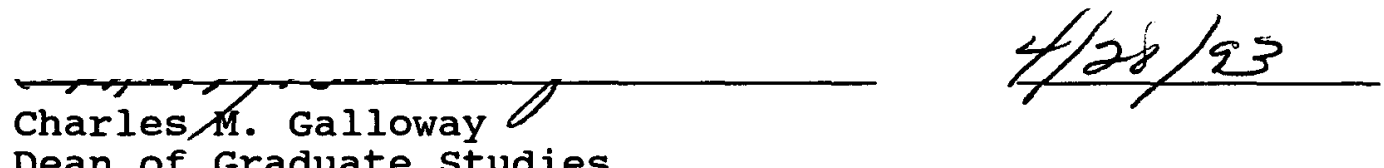

Dean of Graduate studies 
Acknowledgement/Dedication

I wish to thank my wife and family for their patience, understanding and support during my second postgraduate education. 
Table of contents

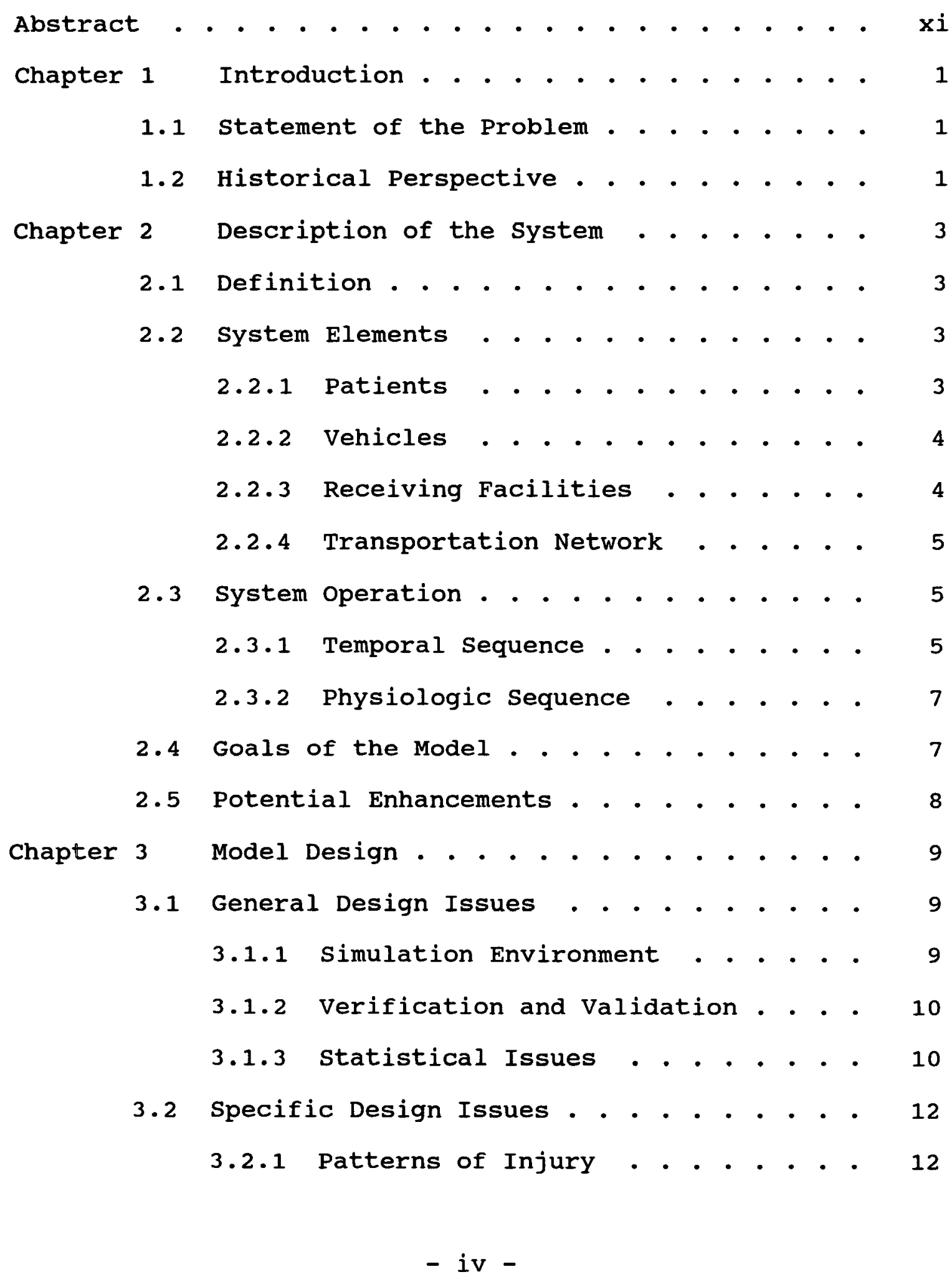


3.2.2 Transportation Network . . . . . 13

3.2.3 Edge Effects . . . . . . . . . 14

3.2.4 Ambulance Routing . . . . . . . 15

3.2.5 Physiologic Model • . . . . . 15

3.2.6 Injury Pattern . . . . . . . . 16

3.2.7 Critical outputs . . . . . . . 17

Chapter 4 Implementation . . . . . . . . . . . . 18

4.1 Overview . . . . . . . . . . . . . 18

4.2 Data structures . . . . . . . . . . 18

4.2.1 Permanent Entities ........ 20

4.2.2 Temporary Entities . . . . . . 23

4.3 Procedures . . . . . . . . . . . . 26

4.3.1 Initialization Procedures . . . . 27

4.3.2 Trace and Reporting
Procedures . . . . . . . 30

4.3.3 Modeling Procedures . . . . . . 31

4.3.4 Flow of Control . . . . . . . 37

4.4 Selection of Input Distributions . . . . 39

Chapter 5 Verification and Validation . . . . . . 43

5.1 Verification . . . . . . . . . . 43

5.1.1 Random variate generators . . . . 43

5.1.2 Static and Dynamic Analysis . . . 45

5.2 Validation . . . . . . . . . . . 49

Chapter 6 Demonstrative Experiments . . . . . . . 52

6.1 Triage Policy . . . . . . . . . . 52

6.2 Helicopter Dispatch Policy . . . . . . 55

6.3 Conclusion . . . . . . . . . . . 56 
6.4 Further Work . . . . . . . . . . 56

References . . . . . . . . . . . . . . . . 58

Appendix 1 Program Source Code . . . . . . . . . . 62

Appendix 2 Data Cross-Reference . . . . . . . . . 119

Appendix 3 Data Files . . . . . . . . . . . . . 151

Appendix 4 Sample Output . . . . . . . . . . . . 160

Appendix 5 Fitting Input Distributions . . . . . . . 173

Appendix $6 \quad$ Log of Model Assumptions . . . . . . . . . 183

6.1 Distribution of Accidents . . . . . . . 183

6.2 Definitive Care Survival . . . . . . 183

6.3 Private Travel . . . . . . . . . 183

Appendix 7 Log of Improvements and Enhancements . . 185

7.1 Improvements . . . . . . . . . . . . . . 185

7.1.1 Transit time . . . . . . . . . 185

7.1.2 Choke points . . . . . . . 185

7.1.3 Events . . . . . . . . . . . 185

7.1.4 End-of-run ............ 186

7.1.5 Memory management . . . . . . 186

7.2 Enhancements . . . . . . . . . . . . 186

7.2.1 Non-trauma patients . . . . . . 186

7.2.2 Injury model . . . . . . . . . 187

7.2.3 Transfers............ 187

7.2.4 Data editor .......... . 187

7.2.5 Graphical output . . . . . . . 188

7.2.6 Trace control . . . . . . . . 188

7.2.7 Interruption . . . . . . . . 188

7.2.8 Non-regenerative Simulation . . . 189 
$\begin{aligned} \begin{array}{r}\text { Appendix } 8 \\ 8\end{array} & \text { Log of Program Bugs . . . . . . . . . . . } 190 \\ 8.1 & \text { Discrete-continuous Interaction . . . . . } 190 \\ 8.2 \text { Pended Accidents . . . . . . . . . . . . } & 190 \\ \text { Vita . . . . . . . . . . . . . . . . . . . . . . . . . } & 191\end{aligned}$ 
Figures

Figure 1. Logical model of the overall transportation network. (See Figure 3 for node acronymns). . . . . . . . . . . .

Figure 2. Logical model of the central region of the transportation network. (See 3 for node acronymns). . . . . . . . . . 20

Figure 3. Spatial distribution of trauma incidents in the study area. . . . . . . . . .

Figure 4. Proportion arrivals in 12 hour periods over one week, corresponding to data in

Table 2. . . . . . . . . . . . . 45

Figure 5. Histogram of 2500 variates from mygamma.f given arguments $1.5,1.5 . .$. . . . . 46

Figure 6. Probability plot of 2500 variates from mygamma.f given arguments $1.5,1.5 .$. .

Figure 7. Quantile plot comparing the model's transport times with those provided by campbell. . . . . . . . . . . .

Figure 8. Distribution given need to secure. . . . 173

Figure 9. Probability plot: exponential. . . . . . 173

Figure 10. Quantile plot: exponential. . . . . . 173

Figure 11. Probability plot: Weibull distribution. . 174

Figure 12. Quantile plot: Weibull(6.686, 1.412). . . 174

Figure 13. Probability plot: lognormal. . . . . . 174

Figure 14. Quantile plot: lognormal. . . . . . . 174

Figure 15. Distribution of time to patient. . . . . 175

Figure 16. Probability plot: exponential. . . . . . 175

Figure 17. Quantile plot: exponential. . . . . . 175 
Figure 18. Distribution of scene treatment time

(includes extrication if needed). . . . 176

Figure 19. Probability plot: Weibull. . . . . 176

Figure 20. Quantile plot: Weibull(11.023, 1.892). . 176

Figure 21. Probability plot: gamma(3). . . . . . 177

Figure 22. Quantile plot: gamma(3). . . . . . . 177

Figure 23. Weibull (dashed line) and gamma pdf's. . 177

Figure 24. Distribution of time to hospital. . . . . 178

Figure 25. Probability plot: Weibull. . . . . . 178

Figure 26. Quantile plot: Weibull(9.974, 2.242). . . 178

Figure 27. Probability plot: lognormal. . . . . 179

Figure 28. Quantile plot: lognormal. . . . . . 179

Figure 29. Probability plot: gamma(3). . . . . . 179

Figure 30. Quantile plot: gamma(3)........ 179

Figure 31. Distribution of time to release of

patient. . . . . . . . . . . 180

Figure 32. Probability plot: Weibull. . . . . . 180

Figure 33. Quantile plot: Weibull(2.718, 1.810). . 180

Figure 34. Probability plot: lognormal. . . . . . 181

Figure 35. Quantile plot: lognormal. . . . . . 181

Figure 36. Probability plot: gamma. . . . . . . 181

Figure 37. Quantile plot: gamma(1.5)........ 181

Figure 38. Probability plot: exponential. . . . . 182

Figure 39. Quantile plot: exponential. . . . . . 182 
Tables

Table 1. Random variables used in the model. . . . . 42

Table 2. Example data file of mean arrivals by interval for testing the nsp.f routine.

Table 3. Characteristics of Iss scores obtained by the model and those reported by Baker. . . .

Table 4. Portions of trace output demonstrating the manifestation of specific model design items in the implementation. . . . .

Table 5. Comparison of outcome estimates produced by the model with those estimated by Jacksonville Fire/Rescue. . . . . . .

Table 6. System performance (mean $\pm 95 \%$ confidence interval) under different trauma center triage criteria. . . . . . . . . .

Table 7. Convergence points including at least a full seven day cycle. . . . . . . . . .

Table 8. System performance (mean $\pm 95 \%$ confidence interval) under alternate helicopter dispatch criteria. . . . . . . . . . 
Abstract

Prehospital emergency care systems are complex and do not necessarily respond predictably to changes in management. A combined discrete-continuous simulation model focusing on trauma care was designed and implemented in SIMSCRIPT II.5 to allow prediction of the systems response to policy changes in terms of its effect on the system and on patient survival.

The utility of the completed model was demonstrated by the results of experiments on triage and helicopter dispatching policies. Experiments on current and two alternate triage policies showed that helicopter utilization is significantly increased by more liberal triage to Level 1 trauma centers, which was expected, but that the waiting time for pending accidents tended to decrease, an unexpected consequence. Experiments on helicopter dispatch policy showed that liberalization of the dispatch policy would have much greater consequences than would changing the triage criteria. Again, this result was unexpected and has received little attention from system planners and administrators, especially with respect to the degree of discussion and controversy surrounding triage criteria. 
Chapter 1

Introduction

\subsection{Statement of the Problem}

Prehospital care of the sick and injured has developed into a complex system in the last 30 years. Much of this development has been "bottom-up," driven by technological factors and the availability heuristic (any available tool will eventually be used). This has eventually led to considerable debate in the medical literature over the appropriate role of several treatment modalities routinely employed in many localities. Furthermore, as resource constraints and other external factors have stressed the system, the need for a systematic overview of the system has become apparent. This project will develop a simulation model of a prehospital trauma care system in order to provide a method by which the effect of modifications to the system can be estimated.

\subsection{Historical Perspective}

Since prehospital care systems form complex networks of interacting entities that are difficult to work with analytically, simulation has frequently been used as an aid in planning and organizing such systems. The majority of 
these simulations have concentrated on relatively static aspects of the system, such as the number and location of responders [Fitzsimmons82, Uyeno84], improvements in response or transport time, etc. [Valenzuela90]. This project will focus more on clinical issues which are more easily modified on a dynamic basis by changing clinical and administrative policies. 
Chapter 2

Description of the system

\subsection{Definition}

The system under consideration is the that portion of the pre-hospital emergency medical care system (EMS) which deals with injury in the seven county service area of northeast Florida and southeast Georgia. The EMS system is obviously impacted by non-traumatic illness as well, so the model must include some representation of their effects, but they will not be the focus of the model.

\subsection{System Elements}

The system can be decomposed into four fundamental elements: patients, vehicles, receiving facilities, and a transportation network over which vehicles move patients from sites of injury to or between receiving facilities.

2.2.1 Patients. Patients suffer injuries in a particular temporal and spatial distribution. Their occurrence is frequently not independent; for example, most automobile accidents involve two cars and therefore at least two patients. In addition, injuries occur in the two broad, nonexclusive categories of blunt and penetrating. Within these categories, patterns of correlated injuries exist; for 
example, brain injury is typically isolated in penetrating trauma, but typically associated with chest and abdominal injuries in blunt. Injuries differ in severity, which affects the probability of survival.

2.2.2 Vehicles. Vehicles in the system are helicopter ambulances, ground ambulances, and private conveyances. Helicopter ambulances are typically few and therefore subject to more stringent dispatching criteria than ground ambulances. The receiving facilities have a degree of control over the destination of ambulances, and receive prior notification of incoming ambulance patients, but benefit from neither with respect to patients arriving by private conveyances. Additionally, ambulance personnel may perform a limited number of therapeutic interventions prior to transporting the patient to a receiving facility. Ground ambulances and private conveyance are constrained to use the transportation network; helicopter ambulances generally travel faster and by line of sight, but are constrained by weather conditions and the need for a safe landing zone.

\subsubsection{Receiving Facilities. Receiving facilities in the} system are hospitals and other acute care facilities such as clinics or physicians' offices. Hospitals may be classified into Level 1, 2, or 3 trauma centers as defined by Florida statute. Alternatively, they may choose not to participate in the trauma center system; their actual capabilities typically do not change by virtue of this decision. 
Receiving facilities will perform initial resuscitation and evaluation of incoming patients, and then transfer them out of the system to definitive care.

2.2.4 Transportation Network. The transportation network consists of existing major roads, highways and bridges. A patient's transport time by ground conveyance is a function of the available path through the transportation network and the time of day. Geographic barriers such as the st. John's River are reflected in the transportation network. Because ambulances are most commonly directly managed by county governments, political boundaries also may affect transportation decisions. For example, in patients with relatively minor injuries, the target receiving facility may be chosen such that the path to it does not involve crossing a county or state line; these considerations are dropped in the face of severe injury.

\subsection{System Operation}

System operation consists of a temporal sequence of events running in parallel and interacting with a continuous pattern of physiological changes.

2.3.1 Temporal Sequence. A typical cycle begins with an injury-producing episode which generates one or more patients at a particular location and time with a given pattern and severity of injuries. The prehospital system is then activated and an ambulance dispatched to the location, 
typically on a proximity basis. The time from injury to arrival on scene is termed "activation time," and will be noted as $t_{a}$. Once on scene, EMS personnel may have to locate and/or extricate patients, and may perform some therapeutic services such as starting intravenous fluids, endotracheal intubation, etc. These maneuvers typically will extend the "on scene time" $\left(t_{s}\right)$. Their efficacy is a matter of some debate and could be an item of study in the simulation model.

once extrication, initial assessment, and initial therapy (if any) have been performed, the patient is transported to a receiving facility in "transport time" $\left(t_{t}\right)$. The means of choosing a receiving facility (e.g., nearest hospital, nearest hospital of a given level, etc.) has also provoked considerable debate, and will be examined in the simulation.

The receiving facility will perform initial resuscitation and evaluation and will then deliver the patient to definitive care (e.g., the operating room, admitted to the hospital, etc.) after "resuscitation time" $\left(t_{r}\right)$ and some additional waiting time $\left(t_{x}\right)$. Definitive care is considered to be outside the system. In some cases, the receiving facility may transfer the patient to another facility, repeating the transport and resuscitation stages of the cycle. 
2.3.2 Physiologic Sequence. During this process, the patient's physiological state will change depending on his injuries and the therapy received. Some patients will die before being delivered to definitive care; for those that do not, their probability of survival will be estimated from their injuries and their physiological state at the time of exit from the system [Wears90, Champion91]. Based on their major immediate physiologic effects, injuries can be categorized into three large groups: those producing blood loss; those interfering with respiratory exchange; and those affecting the central nervous system. The physiologic state in each of these deteriorates over time without intervention. Indirect evidence of the severity of injury in these categories is combined into a "trauma score" which is used by EMS personnel to make therapeutic and transportation decisions.

\subsection{Goals of the Model}

Any simulation model should be constructed to answer specific questions, rather than just show that a model can be constructed. This model will be designed to estimate the effects of changes in:

a. Triage criteria that determine the center to which a patient should be routed.

b. Number of trauma centers of specified level.

c. Criteria for helicopter transportation vs ground transportation. 
d. Divert policy (the circumstances and length of time during which a hospital may divert incoming cases to another facility).

e. Location of trauma centers.

These effects will be measured from two perspectives: from the point of view of the system (numbers of patients received, percent utilization, etc.) and from the point of view of the patient (length of time until definitive care, change in survival probability).

\subsection{Potential Enhancements}

While not an immediate goal of this project, the potential for enhancement of the model to handle additional questions will be kept in mind as a secondary goal. Such additional questions might include analysis of the system during periods of drastically increased demand and/or reduced capacity, as might occur during a natural or man-made disaster; extension of the model to handle non-traumatic medical conditions. Another secondary goal will be portability to other geographic areas without recompilation; thus to the extent it is practical, areaspecific information will be represented by data elements read in from a file, perhaps in a pre-computing step, rather than directly embedded in the program code. 


\section{Chapter 3}

Model Design

\subsection{General Design Issues}

General design issues for this project are those common to virtually all simulation models: selection of a simulation environment and the appropriate level of detail, verification of the implementation, validation of model, and the design and analysis of appropriate experiments.

3.1.1 Simulation Environment. The model was implemented in SIMSCRIPT II.5 (CACI Products, La Jolla, CA) for several reasons. SIMSCRIPT is available on a large number of computer systems and has wide general acceptance as a simulation language, thereby facilitating the potential portability of the model. The EMS model proper lends itself easily to discrete simulation, while the physiologic model is more naturally thought of as continuous; SIMSCRIPT provides support for simultaneous continuous and discrete simulation, thus facilitating modeling the interaction between these two components. And finally, local expertise and experience with SIMSCRIPT was available. 
3.1.2 Verification and Validation. Separate verification runs checking aspects of the model's logic have been performed and compared to specific test cases derived from available Trauma Registry data. Many of these verification runs were initially performed at the module level so that the desired (true) behavior of the model can be more easily predicted. An activity trace is produced by the model to aid in verification and validation.

The model was validated by checking its output against aggregate data on injury types, patterns of transportation and survival using published data and University Medical Center's local trauma registry. It is unfortunately the case that detailed data on the overall operation of the prehospital care system are not maintained; a modified Turing test may assist in further model validation. The current level of validation of the model is not considered sufficiently definitive for the model to be used in establishing policy. Further validation will require explicit collection of data from the system for comparison to model output.

3.1.3 Statistical Issues. Care has been taken to maintain synchronization of the random number streams when considering policy alternatives; this reduces the variance of the difference between policy alternatives, yielding an increase in statistical power and perhaps a reduction in computing time. 
The system under study does not possess well-defined starting and ending times. However, it is the case that the system as defined here does empty out from time to time'. Therefore, no warm-up period to eliminate the effect of start-up transients was used. Instead, the model is started empty and idle, and the regenerative method will be used to determine run lengths; i.e., a run will be ended when the system returns to the empty and idle state. It should be noted that this method of experimental design might not be desired when the goal is determining system performance under overload (mass casualty) situations; however, only the method of experimentation, not the actual model, would have to be changed.

The primary goal of the model is effect estimation, not hypothesis testing. statistical testing of the differences between model outputs under differing policies is complicated by the use of the regenerative method, since it cannot be guaranteed that parallel runs will always be directly comparable, even though every random component for each patient is guaranteed to be comparable. For example, individual runs might not necessarily have the same numbers of patients; in general, parallel runs will diverge and reconverge at unpredictable points. A naive direct

1 This does not make it a terminating simulation, because even though the system is empty of patients, the ending value of time for the first run is the beginning value of time for the second, and the time until the next accident is dependent on the current time [Law91]. 
comparison of alternatives as if they were independent will typically overestimate the variance of the difference in effect. To compare the alternatives properly, summary measures must be calculated at a point where the model has reconverged under each alternative.

\subsection{Specific Design Issues.}

Certain problems peculiar to this project arose in the development of the model, and were dealt with as follows.

3.2.1 Patterns of Injury. The spatial pattern of injury was assumed to be roughly proportional to population density. This has been shown to be the case in at least one major city [Zachariah92]. Zachariah also showed that the distribution of types of accidents (e.g., assault, auto accident, gun-shot wound, etc.) was to a large extent invariant across time and space; therefore these variables were assumed to be constant in the model.

The temporal pattern of injury was modeled by a nonstationary batch Poisson process, using the method of Chinlar [Çinlar75]. Raw data kindly provided by Zachariah (personal communication) was used to estimate the diurnal pattern of injury occurrence. Variation across days of the week was obtained from Baker92, and the two items combined to produce the weekly cycle of injury incidence used in the model. 
3.2.2 Transportation Network. The geographic area of interest was represented at a higher level than blocks or map coordinates by modeling the area as a digraph. Nodes in this graph represent certain critical areas, such as: neighborhoods or fire-rescue service areas from which requests for care arise; choke points -- areas such as bridges which transporters must traverse en route to their destination; and receivers, typically hospitals categorized according to Florida's trauma statute. Arcs in the digraph were assigned weights representing transport time across that arc; these weights may vary with time of day. While some information on average transport times is available from the Fire-Rescue system, information about the distribution of transport times is not. However, Campbell [Campbel192] has published detailed summary results of a variety of pre-hospital time intervals, and kindly agreed to provide his raw data for use in the project (personal communication). Therefore, distributions were fit to Campbell's data using quantile and probability plots, or occasionally using the method of moments.

Since there are extensive and highly functional mutual assistance agreements among the political jurisdictions in the study area, political boundaries have not been explicitly represented in this model. It would be possible, if desired, to represent political boundaries by placing an empirical penalty function on the pertinent arcs; such a 
penalty function should be greater for minor injuries and zero for major injuries.

3.2.3 Edge Effects. Only a finite area will be simulated, but resources located near the boundary of the simulated area might be called to service events occurring beyond the boundary; similarly, injuries occurring within the boundary might be managed at hospitals outside the boundary. Carter74 handled this problem by simulating those events at a lower level of detail. However, this merely moves the problem further away, although at a smaller cost than simply enlarging the simulated area. In the system under consideration here, the boundaries tend to fall at "watershed" lines, where events are rare, and very little boundary crossing occurs. For example, it is common for ambulances in St. John's county to respond to calls in Duval county or to transport patients into Duval county. It is very uncommon that they do so with respect to Flagler county, because of the population densities and pre-existing referral patterns. Therefore we will neglect edge effects in this model (although this assumption might be subjected to sensitivity analysis), save for judiciously choosing the boundaries of the simulated area to keep such effects to a minimum. In the current model, the Keystone Heights area of clay county was removed from consideration, since the flow of referral in that area tends to move towards stark and Gainesville, i.e., away from the center of the study system. 
For similar reasons, only the Kings Bay area in Georgia was included in the model.

3.2.4 Ambulance Routing. Average node to node times within the transportation network routes are precomputed and stored prior to a simulation run. These times are used to generate ambulance call lists for each node, and hospital destination lists for each node, and the basis of shortest expected travel time. The call and dispatch lists are saved in a file that can be edited to reflect special circumstances. Helicopter ambulances are assumed to be callable to any locations, and to alternate calls. The choice of helicopter vs ground ambulance is based on Trauma score and distance by current policy, and will be the subject of experimentation.

3.2.5 Physiologic Model. Each patient will be represented as a distinct entity within the model, as will resources such as ambulances, helicopters, and hospitals. A limited set of physiologic variables will be modeled for each patient; however, since detailed physiological modelling [Mazzoni88] is computationally intensive, this information will be kept to the minimum necessary to assess probability of survival at different times.

The model of hemorrhage developed by Wears and winton [Wears90] will be adapted for use in this project. This model can be easily extended to accommodate respiratory exchange as well. Direct CNS injury seems to be a distinct 
problem [Baxt87], which is synergistic with both hemorrhage and respiratory injury. It will be modeled as a "black box" process, whose main effect is to cause a downward adjustment in the probability of survival.

The three components of the physiologic model will be used to compute the Revised Trauma Score (RTS), [Champion81, Champion91], which, in conjunction with the Injury Severity Score [Baker74] or ISS, has achieved general acceptance in predicting survival. The RTS assigns each component of the physiologic model a value on a 0 to 4 scale. These scores may then be simply summed to form a 0 to 12 scale, but a weighted sum [Champion91] with a maximum total of 7.804 is thought to provide better prediction. A mapping between the hemorrhage component and these scores has already been developed in Wears90.

\subsubsection{Injury Pattern. Injuries occur in identifiable} patterns which a model should represent in order to achieve face validity. This would ideally require generation of categorical variables having a given correlation pattern. While many simulation models have assumed independence of variables, apparently successfully, there is are several instances [Law91] in which it has been shown that the failure to model correlation between variables substantially affected the results. Devroye [Devroye86] offers several plausible approaches towards the general problem of generating correlated random variates, although he does not 
specifically address this particular situation. Alternative approaches have been suggested by Johnson [Johnson87] . Unfortunately, the covariance structure of injury patterns has yet to be described quantitatively. Therefore, it was assumed that blunt and penetrating injuries had the same ISS distribution. Injuries were then modeled by assigning an IsS value (drawn from a scaled beta distribution fit to data from MacKenzie86], partitioning the total Iss among the three major categories of physiologic derangement as suggested in Baxt87 and MacKenzie86, and mapping those components to either direct physiologic variables (e.g., blood pressure) or to RTS components. The Revised Trauma Score values thus computed were validated by comparing their distribution to the distribution of TS reported by Champion81 and Morris86, with good agreement.

\subsubsection{Critical outputs. Certain critical variables were} used as the basis of comparison between policy alternatives. These included the dynamic proportion of utilization of trauma centers at each level. Since trauma centers typically must maintain excess capacity, an alternative measure of utilization, the proportion of time the center is at or over capacity, will also be tracked. other important outcome measures include the total time in the system, the mortality in each phase prior to definitive care, and the overall probability of survival following definitive care. 
Chapter 4

Implementation

\section{1 overview}

The model's realization in SIMSCRIPT is provided in detail in the Appendices. Appendix 1 contains the program code and Appendix 3 the data files used to instantiate the model. This chapter provides an overview of the entire implementation. The geographic area selected was modelled as a digraph as illustrated in Figure 1 and Figure 2 . (Routes in these Figures are shown with single lines for clarity only; inspection of the data files in Appendix 3 will confirm the implementation as a digraph). The spatial distribution of trauma incidents used in the model is illustrated in Figure 3, and roughly corresponds to population density in the target area. The remainder of the implementation can be divided into two major sections; data structures and procedures.

\subsection{Data structures}

A variety of SIMSCRIPT data structures were used to represent the various model elements. Two general principles were used in representing entities in the model. First, entities having a potential lifespan in the model greater than a typical run length were be represented as 


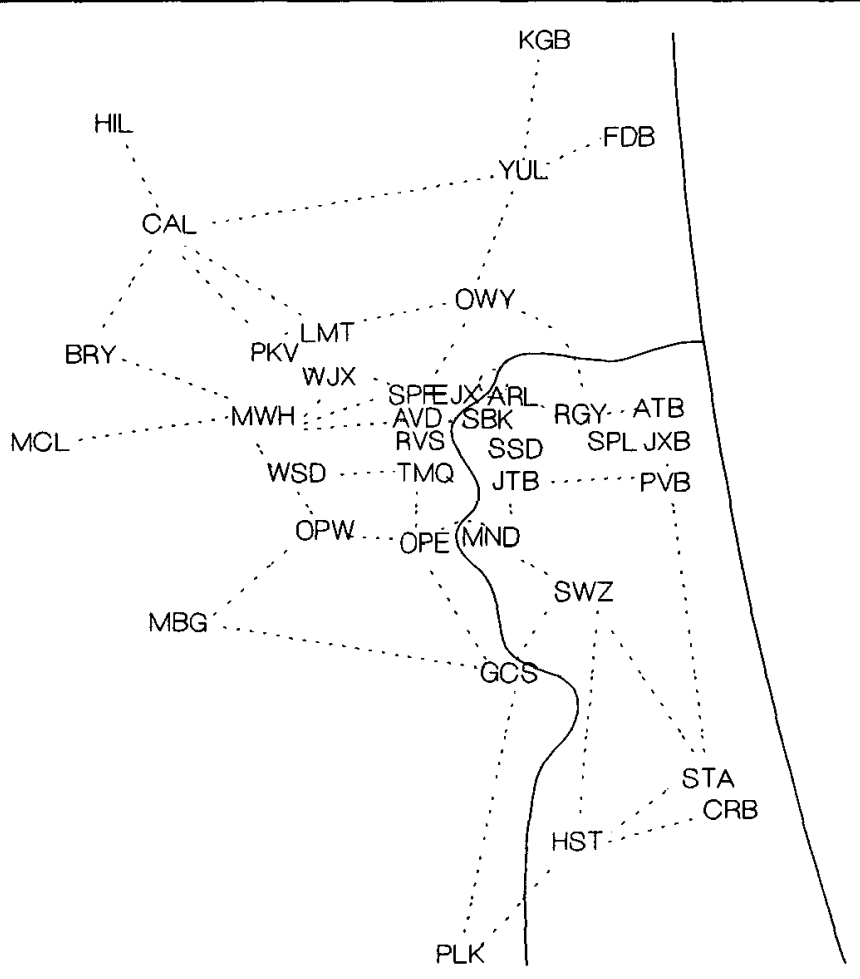

Figure 1. Logical model of the overall transportation network. (See Appendix 3 for node acronymns).

SIMSCRIPT permanent entities, while entities that potentially might "come and go" during the course of a run were represented as SIMSCRIPT temporary entities. Second, no entity should have greater knowledge about itself or about conditions in the system than its would its real-world analog. Application of these principles to the model entities described in 2.2 produced the following set of data structures (lines $39-256$ in the preamble, Appendix 1.)

4.2.1 Permanent Entities. The following structures are set up by the initialization code and exist throughout the entire simulation. 


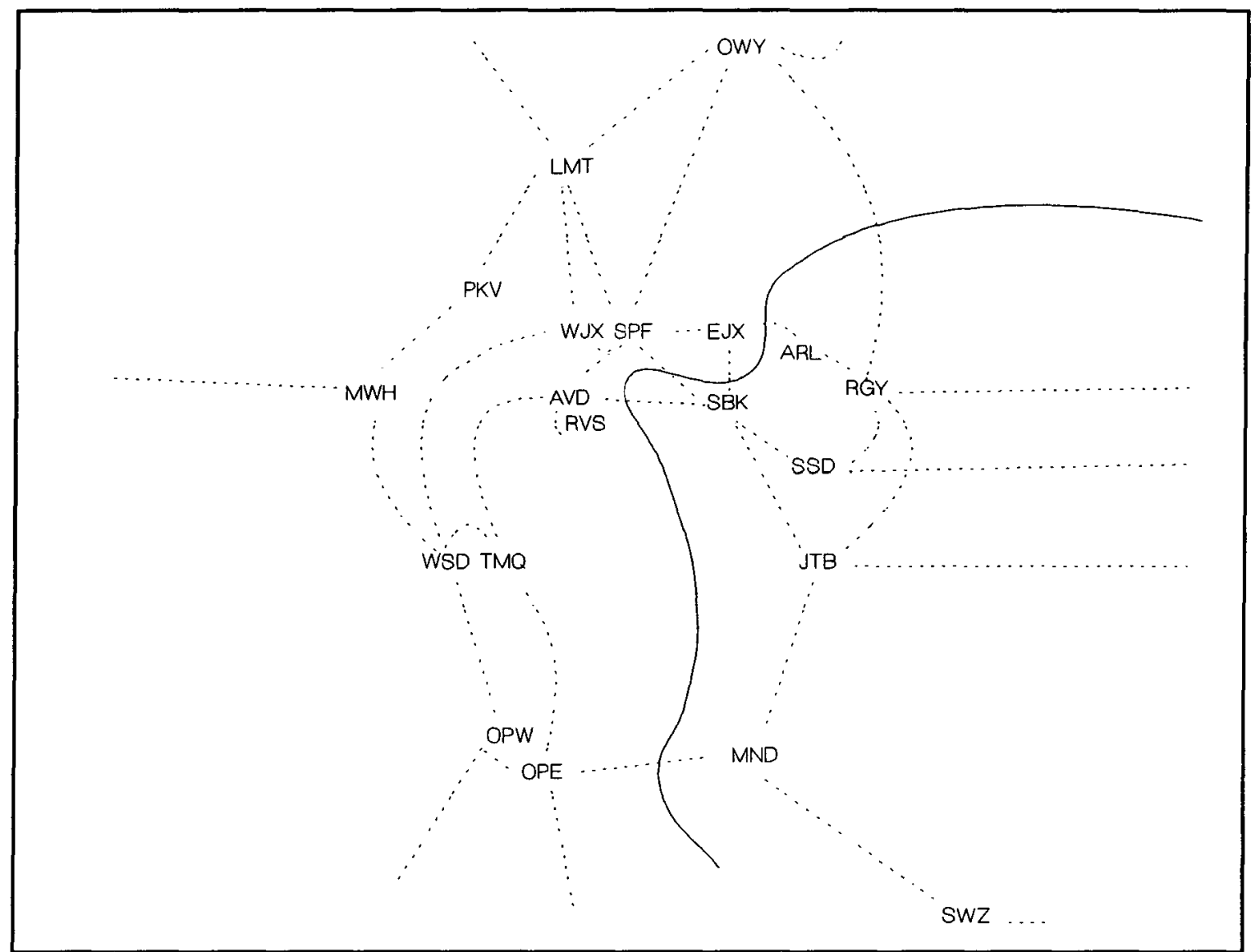

Figure 2. Logical model of the central region of the transportation network. (See Appendix 3 for node acronymns).

4.2.2 Nodes (lines $43-54$ ). Nodes in the transportation network represent areas in which accidents might arise. They are identified by location (latitude and longitude), and have an edge.set of arcs representing paths to and from other nodes. Additionally, nodes can own ambulances or hospitals if one is located in a node's area. Each node has a list of ambulances to call for events occurring in its area, and a list of hospitals to which patients will be transported from accidents occurring in the node. Nodes are 


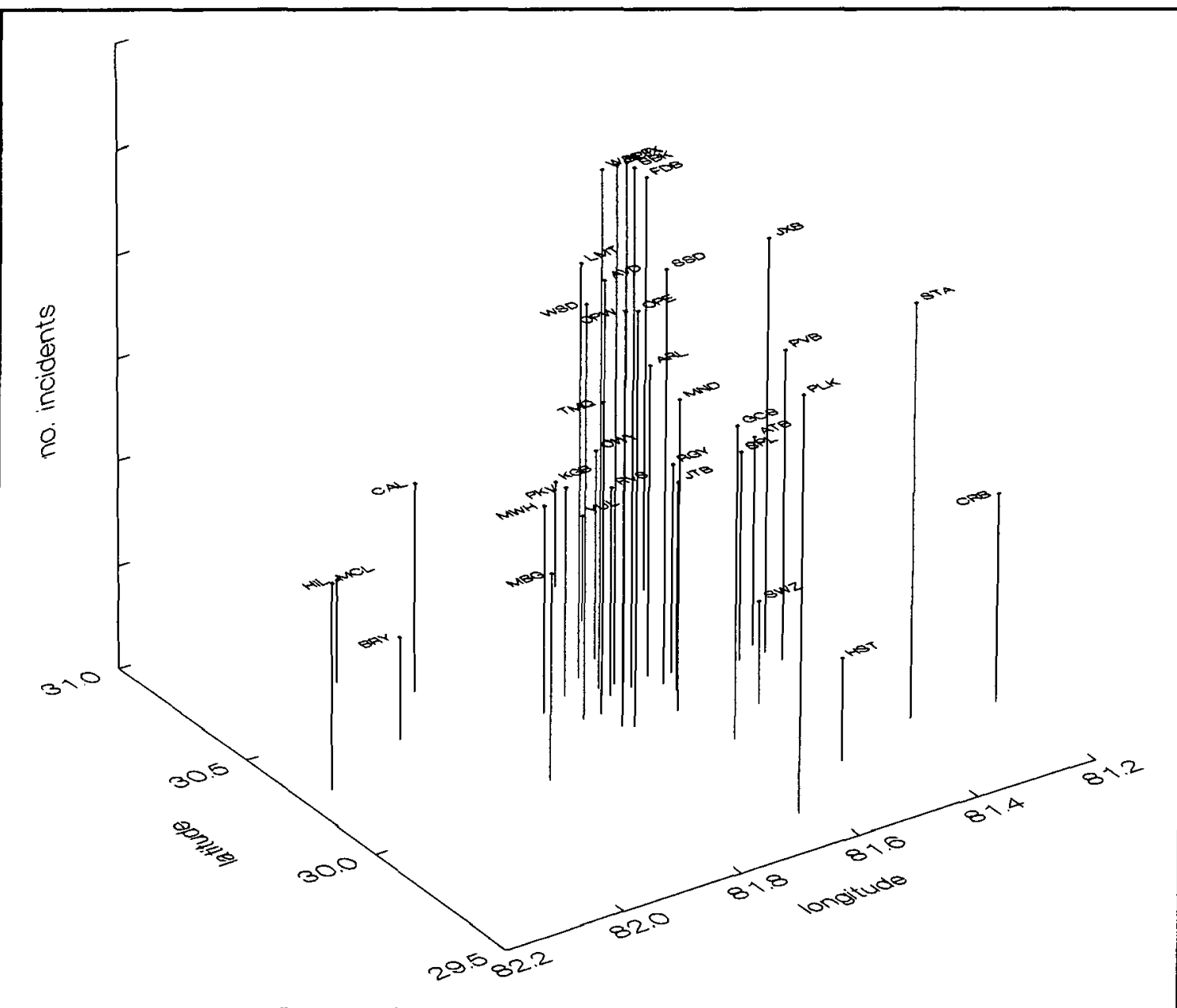

Figure 3. Spatial distribution of trauma incidents in the study area.

collected in sets so that nodes containing hospitals or ambulance bases may be easily identified.

4.2.2.1 Paths (lines 56 - 63). Every node - node pair is connected by a path in each direction. The path is held in the pair's route set, and consists of the sequence of arcs to be traversed in proceeding from one node to the other. Each path is associated with a mean transit time and a flight time. Unidirectional paths may be implemented by 
assigning them an essentially infinite travel time in the reverse direction.

4.2.2.2 Hospitals (lines $65-100)$. Each hospital in the system is assigned a level according to Florida Trauma Center designation standards. Hospitals also are assigned a capacity, based on the maximum number of active resuscitations they can handle, and a number of flags indicated whether they are allowed to divert, whether or not they have diverted in a given period, etc. Hospitals also track the number of patients they are currently resuscitating, and a variety of other statistical counters. Hospital divert status is represented by membership in a green (no divert) and a red (divert) set.

4.2.2.3 Ambulances (lines 102 - 117). Each ambulance has a type, indicating whether it is a ground or an air (helicopter) ambulance, and a base node. It also maintains a pointer to an ambulance run process (if any) representing an actual run, and has storage for its current location, although this attribute is not always guaranteed to be current. Ambulances belong to a variety of sets to track their activity, the most important being the ready.set. Membership in the ready.set indicates the ambulance is available to be called to an accident. This representation was chosen over SIMSCRIPT's built-in 'resource' entity since ambulances are not entirely interchangeable. 
4.2.3 Temporary Entities. The following structures may be created and destroyed as needed throughout the simulation. The procedures (if any) associated with temporary entities are discussed in section 4.3 .

4.2.3.1 Arcs (1ines 121 - 132). Arcs representing logical (not necessarily physical) routes of travel are implemented as temporary entities under the supposition that they could, at least in theory, come into and disappear from existence during the course of a simulation. Arc's are unidirectional and are identified by their source and sink nodes, and a weight representing the average travel time in minutes from the center of the source node to the center of the sink node. A choke weight is also available to represent the average additional delay that might be experience at a choke point. Cumulative weights are used in the calculation of best routes from node to node, but are not subsequently used during the simulation. Since an arc may not belong to more than one set of a given type in SIMSCRIPT, but a given arc may be part of many different routes, duplicate arcs are created, at some cost in storage space (see Appendix 7.1.5).

4.2.3.2 Dispatch lists (lines 134 - 143). Two dispatch lists are maintained by each node; a list of call.items (pointers to ambulances) to be called for incidents occurring in that node, and a list of go.items (pointers to hospitals) indicating destination hospitals for incidents occurring in a node. 
4.2.3.3 Ambulance runs (lines 148 - 165). An ambulance run is represented by a process that is created when the dispatcher assigns an ambulance to an accident, and ends when the ambulance returns to its base and is back in service. Ambulance runs are divided into two kinds, trauma and medical. An ambulance run is always associated with a particular ambulance, and has attributes for identifying the accident it is serving, the node from which it travels, and the node, hospital, and hospital's level to which it is bound. Two flags are maintained: status, to identify when a run ends in a recall, and helo.coming, to indicate when an ambulance should wait for the helicopter's arrival, even though it would otherwise be ready to travel (i.e., its scene.time is over). Ambulances keep track of the patients they manage on a run by filing them in the amb.patient.set.

\subsubsection{Patients (lines 167 - 213). Patients are} represented as processes created by accidents, and are destroyed when they either die or are transferred to definitive care. A patient's condition may be alive or dead; they move through several phases (e.g., awaiting treatment, scene treatment, transport, etc.), with phase changes being triggered by setting the change.flag. Physiologic information about a patient consists of the hemodynamic components of the Lewis model of hemorrhage [Lewis86] as modified by Wears and Winton [Wears90], extended to account for the impact of respiratory 
embarrassment on oxygen delivery. The patient's degree of injury is measured by the ISS. From the ISS and systolic blood pressure (sbp), the components of the revised Champions trauma score, and the score itself can be determined. A functional attribute, cts.f, allows the trauma score to be updated periodically to reflect the patient's changing condition. Finally, patient maintains a variety of time intervals of interest for reporting purposes.

4.2.3.5 Accidents (lines $216-235$ ). Accidents are represented as processes that are created by the generator and are destroyed when the last patient associated with an accident is removed from the accident site. Accidents are of two kinds, medical and trauma. In the current model, medical accidents are served by ambulances just as trauma accidents are; they create no patients but do constitute a demand on the system. Trauma accidents may create several patients, and may be blunt or not (i.e., penetrating). Both medical and trauma cases may be placed on a pending list if insufficient ambulances are available to meet their needs.

4.2.3.6 Events (lines $240-244$ ). Events were used to handle a hospital's going on and coming off of divert status. A hospital that places itself on divert status frequently must reopen to ambulances after a certain period of time, regardless of its status at that time. The event go.off.red is used to schedule this status change. In 
addition, many jurisdictions clear all their divert status once a day; the event clear.reds performs this function. Finally, the event resp.support is used to model the effect of therapeutic interventions assisting respiration and ventilation occurring in the course of scene treatment or resuscitation.

\subsection{Procedures}

The model has a natural structure that can be described as a collection of independent but communicating entities. This suggests that an object-oriented approach would have provided the most natural implementation. Since an objectoriented simulation environment was not available, a monitor process was used to handle interprocess communications. A natural monitor, the dispatcher, exists in the real-world system, so this approach meshed nicely with the target model. Interestingly, the monitor function was more easily provided as a procedure, rather than as a SIMSCRIPT entity. Thus the dispatcher is the only major real world entity that has only an implicit representation in the model.

In this implementation, procedures can be divided into three classes: initialization procedures, trace and reporting procedures, and the actual modeling procedures (with their supporting utility procedures). The individual procedures are described here; their relationship and the flow of control among the procedures is described in section 4.3.4. 
4.3.1 Initialization Procedures. The initialization procedures get system information from a set of files and create the data structures outlined in section 4.2 . They are not called again and in principle could be physically separated from the simulation code itself.

4.3.1.1 Main (lines 417 - 498). Main is the fundamental control routine in a SIMSCRIPT program. Main opens the output files and then calls the routine initialize (see 4.3.1.2). At this point, main could begin a loop for each arm of an experiment; this has been left for future implementation if desired. Next, important global variables such as time.v, nsp.tprime and nsp.last.time (used by the non-stationary Poisson routine nsp.f) are initialized to zero, and the run loop is entered. This loop resets all the runwise totals and schedules the next time for clearing hospital divert status, and then activates the generator process to start the simulation. Once a run is finished, runwise statistics are calculated and the run.report routine is called, and then the loop is re-executed until the requested number of runs has been obtained. The routine final.report is then called and the program terminates.

4.3.1.2 Initialize (Iines 2333 - 2365). Initialize gets data to characterize this instantiation of the model. It calls a series of initialization routines (get.table, get.sim, get.net, get.hosp, get.ems, get.accs) that read information from datafiles into model variables in a 
straightforward manner. In addition to simply reading in data on the transportation network, the routine get.net creates the digraph of nodes and arcs, and calculates mean transit times to all nodes in the system by calling the function best.route (see 4.3 .1 .5 ).

The ambulance call list and hospital preference list are either read from datafiles, if they exist, or are constructed (and written to datafiles for editing or future use) using default dispatching rules if they do not. This process is controlled by the routine get.list (lines 1853 1873), which is driven by its subprogram variable (SIMSCRIPT's term for pointer to function) arguments. The actual construction of the lists is performed by the routines build.call.list (see 4.3 .1 .3 ) and build.hosp.list (see 4.3.1.4). Before returning, the initialize calls the routine print.net to output the data it has read for verification of the model's initialization.

4.3.1.3 Build.call.list (lines 884 - 972). Build.call.list uses the internode transit times along the best path to construct for each node a list of ambulances to be called for incidents in that node, based on least travel time. The default rules governing ambulance selection are: helicopter ambulances will travel to all nodes; every node will have a minimum of min.amb ambulances on its list; ambulances are ranked on the list in order of closest travel time; and that travel times that are within a given proportion of each 
other (stored in the global variable atol) are presumed to be sufficiently equal that all such units will be placed on the list, even if the minimum number of ambulances is exceeded. This is necessary to handle ties in travel time, and to prevent the list from being unreasonably limited by small differences in travel time.

4.3.1.4 Build.hosp.list (lines 975 - 1069). Build.hosp.list constructs for each node a list of hospitals to which victims in that node will be sent. It is functionally similar to build.call.list (above), but handles the additional complication of maintaining a list for each trauma center level. The default rules here are analogous to those for build.call.list, except that every node must have at least one Level 1 center and at least one Level 2 center on its list. Again, as many hospitals whose travel times are with a given proportion (htol) of each other may be put on a list.

4.3.1.5 Best.route (lines $752-828$ ). The function best.route is given a source and a destination node as arguments and returns the shortest possible travel time between nodes using Prim's algorithm. If the path involves an arc identified as a choke point, the path is penalized by adding the choke point's weight (representing the mean additional travel time) to the regular weight. Once the best route has been determined, the routine build.route is called to file the ordered list of arcs in the route set 
owned by the from.node, to.node compound entity. Finally, since the calculated travel time has been based on internode transit times over arterial highways, the function adj.time.f is called to adjust for the time it typically takes to move from secondary and tertiary roads to major highways and back again, and this adjusted time is returned to the caller.

4.3.2 Trace and Reporting Procedures. A collection of procedures named $\operatorname{tr} \mathrm{XXX}$ provides the majority of the trace output (lines 3087 - 3344). These procedures are triggered by filing or removing an entity from a set (see lines 383 411 in the preamble). They do not provide any service in the model other than the trace, and so in theory could be commented out in a final, validated version. However, since trace output can be redirected to a file (or to the NUL device), and since a trace is extremely helpful in debugging, there should be no reason to remove these functions.

In addition to the trace functions there are three other reporting functions: run.report, final.report, and pt.report. Run.report (lines 3006 - 3084) is called after the completion of a run and writes summary information on that run to two files: a text file called summary.res and a formatted data file named run.res. Summary.res contains easily read summary information for a quick impression of the model's output, while run.res contains detailed 
information in a record format where each run is a line, and each field in that line is a numeric data item such as the run number, duration, midpoint, number of accidents, etc. This format is easily loaded by spreadsheets and statistical software, so that more sophisticated analysis can be performed.

4.3.3 Modeling Procedures. The following section explains the flow of control in the model, followed by documentation of the procedures involved in the actual execution of the instantiated model.

4.3.3.1 Generator (lines 1591 - 1625). If this instance of the generator process is for the first run of a series, the process calls the function nsp.f to determine the time until the next event occurs. It waits until that event, and then enters a loop where it creates, initializes and activates an accident process; generates the next inter-event time and waits for that event; and then just prior to starting the next event, checks to see if the run termination criteria have been met. If they have, it cancels any scheduled clear.reds events (because this might be the last run), but saves the time remaining (the time.a attribute of clear.reds) so that a clear.reds event can be scheduled at the proper time in the following run (if any). 
If this instance of generator is not the first run in a series, the previous run's value of time.v is retained, and the run will begin by activating an accident process.

4.3.3.2 Accident (lines 501 - 537). The attributes of the process accident will already have been initialized by the procedure init.accident (lines 2204 - 2258). These attributes include the location, type of event (trauma or medical), number of victims, and type of trauma (blunt or penetrating) if traumatic. Init.accident also initializes (by calling init.pt (lines 2261 - 2330) and activates any patients that it has created. Once the accident process is activated, it uses and empiric function based on average severity to compute a probability that the victims will find their own way to the nearest hospital (greater severity implies lower probability of private transport). This function is based on expressions of probability by various domain experts; no data could be found on this topic.

If private travel is chosen, the routine pvt.travel (see 4.3.3.7) is called. If not, the dispatcher is sent an ambulance request after a lag time. This request is updated with more accurate information after another lag. once the dispatcher has been fully notified, the accident process suspends itself. It has no further work to do, but must remain in existence until all patients have been picked up by an ambulance or have otherwise left the scene, since the only way to keep from losing track of a patient is to keep 
it filed in the acc.patient.set until an ambulance assumes responsibility for it.

4.3.3.3 Ambulance.run (lines 561 - 728). The ambulance run process is complex, since it must represent two different ambulances and the interaction between them. The process does some initialization and calls the utility routine travel (lines $3367-3377$ ) to model travel to the accident site. It may be interrupted by the dispatcher to be recalled during this time. Once at the scene, the process may take one of two branches (lines $602-628$ and lines 628 - 671) depending on whether the ambulance is an air or ground unit. The branches are largely similar except for their provision for inter-ambulance interaction; an air ambulance takes a patient from a ground ambulance and leaves, while a ground ambulance must consider if it needs an air ambulance, wait for one to arrive if it has been called (even if the ground unit would have been ready to roll), obtains its patient(s) via the get.patient routine, may give its patient to the helicopter ambulance and then check to see if there are more patients needing care before leaving. Ground ambulances also must handle the medical calls, since these rarely require helicopter transportation. Finally, as each ambulance leaves the scene, it calls the routine check.accident which does housekeeping on the accident process; if all the patients belonging to that accident have been taken care of, it reactivates the 
accident so that it may end itself. Ambulance.run then uses the travel routine to model traveling to the hospital and returning to base, notifying the dispatcher of its status at appropriate points along the way.

4.3.3.4 Patient (lines 2646 - 2756). The patient process is used to manage the continuous simulation routines. The design is to enter a 'work continuously' statement, using the function bleed to model the patient's physiologic status, and the function done to determine when this particular phase of the patient's experience is over. The update function is used to make the continuous variables visible to allow for reporting if desired.

The logic used to handle a patient's death requires some explanation. The function living is called periodically to determine if a patient meets the criteria for death. Death before ambulance arrival ends the patient process. In any other phase, death is recorded at the time it occurs, but the patient process continues through the end of the initial resuscitation. This reflects the real world system, in which the initiation of field therapy mandates transport to a hospital and resuscitation, even after the loss of vital signs, before pronouncing a patient dead. This complication is handled by using the routine pass.time (1ines 2581 2643 ) to control the continuous simulation statements, and to reexecute the 'work continuously' statement if a patient dies during continuous simulation. 
Finally, if the patient survives to be delivered to definitive care, his probability of survival is calculated from his ISS and RTS, using logistic regression coefficients from the MTOS [Champion90].

4.3.3.5 Dispatcher (lines 1238 - 1391). The dispatcher routine serves to coordinate the various processes in the simulation. It consists entirely of a multiway branch (select case) statement. Only one branch is executed each time dispatcher is called. The branches correspond to the various notifications that the real world dispatcher receives, such as request for ambulance or helicopter, updates to previous requests, and reports from ambulances on their status (en route to scene, on scene, at hospital, returning to base, and need assistance). The dispatcher also manages requests that can't be satisfied by filing requesting accidents in a pending set. When an ambulance is placed back in service, either when it returns to its base, or when it is recalled from a run, the dispatcher checks the pending set to see if that ambulance can be dispatched to an accident (if any) on the pending list. Finally, the dispatcher receives notification when the last patient is taken from an accident scene; it can then recall any ambulances still en route, and reactivate the accident so it will terminate. 
4.3.3.6 Get.patient (lines 1944 - 1986). The get.patient procedure updates every patients current RTS and ensures that patients are assigned to ambulances in RTS priority. It then chooses a destination level based on the logic previously described, although this is overridden in the case of helicopter ambulances who always transport back to their own base hospitals, unless a higher level of care is required. Get.patient does some housekeeping by moving the patient from the accident to the ambulance's set, setting intravenous fluid starting times and respiratory support times for the patient, and then uses the system's rules for deciding whether to request the helicopter or not. Get.patient only assigns one patient, and so it is called repeatedly to assign multiple patients to an ambulance if their acuity levels are low enough.

\subsubsection{Pvt.travel (lines 2892 - 2930). The routine} pvt.travel handles a patient's transportation to a hospital outside of and unknown to the EMS system. In this setting patients are assumed to go to the nearest hospital, regardless of its ability to handle their injury, and regardless of its divert status. Private transport is also assumed to take longer that EMS transport, although the overall time may be shorter since there is no wait for the ambulance to arrive and no on-scene treatment. 
4.3.4 Flow of control. The flow of control in this implementation, as in the real world system, is complex. The dispatcher function is critical to understanding the implementation, since it serves as a monitor to coordinate communication between the independent entities in the model. Although not specifically implemented as such, entities such as ambulances and patients can be viewed as finite state automata, with the dispatcher functioning to oversee state transitions. A typical sequence is given in the following.

An episode begins when the generator function creates an accident, and initializes it to have some number of patients, which some constellation of injury characteristics. Each patient process is activated and enters a continuous simulation phase that models the physiologic effect of its injuries. After a brief delay, the accident notifies the dispatcher of its existence, location, an approximate number of patients. The dispatcher determines the number of ambulances that should respond, selects particular ambulances from those available, and creates and activates ambulance run processes for each. Finally, the dispatcher files the accident in the pending set if more ambulances are needed, and then exits. The dispatcher function is reinvoked upon arrival of an ambulance at the scene, or after a lag interval, whichever occurs first. At this point, information assumed to be accurate about the number of victims is sent to the 
dispatcher, which may in turn recall some of the enroute ambulances, or may dispatch additional units as needed.

At this point, patient and ambulance run processes are executing simultaneously. Once an ambulance run process was worked for its designated travel time, it notifies the dispatcher that it has arrived on scene, and after a brief interval, picks up patients from the accident in order of apparent severity. Once the ambulance run "owns" some patients, it adjusts the patient's characteristics to reflect interventions such as respiratory support and intravenous fluid therapy. It also determines the appropriate destination, based on the level of care needed for the degree of injury. (One might think the dispatcher should do this, but the real world system operates in this manner). The ambulance run may also call for the helicopter ambulance to come to the scene and take over, depending on the severity of injury and distance from the appropriate level of care. The accident process terminates when the last patient is picked up by an ambulance.

After scene care has been rendered, the ambulance run notifies the dispatcher that it is enroute to a hospital. This notification also includes a request for additional help if there is still a disparity between the number of victims remaining and the number of ambulances on scene or enroute to the accident. The dispatcher updates the 
ambulance run's set membership appropriately to reflect this new status.

After the hospital transport time has passed, the ambulance run notifies the dispatcher of its arrival at the hospital. The patient(s) are then transferred to the resus.set, and undergo their resuscitative care, after which they are transferred to definitive care and leave the system. After a cleanup time, the dispatcher sends the ambulance back to its base, and upon arrival there, refiles the ambulance in the ready.set and terminates the ambulance.run process. The cycle is now ready to begin anew.

\subsection{Selection of Input Distributions}

The distributional form of the input random variables was chosen after consideration of both theoretical and practical issues. For example, for those distributions known to be bounded, beta distributions were chosen since they were also bounded, and were then scaled and fit using moment matching or maximum likelihood methods. Similarly, if a distribution was known to be skewed to the right, or nonnegative, candidate distributions were restricted to those having the appropriate general characteristics.

For all distributions for which empirical data was available, the choice among candidate distributions was made by visually assessing probability and quantile plots [Law91], after matching the first two moments (mean and 
variance) to the empirical data. For each quantile ordinate, the quantile plot graphs the abscissa of the candidate distribution corresponding to that ordinate against the abscissa of the empiric distribution corresponding to that ordinate. A good fit will thus appear as a straight line, and differences in the tails of the candidate and empirical distributions will show up as deviations from a straight line. In the probability plot, for each abscissa value, the ordinate of the cumulative distribution function of the empiric distribution is plotted against the ordinate of the candidate distribution for the same abscissa value. Again, good fit will appear as a straight line, but differences in the middle of the distributions are magnified and appear as deviations from a straight line. In addition, the slope and intercept of the plots (or the logged plots, for Weibull distributions) can be used to estimate the parameters of the fitted distributions [Wilkinson90]. Several examples of distributions fitted using these techniques are given in Appendix 5 .

Finally, although several of the time duration variables were well-approximated by Weibull distributions, the final decision was made to use gamma variates instead, since the parameters of a gamma distribution are simple functions of the mean, which is not the case for the Weibull. This allows more flexibility in using the model, since mean times 
can be easily changed in the data file. Inspection of the probability and quantile plots in 5 shows that this is not likely to produce large differences in the output, since gamma distributions also fit the data very well. A listing of all the random variables used in the model, the distributions and arguments chosen to generate them and the random number streams assigned is provided in Table 1. 


\begin{tabular}{|c|c|c|c|c|}
\hline module & variable & distribution & arguments & stream \\
\hline $\begin{array}{l}\text { accident } \\
\text { accident } \\
\text { accident }\end{array}$ & $\begin{array}{l}\text { notification lag } \\
\text { pvt vs ambulance } \\
\text { update lag }\end{array}$ & $\begin{array}{l}\text { exponential.f } \\
\text { random.f } \\
\text { exponential.f }\end{array}$ & $\begin{array}{l}\text { alarm.lag } \\
n / a \\
\text { info.lag }\end{array}$ & $\begin{array}{l}15 \\
3\end{array}$ \\
\hline $\begin{array}{l}\text { ambul ance. run } \\
\text { " } \\
\text { " }\end{array}$ & $\begin{array}{l}\text { scene time } \\
\text { time to patient } \\
\text { cleanup time } \\
\text { secure time }\end{array}$ & $\begin{array}{l}\text { mygamma.f } \\
\text { exponential.f } \\
\text { exponential.f } \\
\text { lognormal.f }\end{array}$ & $\begin{array}{l}\text { t.on.scene, } 3 \\
\text { t.to.pt } \\
3 \\
\text { m.secure, }\end{array}$ & $\begin{array}{l}4 \\
5 \\
6\end{array}$ \\
\hline$"$ & need secure time? & random.f & $\begin{array}{l}\text { s.secure } \\
\text { n/a }\end{array}$ & $\begin{array}{l}18 \\
19\end{array}$ \\
\hline choke.time.f & $\begin{array}{l}\text { deliver time } \\
\text { choke point delay }\end{array}$ & $\begin{array}{l}\text { lognormal.f } \\
\text { exponential.f }\end{array}$ & $\begin{array}{l}\text { m.deliver, } \\
\text { s.deliver } \\
\text { choke.pt.wt }\end{array}$ & $\begin{array}{l}21 \\
23\end{array}$ \\
\hline $\begin{array}{l}\text { dispatcher } \\
\text { " }\end{array}$ & $\begin{array}{l}\text { pt count error } \\
\text { to hosp time } \\
\text { to base time }\end{array}$ & $\begin{array}{l}\text { uniform.f } \\
\text { get.travel.time }\end{array}$ & ${ }^{-1,1} 1$ dependent & $\begin{array}{l}7 \\
13 \\
17\end{array}$ \\
\hline find.hosp & hosp proportion & random.f & $n / a$ & 12 \\
\hline generator & $\begin{array}{l}\text { inter-acc interval } \\
\text { prop trauma }\end{array}$ & $\begin{array}{l}\text { nsp.f } \\
\text { random.f }\end{array}$ & $\begin{array}{l}n / a \\
n / a\end{array}$ & $\begin{array}{l}1 \\
22\end{array}$ \\
\hline get.amb & to acc time & get.travel.time & node dependent & 14 \\
\hline get. $10 \mathrm{c}$ & location & random. $f$ & $n / a$ & 8 \\
\hline get.travel.time & netravel time & mygamma.f & trav time, 3 & percaller \\
\hline get.patient & iv.rate & $\log \cdot$ normal.f & $\begin{array}{l}120-\text { sbp, } \\
10 \% \text { cof.var }\end{array}$ & 27 \\
\hline init.accident & $\begin{array}{l}\text { no. victims } \\
\text { blunt } v \text { pen }\end{array}$ & $\begin{array}{l}\text { poisson.f } \\
\text { random.f }\end{array}$ & $\begin{array}{l}1.5 \\
n / a\end{array}$ & $\begin{array}{l}9 \\
28\end{array}$ \\
\hline init.pt $_{1 "}$ & $\begin{array}{l}\text { severe brain inj } \\
\text { hem } v \text { resp inj } \\
\text { iss }\end{array}$ & $\begin{array}{l}\text { random.f } \\
\text { random.f } \\
\text { mybeta }\end{array}$ & $\begin{array}{l}n / a \\
n / a \\
1.390,9.632\end{array}$ & $\begin{array}{l}25 \\
26 \\
10\end{array}$ \\
\hline patient & $\begin{array}{l}\text { resus time } \\
\text { transfer time }\end{array}$ & $\begin{array}{l}\text { mygamma.f } \\
\text { exponential.f }\end{array}$ & $\begin{array}{l}\text { t.resus, } 3 \\
\text { t.tx }\end{array}$ & $\begin{array}{l}11 \\
24\end{array}$ \\
\hline pvt.travel & $\begin{array}{l}\text { hosp proportion } \\
\text { travel time }\end{array}$ & $\begin{array}{l}\text { random.f } \\
\text { mygamma.f }\end{array}$ & $\begin{array}{l}n / a \\
3^{2} .2^{\star} \text { trav time, }\end{array}$ & $\begin{array}{l}16 \\
20\end{array}$ \\
\hline
\end{tabular}

Table 1. Random variables used in the model. 


\section{Chapter 5 \\ Verification and Validation}

\subsection{Verification}

Major components of the implementation were verified against predictable model elements wherever possible. This was done by independent testing of "stub" routines where practical, and by inspection of the simulation trace or outputs elsewhere.

5.1.1 Random variate generators. Two new random number generators were implemented and verified; the non-stationary Poisson distribution routine nsp.f, and mygamma.f, a replacement for SIMSCRIPT's error-prone gamma variate generator.

5.1.1.1 Nsp.f. Çinlar's method [Çinlar75] of generating the interarrival times for a non-stationary Poisson arrival process was implemented in the function nsp.f (lines 2545 2578). An example test data set is given in Table 2, approximating the mean cumulative "arrivals" for a week. The nsp.f routine used this data to produce the 5000 arrival times summarized in Figure 3, Figure 4. The variation in generated arrival times closely follows the data in Table 2; a goodness of fit test shows no evidence of bad fit $\left(\chi_{13}^{2}=\right.$ 13.752, $P=.392$ ). 


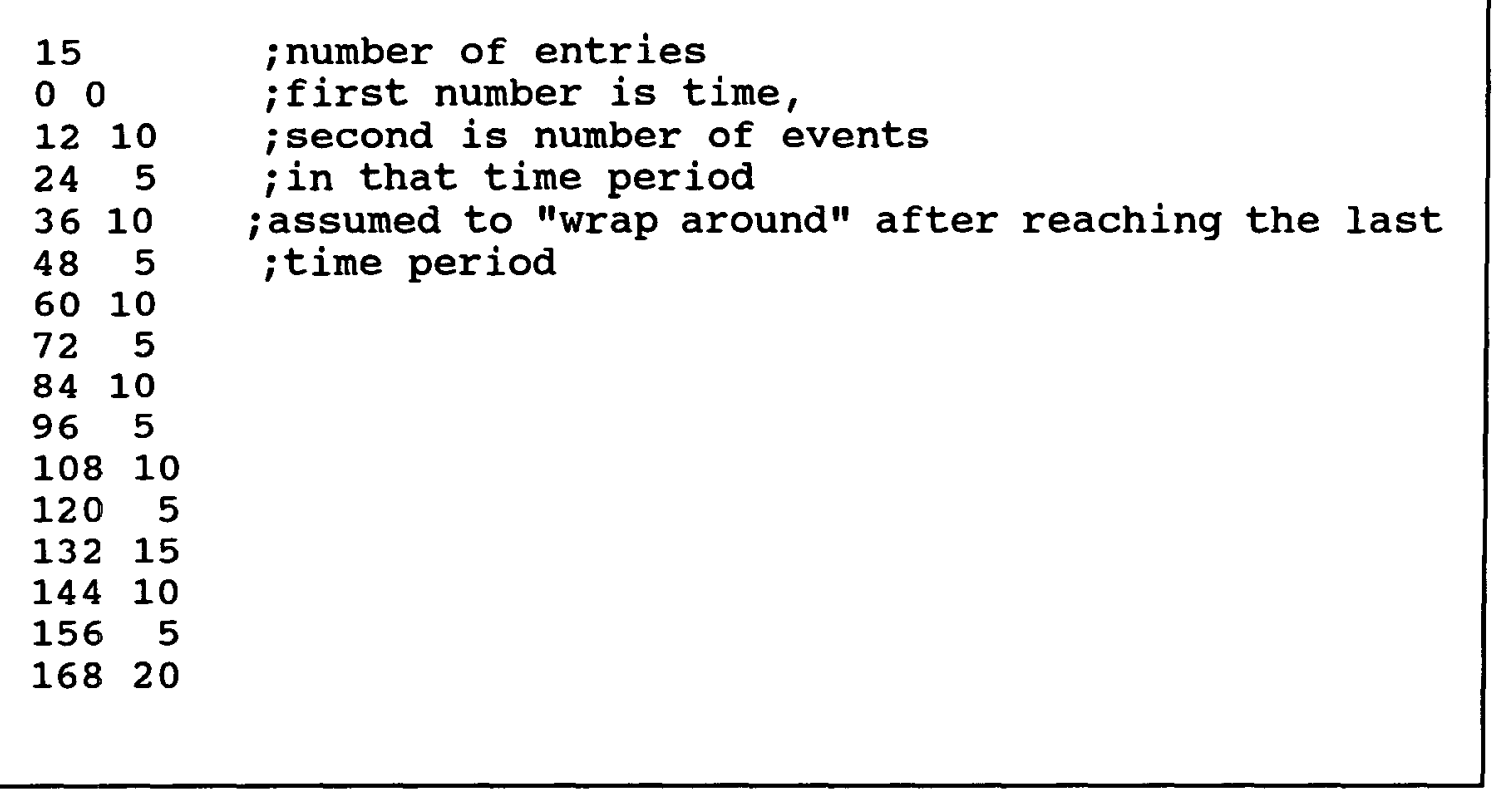

Table 2. Example data file of mean arrivals by interval for testing the nsp.f routine.

This process was repeated for a variety of data sets to establish acceptance of the nsp.f function.

5.1.1.2 Mygamma.f. A new gamma variate generator (lines 2442 - 2512) was implemented from two published algorithms [Bratley87]. For shape parameter greater than one, Tadikamalla's method was used, and for order one or less, Ahrens' method was used. Verification examples were produced over a wide range of arguments including those known to return invalid results for the SIMSCRIPT generator. An example of results for 2500 variates from mygamma.f given arguments $1.5,1.5(\alpha=1.5, B=1.0)$. This distribution has theoretical mean and variance equal to 1.5 . The sample mean and variance of the output from mygamma.f was 1.517 and 1.529. Figure 5 presents a histogram of the output; the 


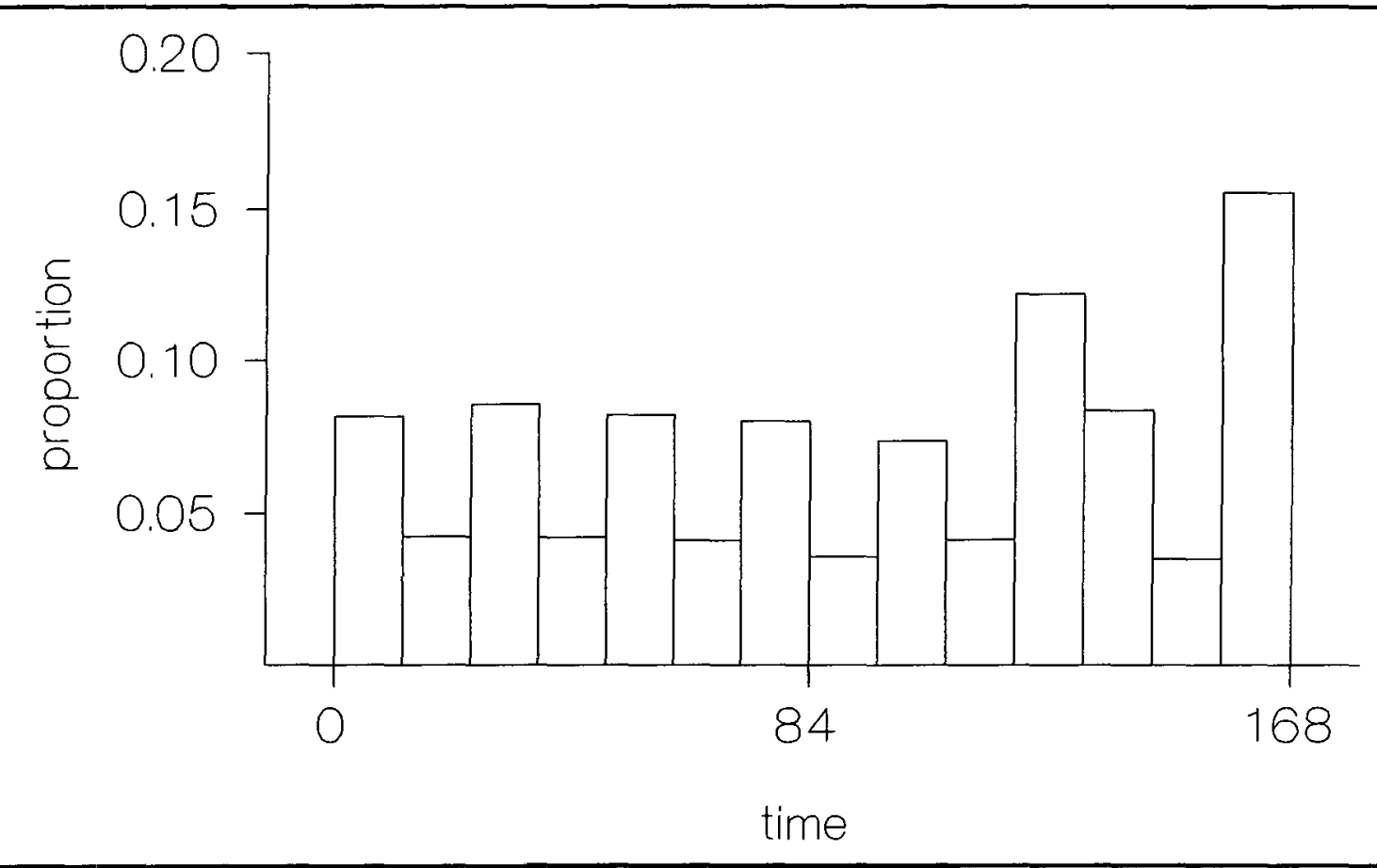

Figure 4. Proportion arrivals in 12 hour periods over one week, corresponding to data in Table 2 .

probability plots Figure 6 demonstrate the closeness to the theoretical distributional shape.

5.1.2 Static and Dynamic Analysis. Attributes of entities in the implementation were checked to confirm that they indeed matched the input parameters and distributional form specified in the model. For example, the distribution of observed ISS scores in the model compared reasonably well to that described by Baker [Baker92], which it was designed to match (Table 3). Similarly, the proportion of blunt to penetrating injury, the spatial distribution of injuries, the number of victims per accident, and other elements were confirmed to approximately match their inputs. 


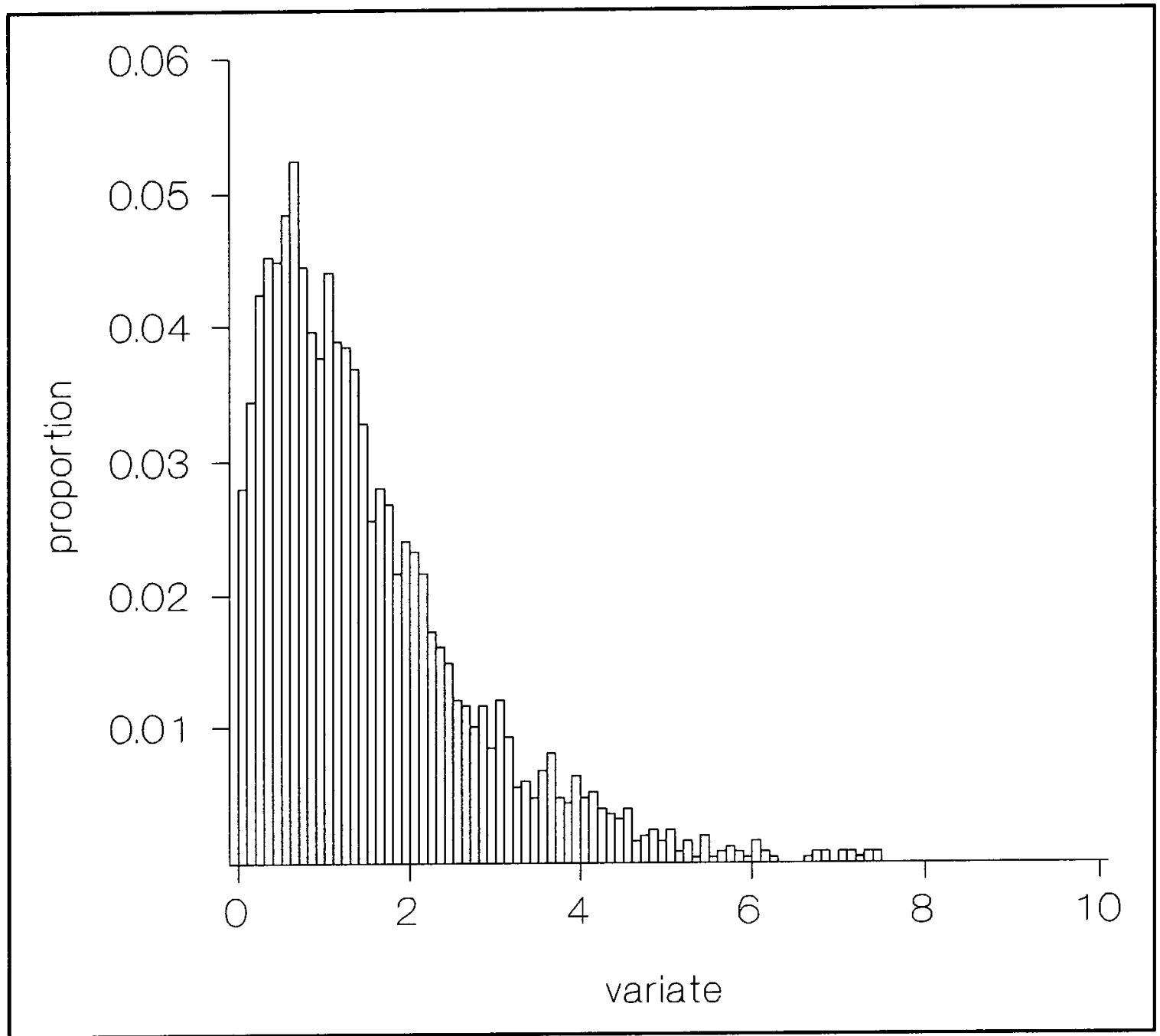

Figure 5. Histogram of 2500 variates from mygamma.f given arguments $1.5,1.5$.

\begin{tabular}{|lrr|}
\hline & model & Baker \\
statistic & 1082 & 8791 \\
$\mathrm{~N}$ & 9.86 & 9.46 \\
mean & 8.00 & 10.00 \\
median & 7.30 & 7.18 \\
std deviation & 1.26 & 1.71 \\
skewness & & \\
& & \\
\hline
\end{tabular}

Table 3. Characteristics of Iss scores obtained by the model and those reported by Baker.

The dynamic behavior of the implementation were verified to be compatible with the model by careful inspection of the 


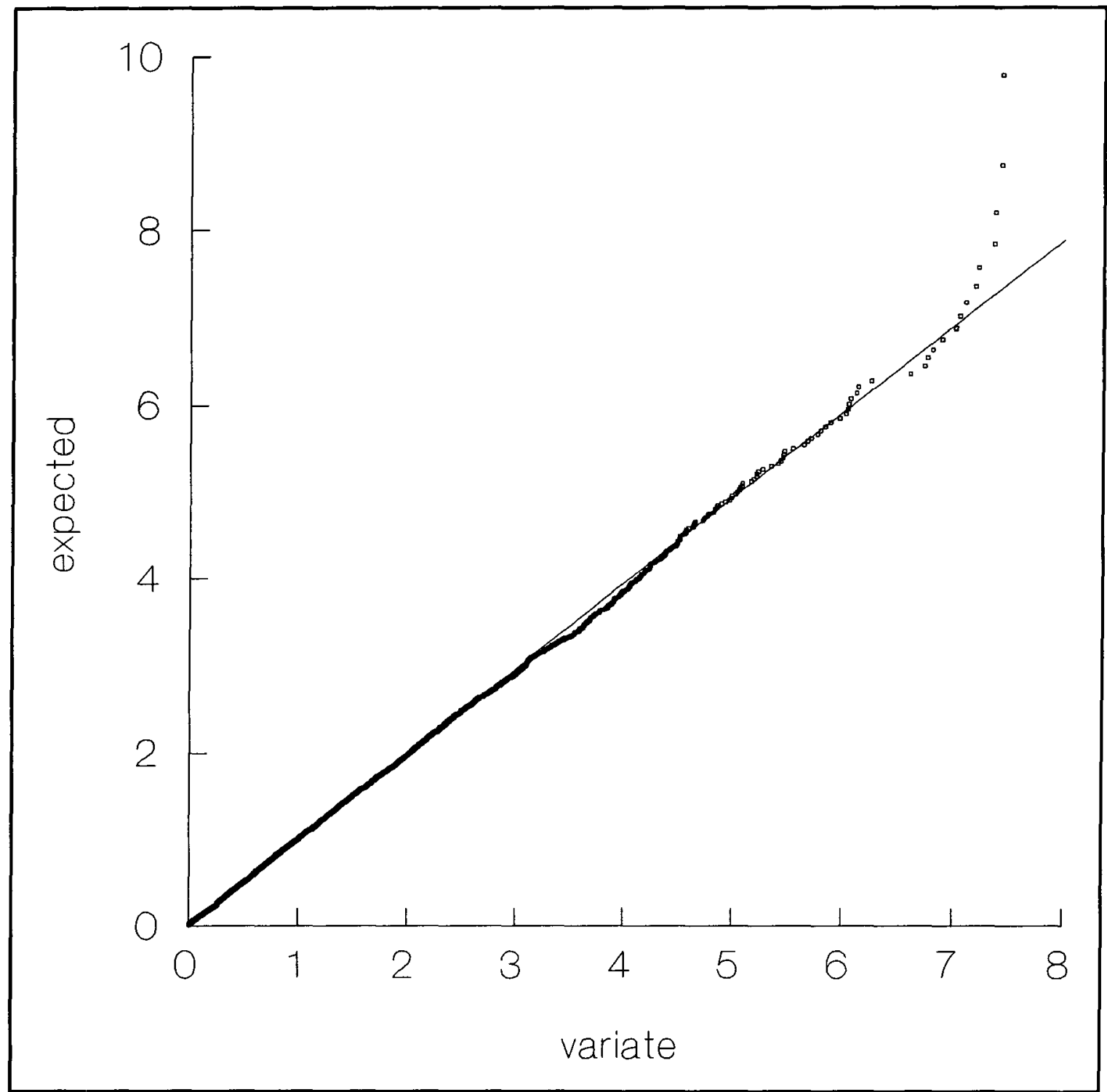

Figure 6. Probability plot of 2500 variates from mygamma.f given arguments $1.5,1.5$.

trace output and temporal outputs such as blood pressure. special attention was paid to dispatching rules, such as alternating assignments between helicopter ambulances, or between two ambulances based in the same node. It was possible to confirm from the trace dispatched ambulances that were recalled had indeed not reached the scene. It was also confirmed that ambulances treated patients in order of 
trace (edited for clarity)

event 1 (acc) occurs in WJX at $0: 42$

acc 1 has pt 1

acc 1 has pt 2

acc 1 has pt 3

acc 1 has pt 4

D7 enroute to acc 1 at $0: 44$

D4 enroute to acc 1 at $0: 44$

D9 enroute to acc 1 at $0: 44$

new info fr event 1 at $0: 46$

D9 recalled at $0: 46$

acc 25 has pt 26

acc 25 has pt 27

D28 treating pt 27 , cts $=7.6$ at $13: 37$

D42 treating pt 26, cts $=7.8$ at $13: 42$

D28 enroute to UMC at $13: 45$ with 1 pts

D42 enroute to UMC at 13:55 with 1 pts

STL went red at $12: 11$

D30 on scene at acc 139 in SSD at $12: 14$

D30 treating pt 165 , cts $=12$ at $12: 16$

D30 diverted from STL at 12:16

D42 on scene at acc 141 in JTB at $12: 30$

D42 treating pt 167 , cts $=12$ at $12: 31$

D42 diverted from STL at 12:31

D13 treating pt 168 , cts $=12$ at $12: 31$

D13 diverted from STL at 12:31

D20 diverted from STL at $12: 32$

D20 enroute to UMC at 12:32 with 1 pts

D30 enroute to MMC at $12: 37$ with 1 pts

D42 diverted from STL at $12: 38$

D42 enroute to UMC at $12: 38$ with 1 pts

D13 diverted from STL at 12:40

D13 enroute to MMC at 12:40 with 1 pts

STL went green at 13:11 comments

Ambulances are dispatched in order of travel time to WJX. The last ambulance that has not yet arrived (D9) is recalled when more information on numbers of patients is available.

Ambulances begin treating sicker patients (lower RTS) first. Both patients meet Level 1 criteria, so they are transported to UMC, not the nearest hospital.

St. Luke's goes on divert at 12:11. All subsequent runs which might routinely go to St. Luke's are diverted to alternate destinations until St. Luke's can began accepting incoming ambulances again at $13: 11$

Table 4. Portions of trace output demonstrating the manifestation of specific model design items in the implementation.

severity as manifested by the current value of the RTS. And finally, the trace confirmed that no ambulance was dispatched to the "wrong" node or to the "wrong" hospital, and that no ambulance traveled to a hospital without carrying a patient. This method of verification can never absolutely confirm the reliability of the system, but it does serve to increase confidence that the implementation behaves according to the model's specifications. Table 4 
shows a portion of the trace output that demonstrates the appearance in the implementation of several specific model behaviors.

\subsection{Validation}

Rigorous validation of a system such as this is extremely difficult, primarily because of the inadequacy of existing data sets useful for confirming model performance [McCoy92] However, it was possible to compare measures of the model's performance to locally available data elements, to establish at least order of magnitude validity. The following items had sufficient data available to allow such comparisons: number of ambulance runs, number of helicopter runs, proportion of deaths prior to definitive care, etc. The model's predictions for these variables are compared with

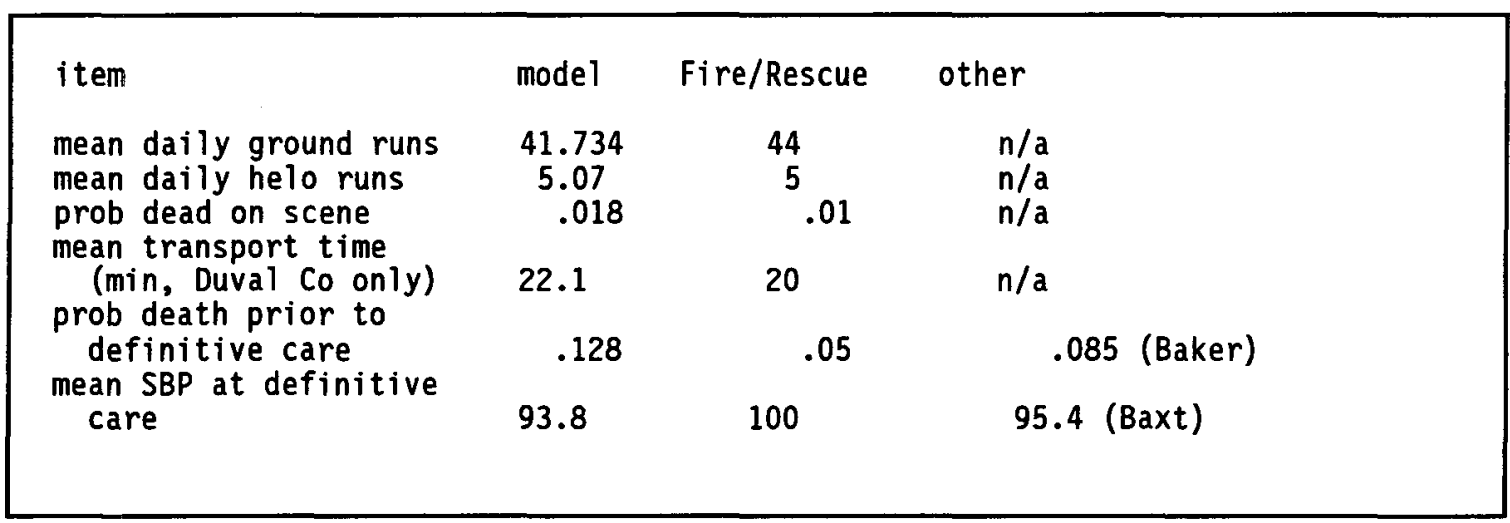

Table 5. Comparison of outcome estimates produced by the model with those estimated by Jacksonville Fire/Rescue.

convenience sample estimates from Jacksonville Fire Rescue and published data in Table 5. The distribution of transit times was compared with that derived from Campbell's data. The mean transit times were different, reflecting differing 
geography, but quantile plots of the two data sets revealed that they have approximately the same differing only by a scaling factor (see Figure 7). 


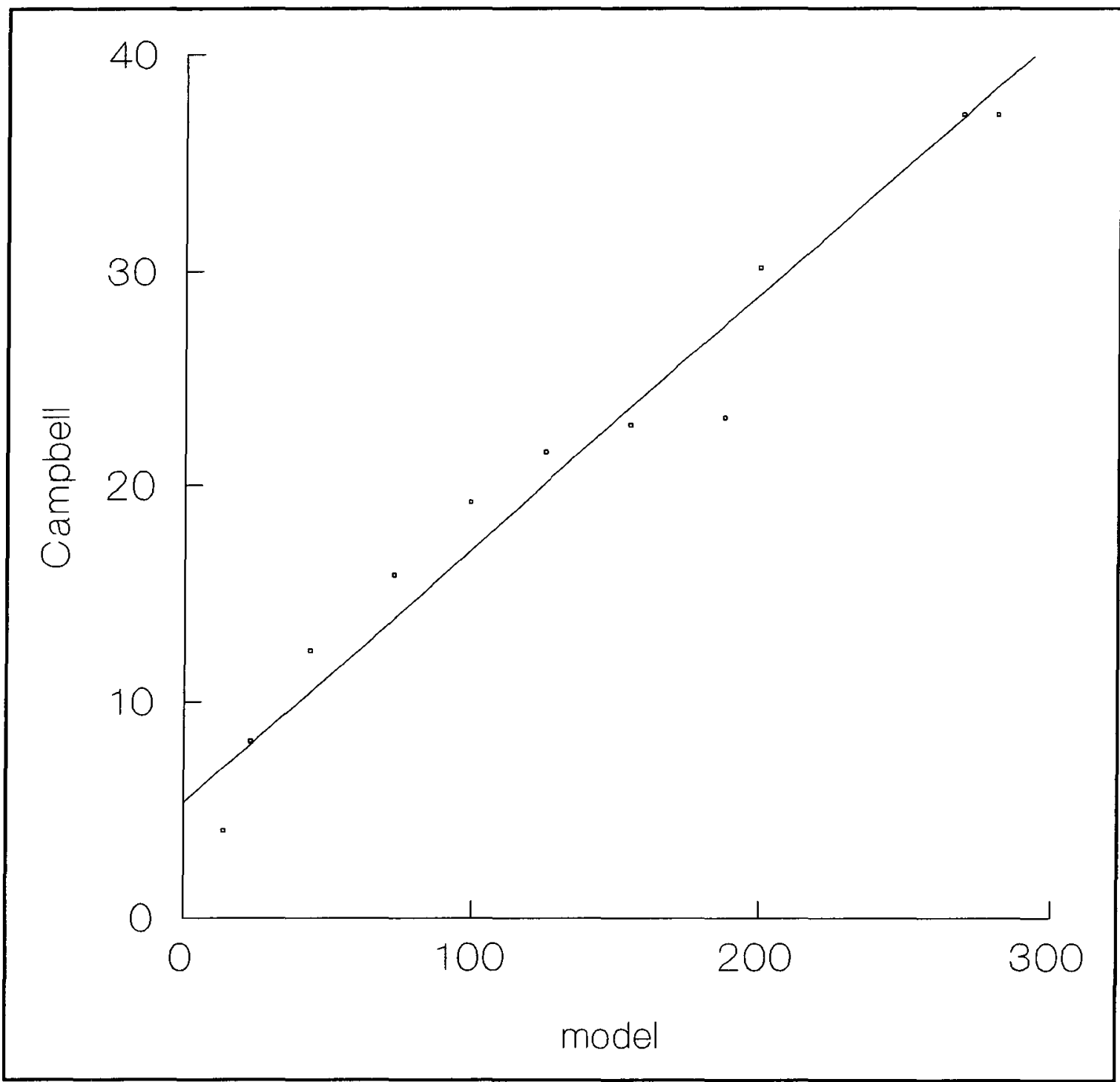

Figure 7. Quantile plot comparing the model's transport times with those provided by campbell. 


\section{Chapter 6}

\section{Demonstrative Experiments}

\subsection{Triage Policy}

To demonstrate the utility of the model in assessing policy choices, three sets of runs were performed using a different cutoff point to determine when a patient should be triaged directly to a Level 1 trauma center, bypassing other (possibly closer) hospitals. Current standard operating procedure calls for all patients with an RTS less than or equal to $90 \%$ of the maximum of 7.8408 (this corresponds to a score of approximately 10-11 on the 0-12 RTS scale) to be transported directly to a Level 1 center; this baseline case and several alternative cases were simulated. The minimum run length was set to 24 hours, and a total of 28 runs (approximately one month) were performed. The following outputs were used as measures of system performance under each scenario: trauma center utilization, red time, and reserve; proportion of accidents pended (i.e., no ambulance immediately available), mean waiting time until ambulance is dispatched among pended accidents; helicopter utilization; mean probability of death prior to receiving definitive care; unmet need (patients who met helicopter dispatch criteria but for whom a helicopter was unavailable); and total waiting time until EMS arrival $\left(t_{a}\right)$. The classical 
approach [Law91] was used to calculate point and interval estimates from the results of the 28 regeneration cycles. For this experiment, and the following one, output from the formatted data files was more useful than that directly reported by the program. An example of the direct output is provided in Appendix 4.

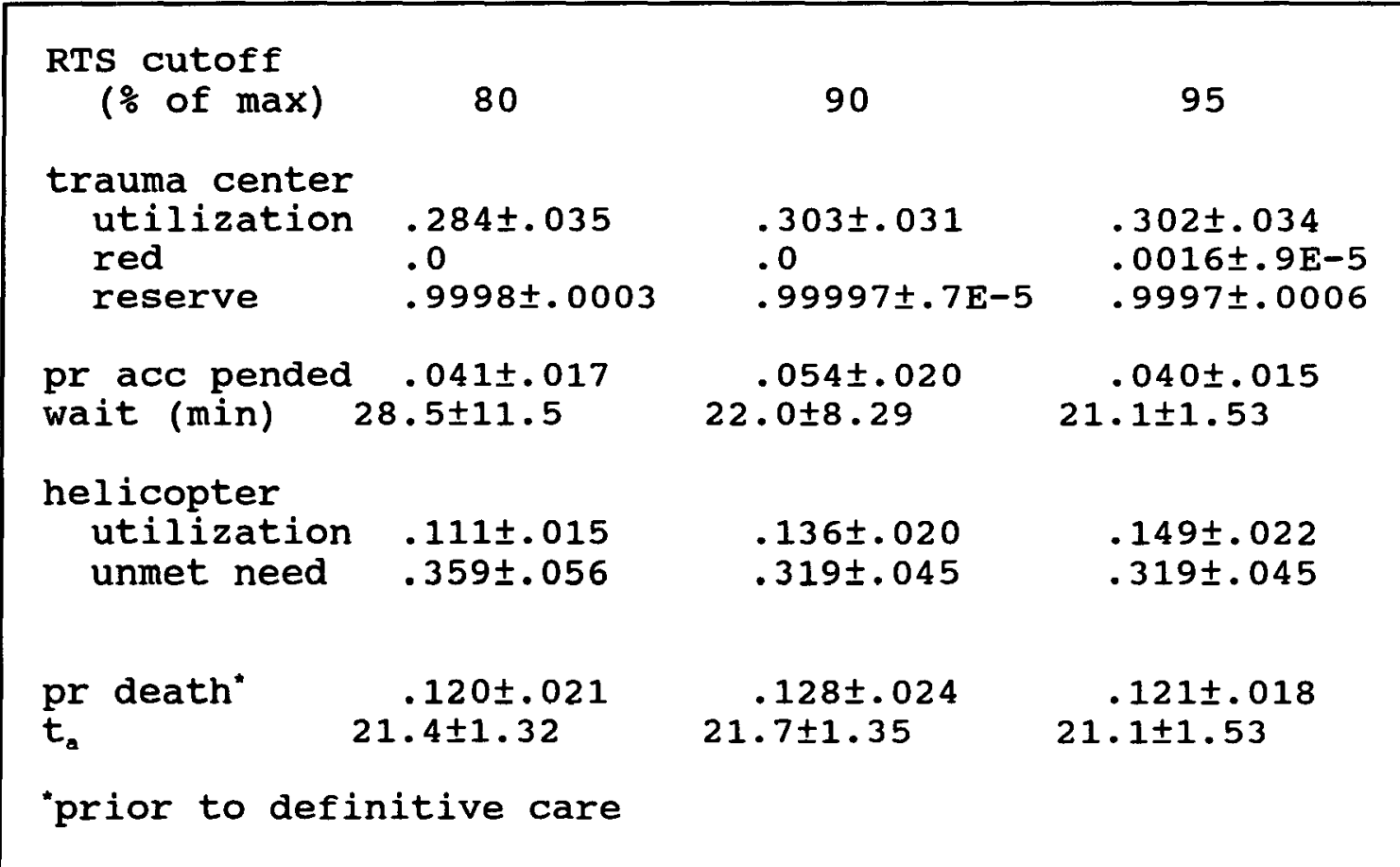

Table 6. System performance (mean $\pm 95 \%$ confidence interval) under different trauma center triage criteria.

The results for the baseline case and two alternatives (triage cutoffs of $80 \%$ and $95 \%$ of maximum) are summarized in Table 6. Compared to the baseline case, the main effects of liberalizing the triage cutoff are an increase in helicopter utilization, and a decrease in the length of time that a pended accident must wait to have an ambulance assigned to it. 


\begin{tabular}{|c|c|c|c|c|c|c|}
\hline \multirow[b]{2}{*}{$\begin{array}{l}\text { triage cutoff } \\
\text { convergence } \\
\text { time (days) }\end{array}$} & \multirow{2}{*}{$\begin{array}{l}\text { helo } \\
80\end{array}$} & \multicolumn{2}{|c|}{ utilization } & \multicolumn{3}{|c|}{ waiting time } \\
\hline & & 90 & 95 & 80 & 90 & Б \\
\hline $\begin{array}{l}13.919 \\
30.928\end{array}$ & $\begin{array}{l}.128 \\
.100\end{array}$ & $\begin{array}{l}.139 \\
.133\end{array}$ & $\begin{array}{l}.163 \\
.136\end{array}$ & $\begin{array}{l}34.2 \\
28.0\end{array}$ & $\begin{array}{l}21.0 \\
28.3\end{array}$ & $\begin{array}{l}163 \\
212\end{array}$ \\
\hline
\end{tabular}

Table 7. Convergence points including at least a full seven day cycle.

The three alternative models converged at six points in the simulation; results at the two convergence points spanning at least a full week cycle are shown in Table 7 . After adjusting for multiple comparisons, the results show that helicopter utilization is significantly different under the $80 \%$ and $95 \%$ triage cutoffs $(P=.013$, paired $t$ test $) ;$ the 95\% confidence interval on the difference in utilization between these two alternatives is $.036 \pm .0014$, or about a 33\% increase. Although the mean difference in waiting time for pended accidents is large between the $80 \%$ and $95 \%$ policies (12.3 minutes), the standard deviation of the difference is also large (7.81 minutes), so the results are not statistically significant. This result could be due to inadequate power since only two point estimates were obtained; further runs would be required to improve the precision of the estimate to determine if a true effect on waiting time should be expected. 


\subsection{Helicopter Dispatch Policy}

Currently, helicopter ambulances are dispatched for patients needing a level 1 center whose transport time is over 19 minutes, and patients needing a level 2 center whose transport time is over 39 minutes. The effects of reducing these times by about $50 \%$ (to 10 and 20 minutes, respectively) are shown in Table 8 ; the triage cutoff was kept at $90 \%$ of maximum, so these results should be compared to the center column in Table 6 . It appears that the effect of liberalizing time and distance transport criteria on helicopter utilization is much greater than that of liberalizing the triage cutpoint, yet the latter has received considerably more attention.

$$
\begin{array}{lr}
\begin{array}{l}
\text { trauma center } \\
\text { utilization } \\
\text { red } \\
\text { reserve }
\end{array} & .298 \pm .037 \\
& .000 \pm .999 \pm \pm .0001 \\
\text { pr acc pended } & .042 \pm .019 \\
\text { wait (min) } & 24.4 \pm 8.86 \\
\begin{array}{l}
\text { helicopter } \\
\text { utilization } \\
\text { unmet need }
\end{array} & .160 \pm .021 \\
\begin{array}{l}
\text { pr death" } \\
\text { ime til } \\
\text { arrival }
\end{array} & .293 \pm .037 \\
& 22 \pm .2 \pm 1.74 \\
\text { prior to definitive care }
\end{array}
$$

Table 8 . System performance (mean $\pm 95 \%$ confidence interval) under alternate helicopter dispatch criteria. 


\subsection{Conclusion}

It is interesting to note that the trauma triage cutoff, which has been the subject of vehement debate at times, had little effect on the overall load on the system, while a factor that has received little attention, the retriaging of less severely injured patients to a higher level of care if such a center is reasonably "close" had a much greater impact. This leads to the conclusion that the common knowledge of domain experts may not always be helpful in predicting the response of a complex system to change, and that computer models of such systems may enhance the decision makers accuracy and reliability by adding insight into the possible responses of the system to variables that were not previously thought important.

\subsection{Further Work}

Concern for the validity of current disaster planning and a demonstration of the potential of this model has led to community-wide interest in using a more fully validated version of the model to assist in planning for several events of importance in northeast Florida. The particular areas of interest are:

a. Loss of a hospital and subsequent evacuation of its patients to other facilities.

b. Loss of a major "choke point" such as a bridge for a period of hours to days. 
c. Widespread flooding of low areas eliminating multiple transportation routes and isolating some hospitals and nodes.

d. An area-wide disaster such as a hurricane, which might combine all of the preceding elements.

e. Modification of the physiologic model to use the a more detailed physiologic score such as ASCOT [Champion90], and to estimate the covariance structure of injuries from the American College of Surgeons National Trauma Registry Data (TRACS). 


\section{References}

[Baker 74]

Baker, Susan P., O'Neill Brian, Haddon Jr., William, and Long, William. "The injury severity score: a method for describing patients with multiple injuries and evaluating emergency care." Journal of Trauma, 26, 3 (March 1974), pp. 187-196.

[Baker92]

Baker, Susan P., O'Neill Brian, Ginsburg Marvin J., Li Guohua. The Injury Fact Book. oxford University Press, oxford, 1992.

[Baxt87]

Baxt, William G., and Moody, Peggy. "The differential survival of trauma patients." Journal of Trauma, 27, 6 (June 1987), pp. 602-606.

[Bratley87]

Bratley, B, Fox, BL, and Schrage, LE. A Guide to

Simulation. Springer-Verlag, New York, 1987.

[CACI88]

SIMGRAPHICS: User's Guide and Casebook. CACI Products Corporation, La Jolla, 1988.

[Campbel192]

Campbell JP. Time-to-patient interval: the hidden component of response time [abstract]. Annals of Emergency Medicine 1992; 21:643.

[Carter74]

Carter, Grace M. Simulation Model of Fire Department Operations: Program Description. The New York City Rand Institute, New York, 1974, pp. 8, 110-111.

[Champion81]

Champion, Howard R., Sacco, William J., Carnazzo, Anthony J., Copes, Wayne, and Fouty, William J. "Trauma score." Journal of Trauma 9, 9 (September 1984), pp. 672-676. 
[Champion86]

Champion, Howard R., Frey C. F., Sacco, W. J., et al. "Major trauma outcome study in quality assurance." Presented at the 4th Annual Meeting, Committee on Trauma, American College of Surgeons, Ft Lauderdale, FL, 1986 .

[Champion90]

Champion, Howard R., Copes, W. S., Sacco, W. J., et al. A new characterization of injury severity. Journal of Trauma 1990; 30:539.

[Chanpion91]

Champion, Howard R., Sacco William J., Copes, Wayne S. "Trauma Scoring," in Moore, Ernest E., Mattox Kenneth L., and Feliciano David V. [editors], Trauma. Appleton \& Lange, Norwalk, Connecticut, 1991.

[Çinlar75]

Cinlar, E. Introduction to Stochastic Processes. Prentice-Hall, Englewood Cliffs, NJ, 1975.

[Devroye86]

Devroye, Luc. Non-Uniform Random Variate Generation. Springer-Verlag, New York, 1986.

[Fitzsimmons82]

Fitzsimmons, James A., and Srikar, Bellur N.

"Emergency ambulance location using the contiguous zone search routine." J operations Management 2, 4 (August 1982), pp. 225-237.

[Johnson87]

Johnson, Mark E. Multivariate statistical simulation. John Wiley \& Sons, New York, 1987.

[Law91]

Law, Averill M., and Kelton, W. David, Simulation Modeling and Analysis. McGraw-Hill, New York, 1991.

[Lewis79]

Lewis, P. A. W., and Shedler, G. S. "Simulation of nonhomogeneous Poisson process by thinning." Nav Res Logist Quart, 26, (? 1979) pp.403-413.

[Lewis86]

Lewis, Frank R. Jr. "Prehospital intravenous fluid therapy: physiologic computer modelling." Journal of Trauma 26, 9 (September 1986), pp. 804-811. 
[MacKenzie86]

MacKenzie, Ellen J., Shapiro, Sam, Moody, Mark, Siegel, John H., and Smith, Richard T. "Predicting posttrauma functional disability for individuals without severe brain injury." Medical Care, 24, 5 (May 1986), pp. 377-387.

[May90]

Adolf May. Traffic Flow Fundamentals. Englewood Cliffs, NJ, 1990 .

[Mazzoni 88]

Mazzoni, M. C., Borgström, P., Arfors, K. E., Intaglietta, M. "Dynamic fluid redistribution in hyperosmotic resuscitation of hypovolemic hemorrhage." American Journal of Physiology 255, 3 (Part 2, September 1988), pp. H629-H637.

[McCoy92]

McCoy, Lois clark, S. Ruby, G. W. Reynolds, et al. "The hidden disaster in emergency management: The missing data base -- so you think there are data bases in notebooks waiting to be input into a computer." Abstract presented at 1992 Simulation MultiConference, orlando, FL, 1992.

[Morris86]

Morris, John A., Auerbach, Paul S., Marshall, Gregory A., Bluth, Raymond F., Johnson, Lynda G., and Trunkey, Donald D. "The trauma score as a triage tool in the prehospital setting." Journal of the American Medical Association 256, 10 (September 12, 1986), pp. 13191325 .

[Uyeno84]

Uyeno, Dean H., and Seeburg, C. "A practical methodology for ambulance location." simulation 48, 2 (August 1984), pp. 79-87.

[Valenzuela90]

Valenzuela, Terrence D., Goldberg, Jeffery, Keeley, Kevin T., and Criss, Elizabeth A. "Computer modeling of emergency medical system performance." Annals of Emgergency Medicine 19, 8 (August 1990), pp. 898-901.

[Wears90]

Wears, Robert L., and Winton, Charles N. "Load and go vs. stay and play: analysis of prehospital intravenous fluid therapy by computer simulation." Annals of Emergency Medicine 19, 2 (February 1990), pp. 163-168. 
[Wilkinson90]

Wilkinson, Leland. SYSTAT: The system for statistics. SYSTAT, Inc., Evanston, IL, 1990.

[Zachariah92]

Pepe PE, Curka PA, Zachariah BS, et al. Urban trauma:

diurnal variations in the incidence, severity and geographical distribution of various mechanisms of injury [abstract]. Annals of Emergency Medicine 1992; $21: 618$. 
Appendix 1

\section{Program Source Code}

Table of Contents

module

preamble

main

accident

adj.time $f$

ambul ance. run

assign.amb

best.route

bleed

build.call.list

build.hosp.list

build. route

check.accident

check.red

choke.f

clear.reds

cts.f

dispatcher

done

final. report

find.hosp

find. $10 \mathrm{C}$

ftime.f

generator

get.accs

get.amb

get . ems

get.hosp

get.iv.rate

get. level

get.list

get.net

get . num. amb

get.patient

get.sim

get.table

get.travel .time

go.green

go.off.red

go.red

init.accident

init.pt

initialize

lin.int.f

living

mybeta.f

mygamma. $f$

no.pts

nsp.f

pass.time line number

2
418
502
541
562
732
757
836
889
980
1077
1100
1133
1166
1184
1208
1238
1395
1429
1482
1538
1575
1592
1629
1661
1744
1783
1815
1826
1854
1877
1933
1945
1990
2088
2116
2142
2160
2186
2205
2262
2334
2389
2414
2427
2443
2516
2546
2582


patient

print.net

pt.report

2869

pvt.travel

2893

read.call.list

2934

read.hosp.list

2955

recall

resp.support

2977

run. report

3014

tr.check.in.acc 3108

3027

tr.check.in.amb

3126

tr.check.in.pt

tr.check.out.acc

3138

tr.check.out.pt

3149

tr.deliver.pt

tr.enroute.hosp

3167

3179

3192

tr.go.green

3212

tr.go.red

3223

tr.on.scene

tr.pickup.pt

tr.pvt.tr.pt

3234

3254

3274

3286

tr.resus.pt

3300

r. send.amb

3320

tr.to home

3338

tr.unstack. acc

3350

travel

update

write.call.list

3368

3381

3405

write.hosp.list

3426

3443 


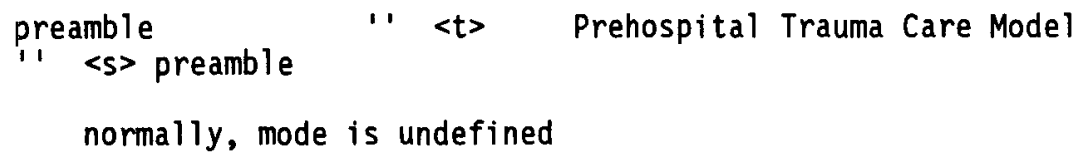




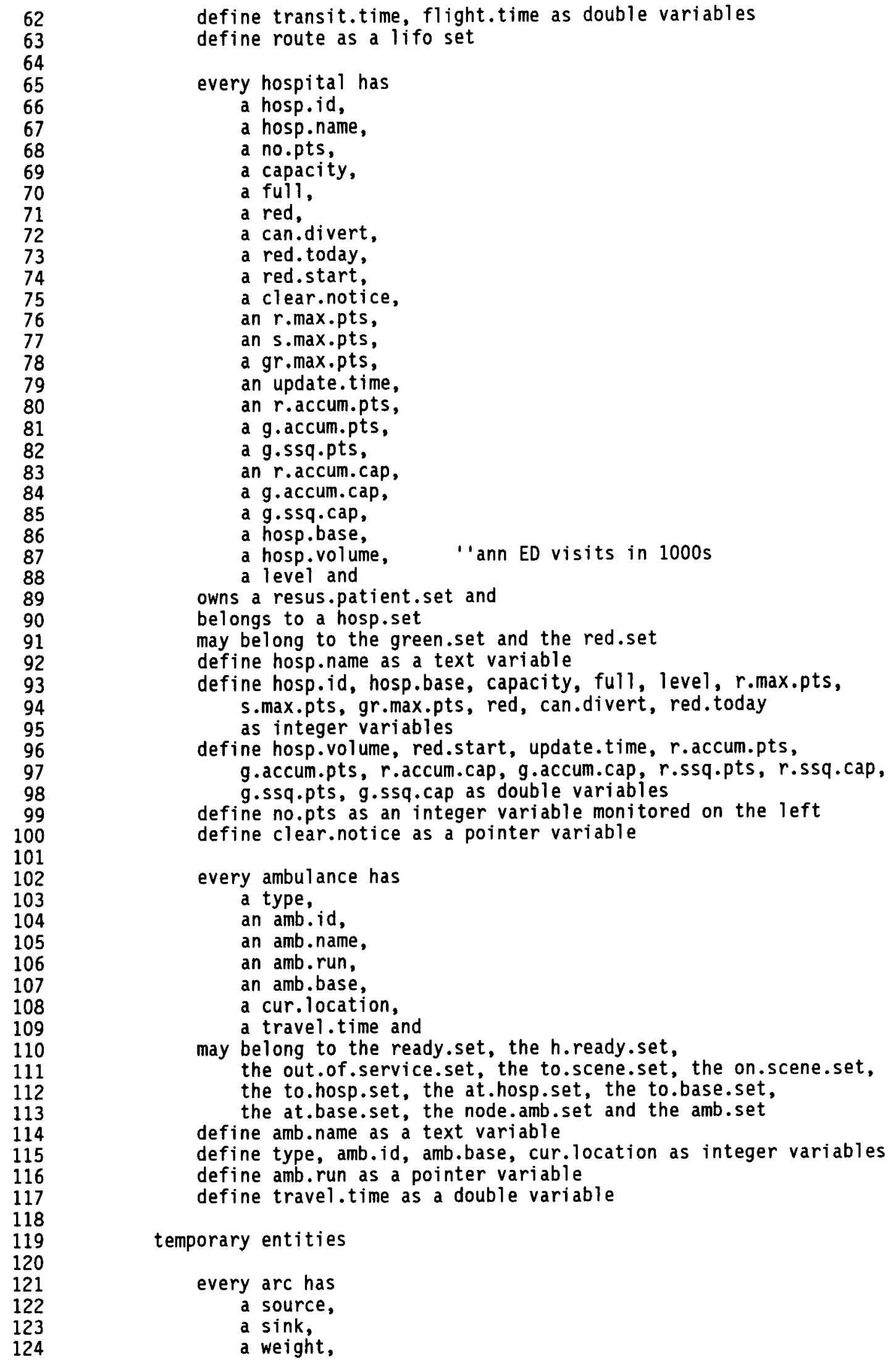




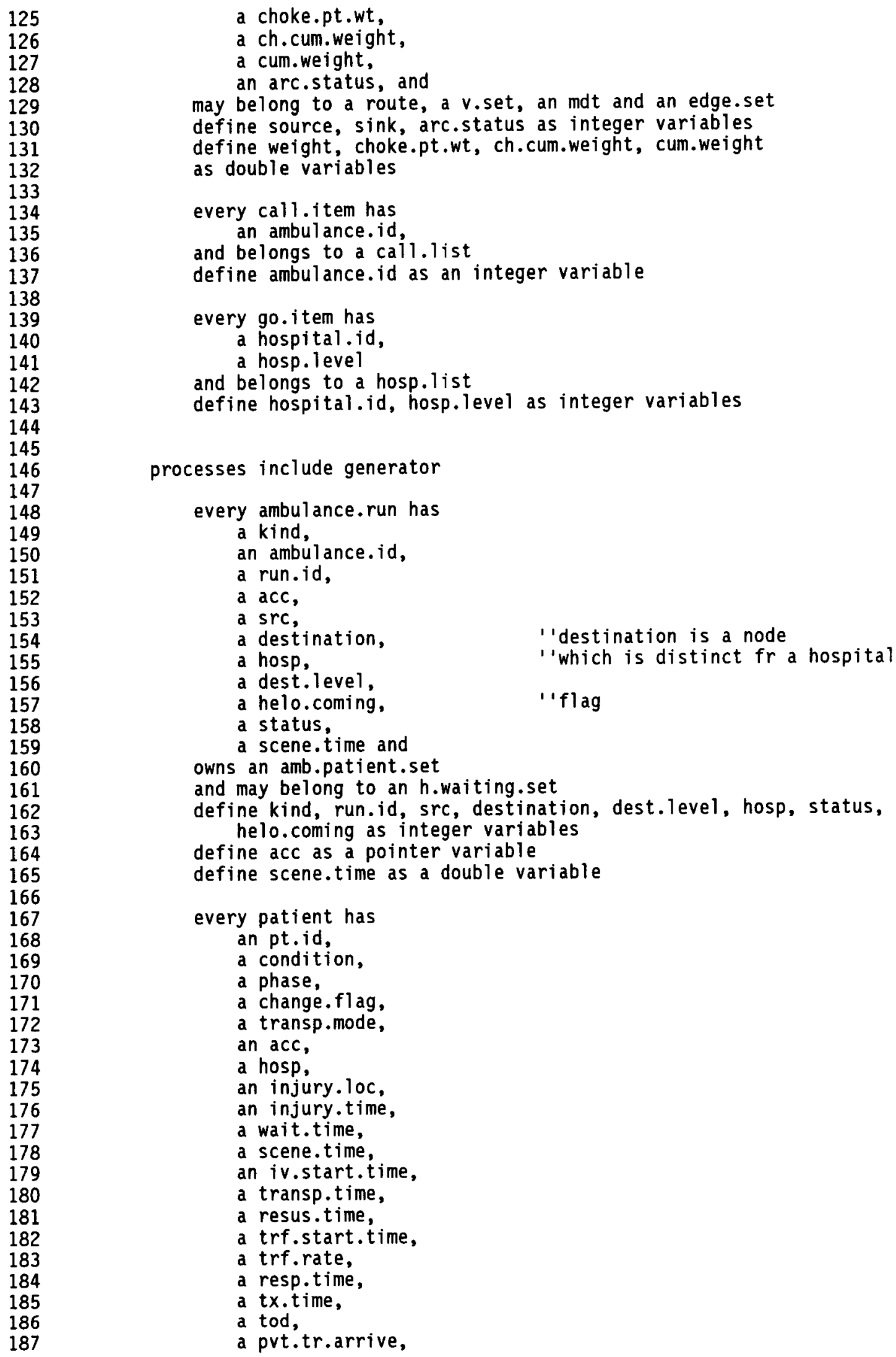

a choke.pt.wt,

a ch.cum. weight,

a cum.weight,

an arc.status, and

may belong to a route, a v.set, an mdt and an edge.set define source, sink, arc.status as integer variables define weight, choke.pt.wt, ch.cum.weight, cum.weight as double variables

every call.item has an ambulance.id, and belongs to a call.list define ambulance.id as an integer variable

every go.item has

a hospital.id, a hosp. level

and belongs to a hosp.list

define hospital.id, hosp. level as integer variables 
a rescue.bp, a hosp.bp, a def.bp,

a r.cts, "Champion trauma score components

a h.cts,

a n.cts,

a cts.f function,

a cts,

an iss,

" revise tr score

a prob.surv,

a bleeding. rate, a br. 0 ,

a blood.volume, an sbp, an 02.sat,

an rbc.mass, a hct, an 02.delivery,

an iv.start.time, an iv.rate,

a blunt, $"$ "blunt $v$ penetrating flag

a need.helo, a got.helo '" flags and

belongs to the patient.set and

may belong to the prt.tr.set, an acc.patient.set, a resus.patient.set, and an amb.patient.set

define pt.id, condition, phase, transp.mode, r.cts, h.cts, n.cts, iss, change.flag, blunt, injury.10c, need.helo, got.helo as integer variables

define pvt.tr.arrive, injury.time, wait.time, resus.time, tx.time, transp.time, br.o, iv.start.time, prob.surv, iv.rate, trf.start.time, trf.rate, rescue.bp, hosp.bp, def.bp, tod, resp.time, 02.sat, cts as double variables

define cts.f as a double function

define blood.volume, rbc.mass, sbp, bleeding.rate, hct, 02.delivery as continuous double variables

' note that accident is used for medical calls as well

every accident has

a kind,

an acc.id,

a site,

a no.victims,

a needed,

a sent,

an updated, $\quad \because$ flag

a pended, $\quad$ '' flag

an acc.start.time,

an acc.arrive.time and

an acc.end.time,

a blunt and

owns an acc.patient.set, an h.waiting.set and an amb.set, and may belong to the pending.set and

may belong to the active.set

define acc.id, site, no.victims, needed, sent, updated, pended as integer variables

define acc.start.time, acc.arrive.time, acc.end.time

as double variables

'I define acc.patient.set as a set ranked by low cts

$\because$ events

event notices include clear.reds

every go.off.red has a gor.hsp

define gor.hsp as an integer variable

every resp.support has an r.pt

define r.pt as a pointer variable

the system owns

the amb.base.set, the hosp.base.set, the temp.set, the assignment.set, 
the node.set, the v.set, the mdt, the patient.set, the pvt.tr.set,

the ready.set, the $h$.ready.set, the out.of service.set, the to.scene.set, the on.scene.set, the to.hosp.set, the at.hosp.set, the to.base.set, the at.base.set, the pending.set, the active.set, the green.set and the red.set define h.ready.set as a fifo set "helos alternate response

$\because$ convenient defines

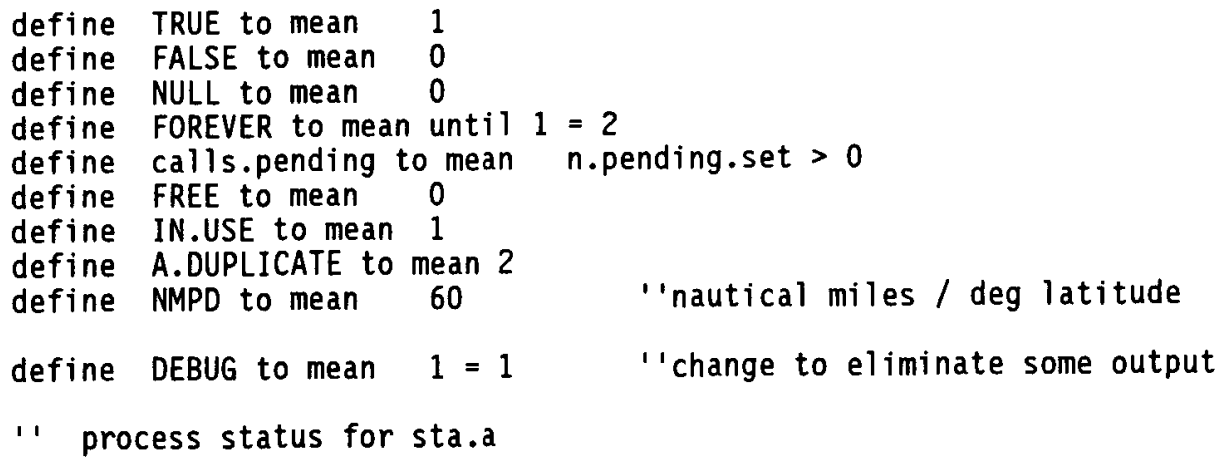




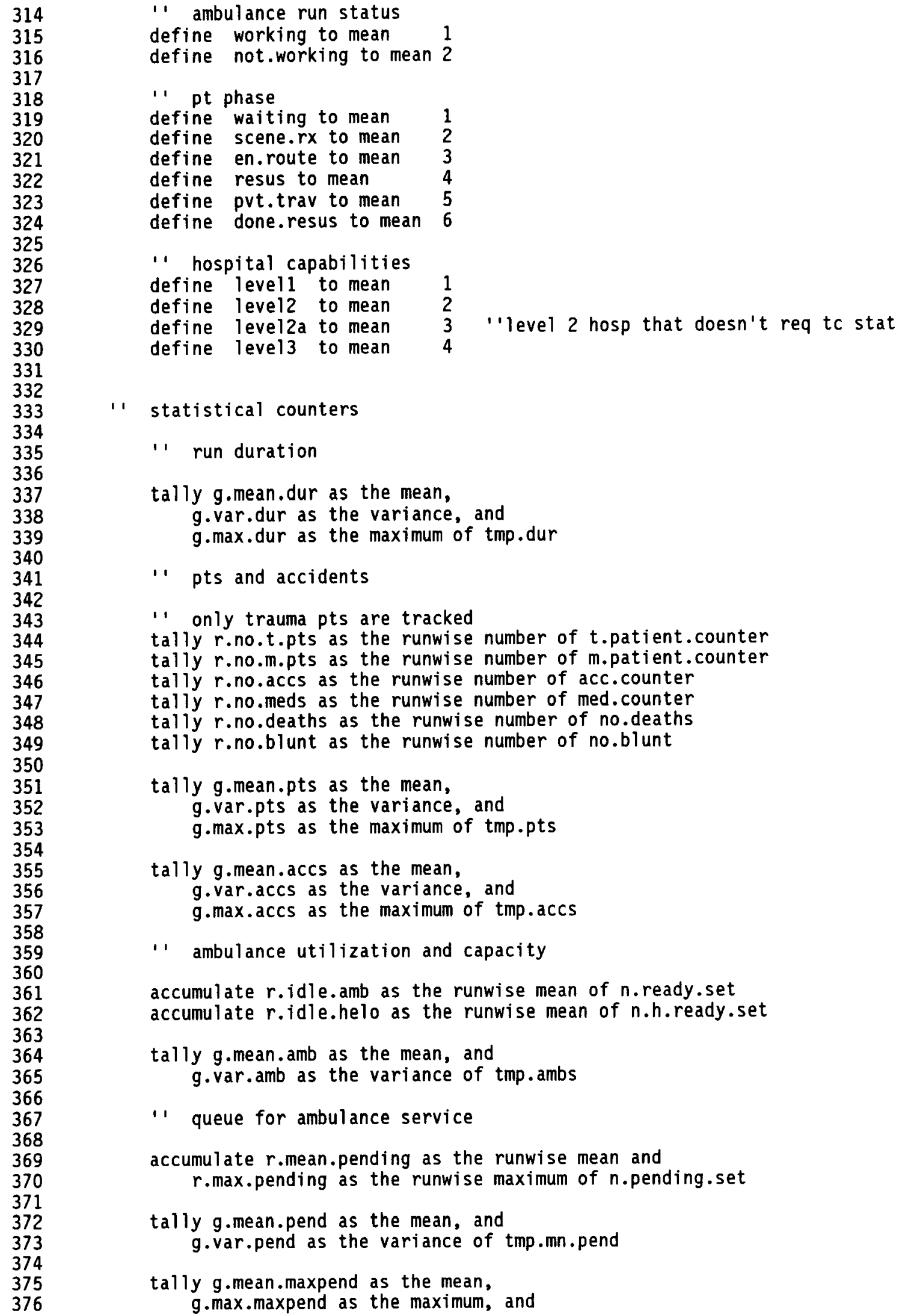


' hospitals

accumulate $r$.mean.red as the runwise mean of red

tally r.no.divert as the runwise number of divert.counter

tally r.no.override as the runwise number of override.counter

tally r.no.pended as the runwise number of no.pended

\section{' trace routines}

'1 ambulances

after filing in the ready.set, call tr.check.in.amb

after filing in the h.ready.set, call tr.check.in.amb before filing in the to.scene.set, call tr.send.amb before filing in the on.scene.set, call tr.on.scene before filing in the to.hosp.set, call tr.enroute.hosp before filing in the at.hosp.set, call tr.deliver.pt before filing in the to.base.set, call tr.to.home

\section{' ' accidents}

before filing in the active.set, call tr.check.in.acc before filing in the pending.set, call tr.stack.acc after removing from the pending.set,call tr.unstack.acc after removing from the active.set, call tr.check.out.acc

$$
\text { ' patients }
$$

before filing in the acc.patient.set, call tr.check.in.pt after removing from the patient.set, call tr.check.out.pt before filing in the amb.patient.set, call tr.pickup.pt before filing in the pvt.tr.set, call tr.pvt.tr.pt before filing in the resus.patient.set, call tr.resus.pt

$$
\text { " hospitals }
$$$$
\text { after filing in the green.set, }
$$

call tr.go.red

end ' ' of preamble

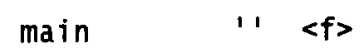




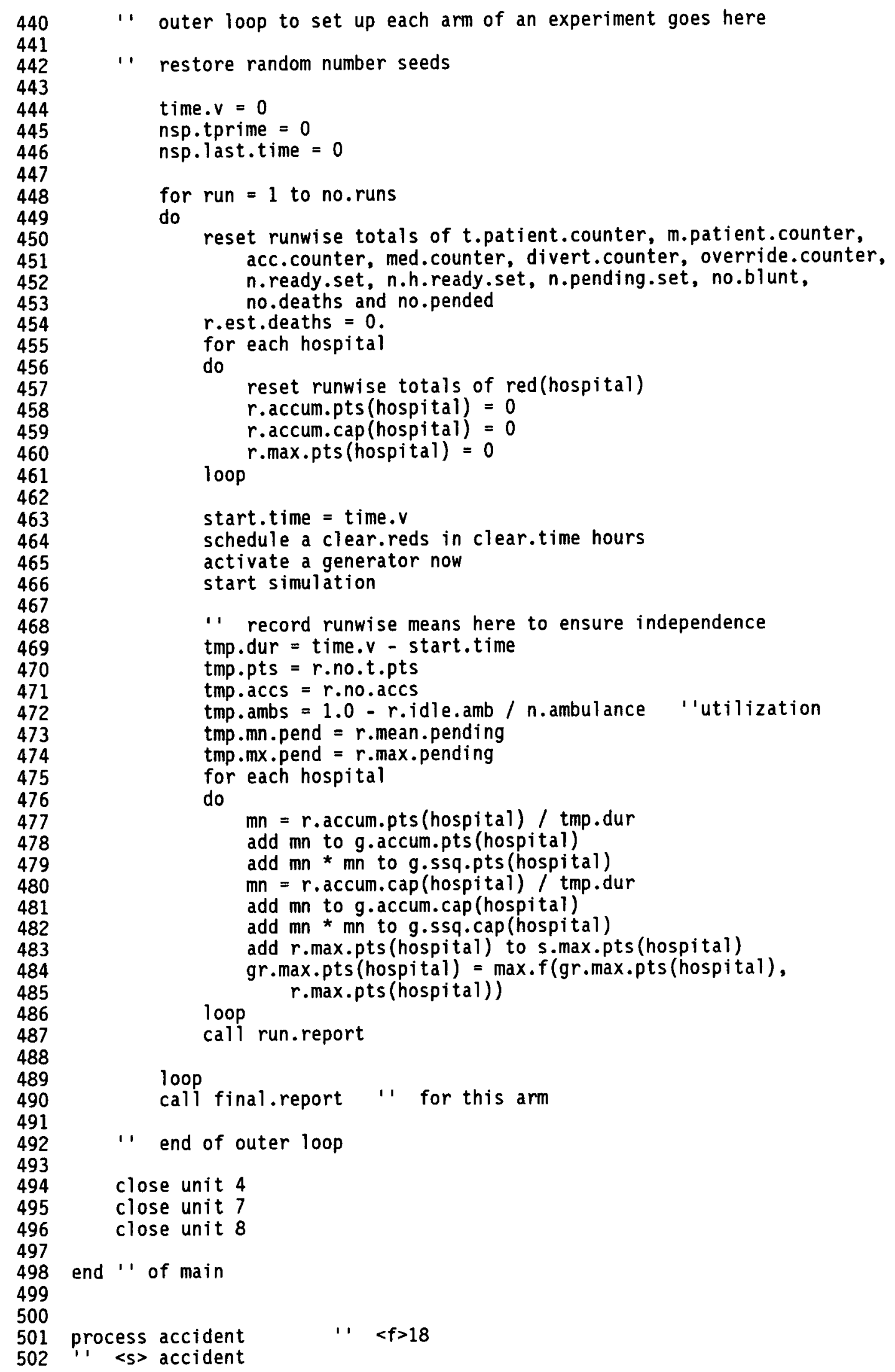




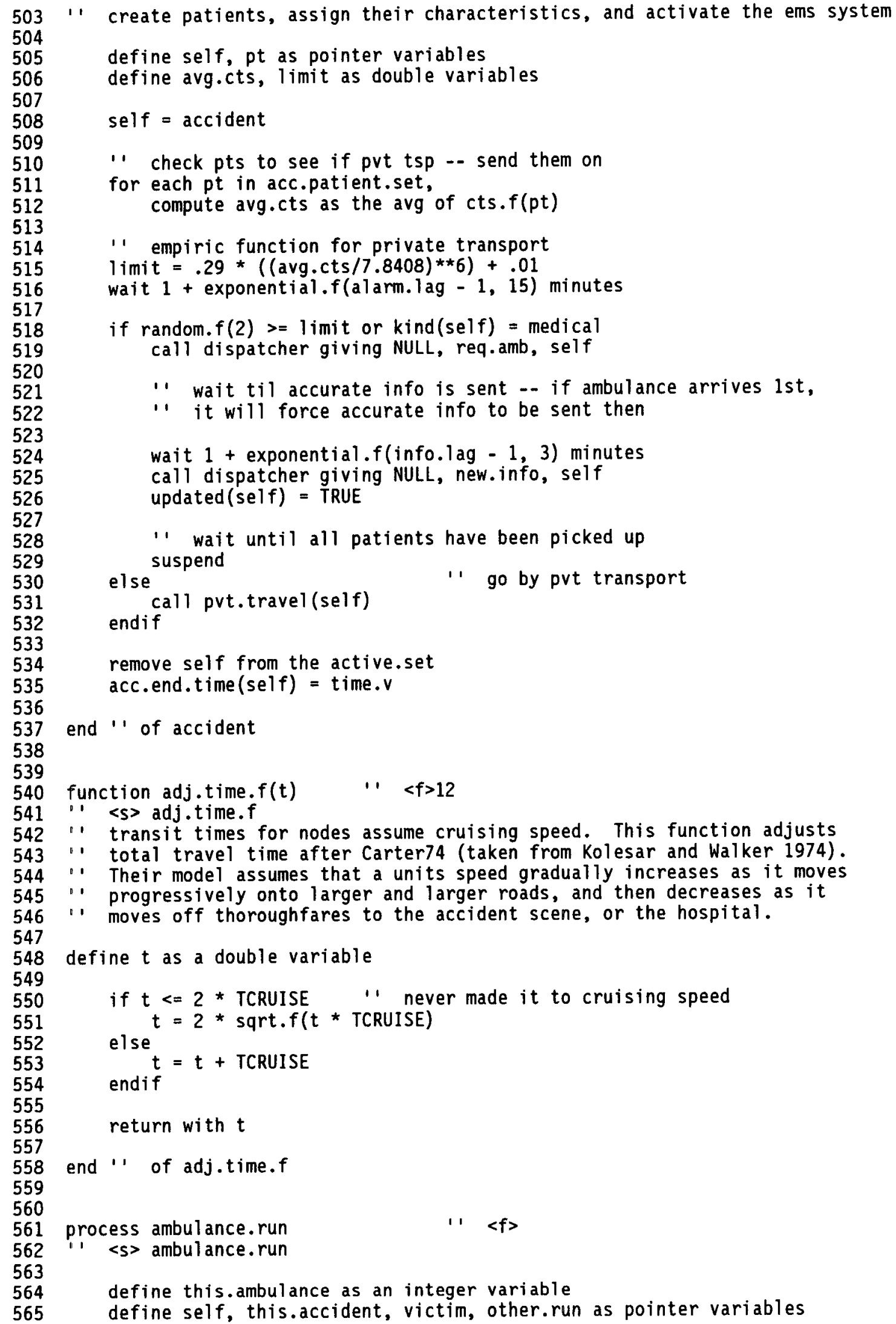




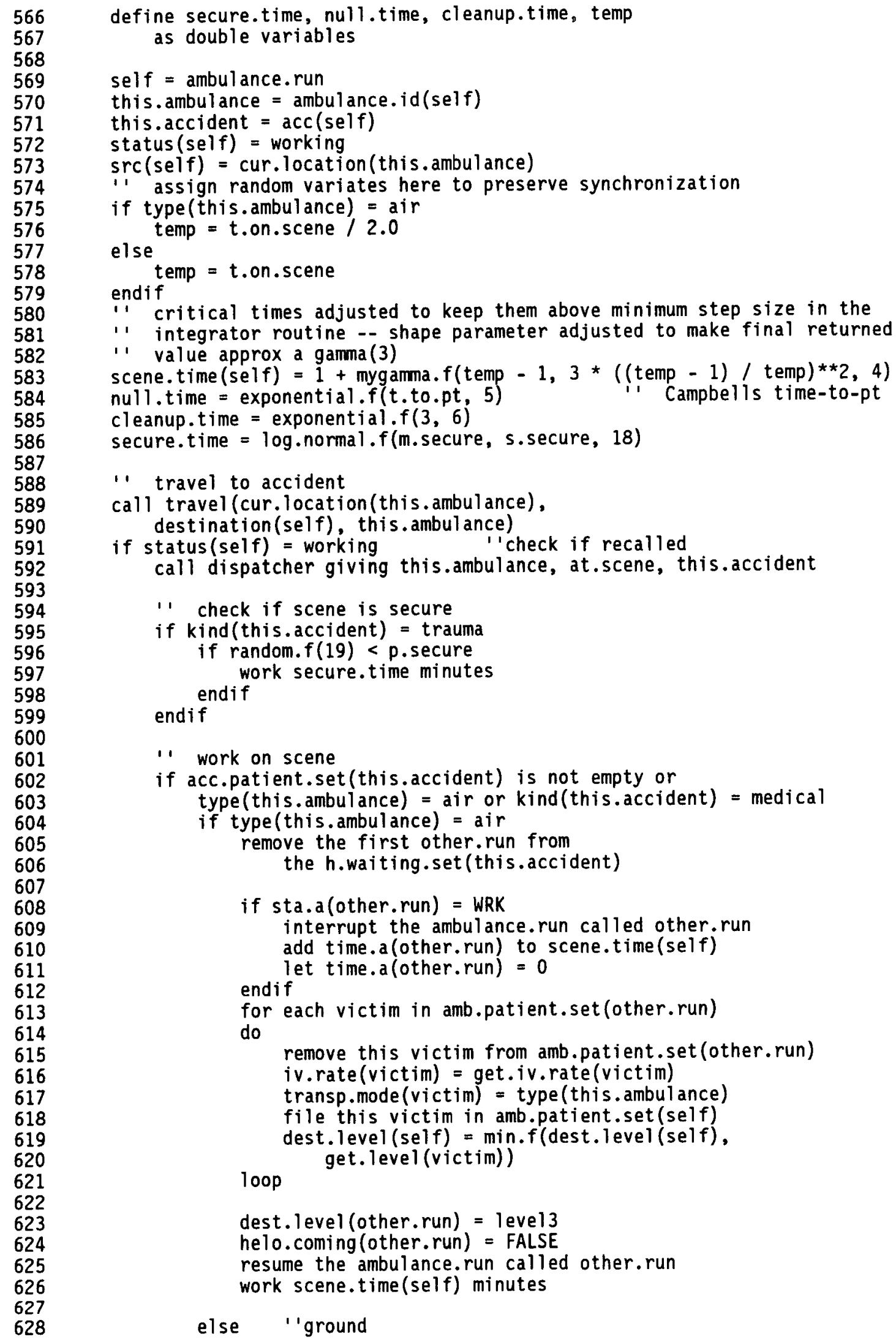




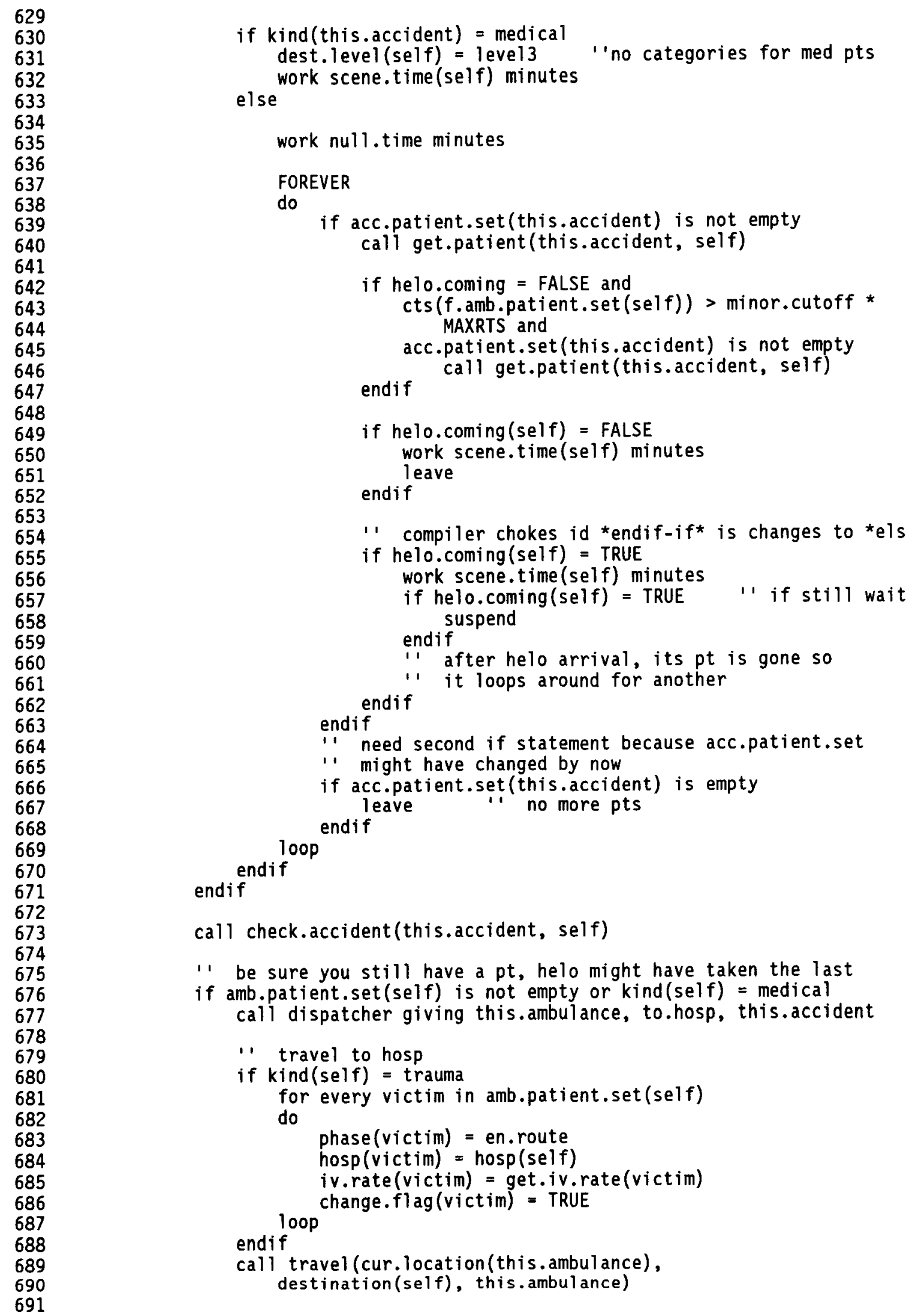

endif 
call dispatcher giving this.ambulance, at.hosp, this.accident

' at hospital

work log.normal.f(m.deliver, s.deliver, 21) minutes

if $\operatorname{kind}($ self $)=$ trauma

for each victim in amb.patient.set(self)

do

phase(victim) = resus

iv.rate(victim) = get.iv.rate(victim)

remove this victim from amb.patient.set(self)

file this victim in the resus.patient.set(hosp(victim)) change.flag(victim) $=$ TRUE

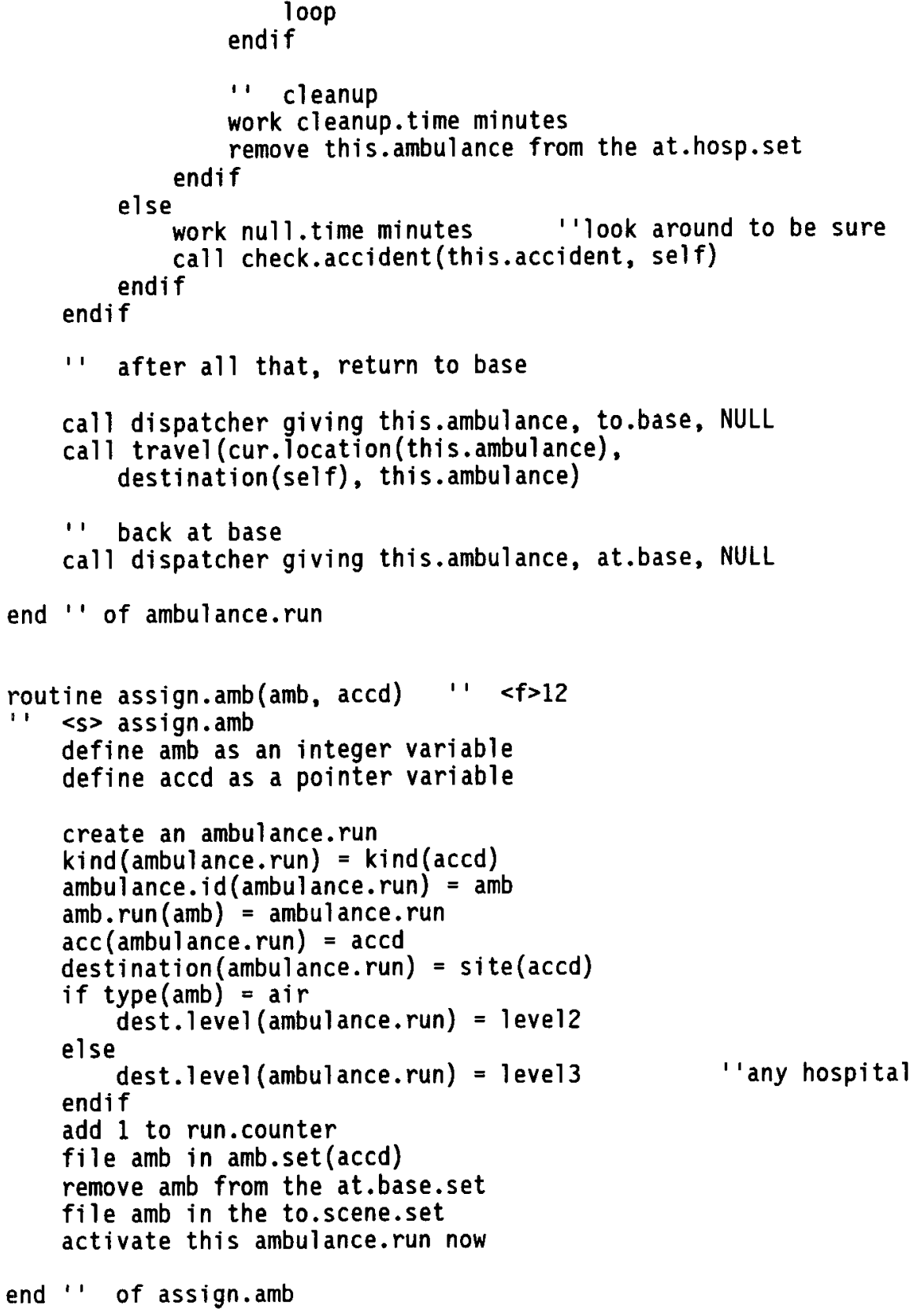

endif 
function best.route given from.node, to.node $\quad$ " $<f>18$

$\because$ <s> best. route

'U Uses Prim's algorithm to find shortest route from 'from' to 'to'.

file from.node in node.set

"' process the graph to produce the minimal distance spanning tree FOREVER

do

for each arc in v.set compute best.arc as the min(arc) of ch.cum.weight(arc)

file best.arc in mdt

if $\operatorname{sink}$ (best.arc) $=$ to. node

endif leave

file sink(best.arc) in node.set

remove best.arc from $v$.set

for each arc in edge.set (sink(best.arc)), when sink (arc) is not in node. set do

cum.weight (arc) $=$ weight (arc) + cum.weight (best.arc) ch.cum. weight (arc) $=$ weight (arc) + choke.pt.wt (arc) + ch.cum.weight (best.arc)

for each check in v.set, " check of new candidates for v.set with $\operatorname{sink}($ check $)=\operatorname{sink}(\operatorname{arc})$

find the first case " at most 1 case

if found "then sink(arc) is al ready a v. set destination if ch.cum. weight (arc) < ch.cum.weight (check) remove check from v.set " arc is better than check endif file arc in v.set $\quad$ "for this destination

811

812

813

814

815

816

817

loop

else " arc gives a destination not already in $v$.set endif

file arc in $v$. set 


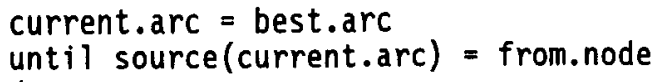




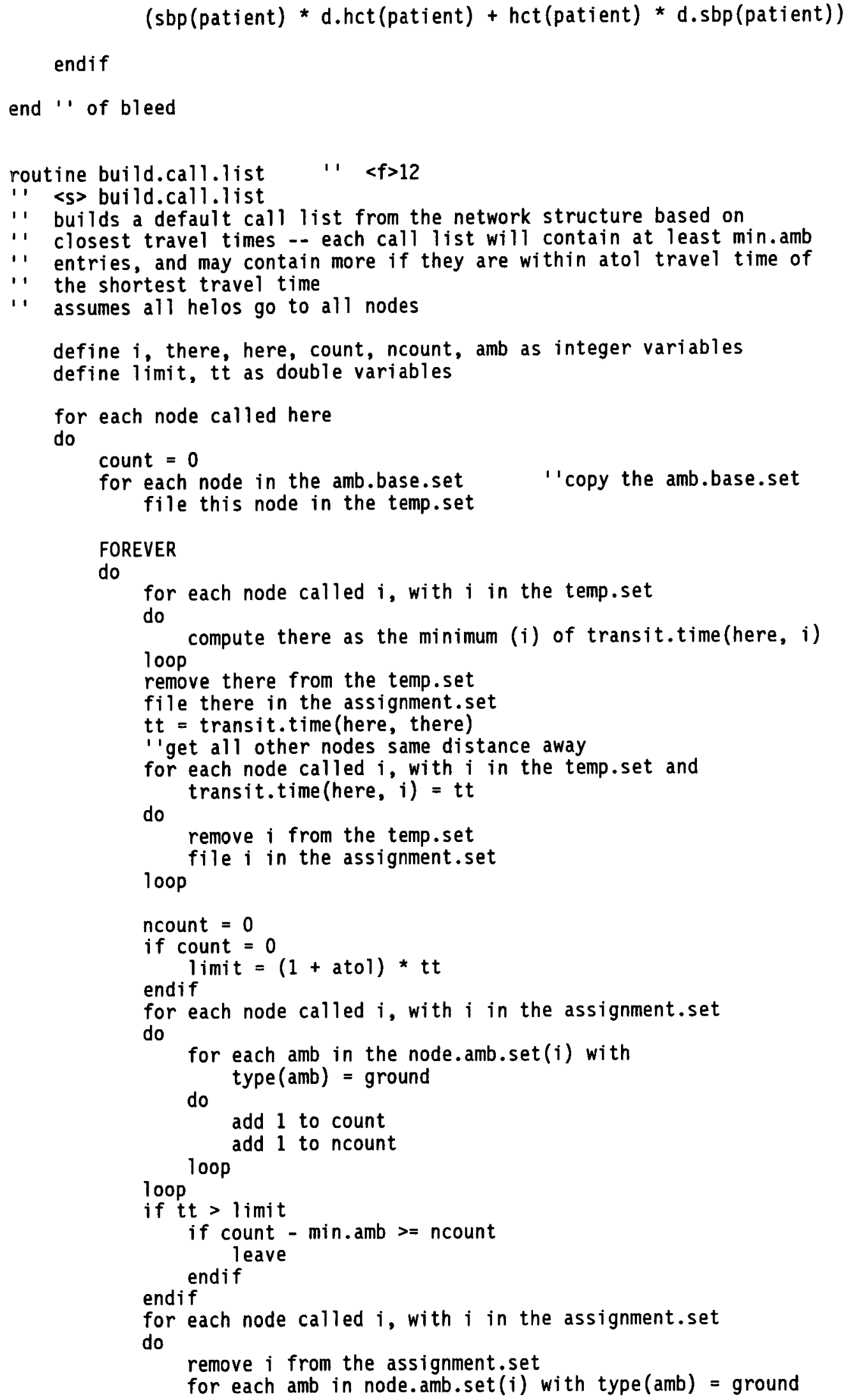




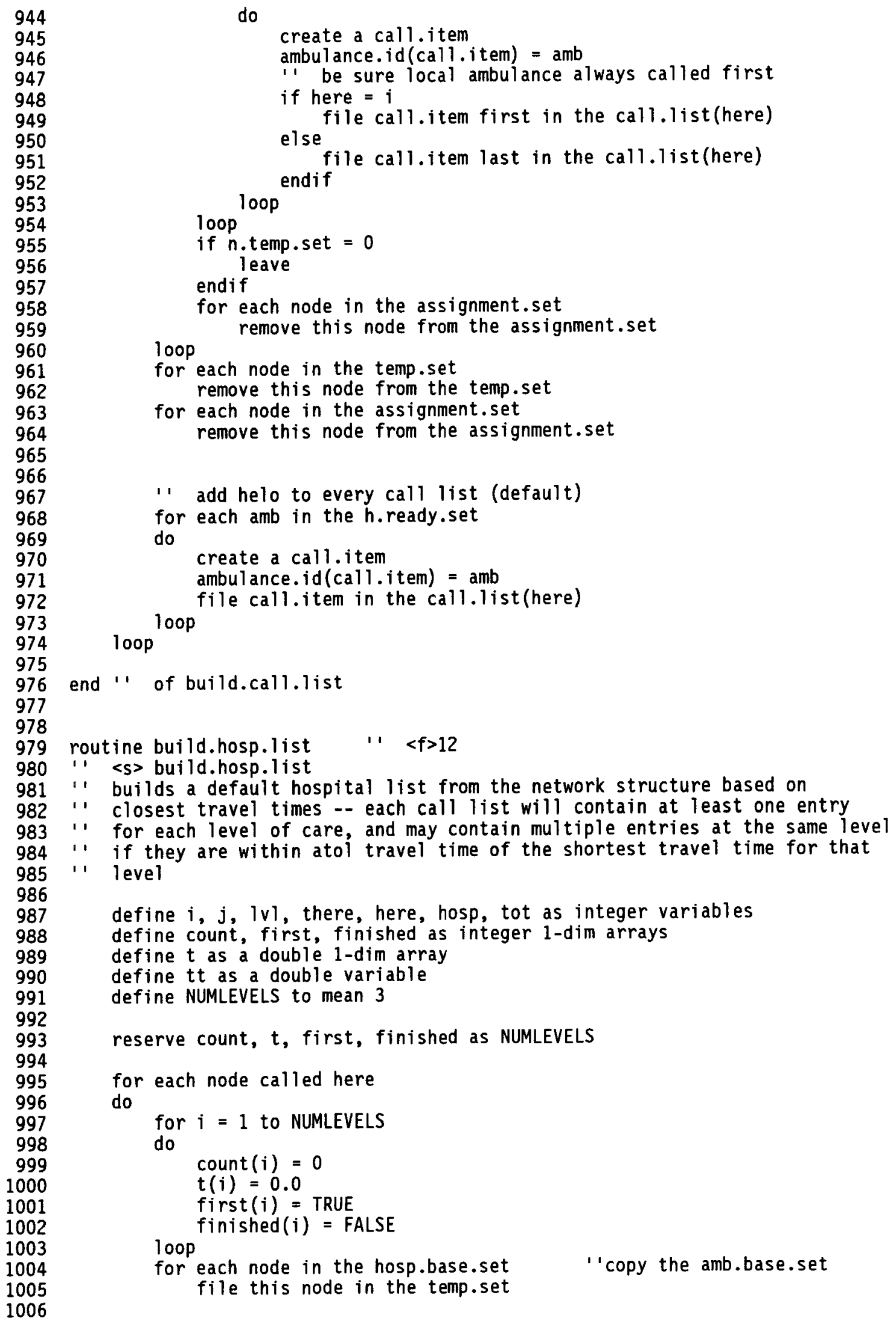




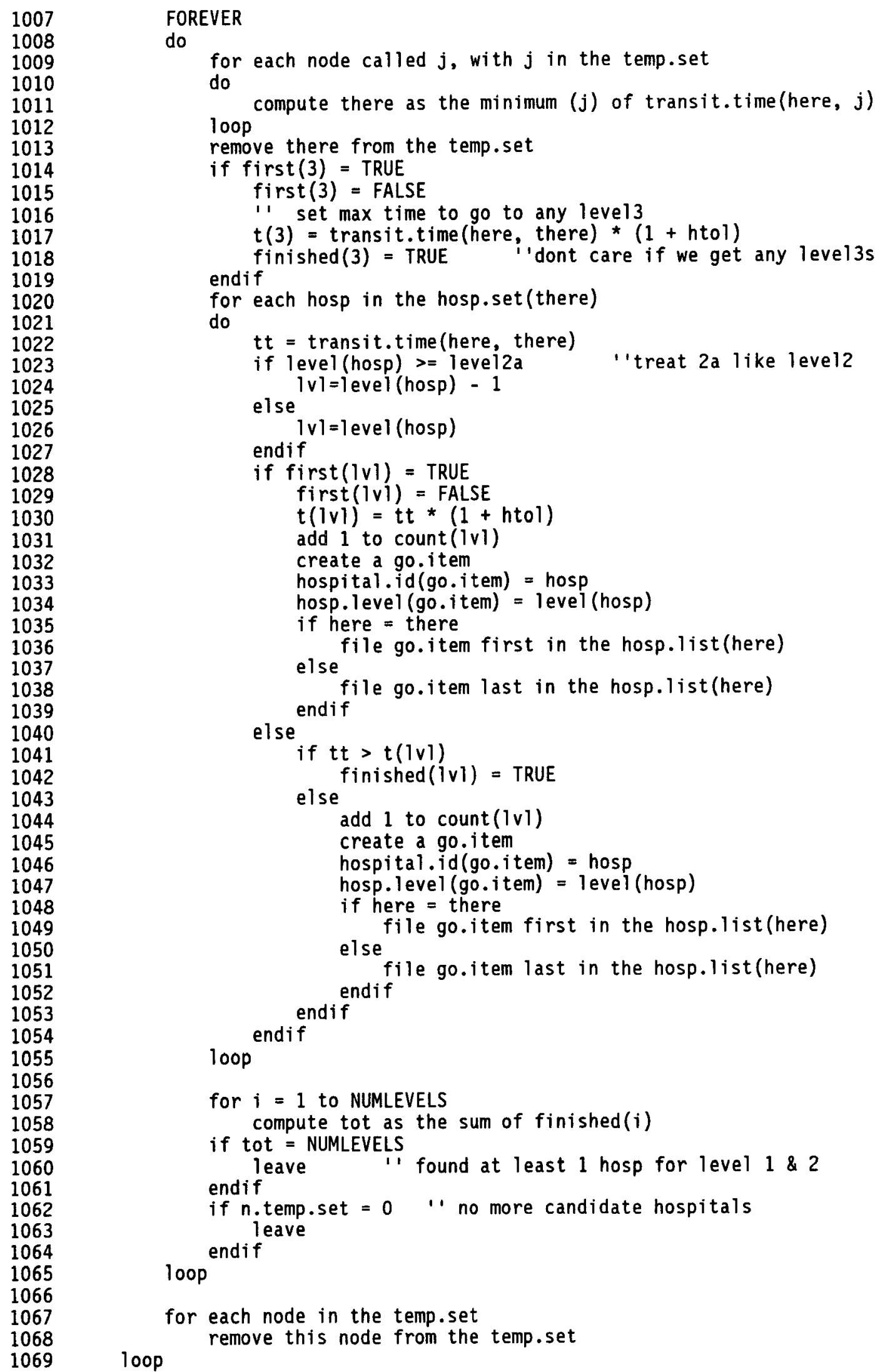




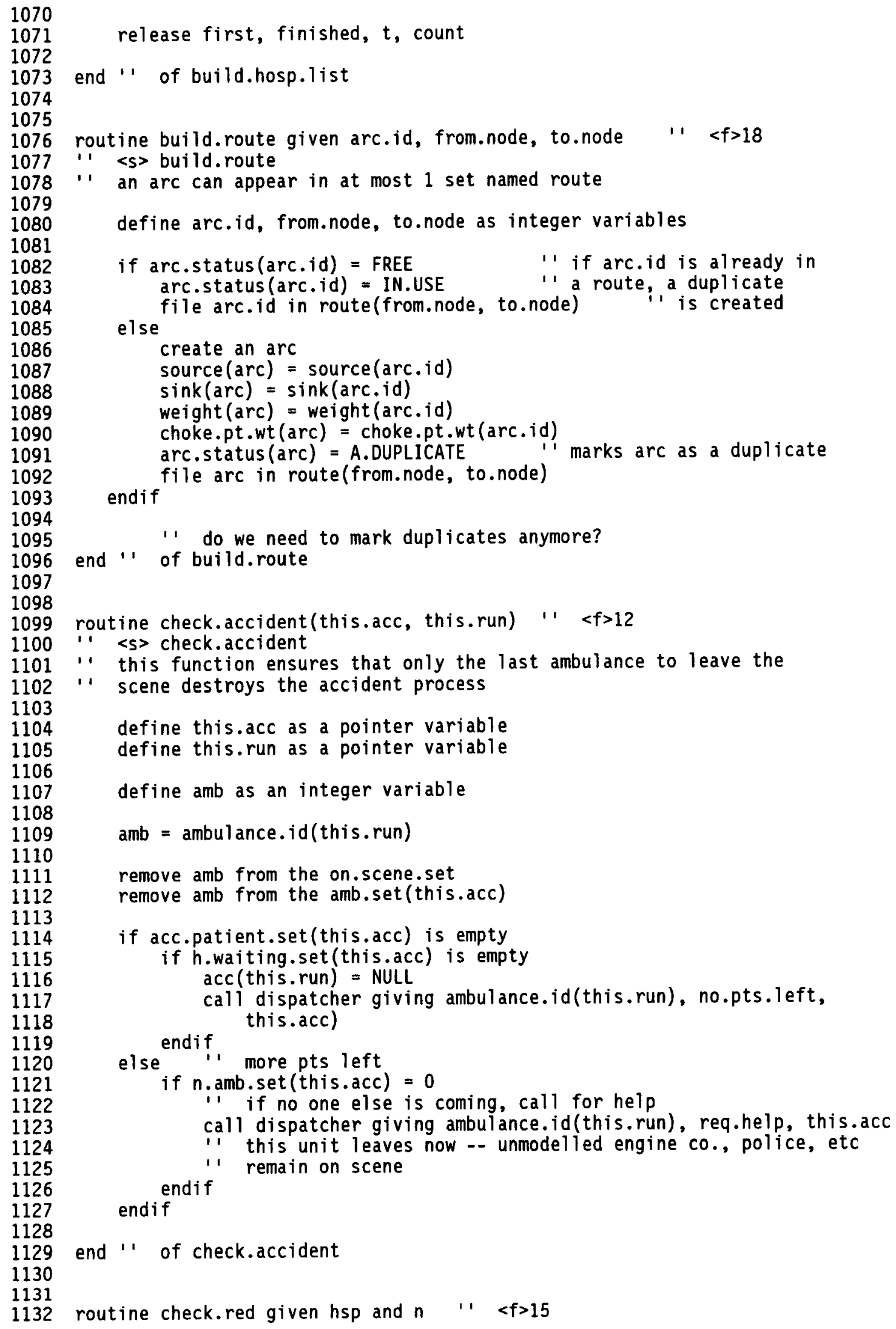




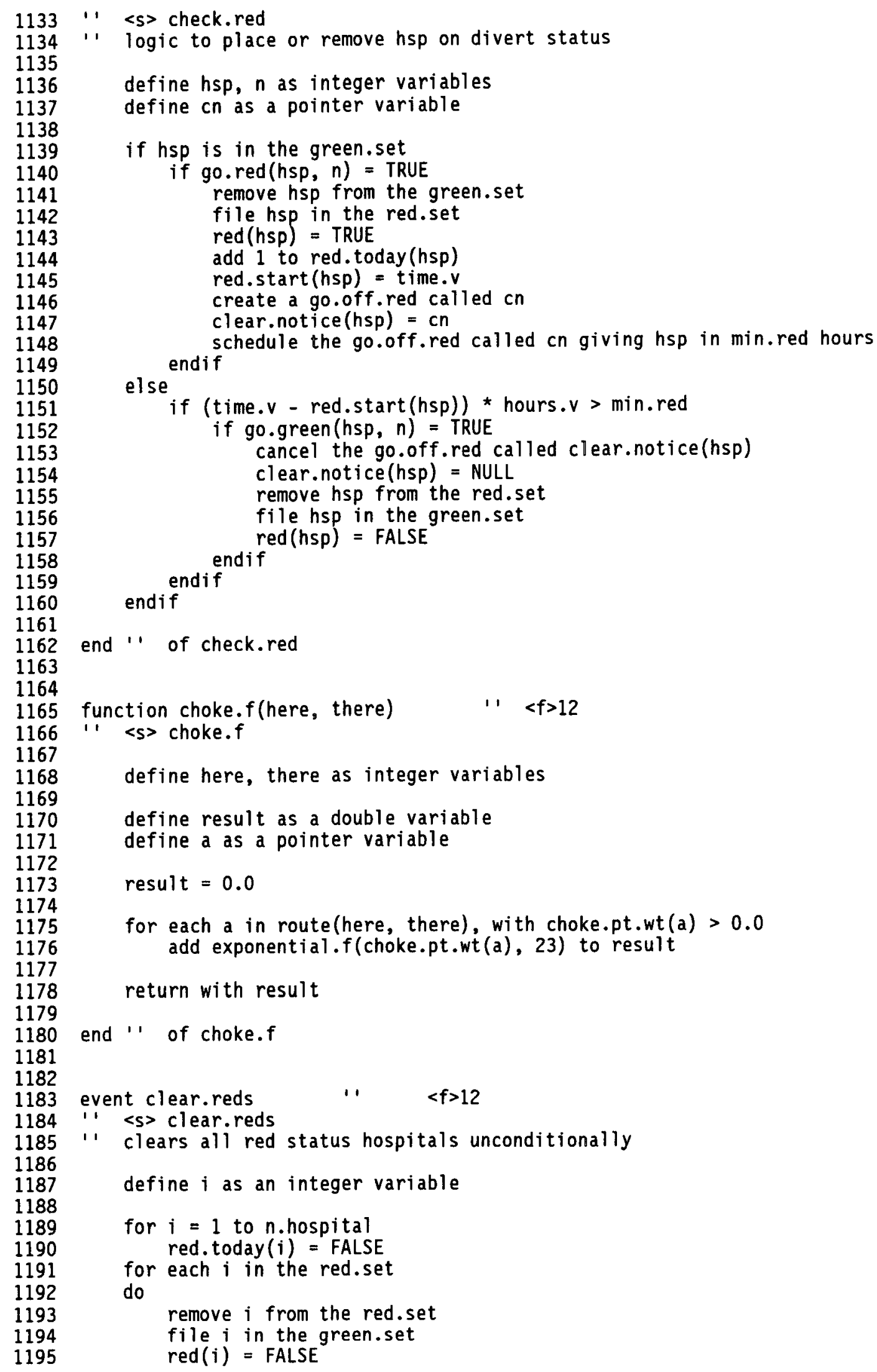




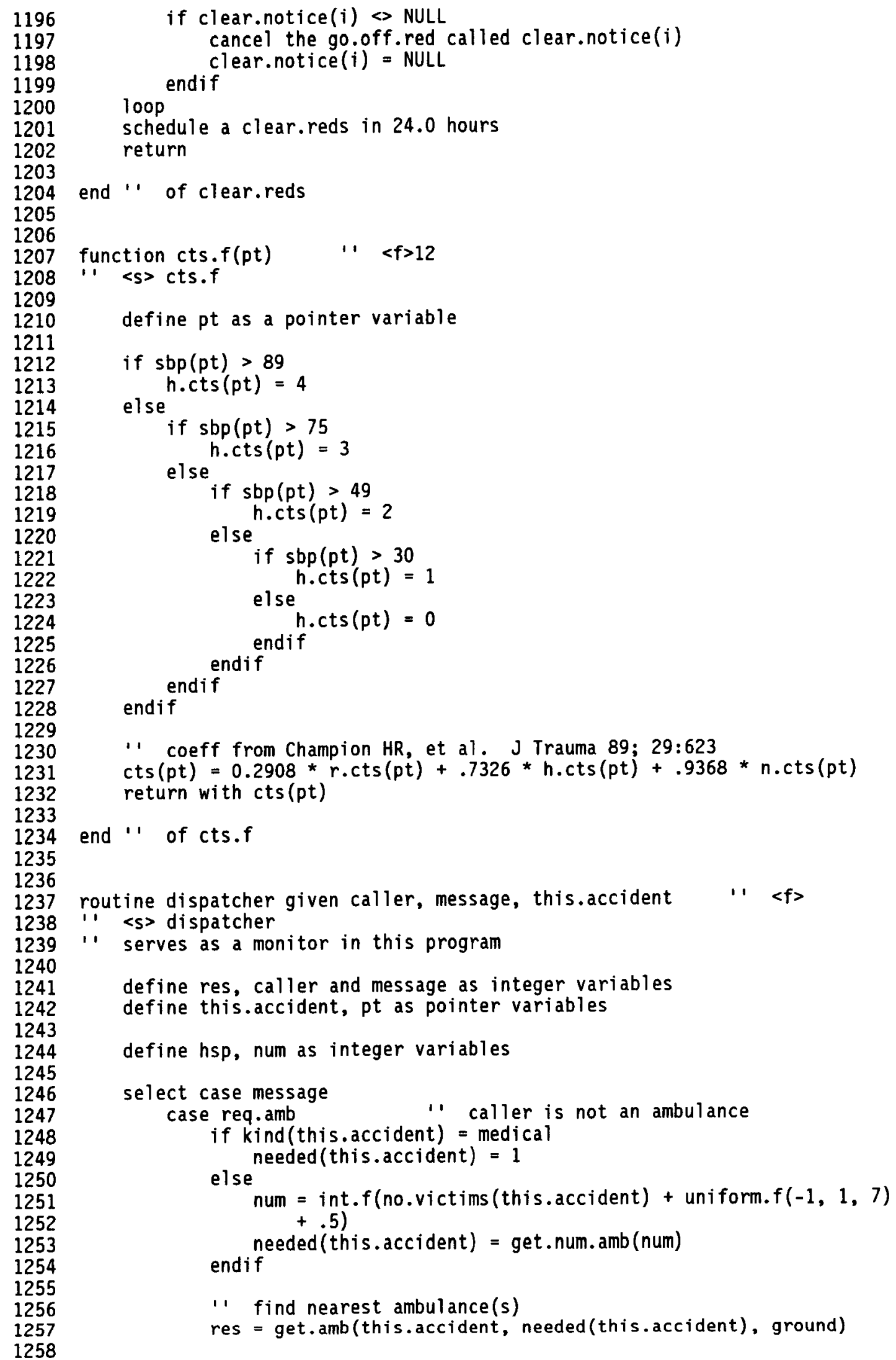




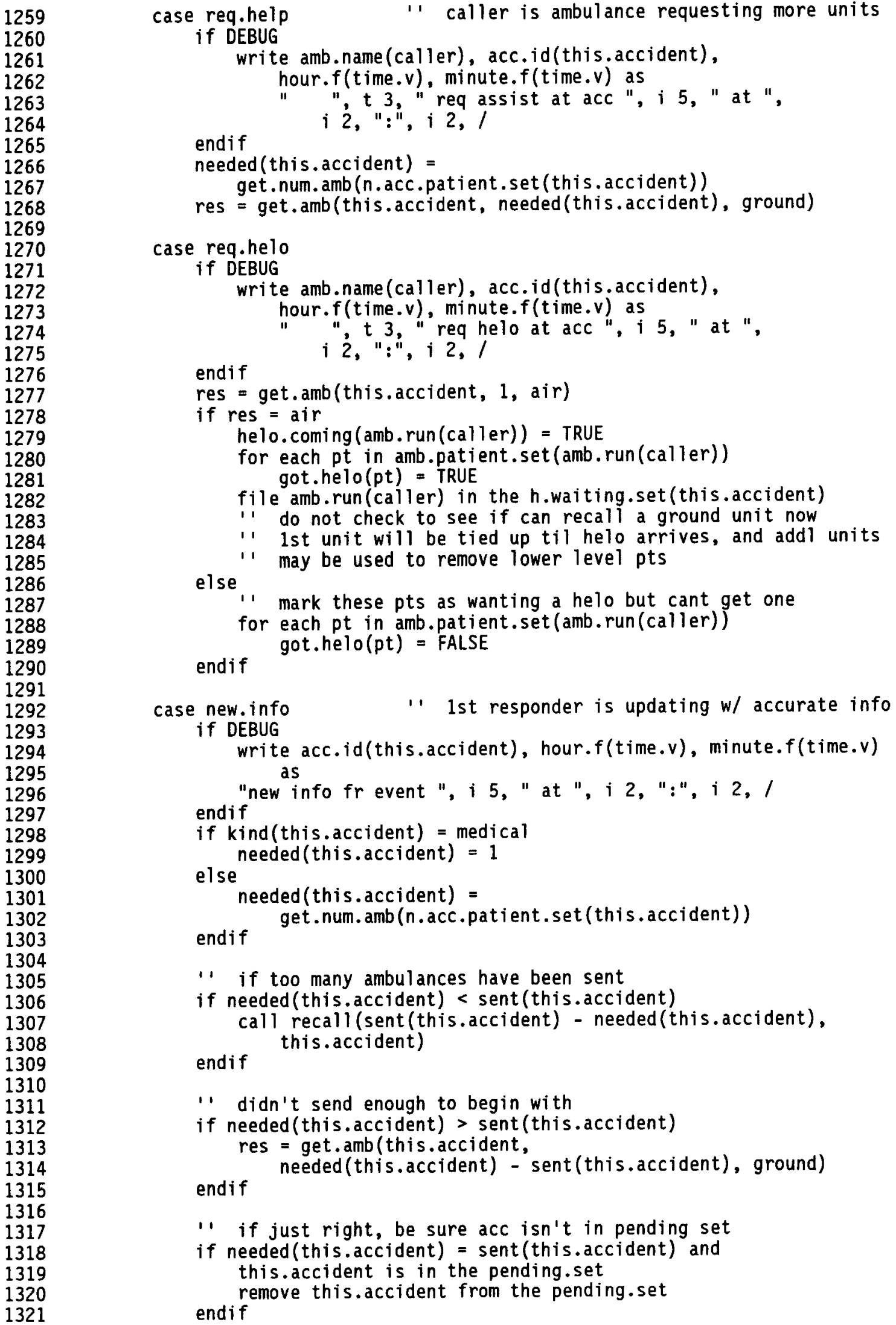


case at.scene

remove caller from the to.scene.set

file caller in the on.scene.set

"if this ambulance is the first to arrive

if acc.arrive.time(this.accident) $=0$ acc.arrive.time (this.accident) $=$ time. $v$

$\therefore$ if update hasn't been sent yet, force it to be

' sent now

if updated(this.accident) = FALSE

interrupt the accident called this.accident

time. a (this.accident) $=0$

endif resume the accident called this.accident

case no.pts. left

' reactivate the accident, allowing it to end

' a DESTROY may not free al located memory, per CACI

if this.accident is in the pending.set remove this.accident from the pending.set endif

if amb.set(this.accident) is not empty endif call recall(n.amb.set(this.accident), this.accident)

$\because$ cant use an else here, because the recall function might

i cause the amb.set to become empty

if amb.set(this.accident) is empty endif resume the accident called this.accident

case to.hosp

' find receiving hosp

hsp $=$ find.hosp (caller)

travel.time (caller) = get.travel.time (cur.location(caller), hosp.base(hsp), type(caller), 13)

hosp (amb.run(caller)) = hsp

file caller in the to.hosp.set

case at.hosp

remove caller from the to.hosp.set

file caller in the at.hosp.set

case to.base

file caller in the to.base.set

destination (amb.run(caller)) = amb.base(caller)

travel.time (caller) = get.travel.time(cur. location (caller), amb.base(caller), type(caller), 17)

case at.base

remove caller from the to.base.set

file caller in the at.base.set

if type(caller) = ground

file caller in the ready. set

if calls.pending remove the first accident from the pending.set endif res = get.amb(accident, 1, ground) " should be only 1 in else file caller in the h.ready.set endif 
default print 1 line with message thus Invalid message $\star \star \star$

endselect

end " of dispatcher

function done(patient) $\quad 1, \quad<f>12$
$1,<s>$ done

define patient as a pointer variable

if condition(patient) = alive ' 'if just now died

if living(patient) = FALSE return with TRUE

endif endif

if phase (patient) = pvt.trav

if time.v > pvt.tr.arrive return with TRUE

endif endif

if phase (patient) $=$ resus

if time. $v>=$ injury.time (patient) + (wait.time(patient) + transp.time (patient) + scene.time(patient) + resus.time(patient)) / hours.v / minutes.v endif return with TRUE

endif

if change.flag(patient) = TRUE

endif return with TRUE

return with FALSE

end " " of done

routine final. report $\quad \prime \prime<f>18$

<s> final.report

define correction as a double variable

use 4 for output

correction = no.runs / (no.runs - 1)

print 8 lines with no.runs, min.length, g.mean.dur, sqrt.f(g.var.dur * correction), g.max.dur, g.mean.accs, sqrt.f(g.var.accs * correction), g.max.accs, 100 * no.blunt / (no.runs * g.mean.accs), g.mean.pts, sqrt.f(g.var.pts * correction), g.max.pts, no.deaths / no.runs and est.deaths / no.runs thus

Results after $* *$ runs of at least $* * * *$ days per run

duration

average sd (of runwise means) no. accidents $\%$ blunt

$\star \star \star \star *$ $\star \star \star * * *$

$\max$

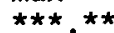
$\star \star \star *$ 


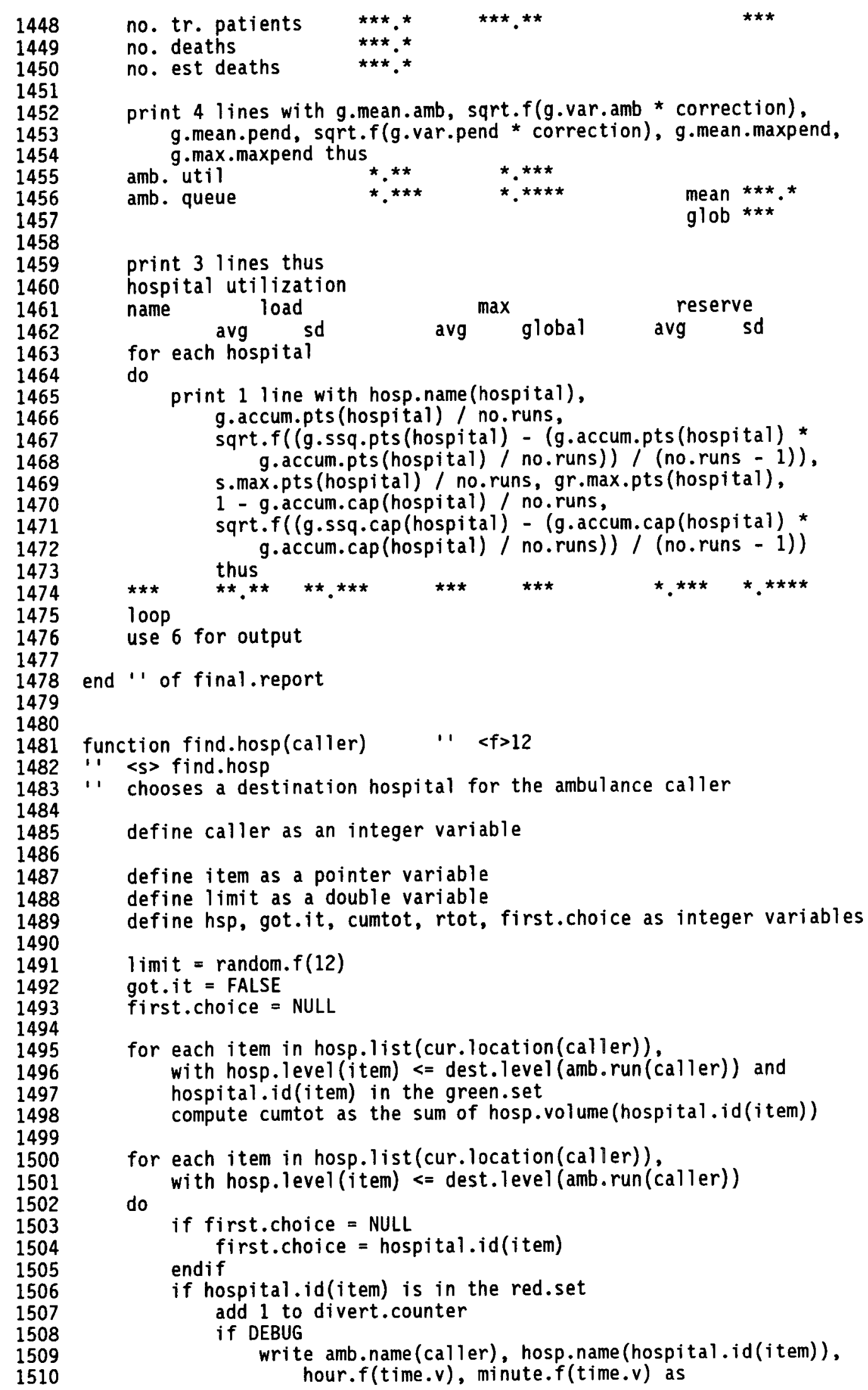

no. tr. patients $\quad \star \star \star * * \quad \star \star \star \star * \star * \quad \star \star \star \star$ no. deaths $* * * * *$ no. est deaths $\star \star \star \star * \star$

print 4 lines with g.mean.amb, sqrt.f(g.var.amb * correction), g.mean.pend, sqrt.f(g.var.pend * correction), g.mean.maxpend, g.max.maxpend thus

amb. util

amb. queue

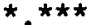

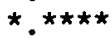

mean $\star * \star * *$

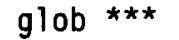

print 3 lines thus

hospital utilization

name load avg avg global max avg sd

for each hospital 


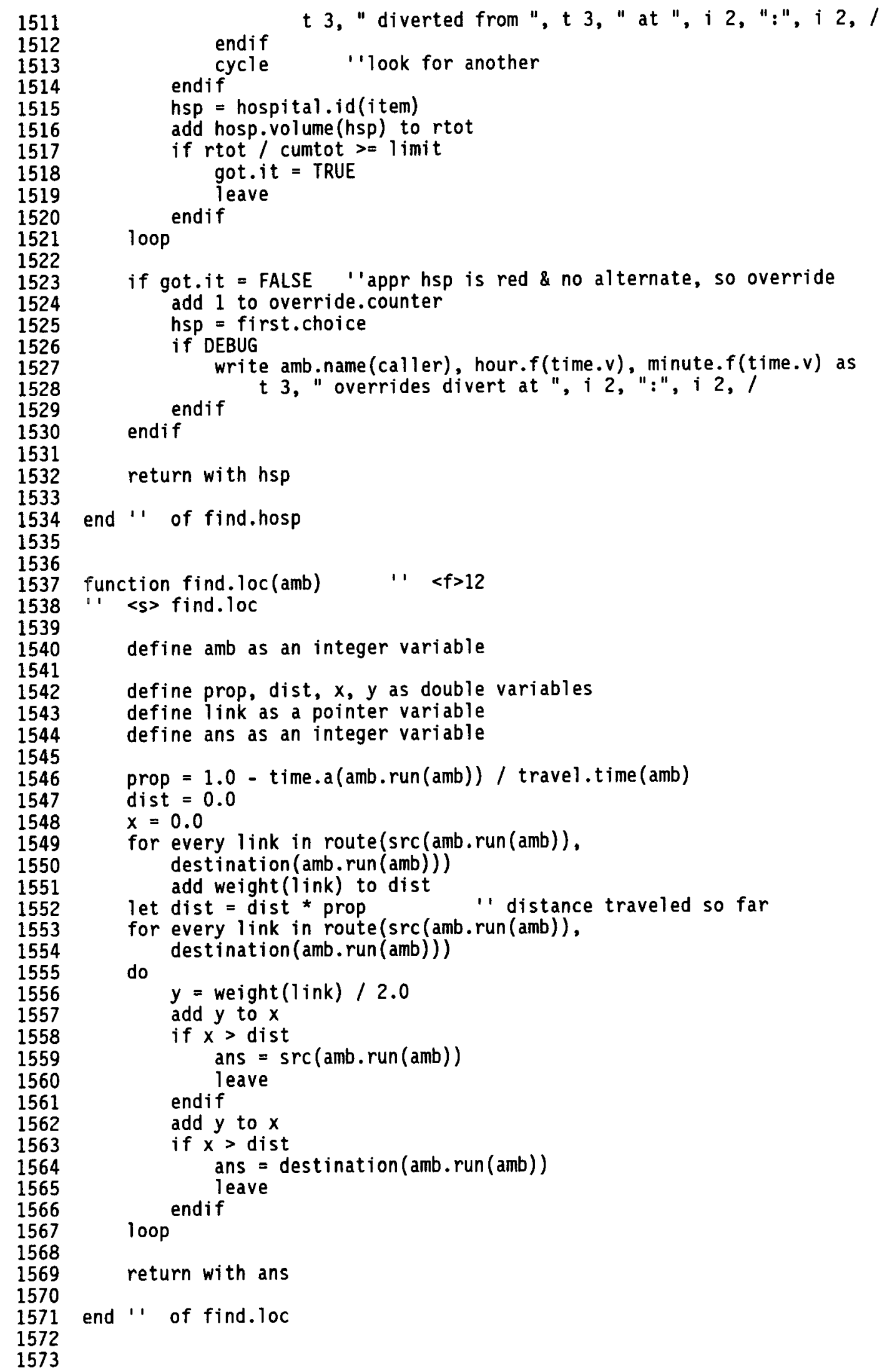




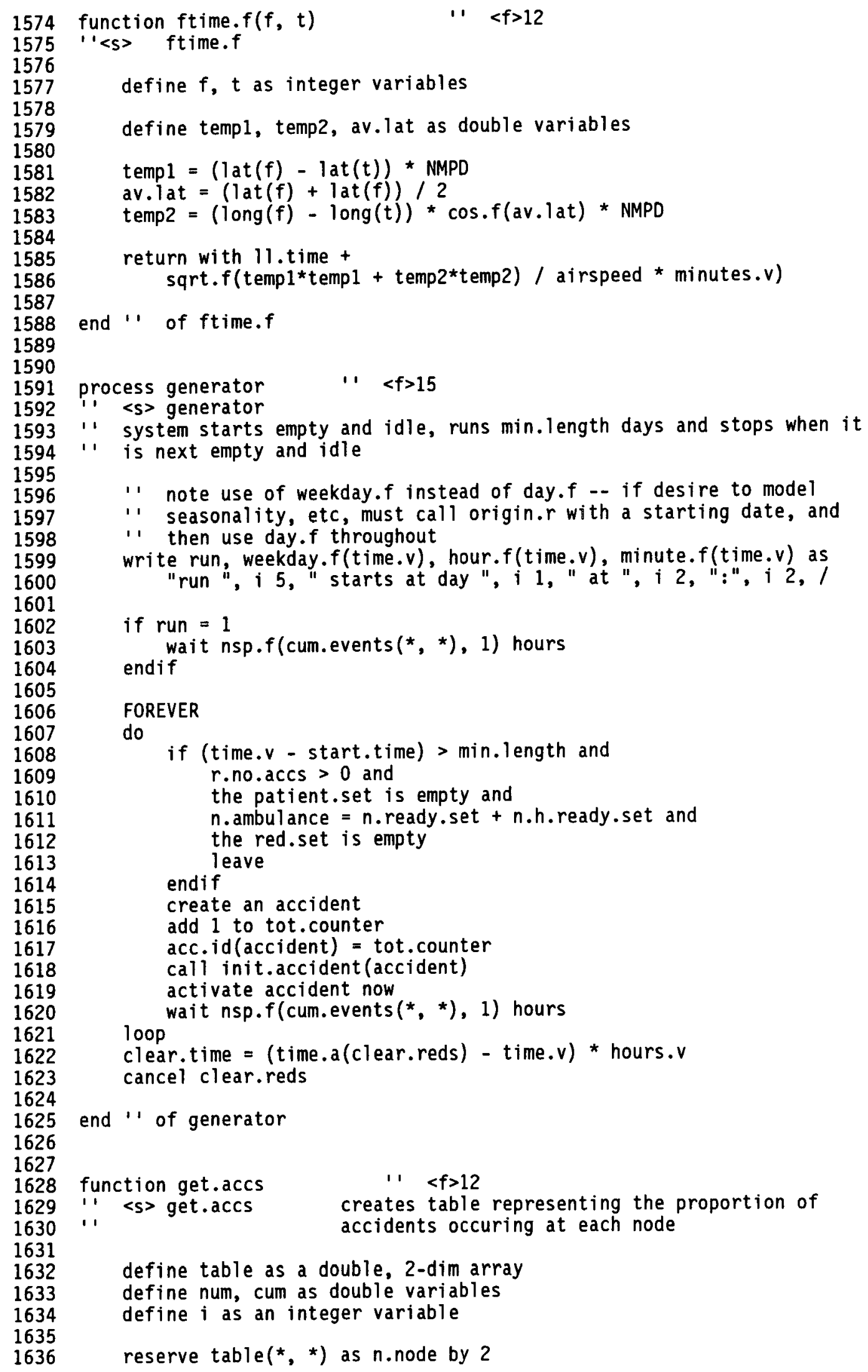

define $f, t$ as integer variables

define templ, temp2, av.lat as double variables

templ $=(1 \mathrm{at}(f)-1 \mathrm{at}(\mathrm{t})) \star$ NMPD

av.lat $=(1 \operatorname{at}(f)+1$ at $(f)) / 2$

temp2 $=($ long $(f)-$ long $(t)) * \cos . f(a v .1$ at $) * N M P D$

return with 11. time + sqrt.f(temp1*temp1 + temp2*temp2) / airspeed * minutes.v)

end ' of ftime.f 


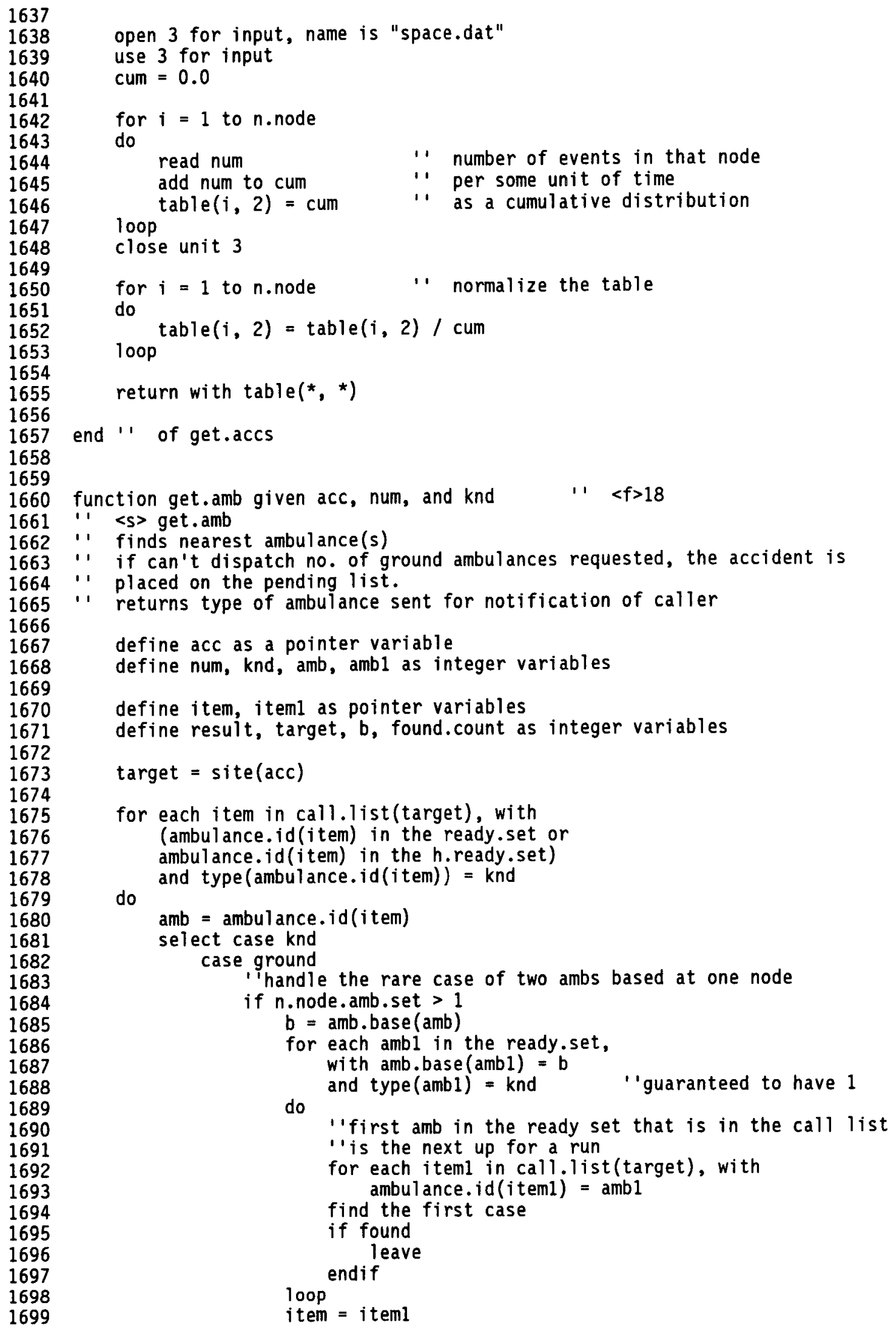


1719

1720

1721

1722

1723

1724

1725

1726

1727

1728

1729

1730

1731

1732

1733

1734

1735

1736

1737

1738

1739

1740

1741

1742

1743

1744

1745

1746

1747

1748

1749

1750

1751

1752

1753

1754

1755

1756

1757

1758

1759

1760

1761

1762

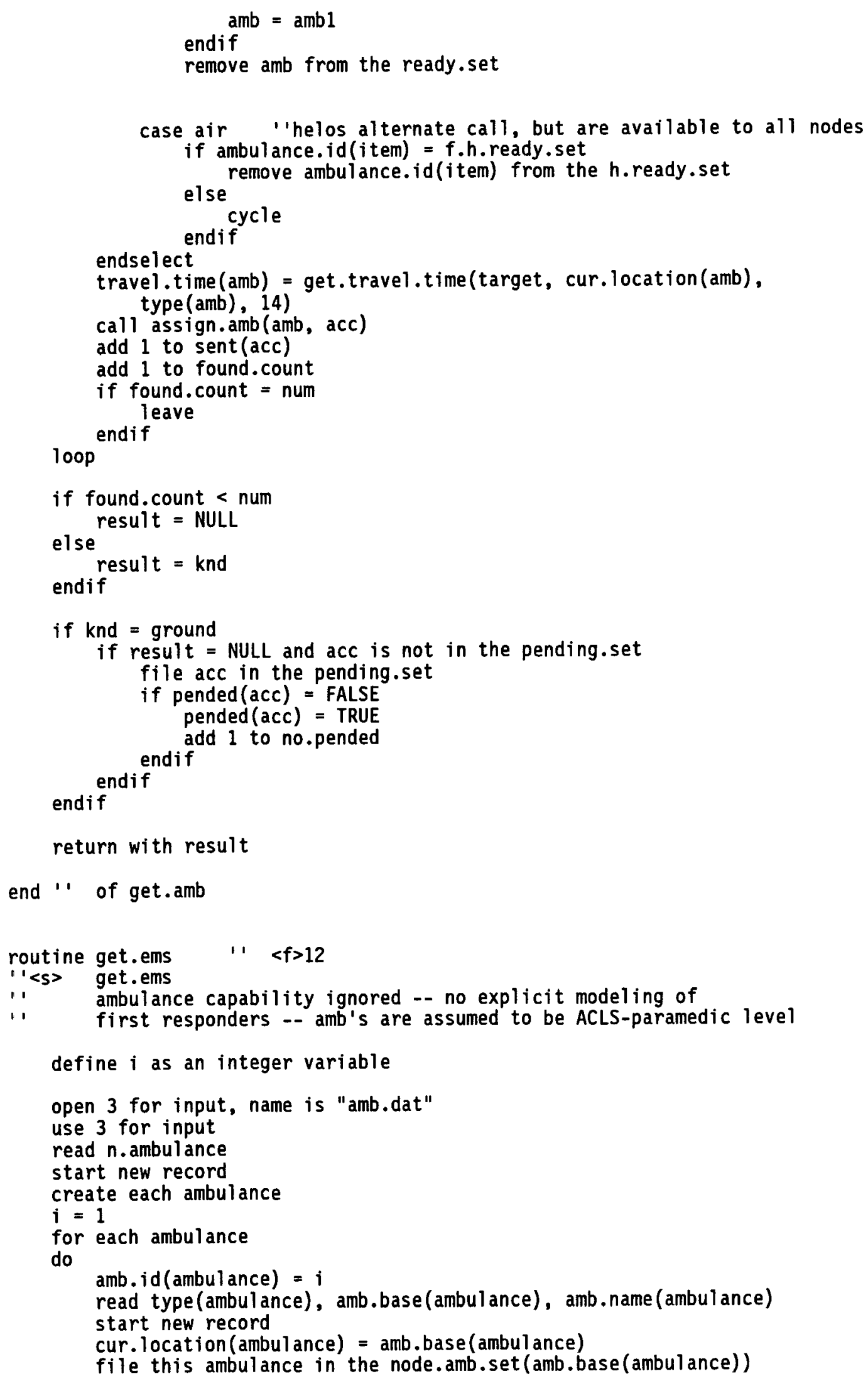


1763

1764

1765

1766

1767

1768

1769

1770

1771

1772

1773

1774

1775

1776

1777

1778

1779

1780

1781

1782

1783

1784

1785

1786

1787

1788

1789

1790

1791

1792

1793

1794

1795

1796

1797

1798

1799

1800

1801

1802

1803

1804

1805

1806

1807

1808

1809

1810

1811

1812

1813

1814

1815

1816

1817

1818

1819

1820

1821

1822

1823

1824

1825

if amb.base(ambulance) is not in the amb.base.set

file amb.base(ambulance) in the amb.base.set endif

if type (ambulance) = ground endif

file this ambulance in the ready.set

if type (ambulance) $=$ air

file this ambulance in the $h$.ready. set

endif add 1 to num.helo

file this ambulance in the at.base.set

add 1 to $i$

loop

close unit 3

end '' of get.ems

routine get.hosp $\quad$ ' $<f>12$

I <s> get.hosp

define $i$ as an integer variable

open 3 for input, name is "hosp.dat"

use 3 for input

read $n$.hospital

start new record

create each hospital

$i=1$

for each hospital

do

hosp.id(hospital) $=i$

read hosp.name(hospital), hosp.base(hospital), hosp.volume(hospital), level (hospital), capacity(hospital), can.divert(hospital)

start new record

file this hospital in the green.set

file this hospital in hosp.set(hosp.base(hospital))

if hosp.base(hospital) is not in the hosp.base.set endif file hosp.base(hospital) in the hosp.base.set

full (hospital) = FALSE

red(hospital) = FALSE

red.today (hospital) = FALSE

add 1 to 1

loop

close unit 3

end ' ' of get.hosp

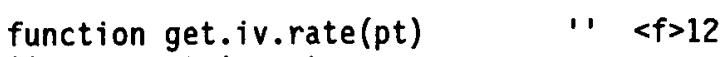

function get.level (pt) $\quad$ II $<f>12$ 


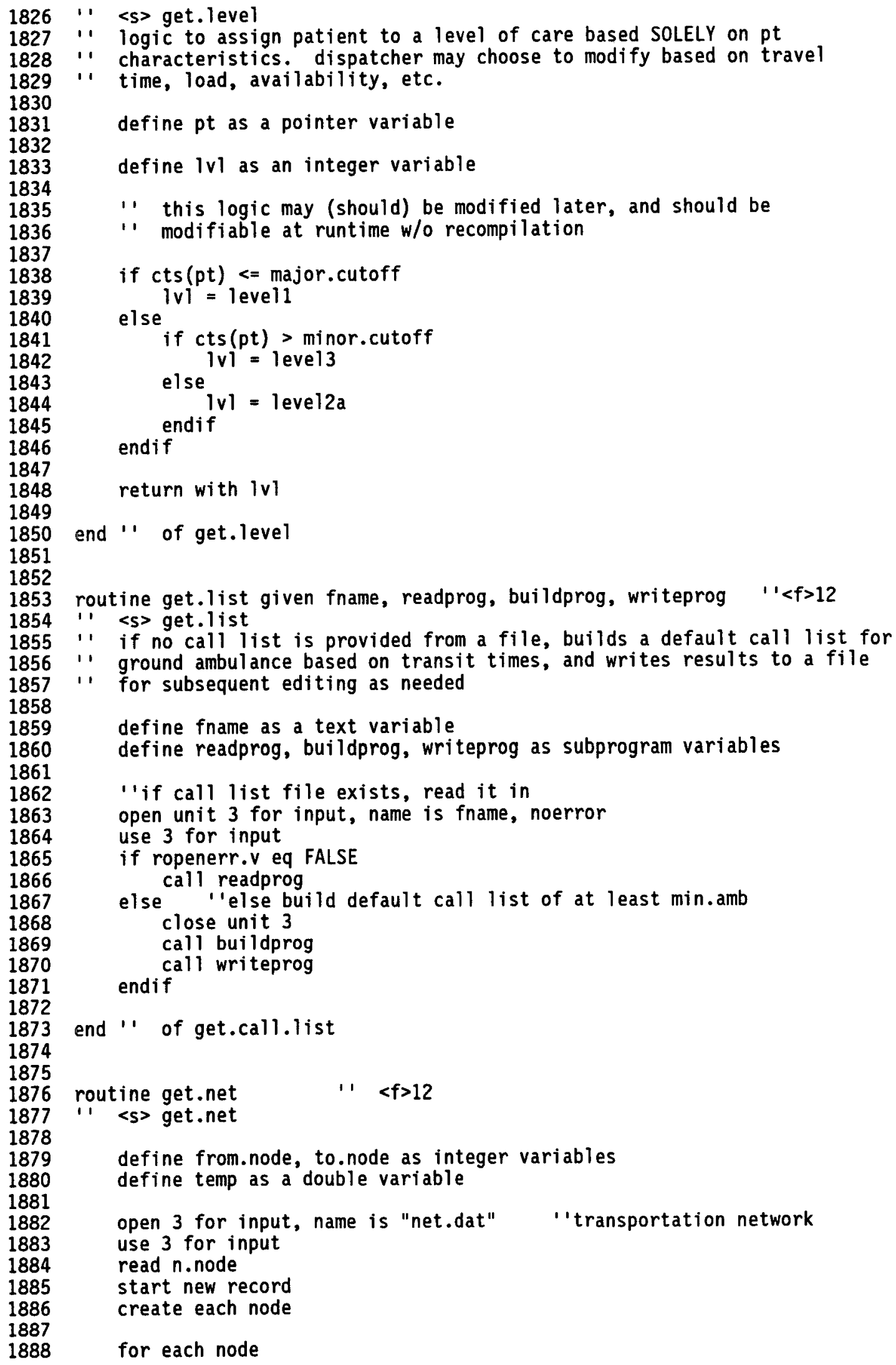




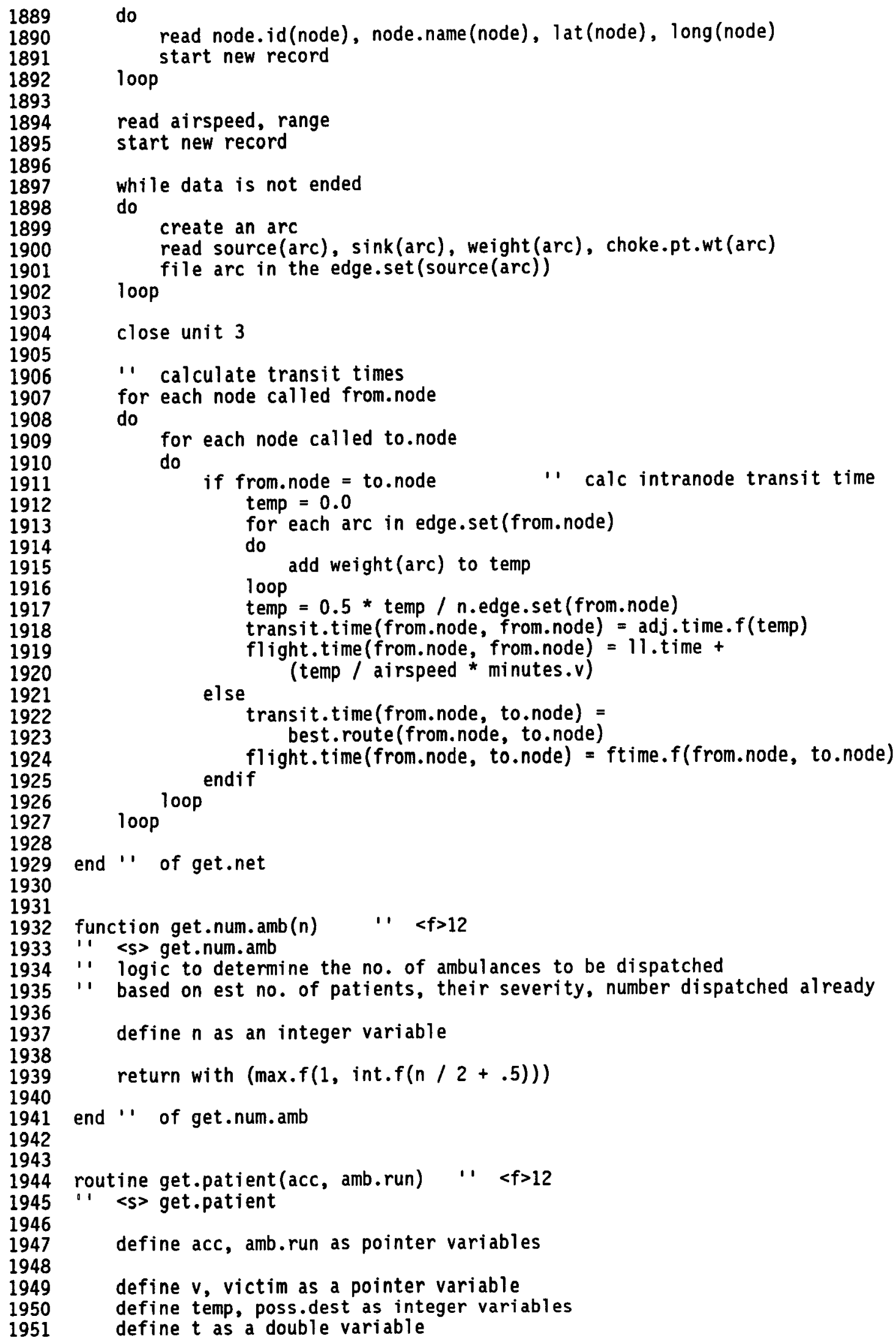

1931

1932

1933

1934

1935

1936

1937

1938

1939

1940

1941

1942

1943

1944

1945

1946

1947

1948

1949

1950

1951

do

read node.id(node), node.name(node), lat (node), long(node)

loop start new record

read airspeed, range

start new record

while data is not ended

do

create an arc

read source(arc), sink(arc), weight (arc), choke.pt.wt (arc)

loop

file arc in the edge.set (source $(\operatorname{arc})$ )

close unit 3

' calculate transit times

for each node called from. node

do

for each node called to.node

do

if from.node $=$ to. node $\quad$ " calc intranode transit time

temp $=0.0$

for each arc in edge.set(from.node)

do

loop add weight(arc) to temp

temp $=0.5 *$ temp $/ n$.edge.set (from.node)

transit.time (from. node, from.node) $=$ adj.time.f(temp)

flight.time (from. node, from.node) $=11$.time +

(temp / airspeed * minutes.v)

else

transit.time(from.node, to.node) = best. route(from. node, to.node) endif

flight.time(from.node, to.node) $=f t i m e . f($ from.node, to.node)

loop loop

end ' ' of get. net

function get.num. $a m b(n) \quad$ ' $\quad<f>12$

$\because \quad<s>$ get.num.amb

$\therefore$ logic to determine the no. of ambulances to be dispatched

$\because$ based on est no. of patients, their severity, number dispatched already

define $n$ as an integer variable

return with $(\max . f(1$, int.f $(n / 2+.5)))$

end " of get.num.amb

routine get.patient (acc, amb.run) $\quad$ ' $<f>12$

i $<s>$ get.patient

define acc, amb.run as pointer variables

define $v$, victim as a pointer variable define temp, poss.dest as integer variables define $t$ as a double variable 
for each $v$ in the acc.patient.set (acc)

do

compute victim as the min(v) of cts.f(v)

1 this should update every pts cts

loop

remove victim from acc.patient.set(acc)

phase (victim) $=$ scene. $r x$

transp.mode (victim) = type (ambulance.id(amb.run))

file victim in amb.patient.set(amb.run)

temp = get. level (victim)

dest. level (amb.run) = min.f(dest.level (amb.run), temp)

iv.start.time (victim) = time.v + (scene.time(amb.run) /

hours.v / minutes.v) / 2

resp.time (victim) = scene.time(amb.run) / 3

schedule a resp.support(victim) in resp.time(victim) minutes

iv. $\operatorname{rate}($ victim) $=$ get.iv.rate(victim)

" should helo be requested? if so, pt is still assigned to

$\therefore$ amb for scene rx, but flag is set to make him wait for helo arrival poss.dest $=$ find.hosp (ambulance.id(amb.run))

if temp < level3

if temp = levell

$t=$ major.time

else

$t=$ minor.time

endif

if transit.time(site (acc), hosp.base(poss.dest)) $>t$ need.helo(victim) = TRUE call dispatcher giving ambulance.id(amb.run), req.helo, acc

endif endif

change. flag(victim) = TRUE

end ' ' of get.patient

routine get.sim $\quad$ ' $<f>12$

<s> get.sim

define $i$, no.streams as integer variables

open 3 for input, name is "ems.dat"

use 3 for input

read no. runs

start new record

read min. length

start new record

read tr.prop

start new record

read pts.per.acc

start new record

read alarm.lag

start new record

read info. $1 \mathrm{ag}$

start new record

read m.secure, s.secure ''mean \& sd secure time

start new record

read $p$.secure

start new record

read t.to.pt

' 'min run length in days

' trauma proportion

start new record
' 'initial alarm latency in minutes

' 'delay til first responder reports

' 'prob of needing secure time

' time til patient 


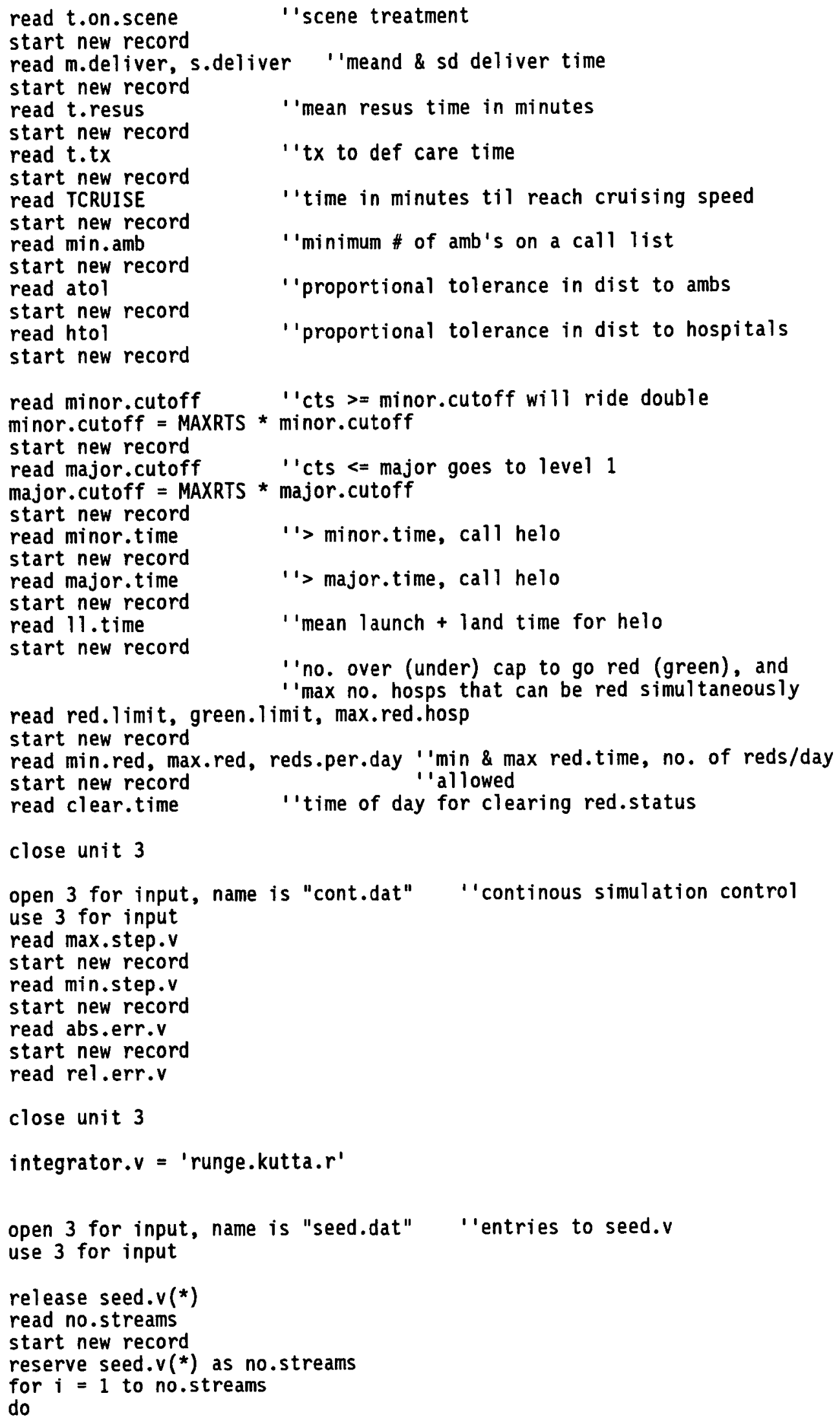




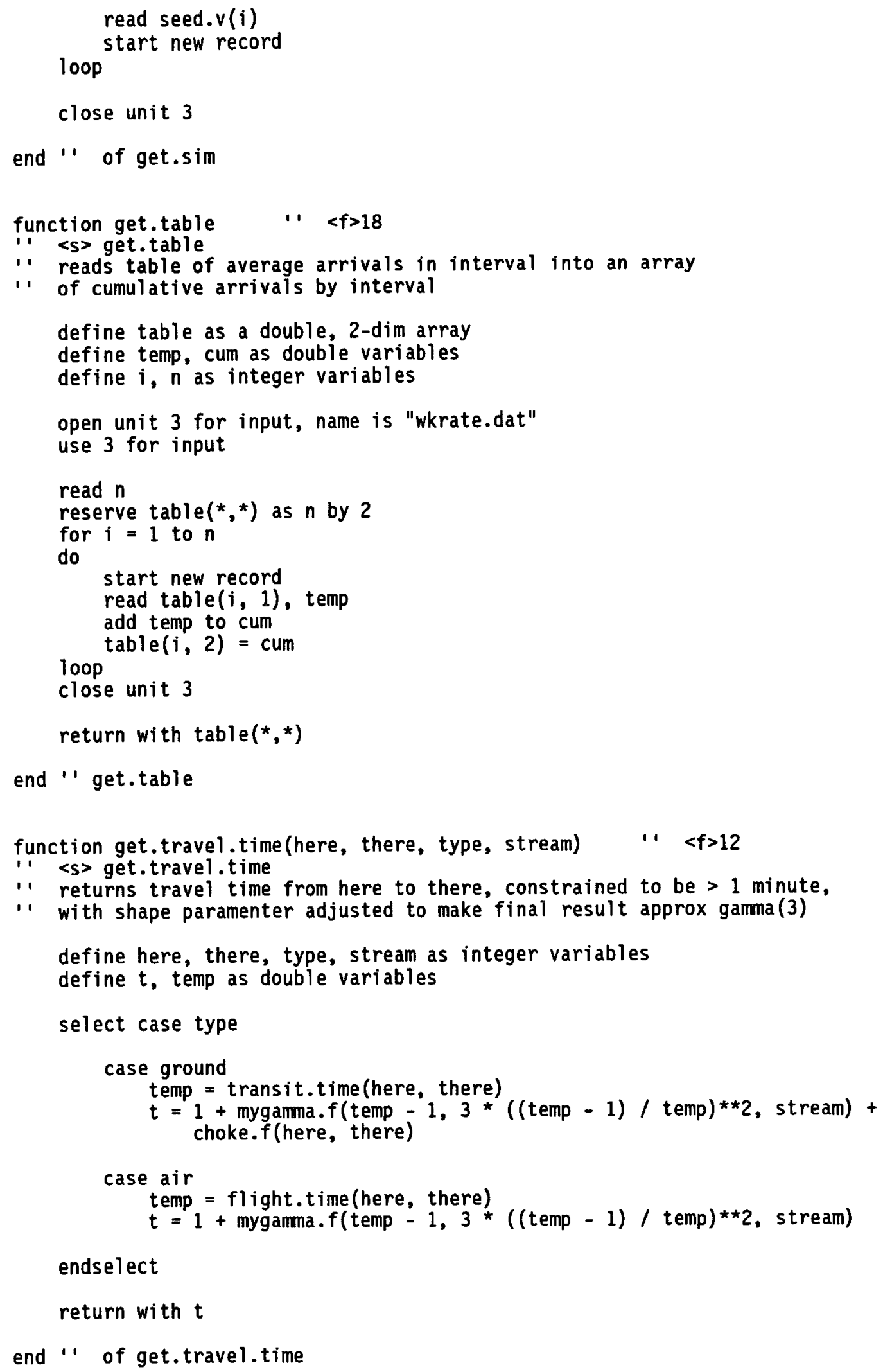




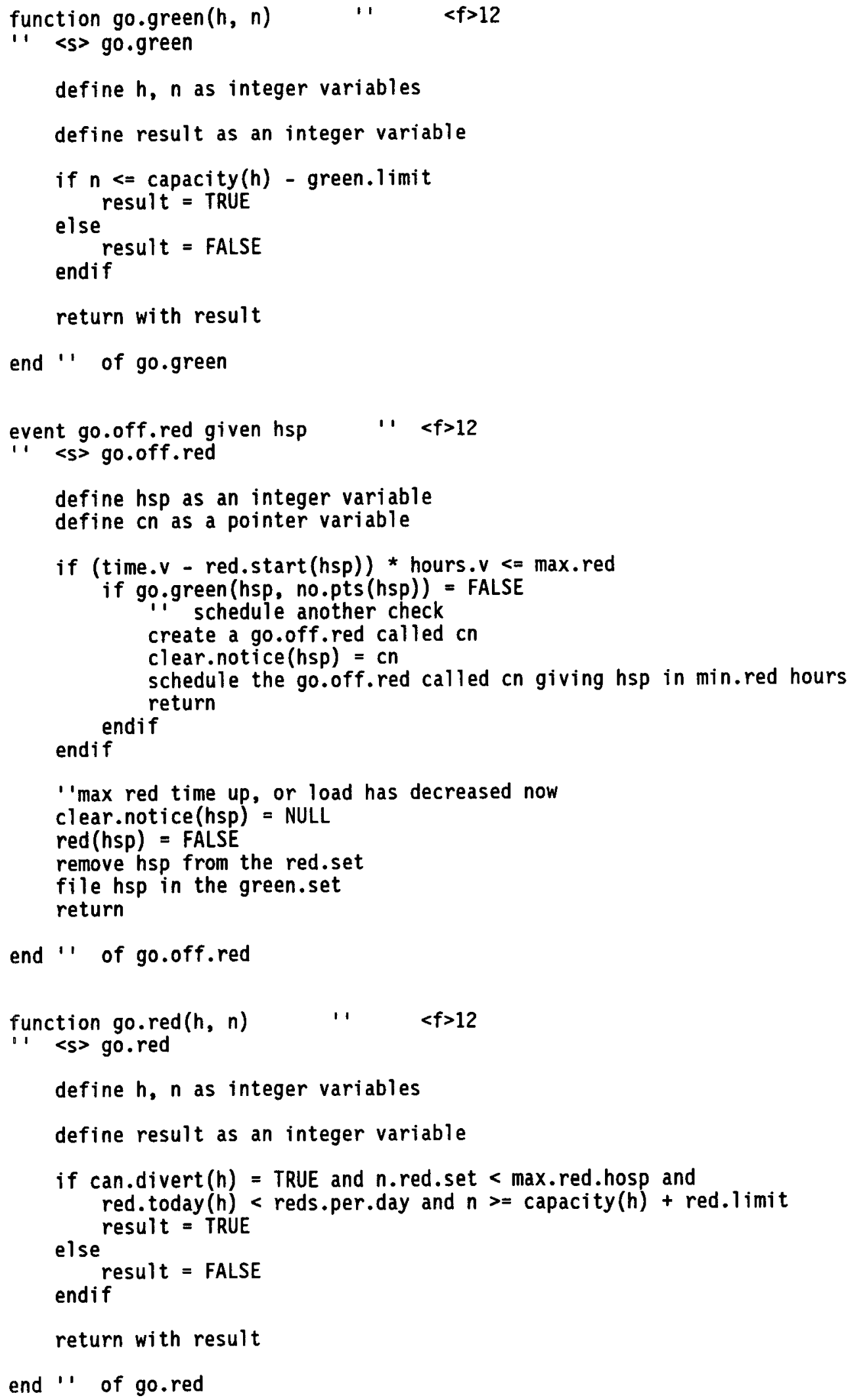




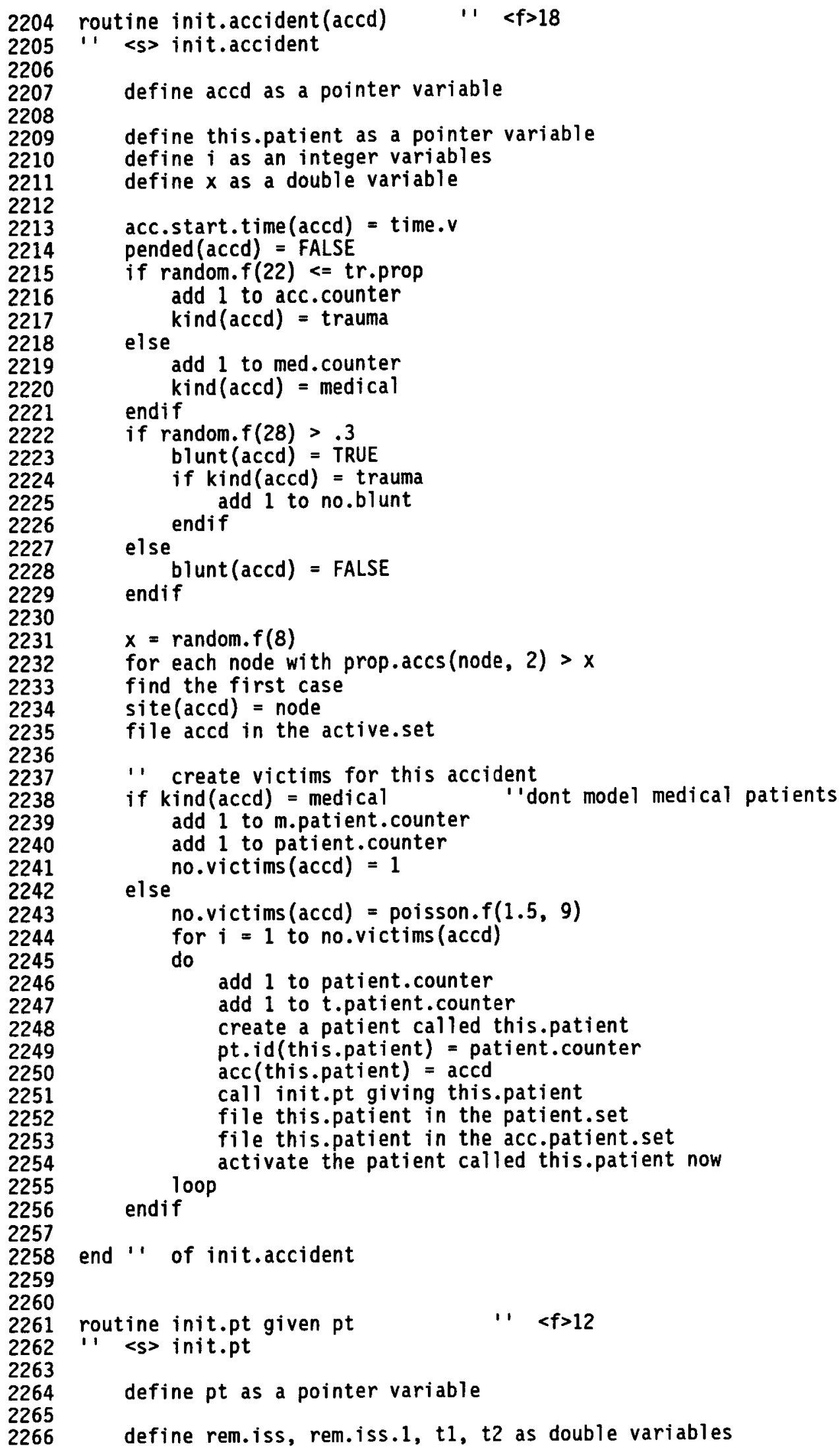




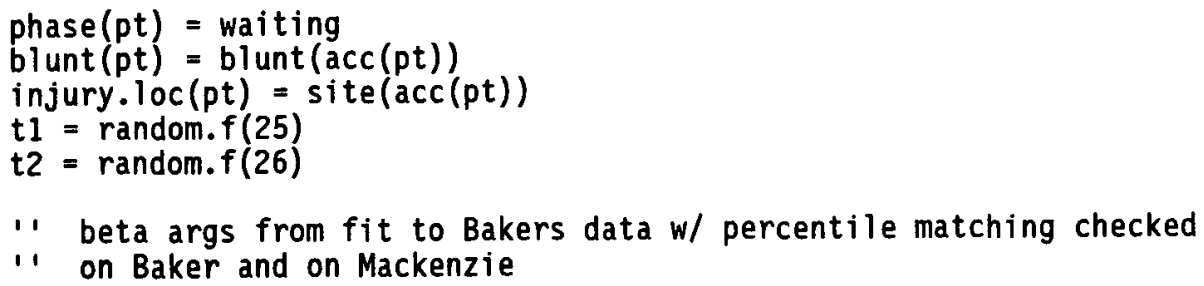


end '" of init.pt

$\begin{array}{lll}\text { routine initialize } & 1 & <f>18 \\ 1,<s>\text { initialize } & & \end{array}$

' ' get time series of runs

cum.events $\left(*,{ }^{*}\right)=$ get.table

' get general simulation data

call get.sim

" get transportation network

call get.net

$\because$ get hospitals

call get.hosp

' get ambulances

call get.ems

' get ambulance call list

call get.list("call.dat", 'read.call.list', 'build.call.list', 'write.call.list')

' get hospital preference list

call get.1 ist("go.dat", 'read.hosp.1ist', 'build.hosp.1ist', 'write.hosp.list')

' output net, call list, etc for confirmation

call print.net

1 initialize distribution of accidents across nodes

prop.accs $(*, *)=$ get.accs

end ' ' of initialize

function laplace.f(location, scale, stream)

returns a laplace variate -- for use in the gamma function

define location, scale as double variables

define stream as an integer variable

define $y, u$ as double variables

let $u=$ random. $f$ (stream)

if $u<.5$

else

let $y=\log _{. e . f(2 * u) * \text { scale }}$

endif let $y=-\log . e . f(2.0-2 * u) *$ scale

return with location $+y$

end "'laplace.f

function lin.int.f(index, table) $\quad$ ' $<f>18$

1 <s lin.int.f

- performs linear interpolation as follows:

' given a value $b=B$ and $a \operatorname{table}(a, b)$, where $b$ is a cumulative value, 1 returns an interpolated value for a 


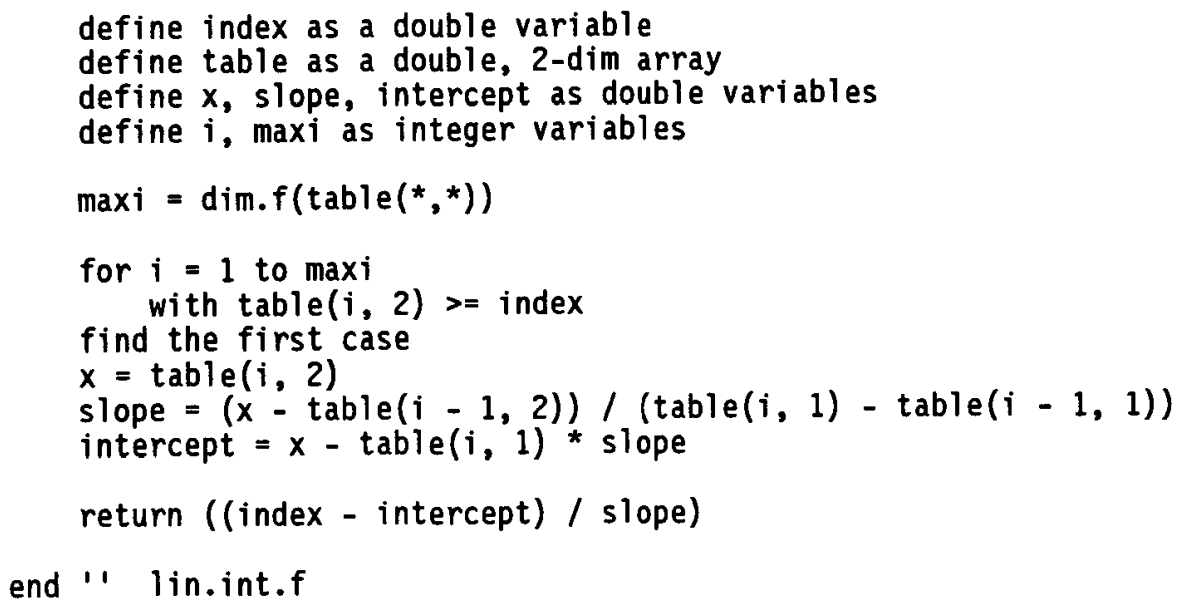


define b, temp, $y, u, g$, scale, $u 1, u 2, p, q$ as double variables

left routine no.pts given hospital ' $<f>12$

$\because$ <s> no.pts

$\therefore$ used to ACCUMULATE pt stats by hospital -- could have been done 
2544

2545

2546

2547

2548

2549

2550

2551

2552

2553

2554

2555

2556

2557

2558

2559

2560

2561

2562

2563

2564

2565

2566

2567

2568

2569

2570

2571

2572

2573

2574

2575

2576

2577

2578

2579

2580

2581

define hospital as an integer variable

define $n$ as an integer variable

define inc as a double variable

enter with $n$ ' 'new value for no.pts

inc $=$ time.v - update.time(hospital)

add (no.pts(hospital) * inc) to r.accum.pts(hospital)

add (full(hospital) * inc) to r.accum.cap(hospital)

if $n>=$ capacity(hospital)

else

full (hospital) = TRUE

endif

full (hospital) = FALSE

call check.red giving hospital and $n$

$r \cdot \max \cdot p t s($ hospital) $=\max \cdot f(r \cdot \max \cdot p t s($ hospital), n)

update.time(hospital) = time.v

move from $n$

return

end ' $'$ of no.pts

function nsp.f(table, stream) $\quad$ ' $<f>24$

$\because$ <s> nsp.f

$\because$ returns time til the next event for a non-stationary Poisson arrival

$\because$ process, given a table of times and cumulative mean arrivals

$\therefore$ The arrival times are assumed to wrap around when the end of the

$\because$ table is reached. Caller is responsible for ensuring that start of

1 simulation is at the time represented by the first entry in the table.

" algorithm from Cinlar, E. "Introduction to Stochastic Processes,"

'Prentice-Hall, Englewood Cliffs, NJ, 1975, pp 94-101

define table as a double, 2-dim array

define stream as an integer variable

define maxi, $x$ as integer variables

define index, max.arr, $y, z$ as double variables

$\therefore$ define tprime, last.time as saved, double variables

.1 these made global to allow full reset

$\max i=\operatorname{dim} . f(\operatorname{table}(*, *))$

$\max \cdot \operatorname{arr}=$ table $(\max i, 2)$

nsp.tprime $=n s p \cdot t$ prime $-\log \cdot e \cdot f($ random.f $($ stream $))$

$x=$ trunc.f(nsp.tprime / max.arr) ' 'number of wraps around end of table index $=\bmod . f(n s p . t p r i m e, \max . a r r)$ ' 'offset into table

$y=1$ in.int.f(index, table $(*, *))+x *$ table $(\max i, 1)$ ' time of next event

$z=y-n s p . l a s t . t i m e$

nsp.last.time $=y$

return (z)

end ' ' nsp.f

routine pass.time given pt $\quad$, $<f>12$ 


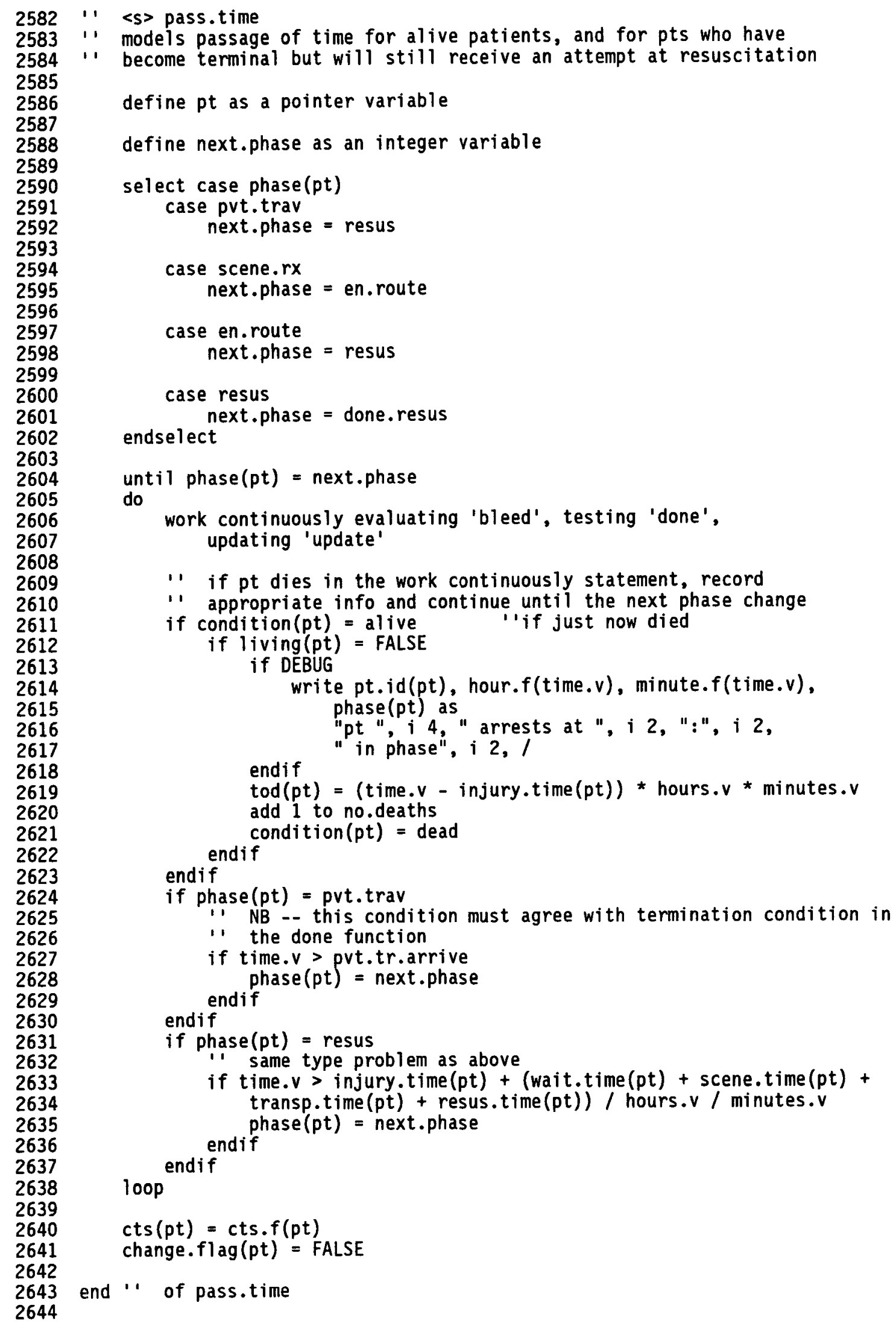


process patient $\quad$ " $<f>18$

<s> patient

define self as a pointer variable

define $t$ as a double variable

self = patient

change.flag(self) = FALSE

injury.time (self) = time.v

$\operatorname{sbp}($ self $)=\operatorname{sbp.0}$

blood.volume (self) $=$ bv.0

$\operatorname{hct}($ self) $=$ hct.0

rbc.mass $($ self $)=.01 * h c t($ self $) *$ blood.volume (self)

02. delivery $($ self $)=\operatorname{sbp}($ self $) * h c t($ self $) * 02$. sat $($ self $)$

bleeding.rate(self) $=b r .0($ self $)$

condition (self) = alive

resus.time (self) $=1+$ mygamma. $f(t$.resus -1 ,

$$
3 *((t \text {.resus }-1) / t \text {, resus }) * \star 2,11)
$$

tx.time (self) $=$ exponential.f(t.tx, 24)

$t=$ time.v

' bleed till arrival

work continuously evaluating 'bleed', testing 'done', updating 'update' change.flag(self) = FALSE

$\operatorname{cts}($ self $)=\operatorname{cts.f(self)}$

if living(self) = FALSE

condition (self) = dead

$\operatorname{tod}($ self $)=($ time.v - injury.time $($ self $))$ * hours.v * minutes. $v$

call pt. report giving self

remove self from acc.patient.set(acc(self))

remove self from the patient.set

add 1 to no.deaths

if DEBUG

write pt.id(self), hour.f(time.v), minute.f(time.v), phase(self) as endif "pt ", $i$ 4, "arrests at ", i 2 , ": ", i 2 , "in phase", i 2, I

endif return

wait.time $($ self $)=($ time.v $-t) *$ hours. $v *$ minutes.v

$\mathrm{t}=\mathrm{time} \cdot \mathrm{v}$

if phase(self) = pvt.trav

call pass.time giving self

remove seif from the pvt.tr.set

file self in resus.patient.set(hosp(self))

phase (self) $=$ resus

transp.time $($ self $)=($ time.v $-t) *$ hours. $v *$ minutes. $v$

else $t=$ time.v

', ambulance arrival

rescue.bp(self) $=\operatorname{sbp}($ self)

call pass.time giving self

scene.time $($ self $)=($ time. $v-t) *$ hours. $v *$ minutes. $v$

$\mathrm{t}=\mathrm{time} \cdot \mathrm{v}$

'1 enroute

call pass.time giving self

transp.time $($ self $)=($ time.v $-t) *$ hours. $v *$ minutes. $v$ 
endif

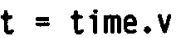

\section{'' hospital arrival}

hosp.bp(self) $=\operatorname{sbp}($ self $)$

trf.start.time(self) = time.v + resus.time(self) / hours.v / minutes.v / 2 schedule a resp.support(self) in resus.time(self) / 3 minutes

trf.rate (self) $=.5 *$ iv.rate (self)

no.pts $($ hosp $($ self $))=$ no.pts $(\operatorname{hosp}($ self $))+1$

call pass.time giving self

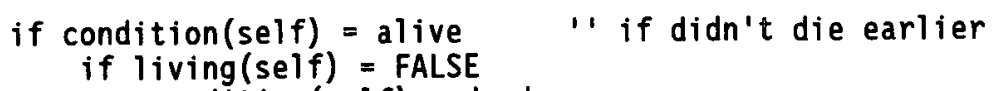


network structure

weights represent arterial route travel time between node centers for $i=1$ to $n$.node

do

print 1 line with $i$, node.name(i), n.edge.set(i) thus

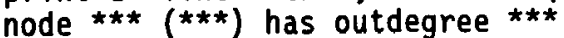

for each arc in edge.set $(i)$

do

print 1 line with sink(arc), node.name(sink(arc)), weight(arc) thus loop arc to $* * \star(* \star *)$ of weight $* * \star * . * *$

loop

skip 1 line

print 1 line thus

hospital locations

for $i=1$ to $n$.hospital

do

select case level(i)

case level1

lvl = "level 1"

case level2

lv1 = "level 2"

case level2a

$\mid v 1=$ "level $2 \mathrm{a}$ "

case level3

endselect

$|v|=$ "level $3 "$

print 1 line with hosp.name(i), lvl, capacity(i), node. name (hosp. base (i)) thus

loop

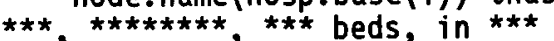

skip 1 line

print 1 line thus

ambulance call list

for each node

do

print 1 line with node.name(node) thus

$\star * *$ will request these ambulances

for each item in call.1ist(node)

do

if type (ambulance.id(item)) = ground else

temp = transit.time (amb.base (ambulance.id(item)), node) endif temp $=$ flight.time (amb.base $($ ambulance.id(item)), node)

print 1 line with amb.name(ambulance.id(item)), node. name (amb.base (ambul ance.id(item))), temp thus

$\star \star \star *$ from $* * *$ with mean travel time $* \star \star \star . \star *$ min

loop $100 p$

skip 1 line

print 1 line thus

hospital dispatch list

for each node

do

print 1 line with node.name(node) thus

$\star \star \star$ victims will go to these hospitals

for each item in hosp.list (node)

do 
2876

2877

2878

2879

2880

2881

2882

2883

2884

2885

2886

2887

2888

2889

2890

2891

2892

2893

2894

2895

2896 select case level(hospital.id(item))

case level1

lv1 = "level 1"

case level2

$|v|=" 1$ evel $2 "$

case level2a

$1 v 1=" l e v e 12 a "$

case level3

endselect Iv1 = "level 3"

print 1 line with hosp.name(hospital.id(item)) Ivi, node.name (hosp.base(hospital.id(item))), transit.time(node, hosp.base(hospital.id(item))) thus

$\star \star \star \star,{ }^{* \star \star \star \star \star \star \star \star}$, in $* \star \star$, with mean travel time ${ }^{\star \star \star *} \cdot{ }^{\star *}$ min

loop loop

skip 1 line

print 7 lines with major.cutoff, minor.cutoff, htol*100, atol*100 thus

Triage rule: Champ TS $<=*{ }^{*}$ goes to level $1,>{ }^{*} .{ }^{*}$ may go to level 3

Travel times exceeding minimum time by less than tolerance included in routine dispatch lists

hospital choice tolerance $\star \star \%$

ambulance choice tolerance $* * \%$

skip 1 line

use 6 for output

end " of print.net

routine pt.report given pt $\quad$ " $<f>12$

$\because$ <s> pt.report

define pt as a pointer variable

use 8 for output

write run, pt.id(pt), blunt (pt), transp.mode(pt), iss(pt), injury.time (pt), wait.time(pt), scene.time (pt), transp.time(pt), resus.time (pt), tx.time(pt), tod(pt), rescue.bp(pt), hosp.bp(pt), def.bp(pt) as

i $3,51, i 5,2$ i 3, i $5, d(22,15), 9 d(10,3),+$

write

prob.surv(pt), br.o(pt) / hours.v / minutes.v, cts(pt), condition (pt), injury. loc (pt), hosp (pt), need.helo(pt), got.helo(pt) as

$3 \mathrm{~d}(10,3), 5$ i 4,1

use 6 for output

end " of pt.report

routine pvt.travel $(\mathrm{acc}) \quad$ " $\quad<f>12$

1 <s> pvt.travel

define acc as a pointer variable 


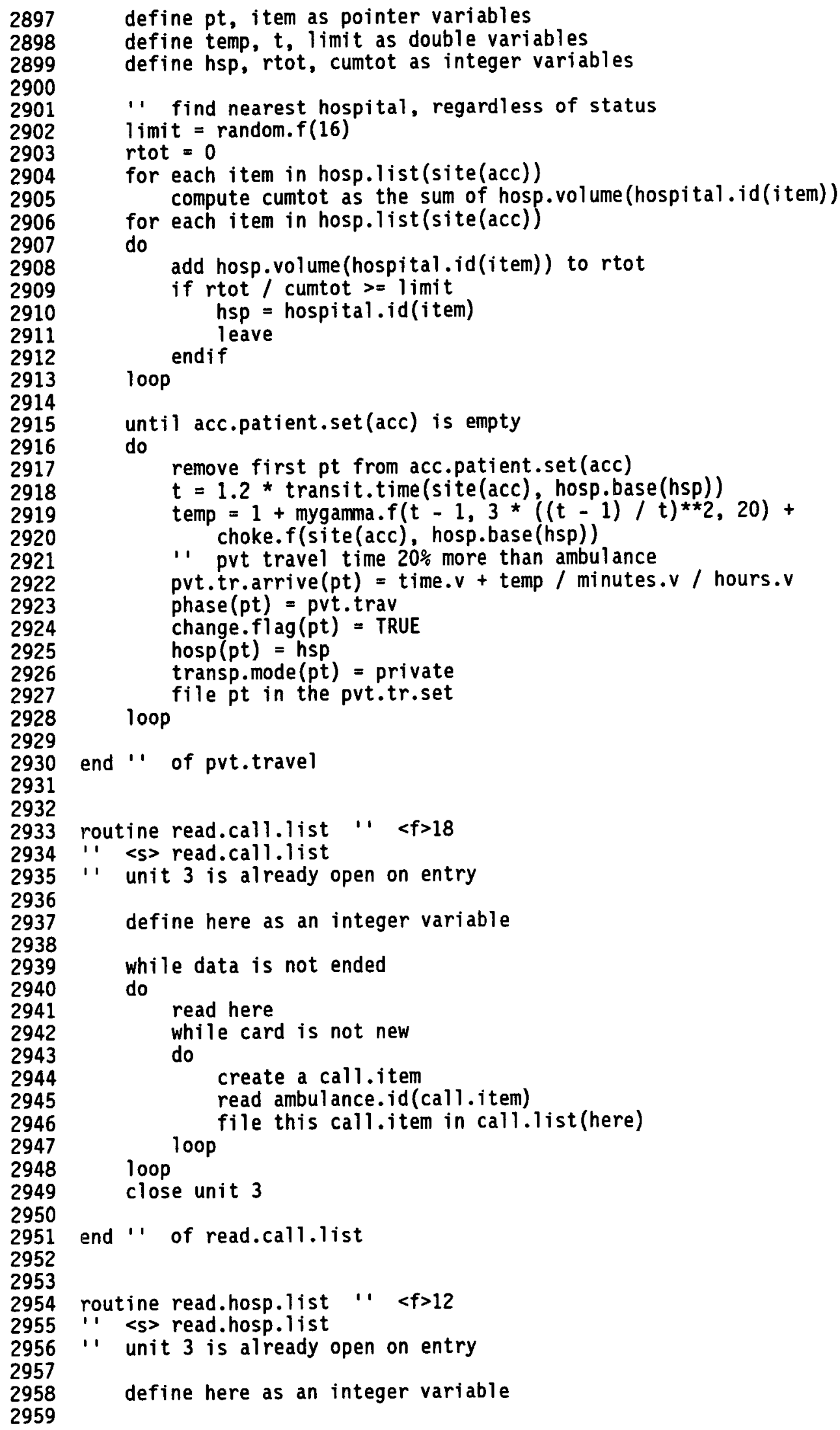




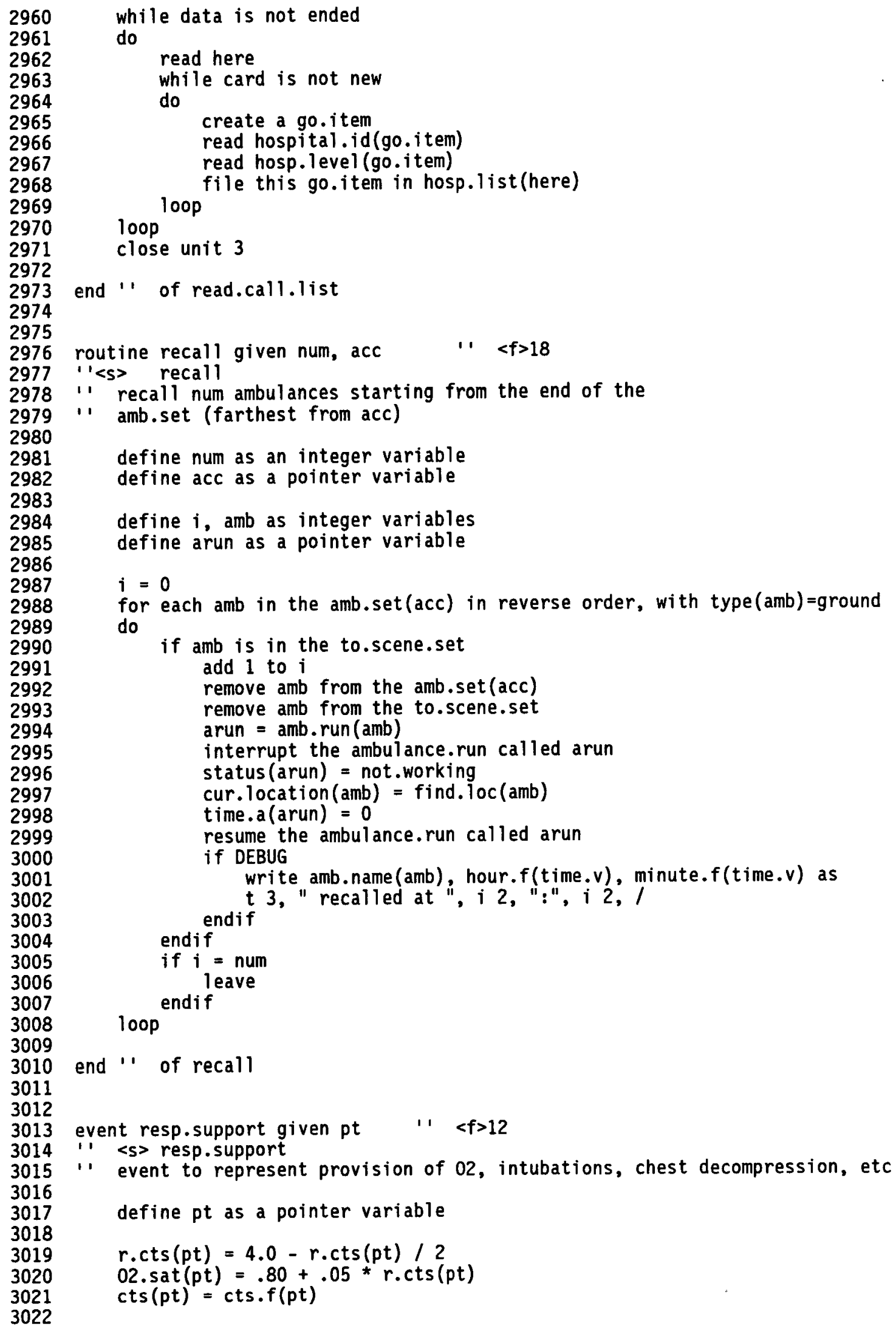


3035

3036

3037

3038

3039

3040

3041

3042

3043

3044

3045

3046

3047

3048

3049

3050

3051

3052

3053

3054

3055

3056

3057

3058

3059

3060

3061

3062

3063

3064

3065

3066

3067

3068

3069

3070

3071

3072

3073

3074

3075

3076

3077

3078

3079

3080

3081

3082

3083

3084

3085

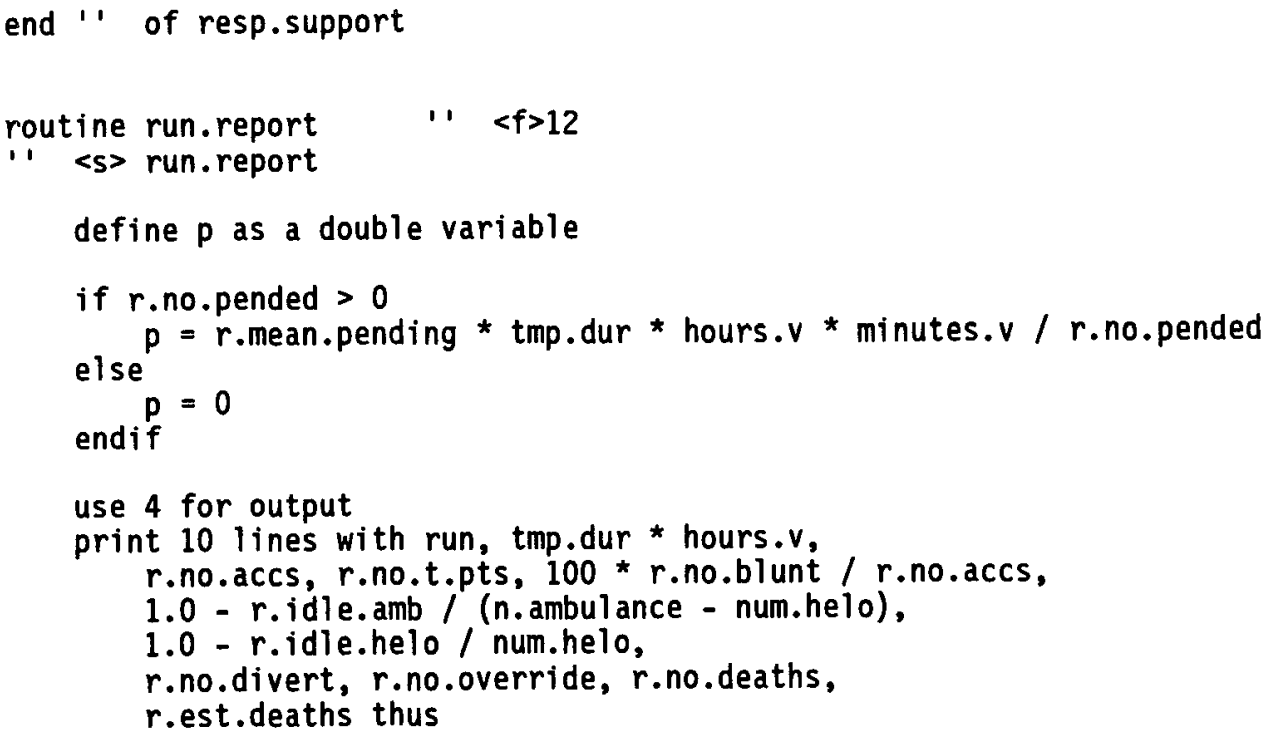




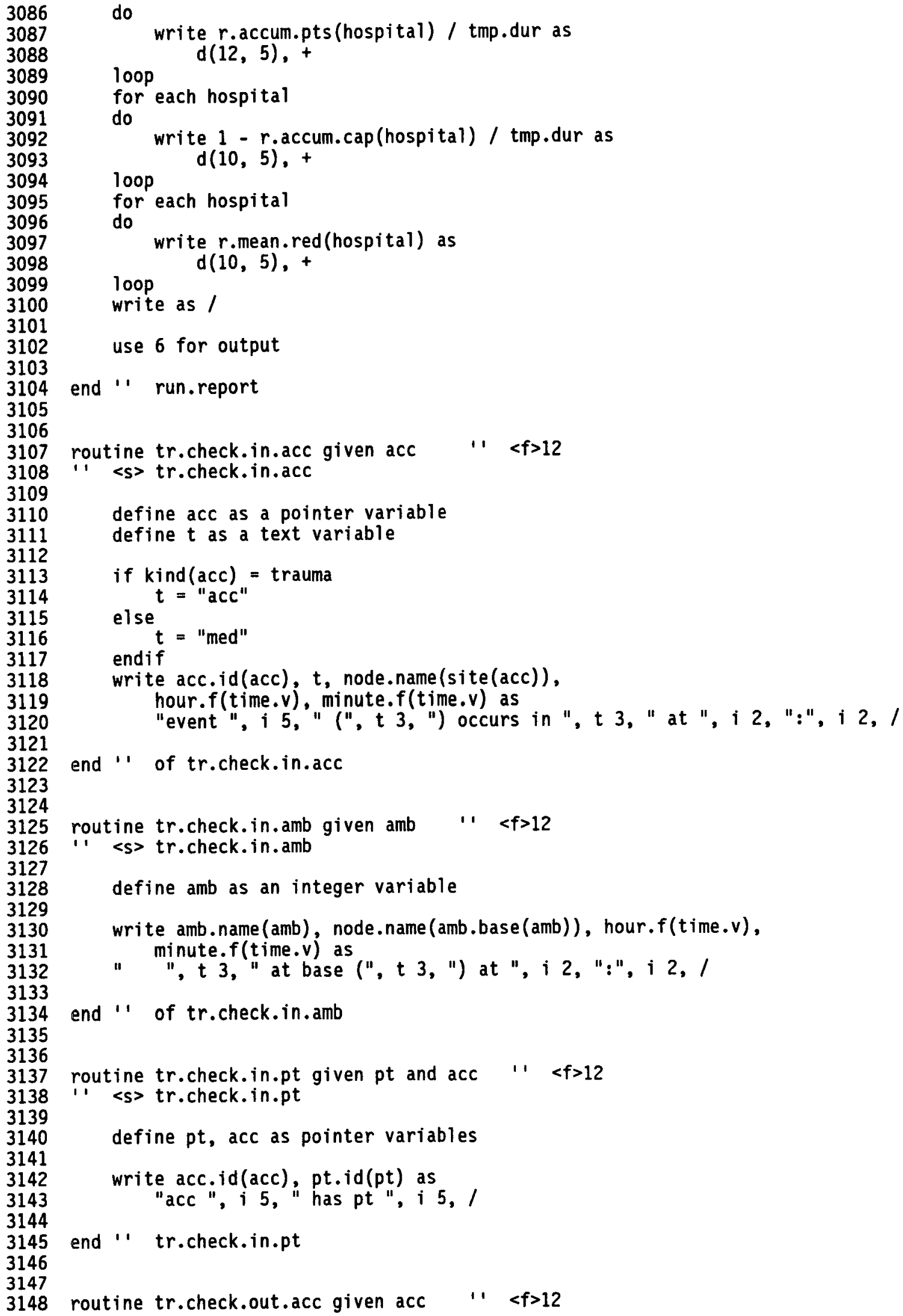




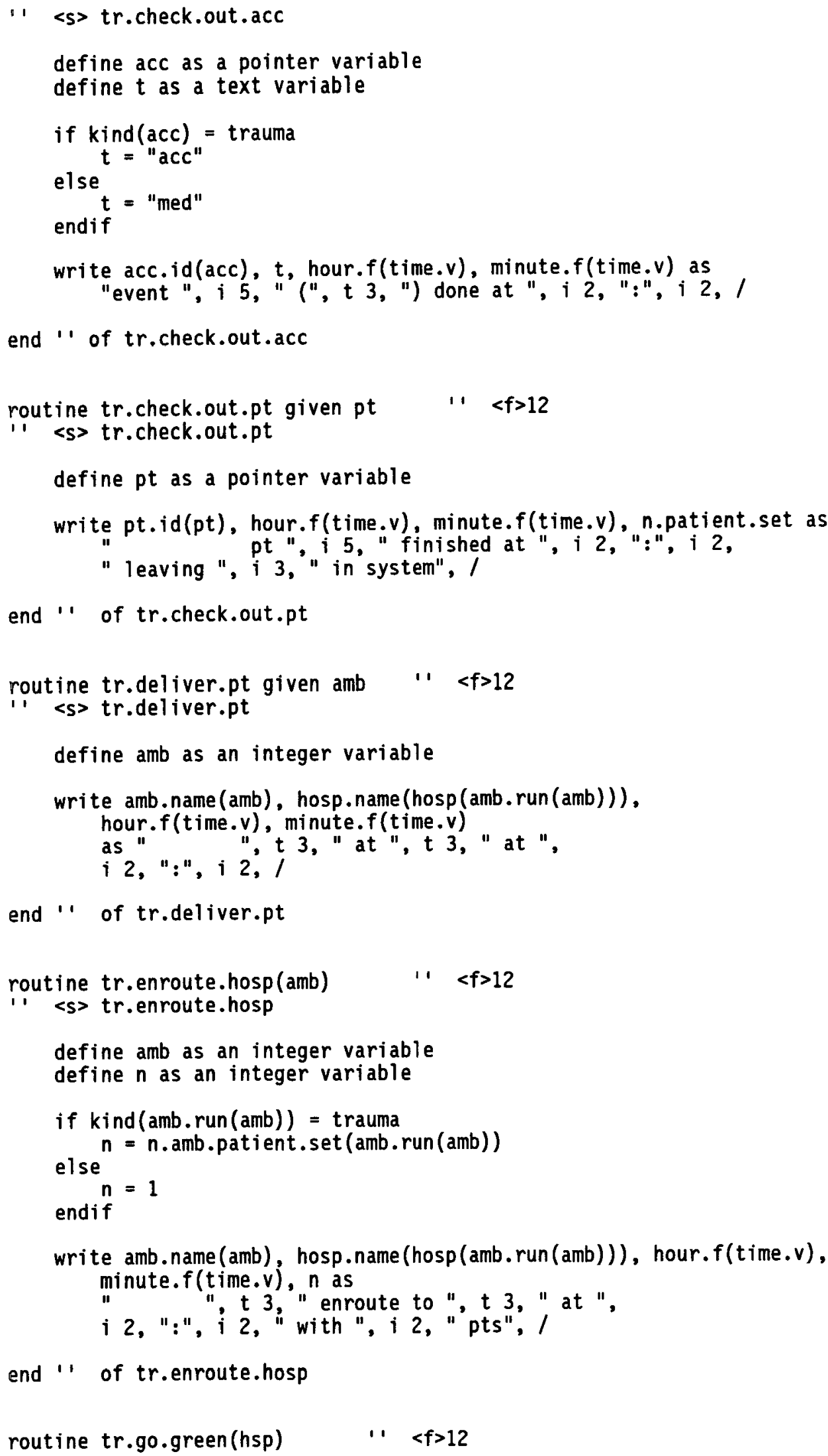




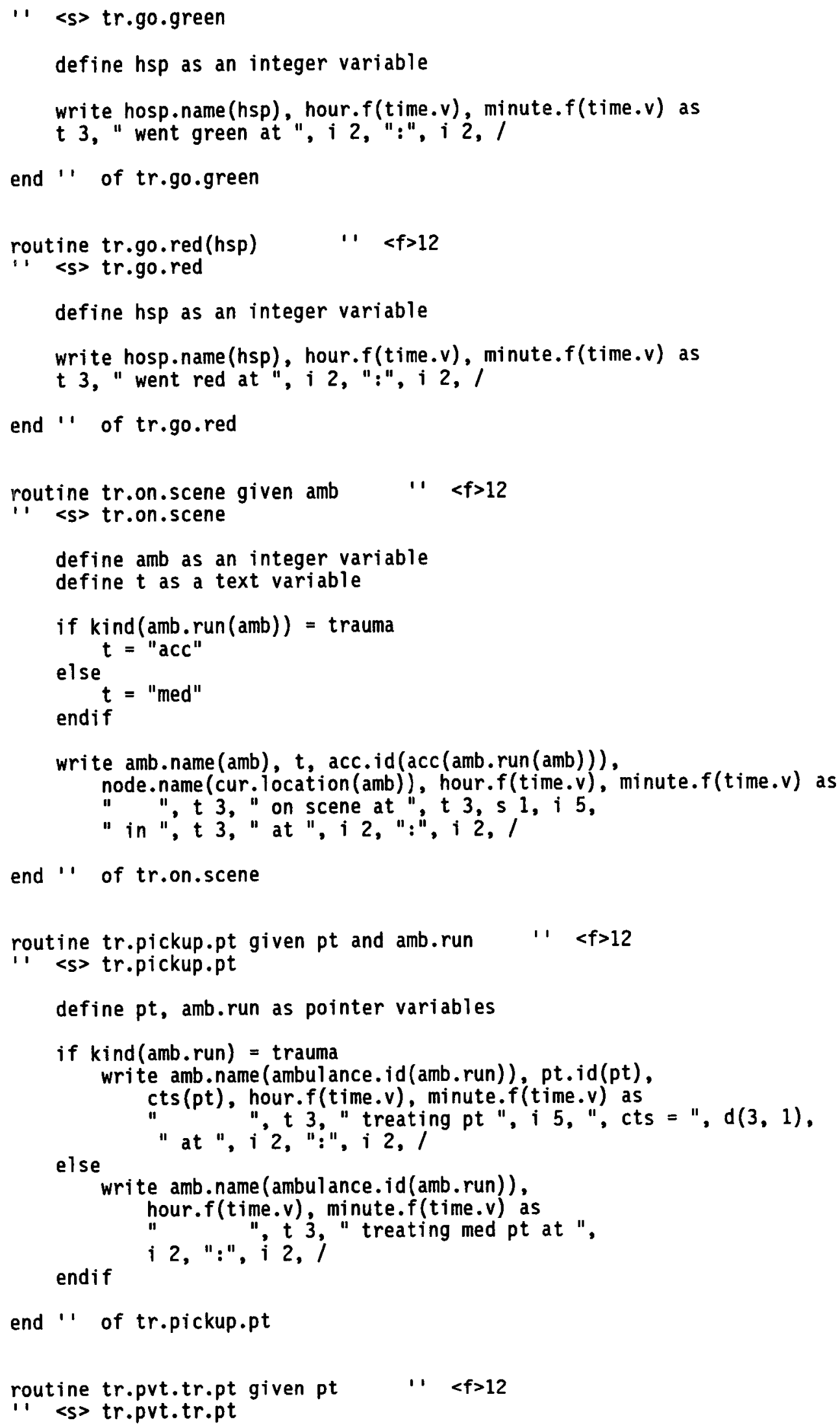




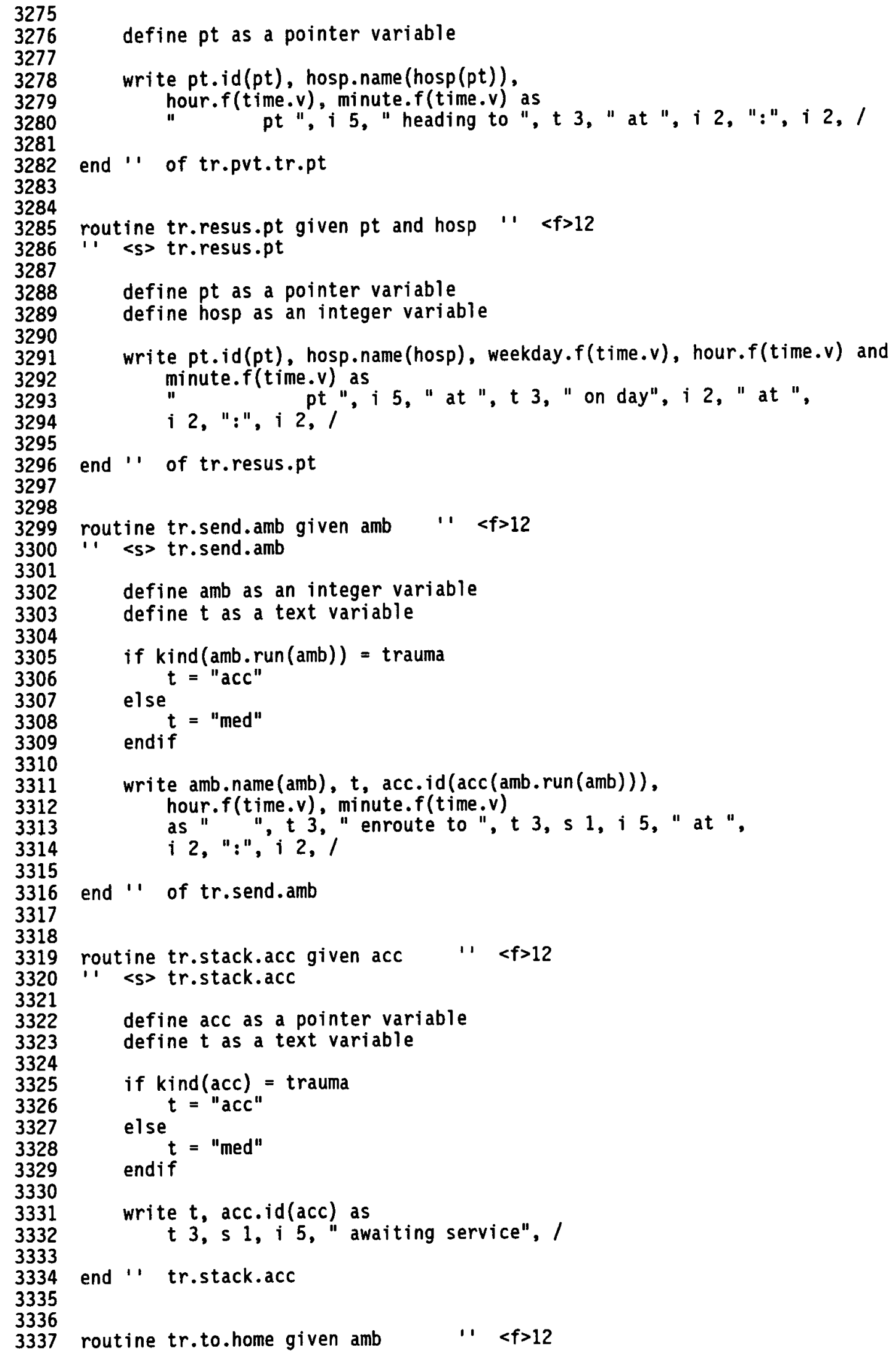




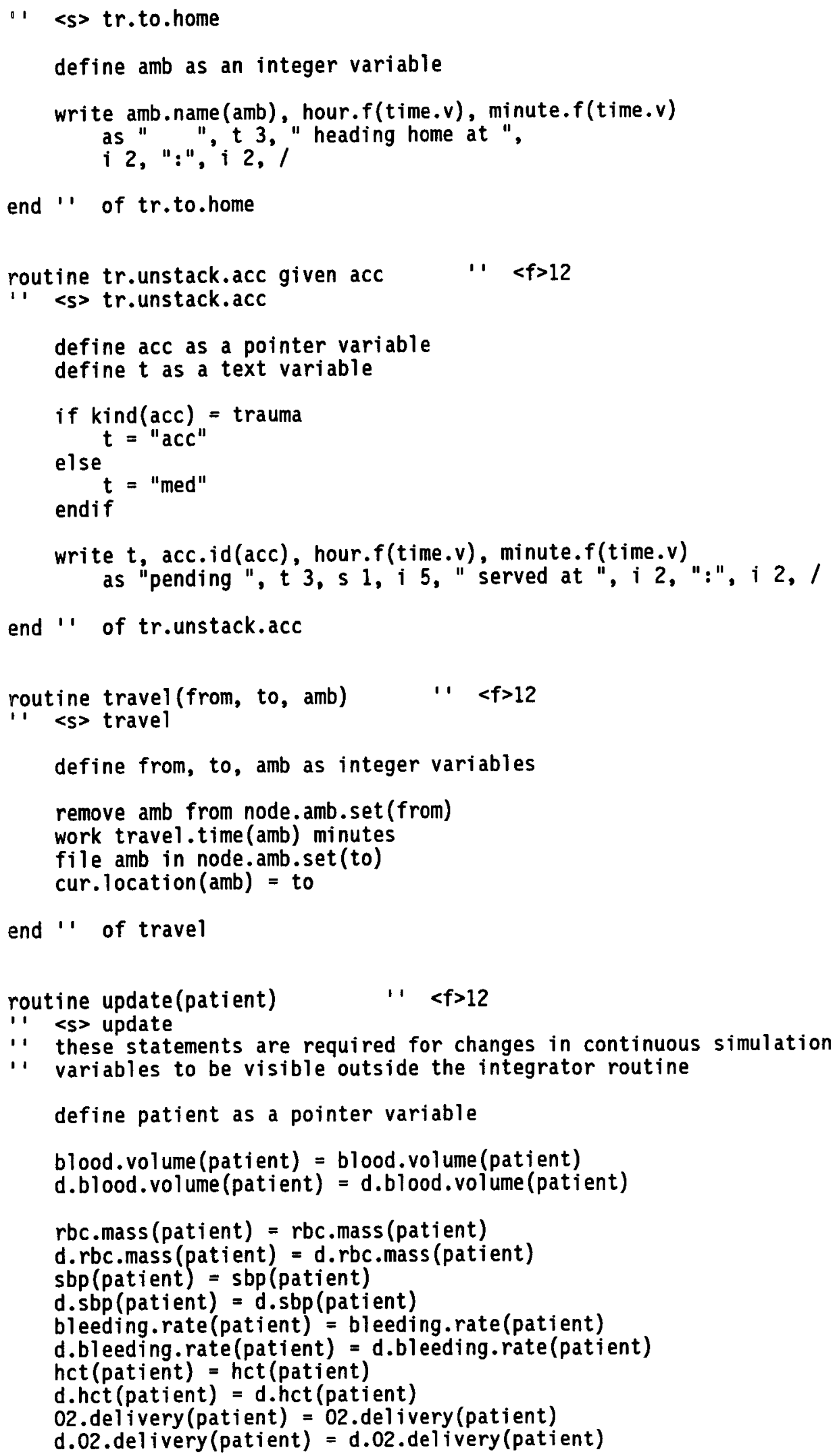




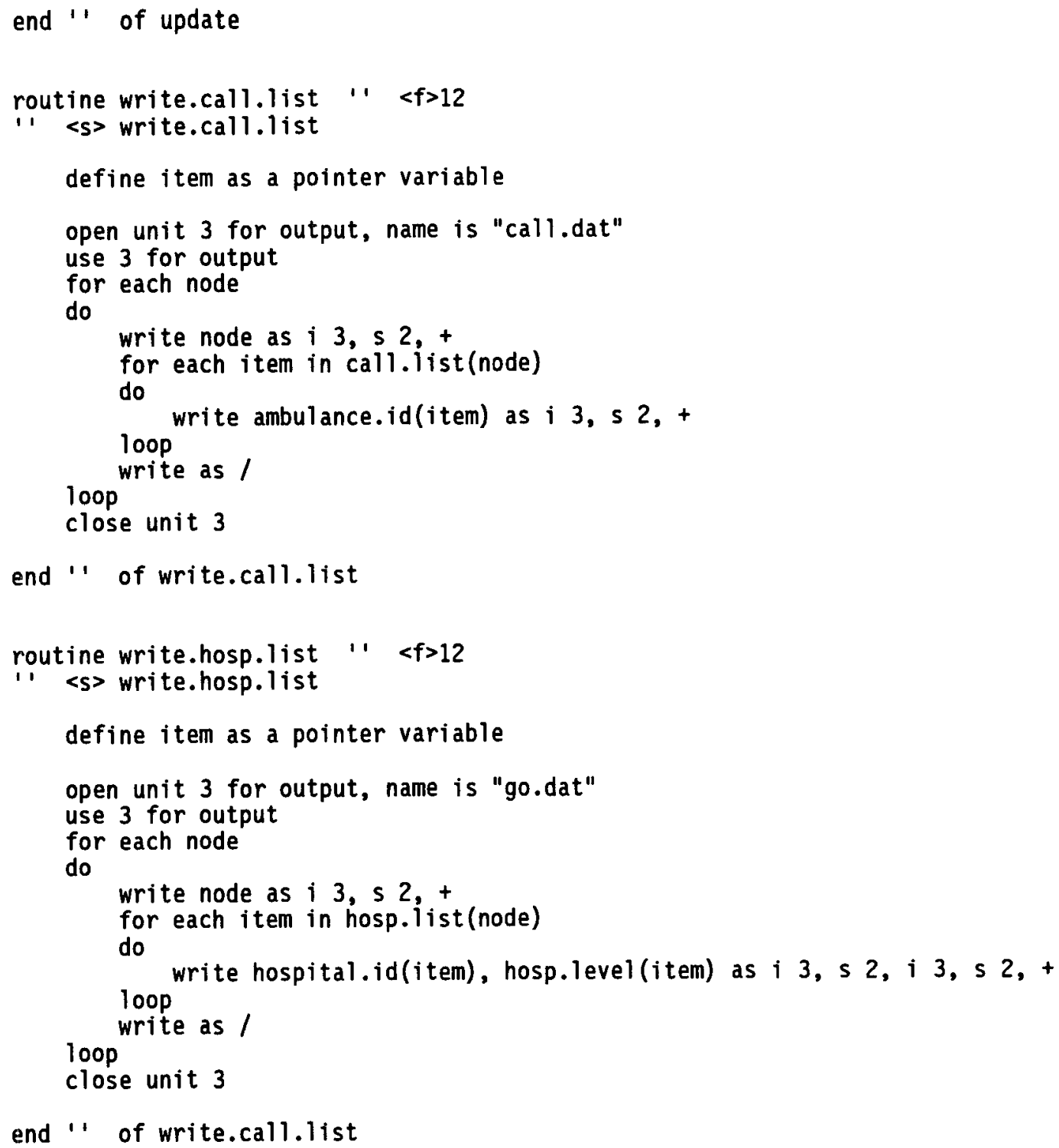




\section{Appendix 2 \\ Data Cross-Reference}

NAME

TYPE
(+ distinct usage) MODE ROUTINE $\quad \begin{array}{r}\text { REFERENCES } \\ (=\text { assigned })\end{array}$

\begin{tabular}{|c|c|c|c|c|}
\hline A.DUPLICATE & Define to mean & & $\begin{array}{l}\text { PREAMBLE } \\
\text { BUILD.ROUTE }\end{array}$ & $\begin{array}{l}1 \\
1\end{array}$ \\
\hline ABS.ERR.V & Permanent attribute & Real & GET.SIM & $1=$ \\
\hline ABS.F & Library routine & & $\begin{array}{l}\text { BLEED } \\
\text { MYGAMMA.F }\end{array}$ & $\begin{array}{l}2 \\
1\end{array}$ \\
\hline ACC & Temporary attribute & Pointer & $\begin{array}{l}\text { PREAMBLE } \\
\text { AMBULANCE. RUN } \\
\text { ASSIGN.AMB } \\
\text { CHECK.ACCIDENT } \\
\text { INIT.ACCIDENT } \\
\text { INIT.PT } \\
\text { PATIENT } \\
\text { TR.ON.SCENE } \\
\text { TR.SEND.AMB }\end{array}$ & $\begin{array}{l}3 \\
1 \\
1= \\
1= \\
1= \\
2 \\
1 \\
1 \\
1\end{array}$ \\
\hline ACC.ARRIVE.TIME & Temporary attribute & Double & $\begin{array}{l}\text { PREAMBLE } \\
\text { DISPATCHER }\end{array}$ & $\begin{array}{l}2 \\
2=\end{array}$ \\
\hline ACC.COUNTER & Global variable & Integer & $\begin{array}{l}\text { PREAMBLE } \\
\text { MAIN } \\
\text { INIT.ACCIDENT }\end{array}$ & $\begin{array}{l}2 \\
1 \\
1=\end{array}$ \\
\hline ACC.END.TIME & Temporary attribute & Double & $\begin{array}{l}\text { PREAMBLE } \\
\text { ACCIDENT }\end{array}$ & $\begin{array}{l}2 \\
1\end{array}=$ \\
\hline ACC.ID & Temporary attribute & Integer & $\begin{array}{l}\text { PREAMBLE } \\
\text { DISPATCHER } \\
\text { GENERATOR } \\
\text { TR.CHECK.IN.ACC } \\
\text { TR.CHECK.IN.PT } \\
\text { TR.CHECK.OUT.ACC } \\
\text { TR.ON.SCENE } \\
\text { TR.SEND.AMB } \\
\text { TR.STACK.ACC } \\
\text { TR.UNSTACK.ACC }\end{array}$ & $\begin{array}{l}2 \\
3 \\
1 \\
1 \\
1 \\
1 \\
1 \\
1 \\
1 \\
1\end{array}$ \\
\hline ACC.PATIENT.SET & Set & & $\begin{array}{l}\text { PREAMBLE } \\
\text { ACCIDENT } \\
\text { AMBULANCE. RUN } \\
\text { CHECK.ACCIDENT } \\
\text { GET.PATIENT } \\
\text { INIT.ACCIDENT } \\
\text { PATIENT } \\
\text { PVT.TRAVEL }\end{array}$ & $\begin{array}{l}3 \\
1 \\
4 \\
1 \\
2 \\
1 \\
1 \\
2\end{array}$ \\
\hline
\end{tabular}




\begin{tabular}{|c|c|c|c|}
\hline ACC.START.TIME & Temporary attribute & Double & $\begin{array}{l}\text { PREAMBLE } \\
\text { INIT.ACCIDENT }\end{array}$ \\
\hline ACCIDENT & $\begin{array}{l}\text { + Global variable } \\
+ \text { Implied subscript }\end{array}$ & Pointer & $\begin{array}{l}\text { PREAMBLE } \\
\text { ACCIDENT } \\
\text { DISPATCHER } \\
\text { GENERATOR } \\
\text { ACCIDENT } \\
\text { DISPATCHER } \\
\text { GENERATOR } \\
\text { INIT.ACCIDENT } \\
\text { ACCIDENT }\end{array}$ \\
\hline ACTIVE.SET & Set & & $\begin{array}{l}\text { PREAMBLE } \\
\text { ACCIDENT } \\
\text { INIT.ACCIDENT }\end{array}$ \\
\hline ADJ.TIME.F & Routine & Double & $\begin{array}{l}\text { PREAMBLE } \\
\text { ADJ.TIME.F } \\
\text { BEST.ROUTE } \\
\text { GET.NET }\end{array}$ \\
\hline AIR & Define to mean & & $\begin{array}{l}\text { PREAMBLE } \\
\text { AMBULANCE. RUN } \\
\text { ASSIGN.AMB } \\
\text { DISPATCHER } \\
\text { GET.AMB } \\
\text { GET.EMS } \\
\text { GET.TRAVEL.TIME }\end{array}$ \\
\hline AIRSPEED & Global variable & Double & $\begin{array}{l}\text { PREAMBLE } \\
\text { FTIME.F } \\
\text { GET.NET }\end{array}$ \\
\hline ALARM. LAG & Global variable & Double & $\begin{array}{l}\text { PREAMBLE } \\
\text { ACCIDENT } \\
\text { GET.SIM }\end{array}$ \\
\hline ALIVE & Define to mean & & $\begin{array}{l}\text { PREAMBLE } \\
\text { DONE } \\
\text { PASS.TIME } \\
\text { PATIENT }\end{array}$ \\
\hline AMB. BASE & Permanent attribute & Integer & $\begin{array}{l}\text { PREAMBLE } \\
\text { DISPATCHER } \\
\text { GET.AMB } \\
\text { GET.EMS } \\
\text { PRINT.NET } \\
\text { TR.CHECK.IN.AMB }\end{array}$ \\
\hline AMB.BASE.SET & Set & & $\begin{array}{l}\text { PREAMBLE } \\
\text { BUILD.CALL.LIST } \\
\text { GET.EMS }\end{array}$ \\
\hline AMB.ID & Permanent attribute & Integer & $\begin{array}{l}\text { PREAMBLE } \\
\text { GET. EMS }\end{array}$ \\
\hline AMB. NAME & Permanent attribute & Text & $\begin{array}{l}\text { PREAMBLE } \\
\text { DISPATCHER } \\
\text { FIND.HOSP } \\
\text { GET. EMS } \\
\text { PRINT.NET } \\
\text { RECALL }\end{array}$ \\
\hline
\end{tabular}




\begin{tabular}{|c|c|c|c|}
\hline AMB.PATIENT.SET & Set & & $\begin{array}{l}\text { PREAMBLE } \\
\text { AMBULANCE.RUN } \\
\text { DISPATCHER } \\
\text { GET.PATIENT }\end{array}$ \\
\hline AMB. RUN & Permanent attribute & Pointer & $\begin{array}{l}\text { PREAMBLE } \\
\text { ASSIGN.AMB } \\
\text { DISPATCHER } \\
\text { FIND.HOSP } \\
\text { FIND.LOC } \\
\text { RECALL } \\
\text { TR.DELIVER.PT } \\
\text { TR.ENROUTE.HOSP } \\
\text { TR.ON.SCENE } \\
\text { TR.SEND.AMB }\end{array}$ \\
\hline AMB.SET & Set & & $\begin{array}{l}\text { PREAMBLE } \\
\text { ASSIGN.AMB } \\
\text { CHECK.ACCIDENT } \\
\text { DISPATCHER } \\
\text { RECALL }\end{array}$ \\
\hline AMBULANCE & $\begin{array}{l}\text { Permanent entity } \\
+ \text { Global variable }\end{array}$ & Integer2 & $\begin{array}{l}\text { PREAMBLE } \\
\text { GET.EMS } \\
\text { GET.EMS }\end{array}$ \\
\hline AMBULANCE.ID & Temporary attribute & Integer & $\begin{array}{l}\text { PREAMBLE } \\
\text { AMBULANCE.RUN } \\
\text { ASSIGN.AMB } \\
\text { BUILD.CALL.LIST } \\
\text { CHECK.ACCIDENT } \\
\text { GET.AMB } \\
\text { GET.PATIENT } \\
\text { PRINT.NET } \\
\text { READ.CALL.LIST } \\
\text { TR.PICKUP.PT } \\
\text { WRITE.CALL.LIST }\end{array}$ \\
\hline AMBULANCE. RUN & $\begin{array}{l}\text { Process notice } \\
+ \text { Global variable } \\
+ \text { Implied subscript }\end{array}$ & Pointer & $\begin{array}{l}\text { PREAMBLE } \\
\text { AMBULANCE.RUN } \\
\text { ASSIGN.AMB } \\
\text { RECALL } \\
\text { AMBULANCE.RUN } \\
\text { ASSIGN.AMB } \\
\text { AMBULANCE.RUN }\end{array}$ \\
\hline ARC & $\begin{array}{l}\text { Temporary entity } \\
\text { + Global variable }\end{array}$ & Pointer & $\begin{array}{l}\text { PREAMBLE } \\
\text { BUI LD. ROUTE } \\
\text { GET.NET } \\
\text { BUILD.ROUTE } \\
\text { GET.NET } \\
\text { PRINT.NET }\end{array}$ \\
\hline ARC.STATUS & Temporary attribute & Integer & $\begin{array}{l}\text { PREAMBLE } \\
\text { BUILD.ROUTE }\end{array}$ \\
\hline
\end{tabular}




\begin{tabular}{|c|c|c|c|}
\hline ASSIGN.AMB & Routine & & $\begin{array}{l}\text { ASSIGN.AMB } \\
\text { GET.AMB }\end{array}$ \\
\hline ASSIGNMENT.SET & Set & & $\begin{array}{l}\text { PREAMBLE } \\
\text { BUILD.CALL.LIST }\end{array}$ \\
\hline AT.BASE & Define to mean & & $\begin{array}{l}\text { PREAMBLE } \\
\text { AMBULANCE. RUN } \\
\text { DISPATCHER }\end{array}$ \\
\hline AT.BASE.SET & Set & & $\begin{array}{l}\text { PREAMBLE } \\
\text { ASSIGN.AMB } \\
\text { DISPATCHER } \\
\text { GET.EMS }\end{array}$ \\
\hline AT.HOSP & Define to mean & & $\begin{array}{l}\text { PREAMBLE } \\
\text { AMBULANCE.RUN } \\
\text { DISPATCHER }\end{array}$ \\
\hline AT.HOSP.SET & Set & & $\begin{array}{l}\text { PREAMBLE } \\
\text { AMBULANCE.RUN } \\
\text { DISPATCHER }\end{array}$ \\
\hline AT. SCENE & Define to mean & & $\begin{array}{l}\text { PREAMBLE } \\
\text { AMBULANCE. RUN } \\
\text { DISPATCHER }\end{array}$ \\
\hline ATOL & Global variable & Double & $\begin{array}{l}\text { PREAMBLE } \\
\text { BUILD.CALL.LIST } \\
\text { GET.SIM } \\
\text { PRINT.NET }\end{array}$ \\
\hline BEST. ROUTE & Routine & Double & $\begin{array}{l}\text { PREAMBLE } \\
\text { BEST.ROUTE } \\
\text { GET.NET }\end{array}$ \\
\hline BLEED & Routine & & $\begin{array}{l}\text { BLEED } \\
\text { PASS.TIME } \\
\text { PATIENT }\end{array}$ \\
\hline BLEEDING . RATE & Temporary attribute & Double & $\begin{array}{l}\text { PREAMBLE } \\
\text { BLEED } \\
\text { PATIENT } \\
\text { UPDATE }\end{array}$ \\
\hline BLOOD. VOLUME & Temporary attribute & Double & $\begin{array}{l}\text { PREAMBLE } \\
\text { BLEED } \\
\text { PATIENT } \\
\text { UPDATE }\end{array}$ \\
\hline BLUNT & Temporary attribute & Integer & $\begin{array}{l}\text { PREAMBLE } \\
\text { INIT.ACCIDENT } \\
\text { INIT.PT } \\
\text { PATIENT } \\
\text { PT.REPORT }\end{array}$ \\
\hline BR. 0 & Temporary attribute & Double & $\begin{array}{l}\text { PREAMBLE } \\
\text { BLEED } \\
\text { INIT.PT } \\
\text { PATIENT } \\
\text { PT.REPORT }\end{array}$ \\
\hline BUILD.CALL.LIST & Routine & & BUILD.CALL.LIST \\
\hline
\end{tabular}




\begin{tabular}{|c|c|c|c|}
\hline & & & INITIALIZE \\
\hline BUILD.HOSP.LIST & Routine & & $\begin{array}{l}\text { BUILD.HOSP.LIST } \\
\text { INITIALIZE }\end{array}$ \\
\hline BUILD.ROUTE & Routine & & $\begin{array}{l}\text { BEST.ROUTE } \\
\text { BUILD.ROUTE }\end{array}$ \\
\hline BV. 0 & Define to mean & & $\begin{array}{l}\text { PREAMBLE } \\
\text { BLEED } \\
\text { PATIENT }\end{array}$ \\
\hline CALL. ITEM & $\begin{array}{l}\text { Temporary entity } \\
+ \text { Global variable }\end{array}$ & Pointer & $\begin{array}{l}\text { PREAMBLE } \\
\text { BUILD.CALL.LIST } \\
\text { READ.CALL. LIST } \\
\text { BUILD.CALL.LIST } \\
\text { READ.CALL. LIST }\end{array}$ \\
\hline CALL.LIST & Set & & $\begin{array}{l}\text { PREAMBLE } \\
\text { BUILD.CALL.LIST } \\
\text { GET.AMB } \\
\text { PRINT.NET } \\
\text { READ.CALL.LIST } \\
\text { WRITE.CALL.LIST }\end{array}$ \\
\hline CALLS.PENDING & Define to mean & & $\begin{array}{l}\text { PREAMBLE } \\
\text { DISPATCHER }\end{array}$ \\
\hline CAN.DIVERT & Permanent attribute & Integer & $\begin{array}{l}\text { PREAMBLE } \\
\text { GET. HOSP } \\
\text { GO.RED }\end{array}$ \\
\hline CAPACITY & Permanent attribute & Integer & $\begin{array}{l}\text { PREAMBLE } \\
\text { GET. HOSP } \\
\text { GO.GREEN } \\
\text { GO.RED } \\
\text { LEFT NO.PTS } \\
\text { PRINT.NET }\end{array}$ \\
\hline CH.CUM.WEIGHT & Temporary attribute & Double & $\begin{array}{l}\text { PREAMBLE } \\
\text { BEST.ROUTE }\end{array}$ \\
\hline CHANGE. FLAG & Temporary attribute & Integer & $\begin{array}{l}\text { PREAMBLE } \\
\text { AMBULANCE. RUN } \\
\text { DONE } \\
\text { GET.PATIENT } \\
\text { PASS.TIME } \\
\text { PATIENT } \\
\text { PVT.TRAVEL }\end{array}$ \\
\hline CHECK.ACCIDENT & Routine & & $\begin{array}{l}\text { AMBULANCE.RUN } \\
\text { CHECK.ACCIDENT }\end{array}$ \\
\hline CHECK.RED & Routine & & $\begin{array}{l}\text { CHECK. RED } \\
\text { LEFT NO.PTS }\end{array}$ \\
\hline CHOKE.F & Routine & Double & $\begin{array}{l}\text { PREAMBLE } \\
\text { CHOKE.F } \\
\text { GET.TRAVEL.TIME } \\
\text { PVT.TRAVEL }\end{array}$ \\
\hline CHOKE.PT.WT & Temporary attribute & Double & $\begin{array}{l}\text { PREAMBLE } \\
\text { BEST.ROUTE }\end{array}$ \\
\hline
\end{tabular}




\begin{tabular}{|c|c|c|c|c|}
\hline & & & $\begin{array}{l}\text { BUILD. ROUTE } \\
\text { CHOKE.F } \\
\text { GET.NET }\end{array}$ & $\begin{array}{l}1= \\
2 \\
1=\end{array}$ \\
\hline CLEAR.NOTICE & Permanent attribute & Pointer & $\begin{array}{l}\text { PREAMBLE } \\
\text { CHECK.RED } \\
\text { CLEAR.REDS } \\
\text { GO.OFF.RED }\end{array}$ & $\begin{array}{l}2 \\
3= \\
3= \\
2=\end{array}$ \\
\hline CLEAR.REDS & $\begin{array}{l}\text { Event notice } \\
+ \text { Global variable }\end{array}$ & Pointer & $\begin{array}{l}\text { PREAMBLE } \\
\text { MAIN } \\
\text { CLEAR.REDS } \\
\text { GENERATOR } \\
\text { MAIN } \\
\text { CLEAR. REDS } \\
\text { GENERATOR }\end{array}$ & $\begin{array}{l}1 \\
1 \\
2 \\
1 \\
1= \\
2= \\
2=\end{array}$ \\
\hline CLEAR. TIME & Global variable & Double & $\begin{array}{l}\text { PREAMBLE } \\
\text { MAIN } \\
\text { GENERATOR } \\
\text { GET.SIM }\end{array}$ & $\begin{array}{l}1 \\
1 \\
1= \\
1=\end{array}$ \\
\hline CONDITION & Temporary attribute & Integer & $\begin{array}{l}\text { PREAMBLE } \\
\text { BLEED } \\
\text { DONE } \\
\text { PASS.TIME } \\
\text { PATIENT } \\
\text { PT.REPORT }\end{array}$ & $\begin{array}{l}2 \\
1 \\
1 \\
2= \\
4= \\
1=\end{array}$ \\
\hline $\cos . F$ & Library routine & & FTIME.F & 1 \\
\hline CROAK & Define to mean & & $\begin{array}{l}\text { PREAMBLE } \\
\text { LIVING }\end{array}$ & $\begin{array}{l}1 \\
1\end{array}$ \\
\hline CTS & Temporary attribute & Double & $\begin{array}{l}\text { PREAMBLE } \\
\text { AMBULANCE.RUN } \\
\text { CTS.F } \\
\text { GET.LEVEL } \\
\text { INIT.PT } \\
\text { PASS.TIME } \\
\text { PATIENT } \\
\text { PT.REPORT } \\
\text { RESP.SUPPORT } \\
\text { TR.PICKUP.PT }\end{array}$ & $\begin{array}{l}2 \\
1 \\
2= \\
2 \\
1= \\
1= \\
4= \\
1 \\
1= \\
1=\end{array}$ \\
\hline CTS.F & Routine & Double & $\begin{array}{l}\text { PREAMBLE } \\
\text { ACCIDENT } \\
\text { CTS.F } \\
\text { GET.PATIENT } \\
\text { INIT.PT } \\
\text { PASS.TIME } \\
\text { PATIENT } \\
\text { RESP.SUPPORT }\end{array}$ & $\begin{array}{l}2 \\
1 \\
1 \\
1 \\
1 \\
1 \\
2 \\
1\end{array}$ \\
\hline CUM.EVENTS & Global variable & Double & $\begin{array}{l}\text { PREAMBLE } \\
\text { GENERATOR } \\
\text { INITIALIZE }\end{array}$ & $\begin{array}{l}1 \\
2 \\
1=\end{array}$ \\
\hline CUM.WEIGHT & Temporary attribute & Double & $\begin{array}{l}\text { PREAMBLE } \\
\text { BEST. ROUTE }\end{array}$ & $\begin{array}{l}2 \\
3\end{array}=$ \\
\hline CUR.LOCATION & Permanent attribute & Integer & $\begin{array}{l}\text { PREAMBLE } \\
\text { AMBULANCE. RUN }\end{array}$ & $\begin{array}{l}2 \\
4\end{array}$ \\
\hline
\end{tabular}




\begin{tabular}{|c|c|c|c|c|}
\hline & & & $\begin{array}{l}\text { DISPATCHER } \\
\text { FIND.HOSP } \\
\text { GET.AMB } \\
\text { GET.EMS } \\
\text { RECALL } \\
\text { TR.ON.SCENE } \\
\text { TRAVEL }\end{array}$ & $\begin{array}{l}2 \\
2 \\
1 \\
1= \\
1= \\
1 \\
1=\end{array}$ \\
\hline D.BLEEDING.RATE & Temporary attribute & Double & $\begin{array}{l}\text { BLEED } \\
\text { UPDATE }\end{array}$ & $\begin{array}{l}2 \\
1\end{array}$ \\
\hline D.BLOOD.VOLUME & Temporary attribute & Double & $\begin{array}{l}\text { BLEED } \\
\text { UPDATE }\end{array}$ & $\begin{array}{l}5 \\
1\end{array}$ \\
\hline D.HCT & Temporary at-tribute & Double & $\begin{array}{l}\text { BLEED } \\
\text { UPDATE }\end{array}$ & $\begin{array}{l}3 \\
1\end{array}$ \\
\hline D.02.DELIVERY & Temporary attribute & Double & $\begin{array}{l}\text { BLEED } \\
\text { UPDATE }\end{array}$ & 2 \\
\hline D. RBC.MASS & Temporary attribute & Double & $\begin{array}{l}\text { BLEED } \\
\text { UPDATE }\end{array}$ & \\
\hline D.SBP & Temporary attribute & Double & $\begin{array}{l}\text { BLEED } \\
\text { UPDATE }\end{array}$ & \\
\hline DEAD & Define to mean & & $\begin{array}{l}\text { PREAMBLE } \\
\text { BLEED } \\
\text { PASS.TIME } \\
\text { PATIENT }\end{array}$ & $\begin{array}{l}1 \\
1 \\
1 \\
2\end{array}$ \\
\hline DEBUG & Define to mean & & $\begin{array}{l}\text { PREAMBLE } \\
\text { DISPATCHER } \\
\text { FIND. HOSP } \\
\text { PASS.TIME } \\
\text { PATIENT } \\
\text { RECALL }\end{array}$ & $\begin{array}{l}1 \\
3 \\
2 \\
1 \\
2 \\
1\end{array}$ \\
\hline DEF.BP & Temporary attribute & Double & $\begin{array}{l}\text { PREAMBLE } \\
\text { PATIENT } \\
\text { PT.REPORT }\end{array}$ & $\begin{array}{l}2 \\
1 \\
1\end{array}$ \\
\hline DEST.LEVEL & Temporary attribute & Integer & $\begin{array}{l}\text { PREAMBLE } \\
\text { AMBULANCE.RUN } \\
\text { ASSIGN.AMB } \\
\text { FIND.HOSP } \\
\text { GET.PATIENT }\end{array}$ & $\begin{array}{l}2 \\
2 \\
1\end{array}$ \\
\hline DESTINATION & Temporary attribute & Integer & $\begin{array}{l}\text { PREAMBLE } \\
\text { AMBULANCE.RUN } \\
\text { ASSIGN.AMB } \\
\text { DISPATCHER } \\
\text { FIND.LOC }\end{array}$ & $\begin{array}{l}2 \\
3 \\
1\end{array}$ \\
\hline DIM.F & Library routine & & $\begin{array}{l}\text { LIN.INT.F } \\
\text { NSP.F }\end{array}$ & 1 \\
\hline DISPATCHER & Routine & & $\begin{array}{l}\text { ACCIDENT } \\
\text { AMBULANCE. RUN } \\
\text { CHECK.ACCIDENT } \\
\text { DISPATCHER } \\
\text { GET.PATIENT }\end{array}$ & $\begin{array}{l}2 \\
5 \\
2 \\
1\end{array}$ \\
\hline
\end{tabular}




\begin{tabular}{|c|c|c|c|}
\hline DIVERT. COUNTER & Global variable & Integer & $\begin{array}{l}\text { PREAMBLE } \\
\text { MAIN } \\
\text { FIND.HOSP }\end{array}$ \\
\hline DONE & Routine & Integer & $\begin{array}{l}\text { PREAMBLE } \\
\text { DONE } \\
\text { PASS.TIME } \\
\text { PATIENT }\end{array}$ \\
\hline DONE.RESUS & Define to mean & & $\begin{array}{l}\text { PREAMBLE } \\
\text { PASS.TIME }\end{array}$ \\
\hline EDGE.SET & Set & & $\begin{array}{l}\text { PREAMBLE } \\
\text { BEST.ROUTE } \\
\text { GET.NET } \\
\text { PRINT.NET }\end{array}$ \\
\hline EN.ROUTE & Define to mean & & $\begin{array}{l}\text { PREAMBLE } \\
\text { AMBULANCE.RUN } \\
\text { PASS.TIME }\end{array}$ \\
\hline ERR.F & Library routine & & MYGAMMA.F \\
\hline EST.DEATHS & Global variable & Double & $\begin{array}{l}\text { PREAMBLE } \\
\text { FINAL.REPORT } \\
\text { PATIENT }\end{array}$ \\
\hline EXP.C & Permanent attribute & Double & MYGAMMA.F \\
\hline EXP.F & Library routine & & $\begin{array}{l}\text { BLEED } \\
\text { MYGAMMA.F } \\
\text { PATIENT }\end{array}$ \\
\hline EXPONENTIAL.F & Library routine & & $\begin{array}{l}\text { ACCIDENT } \\
\text { AMBULANCE. RUN } \\
\text { CHOKE.F } \\
\text { PATIENT }\end{array}$ \\
\hline F.AMB.PATIENT.SET & Temporary attribute & Pointer & AMBULANCE. RUN \\
\hline F.H.READY.SET & Permanent attribute & Integer2 & GET.AMB \\
\hline FALSE & Define to mean & & $\begin{array}{l}\text { PREAMBLE } \\
\text { AMBULANCE.RUN } \\
\text { BUILD. HOSP.LIST } \\
\text { CHECK. RED } \\
\text { CLEAR.REDS } \\
\text { DISPATCHER } \\
\text { DONE } \\
\text { FIND.HOSP } \\
\text { GET.AMB } \\
\text { GET.HOSP } \\
\text { GET.LIST } \\
\text { GO.GREEN } \\
\text { GO.OFF.RED } \\
\text { GO.RED } \\
\text { INIT.ACCIDENT } \\
\text { LIVING } \\
\text { LEFT NO.PTS } \\
\text { PASS.TIME } \\
\text { PATIENT }\end{array}$ \\
\hline FINAL. REPORT & Routine & & MAIN \\
\hline
\end{tabular}




\begin{tabular}{|c|c|c|c|}
\hline & & & FINAL.REPORT \\
\hline FIND.HOSP & Routine & Integer & $\begin{array}{l}\text { PREAMBLE } \\
\text { DISPATCHER } \\
\text { FIND. HOSP } \\
\text { GET.PATIENT }\end{array}$ \\
\hline FIND. LOC & Routine & Integer & $\begin{array}{l}\text { PREAMBLE } \\
\text { FIND. LOC } \\
\text { RECALL }\end{array}$ \\
\hline FLIGHT.TIME & Permanent attribute & Double & $\begin{array}{l}\text { PREAMBLE } \\
\text { GET.NET } \\
\text { GET.TRAVEL.TIME } \\
\text { PRINT.NET }\end{array}$ \\
\hline FOREVER & Define to mean & & $\begin{array}{l}\text { PREAMBLE } \\
\text { AMBULANCE.RUN } \\
\text { BEST.ROUTE } \\
\text { BUILD.CALL.LIST } \\
\text { BUILD.HOSP.LIST } \\
\text { GENERATOR }\end{array}$ \\
\hline FREE & Define to mean & & $\begin{array}{l}\text { PREAMBLE } \\
\text { BUILD.ROUTE }\end{array}$ \\
\hline FTIME.F & Routine & Double & $\begin{array}{l}\text { PREAMBLE } \\
\text { FTIME.F } \\
\text { GET.NET }\end{array}$ \\
\hline FULL & Permanent attribute & Integer & $\begin{array}{l}\text { PREAMBLE } \\
\text { GET.HOSP } \\
\text { LEFT NO.PTS }\end{array}$ \\
\hline G.ACCUM.CAP & Permanent attribute & Double & $\begin{array}{l}\text { PREAMBLE } \\
\text { MAIN } \\
\text { FINAL.REPORT }\end{array}$ \\
\hline G.ACCUM.PTS & Permanent attribute & Double & $\begin{array}{l}\text { PREAMBLE } \\
\text { MAIN } \\
\text { FINAL.REPORT }\end{array}$ \\
\hline G.MAX.ACCS & Global variable & Double & $\begin{array}{l}\text { PREAMBLE } \\
\text { FINAL.REPORT }\end{array}$ \\
\hline G.MAX.DUR & Global variable & Double & $\begin{array}{l}\text { PREAMBLE } \\
\text { FINAL.REPORT }\end{array}$ \\
\hline G.MAX.MAXPEND & Global variable & Double & $\begin{array}{l}\text { PREAMBLE } \\
\text { FINAL.REPORT }\end{array}$ \\
\hline G.MAX.PTS & Global variable & Double & $\begin{array}{l}\text { PREAMBLE } \\
\text { FINAL.REPORT }\end{array}$ \\
\hline G.MEAN.ACCS & Routine & Double & $\begin{array}{l}\text { PREAMBLE } \\
\text { FINAL.REPORT }\end{array}$ \\
\hline G.MEAN.AMB & Routine & Double & $\begin{array}{l}\text { PREAMBLE } \\
\text { FINAL.REPORT }\end{array}$ \\
\hline G.MEAN.DUR & Routine & Double & $\begin{array}{l}\text { PREAMBLE } \\
\text { FINAL.REPORT }\end{array}$ \\
\hline
\end{tabular}




\begin{tabular}{|c|c|c|c|}
\hline G.MEAN.MAXPEND & Routine & Double & $\begin{array}{l}\text { PREAMBLE } \\
\text { FINAL. REPORT }\end{array}$ \\
\hline G.MEAN.PEND & Routine & Double & $\begin{array}{l}\text { PREAMBLE } \\
\text { FINAL.REPORT }\end{array}$ \\
\hline G.MEAN.PTS & Routine & Double & $\begin{array}{l}\text { PREAMBLE } \\
\text { FINAL.REPORT }\end{array}$ \\
\hline G.SSQ.CAP & Permanent attribute & Double & $\begin{array}{l}\text { PREAMBLE } \\
\text { MAIN } \\
\text { FINAL.REPORT }\end{array}$ \\
\hline G.SSQ.PTS & Permanent attribute & Double & $\begin{array}{l}\text { PREAMBLE } \\
\text { MAIN } \\
\text { FINAL. REPORT }\end{array}$ \\
\hline G.VAR.ACCS & Rout ine & Double & $\begin{array}{l}\text { PREAMBLE } \\
\text { FINAL. REPORT }\end{array}$ \\
\hline G.VAR.AMB & Routine & Double & $\begin{array}{l}\text { PREAMBLE } \\
\text { FINAL.REPORT }\end{array}$ \\
\hline G.VAR.DUR & Routine & Double & $\begin{array}{l}\text { PREAMBLE } \\
\text { FINAL. REPORT }\end{array}$ \\
\hline G.VAR.MAXPEND & Routine & Double & PREAMBLE \\
\hline G.VAR,PEND & Routine & Double & $\begin{array}{l}\text { PREAMBLE } \\
\text { FINAL. REPORT }\end{array}$ \\
\hline G.VAR.PTS & Routine & Double & $\begin{array}{l}\text { PREAMBLE } \\
\text { FINAL.REPORT }\end{array}$ \\
\hline \multirow[t]{2}{*}{ GENERATOR } & Process notice & & $\begin{array}{l}\text { PREAMBLE } \\
\text { MAIN } \\
\text { GENERATOR }\end{array}$ \\
\hline & + Global variable & Pointer & MAIN \\
\hline GET.ACCS & Routine & Pointer & $\begin{array}{l}\text { PREAMBLE } \\
\text { GET.ACCS } \\
\text { INITIALIZE }\end{array}$ \\
\hline GET.AMB & Routine & Integer & $\begin{array}{l}\text { PREAMBLE } \\
\text { DISPATCHER } \\
\text { GET.AMB }\end{array}$ \\
\hline GET.EMS & Routine & & $\begin{array}{l}\text { GET.EMS } \\
\text { INITIALIZE }\end{array}$ \\
\hline GET.HOSP & Rout ine & & $\begin{array}{l}\text { GET.HOSP } \\
\text { INITIALIZE }\end{array}$ \\
\hline GET.IV.RATE & Routine & Double & $\begin{array}{l}\text { PREAMBLE } \\
\text { AMBULANCE.RUN } \\
\text { GET.IV.RATE } \\
\text { GET.PATIENT }\end{array}$ \\
\hline GET. LEVEL & Routine & Integer & $\begin{array}{l}\text { PREAMBLE } \\
\text { AMBULANCE. RUN } \\
\text { GET.LEVEL } \\
\text { GET.PATIENT }\end{array}$ \\
\hline
\end{tabular}




\begin{tabular}{|c|c|c|c|}
\hline GET.LIST & Routine & & $\begin{array}{l}\text { GET.LIST } \\
\text { INITIALIZE }\end{array}$ \\
\hline GET.NET & Routine & & $\begin{array}{l}\text { GET.NET } \\
\text { INITIALIZE }\end{array}$ \\
\hline GET.NUM.AMB & Routine & Integer & $\begin{array}{l}\text { PREAMBLE } \\
\text { DISPATCHER } \\
\text { GET.NUM.AMB }\end{array}$ \\
\hline GET.PATIENT & Routine & & $\begin{array}{l}\text { AMBULANCE.RUN } \\
\text { GET.PATIENT }\end{array}$ \\
\hline GET.SIM & Routine & & $\begin{array}{l}\text { GET.SIM } \\
\text { INITIALIZE }\end{array}$ \\
\hline GET.TABLE & Routine & Pointer & $\begin{array}{l}\text { PREAMBLE } \\
\text { GET.TABLE } \\
\text { INITIALIZE }\end{array}$ \\
\hline GET.TRAVEL.TIME & Routine & Double & $\begin{array}{l}\text { PREAMBLE } \\
\text { DISPATCHER } \\
\text { GET.AMB } \\
\text { GET.TRAVEL.TIME }\end{array}$ \\
\hline GO.GREEN & Routine & Integer & $\begin{array}{l}\text { PREAMBLE } \\
\text { CHECK.RED } \\
\text { GO.GREEN } \\
\text { GO.OFF.RED }\end{array}$ \\
\hline GO. ITEM & $\begin{array}{l}\text { Temporary entity } \\
+ \text { Global variable }\end{array}$ & Pointer & $\begin{array}{l}\text { PREAMBLE } \\
\text { BUILD.HOSP.LIST } \\
\text { READ.HOSP.LIST } \\
\text { BUILD.HOSP.LIST } \\
\text { READ.HOSP.LIST }\end{array}$ \\
\hline GO.OFF.RED & $\begin{array}{l}\text { Event notice } \\
+ \text { Global variable }\end{array}$ & Pointer & $\begin{array}{l}\text { PREAMBLE } \\
\text { CHECK.RED } \\
\text { CLEAR.REDS } \\
\text { GO.OFF.RED } \\
\text { GO.OFF.RED }\end{array}$ \\
\hline GO.RED & Routine & Integer & $\begin{array}{l}\text { PREAMBLE } \\
\text { CHECK.RED } \\
\text { GO.RED }\end{array}$ \\
\hline GOR.HSP & Temporary attribute & Integer & $\begin{array}{l}\text { PREAMBLE } \\
\text { CHECK.RED } \\
\text { GO.OFF.RED }\end{array}$ \\
\hline GOT.HELO & Temporary attribute & Integer & $\begin{array}{l}\text { PREAMBLE } \\
\text { DISPATCHER } \\
\text { PT.REPORT }\end{array}$ \\
\hline GR.MAX.PTS & Permanent attribute & Integer & $\begin{array}{l}\text { PREAMBLE } \\
\text { MAIN } \\
\text { FINAL.REPORT }\end{array}$ \\
\hline GREEN.LIMIT & Global variable & Integer & $\begin{array}{l}\text { PREAMBLE } \\
\text { GET.SIM } \\
\text { GO.GREEN }\end{array}$ \\
\hline GREEN.SET & Set & & PREAMBLE \\
\hline
\end{tabular}




\begin{tabular}{|c|c|c|c|}
\hline & & & $\begin{array}{l}\text { CHECK.RED } \\
\text { CLEAR.REDS } \\
\text { FIND.HOSP } \\
\text { GET.HOSP } \\
\text { GO.OFF.RED }\end{array}$ \\
\hline GROUND & Define to mean & & $\begin{array}{l}\text { PREAMBLE } \\
\text { BUILD.CALL.LIST } \\
\text { DISPATCHER } \\
\text { GET.AMB } \\
\text { GET.EMS } \\
\text { GET.TRAVEL.TIME } \\
\text { PRINT.NET } \\
\text { RECALL }\end{array}$ \\
\hline H.CTS & Temporary attribute & Integer & $\begin{array}{l}\text { PREAMBLE } \\
\text { CTS.F } \\
\text { INIT.PT }\end{array}$ \\
\hline H.READY.SET & Set & & $\begin{array}{l}\text { PREAMBLE } \\
\text { BUILD.CALL.LIST } \\
\text { DISPATCHER } \\
\text { GET.AMB } \\
\text { GET.EMS }\end{array}$ \\
\hline H.WAITING.SET & Set & & $\begin{array}{l}\text { PREAMBLE } \\
\text { AMBULANCE.RUN } \\
\text { CHECK.ACCIDENT } \\
\text { DISPATCHER }\end{array}$ \\
\hline HCT & Temporary attribute & Double & $\begin{array}{l}\text { PREAMBLE } \\
\text { BLEED } \\
\text { PATIENT } \\
\text { UPDATE }\end{array}$ \\
\hline НСТ. 0 & Define to mean & & $\begin{array}{l}\text { PREAMBLE } \\
\text { PATIENT }\end{array}$ \\
\hline HELO.COMING & Temporary attribute & Integer & $\begin{array}{l}\text { PREAMBLE } \\
\text { AMBULANCE. RUN } \\
\text { DISPATCHER }\end{array}$ \\
\hline HOSP & Temporary attribute & Integer & $\begin{array}{l}\text { PREAMBLE } \\
\text { AMBULANCE.RUN } \\
\text { DISPATCHER } \\
\text { PATIENT } \\
\text { PT.REPORT } \\
\text { PVT.TRAVEL } \\
\text { TR.DELIVER.PT } \\
\text { TR.ENROUTE.HOSP } \\
\text { TR.PVT.TR.PT }\end{array}$ \\
\hline HOSP.BASE & Permanent attribute & Integer & $\begin{array}{l}\text { PREAMBLE } \\
\text { DISPATCHER } \\
\text { GET.HOSP } \\
\text { GET.PATIENT } \\
\text { PRINT.NET } \\
\text { PVT.TRAVEL }\end{array}$ \\
\hline HOSP.BASE.SET & Set & & $\begin{array}{l}\text { PREAMBLE } \\
\text { BUILD.HOSP.LIST } \\
\text { GET.HOSP }\end{array}$ \\
\hline
\end{tabular}




\begin{tabular}{|c|c|c|c|c|}
\hline HOSP.BP & Temporary attribute & Double & $\begin{array}{l}\text { PREAMBLE } \\
\text { PATIENT } \\
\text { PT.REPORT }\end{array}$ & $\begin{array}{l}2 \\
1= \\
1\end{array}=$ \\
\hline HOSP.ID & Permanent attribute & Integer & $\begin{array}{l}\text { PREAMBLE } \\
\text { GET.HOSP }\end{array}$ & $\begin{array}{l}2 \\
1=\end{array}$ \\
\hline HOSP.LEVEL & Temporary attribute & Integer & $\begin{array}{l}\text { PREAMBLE } \\
\text { BUILD.HOSP.LIST } \\
\text { FIND.HOSP } \\
\text { READ.HOSP.LIST } \\
\text { WRITE.HOSP.LIST }\end{array}$ & $\begin{array}{l}2 \\
2= \\
2 \\
1= \\
1\end{array}$ \\
\hline HOSP.LIST & Set & & $\begin{array}{l}\text { PREAMBLE } \\
\text { BUILD. HOSP.LIST } \\
\text { FIND. HOSP } \\
\text { PRINT.NET } \\
\text { PVT.TRAVEL } \\
\text { READ.HOSP.LIST } \\
\text { WRITE.HOSP.LIST }\end{array}$ & $\begin{array}{l}2 \\
4 \\
2 \\
1 \\
2 \\
1 \\
1\end{array}$ \\
\hline HOSP.NAME & Permanent attribute & Text & $\begin{array}{l}\text { PREAMBLE } \\
\text { FINAL.REPORT } \\
\text { FIND.HOSP } \\
\text { GET.HOSP } \\
\text { PRINT.NET } \\
\text { RUN.REPORT } \\
\text { TR.DELIVER.PT } \\
\text { TR.ENROUTE.HOSP } \\
\text { TR.GO.GREEN } \\
\text { TR.GO.RED } \\
\text { TR.PVT.TR.PT } \\
\text { TR.RESUS.PT }\end{array}$ & $\begin{array}{l}2 \\
1 \\
1 \\
1 \\
2 \\
1 \\
1 \\
1 \\
1 \\
1 \\
1 \\
1\end{array}$ \\
\hline HOSP.SET & Set & & $\begin{array}{l}\text { PREAMBLE } \\
\text { BUILD.HOSP.LIST } \\
\text { GET.HOSP }\end{array}$ & $\begin{array}{l}2 \\
1 \\
1\end{array}$ \\
\hline HOSP.VOLUME & Permanent attribute & Double & $\begin{array}{l}\text { PREAMBLE } \\
\text { FIND.HOSP } \\
\text { GET.HOSP } \\
\text { PVT.TRAVEL }\end{array}$ & $\begin{array}{l}2 \\
2 \\
1 \\
2\end{array}=$ \\
\hline HOSPITAL & $\begin{aligned} & \text { Permanent entity } \\
&+ \text { Global variable }\end{aligned}$ & Integer2 & $\begin{array}{l}\text { PREAMBLE } \\
\text { GET.HOSP } \\
\text { MAIN } \\
\text { FINAL.REPORT } \\
\text { GET.HOSP } \\
\text { RUN.REPORT }\end{array}$ & $\begin{aligned} 1 & \\
1 & = \\
15 & = \\
2 & = \\
10 & = \\
8 & =\end{aligned}$ \\
\hline HOSPITAL.ID & Temporary attribute & Integer & $\begin{array}{l}\text { PREAMBLE } \\
\text { BUILD.HOSP.LIST } \\
\text { FIND.HOSP } \\
\text { PRINT.NET } \\
\text { PVT.TRAVEL } \\
\text { READ.HOSP.LIST } \\
\text { WRITE.HOSP.LIST }\end{array}$ & $\begin{array}{l}2 \\
2= \\
6 \\
2 \\
3 \\
1= \\
1=\end{array}$ \\
\hline HOUR.F & Library routine & & $\begin{array}{l}\text { DISPATCHER } \\
\text { FIND.HOSP } \\
\text { GENERATOR } \\
\text { PASS.TIME } \\
\text { PATIENT }\end{array}$ & $\begin{array}{l}3 \\
2 \\
1 \\
1 \\
2\end{array}$ \\
\hline
\end{tabular}


HOURS.V

HTOL

IN.USE

INFO.LAG

INIT.ACCIDENT

INIT.PT

INITIALIZE

INJURY.LOC

INJURY.TIME

INT.F
Permanent attribute Double

Global variable

Double

Define to mean

Global variable Double

Routine

Routine

Routine

Temporary attribute Integer

Temporary attribute Double

Library routine
RECALL

TR.CHECK. IN.ACC

TR.CHECK. IN.AMB

TR. CHECK. OUT .ACC

TR.CHECK.OUT.PT

TR.DELIVER.PT

TR. ENROUTE.HOSP

TR.GO.GREEN

TR.GO.RED

TR.ON.SCENE

TR.PICKUP.PT

TR.PVT.TR.PT

TR. RESUS.PT

TR.SEND.AMB

TR. TO. HOME

TR. UNSTACK.ACC

$\begin{array}{ll}\text { BLEED } & 1 \\ \text { CHECK.RED } & 1 \\ \text { DONE } & 1 \\ \text { GENERATOR } & 1 \\ \text { GET.IV.RATE } & 1 \\ \text { GET.PATIENT } & 1 \\ \text { GO.OFF. RED } & 1 \\ \text { INIT.PT } & 1 \\ \text { PASS.TIME } & 2 \\ \text { PATIENT } & 6 \\ \text { PT.REPORT } & 1 \\ \text { PVT.TRAVEL } & 1 \\ \text { RUN.REPORT } & 2\end{array}$

RUN. REPORT

PREAMBLE

BUILD.HOSP. LIST

GET.SIM

PRINT.NET

PREAMBLE

BUILD. ROUTE

PREAMBLE

ACCIDENT

GET.SIM

GENERATOR

INIT. ACC IDENT

INIT . ACCIDENT

INIT.PT

MAIN

INITIALIZE

PREAMBLE

INIT.PT

PT. REPORT

PREAMBLE

DONE

PASS.TIME

PATIENT

PT.REPORT

DISPATCHER
1

1

1

1

1

2

1

1

1

1

1

1

1

1

1

1

2 $1=$ 1

1

1

1

$1=$

1

1

1

1

1

1

2

$1=$

1

2

1

$2=$

1

1 


\begin{tabular}{|c|c|c|c|}
\hline & & & $\begin{array}{l}\text { GET.NUM.AMB } \\
\text { INIT.PT }\end{array}$ \\
\hline INTEGRATOR.V & Permanent attribute & Integer & GET.SIM \\
\hline IS.TO.IV & Define to mean & & $\begin{array}{l}\text { PREAMBLE } \\
\text { BLEED }\end{array}$ \\
\hline ISS & Temporary attribute & Integer & $\begin{array}{l}\text { PREAMBLE } \\
\text { INIT.PT } \\
\text { PATIENT } \\
\text { PT.REPORT }\end{array}$ \\
\hline IV.RATE & Temporary attribute & Double & $\begin{array}{l}\text { PREAMBLE } \\
\text { AMBULANCE. RUN } \\
\text { BLEED } \\
\text { GET.PATIENT } \\
\text { PATIENT }\end{array}$ \\
\hline IV.START.TIME & Temporary attribute & Double & $\begin{array}{l}\text { PREAMBLE } \\
\text { BLEED } \\
\text { GET.PATIENT }\end{array}$ \\
\hline KIND & Temporary attribute & Integer & $\begin{array}{l}\text { PREAMBLE } \\
\text { ACCIDENT } \\
\text { AMBULANCE.RUN } \\
\text { ASSIGN.AMB } \\
\text { DISPATCHER } \\
\text { INIT.ACCIDENT } \\
\text { TR.CHECK.IN.ACC } \\
\text { TR.CHECK.OUT.ACC } \\
\text { TR.ENROUTE.HOSP } \\
\text { TR.ON.SCENE } \\
\text { TR.PICKUP.PT } \\
\text { TR.SEND.AMB } \\
\text { TR.STACK.ACC } \\
\text { TR.UNSTACK.ACC }\end{array}$ \\
\hline LAPLACE. F & Routine & Double & $\begin{array}{l}\text { PREAMBLE } \\
\text { LAPLACE.F } \\
\text { MYGAMMA.F }\end{array}$ \\
\hline LAT & Permanent attribute & Double & $\begin{array}{l}\text { PREAMBLE } \\
\text { FTIME.F } \\
\text { GET.NET }\end{array}$ \\
\hline LEVEL & Permanent attribute & Integer & $\begin{array}{l}\text { PREAMBLE } \\
\text { BUILD.HOSP.LIST } \\
\text { GET.HOSP } \\
\text { PRINT.NET }\end{array}$ \\
\hline LEVEL1 & Define to mean & & $\begin{array}{l}\text { PREAMBLE } \\
\text { GET.LEVEL } \\
\text { GET.PATIENT } \\
\text { PRINT.NET }\end{array}$ \\
\hline LEVEL2 & Define to mean & & $\begin{array}{l}\text { PREAMBLE } \\
\text { ASSIGN.AMB } \\
\text { PRINT.NET }\end{array}$ \\
\hline LEVEL2A & Define to mean & & $\begin{array}{l}\text { PREAMBLE } \\
\text { BUILD. HOSP. LIST } \\
\text { GET.LEVEL }\end{array}$ \\
\hline
\end{tabular}




\begin{tabular}{|c|c|c|c|c|}
\hline & & & PRINT.NET & 2 \\
\hline LEVEL3 & Define to mean & & $\begin{array}{l}\text { PREAMBLE } \\
\text { AMBULANCE.RUN } \\
\text { ASSIGN.AMB } \\
\text { GET.LEVEL } \\
\text { GET.PATIENT } \\
\text { PRINT.NET }\end{array}$ & $\begin{array}{l}1 \\
2 \\
1 \\
1 \\
1 \\
2\end{array}$ \\
\hline LIN. INT.F & Routine & Double & $\begin{array}{l}\text { PREAMBLE } \\
\text { LIN. INT.F } \\
\text { NSP.F }\end{array}$ & 1 \\
\hline LINES.V & Temporary attribute & Integer & MAIN & 4 \\
\hline LIVING & Routine & Integer & $\begin{array}{l}\text { PREAMBLE } \\
\text { DONE } \\
\text { LIVING } \\
\text { PASS.TIME } \\
\text { PATIENT }\end{array}$ & \\
\hline LL.TIME & Global variable & Double & $\begin{array}{l}\text { PREAMBLE } \\
\text { FTIME.F } \\
\text { GET.NET } \\
\text { GET.SIM }\end{array}$ & \\
\hline LOG.E.F & Library routine & & $\begin{array}{l}\text { LAPLACE.F } \\
\text { MYGAMMA.F } \\
\text { NSP.F }\end{array}$ & 2 \\
\hline LOG.NORMAL.F & Library routine & & $\begin{array}{l}\text { AMBULANCE.RUN } \\
\text { GET.IV.RATE }\end{array}$ & \\
\hline LONG & Permanent attribute & Double & $\begin{array}{l}\text { PREAMBLE } \\
\text { FTIME.F } \\
\text { GET.NET }\end{array}$ & \\
\hline M.DELIVER & Global variable & Double & $\begin{array}{l}\text { PREAMBLE } \\
\text { AMBULANCE.RUN } \\
\text { GET.SIM }\end{array}$ & \\
\hline M.PATIENT.COUNTER & Global variable & Integer & $\begin{array}{l}\text { PREAMBLE } \\
\text { MAIN } \\
\text { INIT.ACCIDENT }\end{array}$ & \\
\hline M.SECURE & Global variable & Double & $\begin{array}{l}\text { PREAMBLE } \\
\text { AMBULANCE.RUN } \\
\text { GET.SIM }\end{array}$ & \\
\hline MAJOR.CUTOFF & Global variable & Double & $\begin{array}{l}\text { PREAMBLE } \\
\text { GET.LEVEL } \\
\text { GET.SIM } \\
\text { PRINT.NET }\end{array}$ & $\begin{array}{l}2 \\
1\end{array}$ \\
\hline MAJOR.TIME & Global variable & Integer & $\begin{array}{l}\text { PREAMBLE } \\
\text { GET.PATIENT } \\
\text { GET.SIM }\end{array}$ & \\
\hline $\operatorname{MAX} . F$ & Library routine & & $\begin{array}{l}\text { MAIN } \\
\text { GET.IV.RATE } \\
\text { GET.NUM.AMB } \\
\text { INIT.PT } \\
\text { LEFT NO.PTS }\end{array}$ & $\begin{array}{l}1 \\
2 \\
1\end{array}$ \\
\hline
\end{tabular}




\begin{tabular}{|c|c|c|c|}
\hline MAX.RED & Global variable & Integer & $\begin{array}{l}\text { PREAMBLE } \\
\text { GET.SIM } \\
\text { GO.OFF.RED }\end{array}$ \\
\hline MAX.RED.HOSP & Global variable & Integer & $\begin{array}{l}\text { PREAMBLE } \\
\text { GET.SIM } \\
\text { GO.RED }\end{array}$ \\
\hline MAX.STEP.V & Permanent attribute & Real & GET.SIM \\
\hline MAXRTS & Define to mean & & $\begin{array}{l}\text { PREAMBLE } \\
\text { AMBULANCE. RUN } \\
\text { GET.SIM }\end{array}$ \\
\hline MDT & Set & & $\begin{array}{l}\text { PREAMBLE } \\
\text { BEST.ROUTE }\end{array}$ \\
\hline MED. COUNTER & Global variable & Integer & $\begin{array}{l}\text { PREAMBLE } \\
\text { MAIN } \\
\text { INIT.ACCIDENT }\end{array}$ \\
\hline MEDICAL & Define to mean & & $\begin{array}{l}\text { PREAMBLE } \\
\text { ACCIDENT } \\
\text { AMBULANCE. RUN } \\
\text { DISPATCHER } \\
\text { INIT.ACCIDENT }\end{array}$ \\
\hline MIN.AMB & Global variable & Integer & $\begin{array}{l}\text { PREAMBLE } \\
\text { BUILD.CALL.LIST } \\
\text { GET.SIM }\end{array}$ \\
\hline MIN.F & Library routine & & $\begin{array}{l}\text { AMBULANCE.RUN } \\
\text { GET.PATIENT }\end{array}$ \\
\hline MIN.LENGTH & Global variable & Double & $\begin{array}{l}\text { PREAMBLE } \\
\text { FINAL. REPORT } \\
\text { GENERATOR } \\
\text { GET.SIM }\end{array}$ \\
\hline MIN. RED & Global variable & Integer & $\begin{array}{l}\text { PREAMBLE } \\
\text { CHECK.RED } \\
\text { GET.SIM } \\
\text { GO.OFF.RED }\end{array}$ \\
\hline MIN.STEP.V & Permanent attribute & Real & GET.SIM \\
\hline MINOR.CUTOFF & Global variable & Double & $\begin{array}{l}\text { PREAMBLE } \\
\text { AMBULANCE. RUN } \\
\text { GET.LEVEL } \\
\text { GET.SIM } \\
\text { PRINT.NET }\end{array}$ \\
\hline MINOR.TIME & Global variable & Integer & $\begin{array}{l}\text { PREAMBLE } \\
\text { GET.PATIENT } \\
\text { GET.SIM }\end{array}$ \\
\hline MINUTE. F & Library routine & & $\begin{array}{l}\text { DISPATCHER } \\
\text { FIND.HOSP } \\
\text { GENERATOR } \\
\text { PASS.TIME } \\
\text { PATIENT } \\
\text { RECALL } \\
\text { TR.CHECK.IN.ACC }\end{array}$ \\
\hline
\end{tabular}




\begin{tabular}{|c|c|c|c|}
\hline & & & $\begin{array}{l}\text { TR.CHECK.IN.AMB } \\
\text { TR.CHECK.OUT.ACC } \\
\text { TR.CHECK.OUT.PT } \\
\text { TR.DELIVER.PT } \\
\text { TR.ENROUTE.HOSP } \\
\text { TR.GO.GREEN } \\
\text { TR.GO.RED } \\
\text { TR.ON.SCENE } \\
\text { TR.PICKUP.PT } \\
\text { TR.PVT.TR.PT } \\
\text { TR.RESUS.PT } \\
\text { TR.SEND.AMB } \\
\text { TR.TO.HOME } \\
\text { TR.UNSTACK.ACC }\end{array}$ \\
\hline MINUTES.V & Permanent attribute & Double & $\begin{array}{l}\text { BLEED } \\
\text { DONE } \\
\text { FTIME.F } \\
\text { GET.IV.RATE } \\
\text { GET.NET } \\
\text { GET.PATIENT } \\
\text { INIT.PT } \\
\text { PASS.TIME } \\
\text { PATIENT } \\
\text { PT.REPORT } \\
\text { PVT.TRAVEL } \\
\text { RUN.REPORT }\end{array}$ \\
\hline MOD.F & Library routine & & NSP.F \\
\hline MYBETA.F & Routine & Double & $\begin{array}{l}\text { PREAMBLE } \\
\text { INIT.PT } \\
\text { MYBETA.F }\end{array}$ \\
\hline MYGAMMA.F & Routine & Double & $\begin{array}{l}\text { PREAMBLE } \\
\text { AMBULANCE. RUN } \\
\text { GET.TRAVEL.TIME } \\
\text { MYBETA.F } \\
\text { MYGAMMA.F } \\
\text { PATIENT } \\
\text { PVT.TRAVEL }\end{array}$ \\
\hline N.ACC.PATIENT.SET & Temporary attribute & Integer2 & DISPATCHER \\
\hline N.AMB.PATIENT.SET & Temporary attribute & Integer2 & TR.ENROUTE.HOSP \\
\hline N.AMB.SET & Temporary attribute & Integer2 & $\begin{array}{l}\text { CHECK.ACCIDENT } \\
\text { DISPATCHER }\end{array}$ \\
\hline N.AMBULANCE & Global variable & Integer2 & $\begin{array}{l}\text { MAIN } \\
\text { GENERATOR }\end{array}$ \\
\hline N.CTS & Temporary attribute & Integer & $\begin{array}{l}\text { PREAMBLE } \\
\text { CTS.F } \\
\text { INIT.PT }\end{array}$ \\
\hline N.EDGE.SET & Permanent attribute & Integer2 & GET.NET \\
\hline N.H.READY.SET & Permanent attribute & Integer2 & $\begin{array}{l}\text { PREAMBLE } \\
\text { MAIN } \\
\text { GENERATOR }\end{array}$ \\
\hline N.NODE. AMB.SET & Permanent attribute & Integer2 & GET.AMB \\
\hline
\end{tabular}




\begin{tabular}{|c|c|c|c|}
\hline N.PENDING.SET & Permanent attribute & Integer2 & $\begin{array}{l}\text { PREAMBLE } \\
\text { MAIN } \\
\text { DISPATCHER }\end{array}$ \\
\hline N.READY.SET & Permanent attribute & Integer2 & $\begin{array}{l}\text { PREAMBLE } \\
\text { MAIN } \\
\text { GENERATOR }\end{array}$ \\
\hline N.RED.SET & Permanent attribute & Integer2 & GO.RED \\
\hline N.TEMP.SET & Permanent attribute & Integer2 & $\begin{array}{l}\text { BUILD.CALL.LIST } \\
\text { BUILD.HOSP.LIST }\end{array}$ \\
\hline NEED. HELO & Temporary attribute & Integer & $\begin{array}{l}\text { PREAMBLE } \\
\text { GET.PATIENT } \\
\text { PT.REPORT }\end{array}$ \\
\hline NEEDED & Temporary attribute & Integer & $\begin{array}{l}\text { PREAMBLE } \\
\text { DISPATCHER }\end{array}$ \\
\hline NEW. INFO & Define to mean & & $\begin{array}{l}\text { PREAMBLE } \\
\text { ACCIDENT } \\
\text { DISPATCHER }\end{array}$ \\
\hline NMPD & Define to mean & & $\begin{array}{l}\text { PREAMBLE } \\
\text { FTIME.F }\end{array}$ \\
\hline NO.BLUNT & Global variable & Integer & $\begin{array}{l}\text { PREAMBLE } \\
\text { MAIN } \\
\text { FINAL. REPORT } \\
\text { INIT.ACCIDENT }\end{array}$ \\
\hline NO.DEATHS & Global variable & Integer & $\begin{array}{l}\text { PREAMBLE } \\
\text { MAIN } \\
\text { FINAL.REPORT } \\
\text { PASS.TIME } \\
\text { PATIENT }\end{array}$ \\
\hline NO.PENDED & Global variable & Integer & $\begin{array}{l}\text { PREAMBLE } \\
\text { MAIN } \\
\text { GET.AMB }\end{array}$ \\
\hline NO.PTS & Permanent attribute & Integer & $\begin{array}{l}\text { PREAMBLE } \\
\text { GO.OFF.RED } \\
\text { LEFT NO.PTS } \\
\text { LEFT NO.PTS } \\
\text { PATIENT }\end{array}$ \\
\hline NO.PTS. LEFT & Define to mean & & $\begin{array}{l}\text { PREAMBLE } \\
\text { CHECK.ACCIDENT } \\
\text { DISPATCHER }\end{array}$ \\
\hline NO.RUNS & Global variable & Integer & $\begin{array}{l}\text { PREAMBLE } \\
\text { MAIN } \\
\text { FINAL.REPORT } \\
\text { GET.SIM }\end{array}$ \\
\hline NO.VICTIMS & Temporary attribute & Integer & $\begin{array}{l}\text { PREAMBLE } \\
\text { DISPATCHER } \\
\text { INIT.ACCIDENT }\end{array}$ \\
\hline NODE & Permanent entity & & $\begin{array}{l}\text { PREAMBLE } \\
\text { BUILD.CALL.LIST }\end{array}$ \\
\hline
\end{tabular}




\begin{tabular}{|c|c|c|c|}
\hline & $\begin{array}{l}\text { + Global variable } \\
\text { + Implied subscript }\end{array}$ & Integer2 & $\begin{array}{l}\text { BUILD.HOSP.LIST } \\
\text { GET.NET } \\
\text { BEST.ROUTE } \\
\text { BUILD.CALL.LIST } \\
\text { BUILD.HOSP.LIST } \\
\text { GET.NET } \\
\text { INIT.ACCIDENT } \\
\text { PRINT.NET } \\
\text { WRITE.CALL.LIST } \\
\text { WRITE.HOSP.LIST } \\
\text { GET.AMB }\end{array}$ \\
\hline NODE.AMB.SET & Set & & $\begin{array}{l}\text { PREAMBLE } \\
\text { BUILD.CALL.LIST } \\
\text { GET.EMS } \\
\text { TRAVEL }\end{array}$ \\
\hline NODE.ID & Permanent attribute & Integer & $\begin{array}{l}\text { PREAMBLE } \\
\text { GET.NET }\end{array}$ \\
\hline NODE.NAME & Permanent attribute & Text & $\begin{array}{l}\text { PREAMBLE } \\
\text { GET.NET } \\
\text { PRINT.NET } \\
\text { TR.CHECK.IN.ACC } \\
\text { TR.CHECK.IN.AMB } \\
\text { TR.ON.SCENE }\end{array}$ \\
\hline NODE.SET & Set & & $\begin{array}{l}\text { PREAMBLE } \\
\text { BEST.ROUTE }\end{array}$ \\
\hline NOT.WORKING & Define to mean & & $\begin{array}{l}\text { PREAMBLE } \\
\text { RECALL }\end{array}$ \\
\hline NSP.F & Routine & Double & $\begin{array}{l}\text { PREAMBLE } \\
\text { GENERATOR } \\
\text { NSP.F }\end{array}$ \\
\hline NSP.LAST.TIME & Global variable & Double & $\begin{array}{l}\text { PREAMBLE } \\
\text { MAIN } \\
\text { NSP.F }\end{array}$ \\
\hline NSP.TPRIME & Global variable & Double & $\begin{array}{l}\text { PREAMBLE } \\
\text { MAIN } \\
\text { NSP.F }\end{array}$ \\
\hline NTRPT & Define to mean & & PREAMBLE \\
\hline NULL & Define to mean & & $\begin{array}{l}\text { PREAMBLE } \\
\text { ACCIDENT } \\
\text { AMBULANCE.RUN } \\
\text { CHECK.ACCIDENT } \\
\text { CHECK.RED } \\
\text { CLEAR.REDS } \\
\text { FIND.HOSP } \\
\text { GET.AMB } \\
\text { GO.OFF.RED }\end{array}$ \\
\hline NUM.HELO & Global variable & Integer & $\begin{array}{l}\text { PREAMBLE } \\
\text { GET.EMS } \\
\text { RUN.REPORT }\end{array}$ \\
\hline 02.DELIVERY & Temporary attribute & Double & $\begin{array}{l}\text { PREAMBLE } \\
\text { LIVING }\end{array}$ \\
\hline
\end{tabular}




\begin{tabular}{|c|c|c|c|c|}
\hline & & & $\begin{array}{l}\text { PATIENT } \\
\text { UPDATE }\end{array}$ & $\begin{array}{l}1= \\
1=\end{array}$ \\
\hline 02.SAT & Temporary attribute & Double & $\begin{array}{l}\text { PREAMBLE } \\
\text { BLEED } \\
\text { INIT.PT } \\
\text { PATIENT } \\
\text { RESP.SUPPORT }\end{array}$ & $\begin{array}{l}2 \\
1 \\
1= \\
1 \\
1=\end{array}$ \\
\hline 02.SAT. 0 & Define to mean & & PREAMBLE & 2 \\
\hline ON.SCENE.SET & Set & & $\begin{array}{l}\text { PREAMBLE } \\
\text { CHECK.ACCIDENT } \\
\text { DISPATCHER }\end{array}$ & $\begin{array}{l}3 \\
1 \\
1\end{array}$ \\
\hline OPS & Define to mean & & $\begin{array}{l}\text { PREAMBLE } \\
\text { BLEED }\end{array}$ & $\begin{array}{l}1 \\
1\end{array}$ \\
\hline OUT.OF.SERVICE.SET & Set & & PREAMBLE & 2 \\
\hline OVERRIDE.COUNTER & Global variable & Integer & $\begin{array}{l}\text { PREAMBLE } \\
\text { MAIN } \\
\text { FIND.HOSP }\end{array}$ & $\begin{array}{l}2 \\
1 \\
1=\end{array}$ \\
\hline P.SECURE & Global variable & Double & $\begin{array}{l}\text { PREAMBLE } \\
\text { AMBULANCE.RUN } \\
\text { GET.SIM }\end{array}$ & $\begin{array}{l}1 \\
1 \\
1=\end{array}=$ \\
\hline PASS.TIME & Routine & & $\begin{array}{l}\text { PASS.TIME } \\
\text { PATIENT }\end{array}$ & $\begin{array}{l}1 \\
4\end{array}$ \\
\hline PATIENT & $\begin{array}{l}\text { Process notice } \\
+ \text { Implied subscript } \\
\text { + Global variable }\end{array}$ & Pointer & $\begin{array}{l}\text { PREAMBLE } \\
\text { INIT.ACCIDENT } \\
\text { PATIENT } \\
\text { BLEED } \\
\text { DONE } \\
\text { PASS.TIME } \\
\text { PATIENT } \\
\text { PATIENT }\end{array}$ & $\begin{array}{l}1 \\
2 \\
1 \\
1 \\
1 \\
1 \\
2 \\
1\end{array}$ \\
\hline PATIENT. COUNTER & Global variable & Integer & $\begin{array}{l}\text { PREAMBLE } \\
\text { INIT.ACCIDENT }\end{array}$ & $\begin{array}{l}1 \\
3\end{array}=$ \\
\hline PATIENT.SET & Set & & $\begin{array}{l}\text { PREAMBLE } \\
\text { GENERATOR } \\
\text { INIT.ACCIDENT } \\
\text { PATIENT }\end{array}$ & $\begin{array}{l}3 \\
1 \\
1 \\
2\end{array}$ \\
\hline PENDED & Temporary attribute & Integer & $\begin{array}{l}\text { PREAMBLE } \\
\text { GET.AMB } \\
\text { INIT.ACCIDENT }\end{array}$ & $\begin{array}{l}2 \\
2= \\
1=\end{array}$ \\
\hline PENDING.SET & Set & & $\begin{array}{l}\text { PREAMBLE } \\
\text { DISPATCHER } \\
\text { GET.AMB }\end{array}$ & $\begin{array}{l}4 \\
5 \\
2\end{array}$ \\
\hline PHASE & Temporary attribute & Integer & $\begin{array}{l}\text { PREAMBLE } \\
\text { AMBULANCE.RUN } \\
\text { DONE } \\
\text { GET.PATIENT } \\
\text { INIT.PT } \\
\text { PASS.TIME } \\
\text { PATIENT }\end{array}$ & $\begin{array}{l}2 \\
2= \\
2 \\
1= \\
1= \\
7= \\
3=\end{array}$ \\
\hline
\end{tabular}




\begin{tabular}{|c|c|c|c|c|}
\hline & & & PVT.TRAVEL & $1=$ \\
\hline POISSON.F & Library routine & & INIT . ACCIDENT & 1 \\
\hline PRINT.NET & Routine & & $\begin{array}{l}\text { INITIALIZE } \\
\text { PRINT.NET }\end{array}$ & $\begin{array}{l}1 \\
1\end{array}$ \\
\hline PRIVATE & Define to mean & & $\begin{array}{l}\text { PREAMBLE } \\
\text { PVT. TRAVEL }\end{array}$ & $\begin{array}{l}1 \\
1\end{array}$ \\
\hline PROB.SURV & Temporary attribute & Double & $\begin{array}{l}\text { PREAMBLE } \\
\text { PATIENT } \\
\text { PT.REPORT }\end{array}$ & $\begin{array}{l}2 \\
4= \\
1\end{array}=$ \\
\hline PROP.ACCS & Global variable & Double & $\begin{array}{l}\text { PREAMBLE } \\
\text { INIT.ACCIDENT } \\
\text { INITIALIZE }\end{array}$ & $\begin{array}{l}1 \\
1 \\
1=\end{array}$ \\
\hline PSTF & Define to mean & & PREAMBLE & 1 \\
\hline PT.ID & Temporary attribute & Integer & $\begin{array}{l}\text { PREAMBLE } \\
\text { BLEED } \\
\text { INIT.ACCIDENT } \\
\text { PASS.TIME } \\
\text { PATIENT } \\
\text { PT.REPORT } \\
\text { TR.CHECK.IN.PT } \\
\text { TR.CHECK.OUT.PT } \\
\text { TR.PICKUP.PT } \\
\text { TR.PVT.TR.PT } \\
\text { TR.RESUS.PT }\end{array}$ & $\begin{array}{l}2 \\
1 \\
1 \\
1 \\
2 \\
1 \\
1 \\
1 \\
1 \\
1 \\
1\end{array}$ \\
\hline PT.REPORT & Routine & & $\begin{array}{l}\text { PATIENT } \\
\text { PT.REPORT }\end{array}$ & $\begin{array}{l}2 \\
1\end{array}$ \\
\hline PTS.PER.ACC & Global variable & Double & $\begin{array}{l}\text { PREAMBLE } \\
\text { GET.SIM }\end{array}$ & $\begin{array}{l}1 \\
1\end{array}=$ \\
\hline PVT.TR.ARRIVE & Temporary attribute & Double & $\begin{array}{l}\text { PREAMBLE } \\
\text { DONE } \\
\text { PASS.TIME } \\
\text { PVT.TRAVEL }\end{array}$ & $\begin{array}{l}2 \\
1 \\
1 \\
1=\end{array}$ \\
\hline PVT.TR.SET & Set & & $\begin{array}{l}\text { PREAMBLE } \\
\text { PATIENT } \\
\text { PVT.TRAVEL }\end{array}$ & $\begin{array}{l}3 \\
1 \\
1\end{array}$ \\
\hline PVT.TRAV & Define to mean & & $\begin{array}{l}\text { PREAMBLE } \\
\text { DONE } \\
\text { PASS.TIME } \\
\text { PATIENT } \\
\text { PVT.TRAVEL }\end{array}$ & $\begin{array}{l}1 \\
1 \\
2 \\
1 \\
1\end{array}$ \\
\hline PVT. TRAVEL & Routine & & $\begin{array}{l}\text { ACCIDENT } \\
\text { PVT. TRAVEL }\end{array}$ & $\begin{array}{l}1 \\
1\end{array}$ \\
\hline R.ACCUM.CAP & Permanent attribute & Double & $\begin{array}{l}\text { PREAMBLE } \\
\text { MAIN } \\
\text { LEFT NO.PTS } \\
\text { RUN.REPORT }\end{array}$ & $\begin{array}{l}2 \\
2= \\
1= \\
2=\end{array}$ \\
\hline R.ACCUM.PTS & Permanent attribute & Double & $\begin{array}{l}\text { PREAMBLE } \\
\text { MAIN }\end{array}$ & $\begin{array}{l}2 \\
2=\end{array}$ \\
\hline
\end{tabular}




\begin{tabular}{|c|c|c|c|c|}
\hline & & & $\begin{array}{l}\text { LEFT NO.PTS } \\
\text { RUN. REPORT }\end{array}$ & $\frac{1}{2}=$ \\
\hline R.CTS & Temporary attribute & Integer & $\begin{array}{l}\text { PREAMBLE } \\
\text { CTS.F } \\
\text { INIT.PT } \\
\text { RESP.SUPPORT }\end{array}$ & \\
\hline R.EST.DEATHS & Global variable & Double & $\begin{array}{l}\text { PREAMBLE } \\
\text { MAIN } \\
\text { PATIENT } \\
\text { RUN. REPORT }\end{array}$ & $\begin{array}{l}1 \\
1= \\
1= \\
2\end{array}=$ \\
\hline R.IDLE.AMB & Routine & Double & $\begin{array}{l}\text { PREAMBLE } \\
\text { MAIN } \\
\text { RUN.REPORT }\end{array}$ & $\begin{array}{l}1 \\
1 \\
2\end{array}$ \\
\hline R.IDLE.HELO & Routine & Double & $\begin{array}{l}\text { PREAMBLE } \\
\text { RUN. REPORT }\end{array}$ & $\begin{array}{l}1 \\
2\end{array}$ \\
\hline R.MAX.PENDING & Global variable & Double & $\begin{array}{l}\text { PREAMBLE } \\
\text { MAIN } \\
\text { RUN.REPORT }\end{array}$ & $\begin{array}{l}1 \\
1 \\
1\end{array}$ \\
\hline R.MAX.PTS & Permanent attribute & Integer & $\begin{array}{l}\text { PREAMBLE } \\
\text { MAIN } \\
\text { LEFT NO.PTS } \\
\text { RUN. REPORT }\end{array}$ & $\begin{array}{l}2 \\
3= \\
1= \\
1\end{array}$ \\
\hline R.MEAN.PENDING & Routine & Double & $\begin{array}{l}\text { PREAMBLE } \\
\text { MAIN } \\
\text { RUN.REPORT }\end{array}$ & $\begin{array}{l}1 \\
1 \\
2\end{array}$ \\
\hline R.MEAN.RED & Routine & Double & $\begin{array}{l}\text { PREAMBLE } \\
\text { RUN. REPORT }\end{array}$ & $\frac{1}{2}$ \\
\hline R.NO.ACCS & Global variable & Double & $\begin{array}{l}\text { PREAMBLE } \\
\text { MAIN } \\
\text { GENERATOR } \\
\text { RUN. REPORT }\end{array}$ & $\begin{array}{l}1 \\
1 \\
1 \\
2\end{array}$ \\
\hline R.NO.BLUNT & Global variable & Double & $\begin{array}{l}\text { PREAMBLE } \\
\text { RUN. REPORT }\end{array}$ & $\begin{array}{l}1 \\
2\end{array}$ \\
\hline R.NO.DEATHS & Global variable & Double & $\begin{array}{l}\text { PREAMBLE } \\
\text { RUN. REPORT }\end{array}$ & $\begin{array}{l}1 \\
2\end{array}$ \\
\hline R.NO.DIVERT & Global variable & Double & $\begin{array}{l}\text { PREAMBLE } \\
\text { RUN. REPORT }\end{array}$ & $\begin{array}{l}1 \\
2\end{array}$ \\
\hline R.NO.M.PTS & Global variable & Double & PREAMBLE & 1 \\
\hline R.NO.MEDS & Global variable & Double & $\begin{array}{l}\text { PREAMBLE } \\
\text { RUN. REPORT }\end{array}$ & $\begin{array}{l}1 \\
1\end{array}$ \\
\hline R.NO.OVERRIDE & Global variable & Double & $\begin{array}{l}\text { PREAMBLE } \\
\text { RUN. REPORT }\end{array}$ & $\begin{array}{l}1 \\
2\end{array}$ \\
\hline R.NO.PENDED & Global variable & Double & $\begin{array}{l}\text { PREAMBLE } \\
\text { RUN. REPORT }\end{array}$ & $\begin{array}{l}1 \\
4\end{array}$ \\
\hline R.NO.T.PTS & Global variable & Double & $\begin{array}{l}\text { PREAMBLE } \\
\text { MAIN }\end{array}$ & $\begin{array}{l}1 \\
1\end{array}$ \\
\hline
\end{tabular}




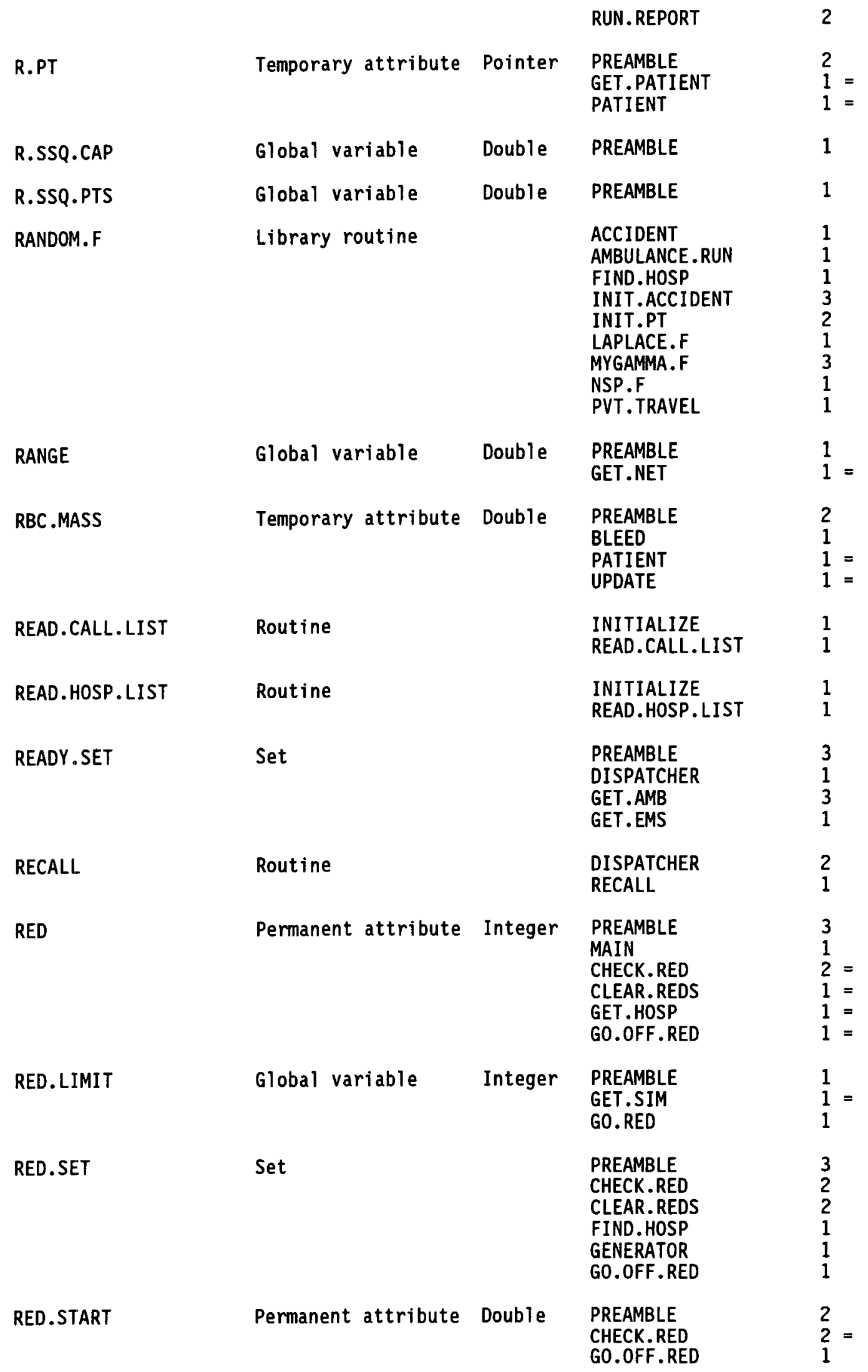




\begin{tabular}{|c|c|c|c|}
\hline RED.TODAY & Permanent attribute & Integer & $\begin{array}{l}\text { PREAMBLE } \\
\text { CHECK.RED } \\
\text { CLEAR.REDS } \\
\text { GET.HOSP } \\
\text { GO.RED }\end{array}$ \\
\hline REDS.PER.DAY & Global variable & Integer & $\begin{array}{l}\text { PREAMBLE } \\
\text { GET.SIM } \\
\text { GO.RED }\end{array}$ \\
\hline REL.ERR.V & Permanent attribute & Real & GET.SIM \\
\hline REQ. AMB & Define to mean & & $\begin{array}{l}\text { PREAMBLE } \\
\text { ACCIDENT } \\
\text { DISPATCHER }\end{array}$ \\
\hline REQ.CAR & Define to mean & & PREAMBLE \\
\hline REQ.HELO & Define to mean & & $\begin{array}{l}\text { PREAMBLE } \\
\text { DISPATCHER } \\
\text { GET.PATIENT }\end{array}$ \\
\hline REQ.HELP & Define to mean & & $\begin{array}{l}\text { PREAMBLE } \\
\text { CHECK.ACCIDENT } \\
\text { DISPATCHER }\end{array}$ \\
\hline RESCUE.BP & Temporary attribute & Double & $\begin{array}{l}\text { PREAMBLE } \\
\text { PATIENT } \\
\text { PT.REPORT }\end{array}$ \\
\hline RESP.SUPPORT & $\begin{array}{l}\text { Event notice } \\
+ \text { Global variable }\end{array}$ & Pointer & $\begin{array}{l}\text { PREAMBLE } \\
\text { GET.PATIENT } \\
\text { PATIENT } \\
\text { RESP.SUPPORT } \\
\text { GET.PATIENT } \\
\text { PATIENT } \\
\text { RESP.SUPPORT }\end{array}$ \\
\hline RESP.TIME & Temporary attribute & Double & $\begin{array}{l}\text { PREAMBLE } \\
\text { GET.PATIENT }\end{array}$ \\
\hline RESUS & Define to mean & & $\begin{array}{l}\text { PREAMBLE } \\
\text { AMBULANCE.RUN } \\
\text { DONE } \\
\text { PASS.TIME } \\
\text { PATIENT }\end{array}$ \\
\hline RESUS. PATIENT.SET & Set & & $\begin{array}{l}\text { PREAMBLE } \\
\text { AMBULANCE.RUN } \\
\text { PATIENT }\end{array}$ \\
\hline RESUS.TIME & Temporary attribute & Double & $\begin{array}{l}\text { PREAMBLE } \\
\text { DONE } \\
\text { PASS.TIME } \\
\text { PATIENT } \\
\text { PT.REPORT }\end{array}$ \\
\hline ROPENERR.V & Temporary attribute & Integer & GET.LIST \\
\hline ROUTE & Set & & $\begin{array}{l}\text { PREAMBLE } \\
\text { BUILD.ROUTE } \\
\text { CHOKE.F } \\
\text { FIND.LOC }\end{array}$ \\
\hline
\end{tabular}




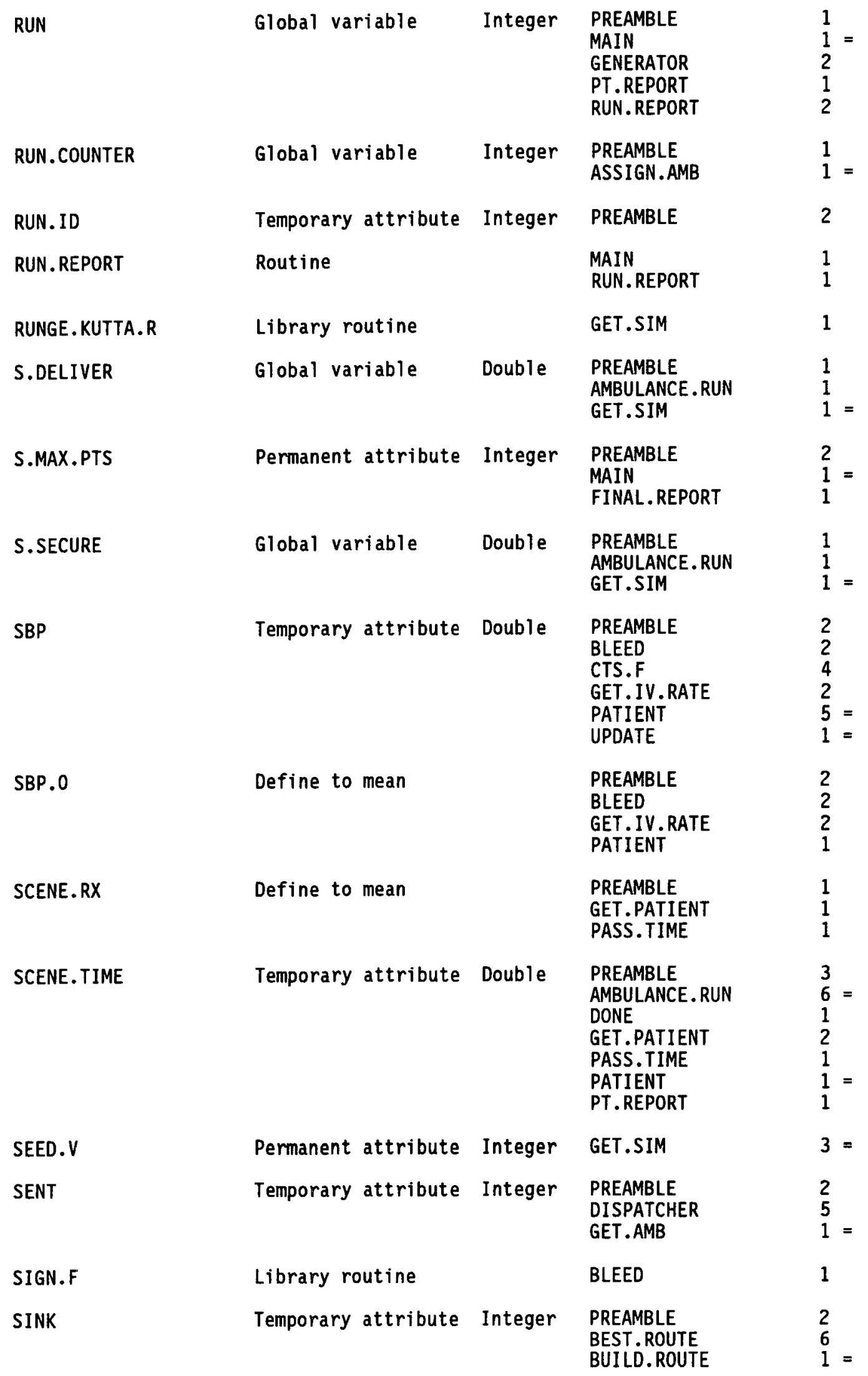




\begin{tabular}{|c|c|c|c|}
\hline & & & $\begin{array}{l}\text { GET.NET } \\
\text { PRINT.NET }\end{array}$ \\
\hline SITE & Temporary attribute & Integer & $\begin{array}{l}\text { PREAMBLE } \\
\text { ASSIGN.AMB } \\
\text { GET.AMB } \\
\text { GET.PATIENT } \\
\text { INIT.ACCIDENT } \\
\text { INIT.PT } \\
\text { PVT.TRAVEL } \\
\text { TR.CHECK.IN.ACC }\end{array}$ \\
\hline SOURCE & Temporary attribute & Integer & $\begin{array}{l}\text { PREAMBLE } \\
\text { BEST.ROUTE } \\
\text { BUILD.ROUTE } \\
\text { GET.NET }\end{array}$ \\
\hline SQRT.F & Library routine & & $\begin{array}{l}\text { ADJ.TIME.F } \\
\text { FINAL.REPORT } \\
\text { FTIME.F } \\
\text { INIT.PT } \\
\text { MYGAMMA.F }\end{array}$ \\
\hline SRC & Temporary attribute & Integer & $\begin{array}{l}\text { PREAMBLE } \\
\text { AMBULANCE. RUN } \\
\text { FIND.LOC }\end{array}$ \\
\hline SSPND & Define to mean & & PREAMBLE \\
\hline STA.A & Temporary attribute & Integer2 & AMBULANCE.RUN \\
\hline START.TIME & Global variable & Double & $\begin{array}{l}\text { PREAMBLE } \\
\text { MAIN } \\
\text { GENERATOR }\end{array}$ \\
\hline STATUS & Temporary attribute & Integer & $\begin{array}{l}\text { PREAMBLE } \\
\text { AMBULANCE.RUN } \\
\text { RECALL }\end{array}$ \\
\hline T.ON.SCENE & Global variable & Double & $\begin{array}{l}\text { PREAMBLE } \\
\text { AMBULANCE. RUN } \\
\text { GET.SIM }\end{array}$ \\
\hline T. PATIENT, COUNTER & Global variable & Integer & $\begin{array}{l}\text { PREAMBLE } \\
\text { MAIN } \\
\text { INIT.ACCIDENT }\end{array}$ \\
\hline T.RESUS & Global variable & Double & $\begin{array}{l}\text { PREAMBLE } \\
\text { GET.SIM } \\
\text { PATIENT }\end{array}$ \\
\hline T.TO.PT & Global variable & Double & $\begin{array}{l}\text { PREAMBLE } \\
\text { AMBULANCE.RUN } \\
\text { GET.SIM }\end{array}$ \\
\hline T.TX & Global variable & Double & $\begin{array}{l}\text { PREAMBLE } \\
\text { GET.SIM } \\
\text { PATIENT }\end{array}$ \\
\hline TCONST & Define to mean & & $\begin{array}{l}\text { PREAMBLE } \\
\text { BLEED }\end{array}$ \\
\hline TCRUISE & Global variable & Double & PREAMBLE \\
\hline
\end{tabular}




\begin{tabular}{|c|c|c|c|}
\hline & & & $\begin{array}{l}\text { ADJ.TIME.F } \\
\text { GET.SIM }\end{array}$ \\
\hline TEMP.SET & Set & & $\begin{array}{l}\text { PREAMBLE } \\
\text { BUILD.CALL.LIST } \\
\text { BUILD.HOSP.LIST }\end{array}$ \\
\hline TIME.A & Temporary attribute & Double & $\begin{array}{l}\text { AMBULANCE. RUN } \\
\text { DISPATCHER } \\
\text { FIND.LOC } \\
\text { GENERATOR } \\
\text { RECALL }\end{array}$ \\
\hline TIME.V & Permanent attribute & Double & $\begin{array}{l}\text { MAIN } \\
\text { ACCIDENT } \\
\text { AMBULANCE. RUN } \\
\text { BLEED } \\
\text { CHECK.RED } \\
\text { DISPATCHER } \\
\text { DONE } \\
\text { FIND. HOSP } \\
\text { GENERATOR } \\
\text { GET.PATIENT } \\
\text { GO.OFF. RED } \\
\text { INIT.ACCIDENT } \\
\text { LEFT NO.PTS } \\
\text { PASS.TIME } \\
\text { PATIENT } \\
\text { PVT.TRAVEL } \\
\text { RECALL } \\
\text { RUN.REPORT } \\
\text { TR.CHECK.IN.ACC } \\
\text { TR.CHECK.IN.AMB } \\
\text { TR.CHECK.OUT.ACC } \\
\text { TR.CHECK.OUT.PT } \\
\text { TR.DELIVER.PT } \\
\text { TR.ENROUTE.HOSP } \\
\text { TR.GO.GREEN } \\
\text { TR.GO.RED } \\
\text { TR.ON.SCENE } \\
\text { TR.PICKUP.PT } \\
\text { TR.PVT.TR.PT } \\
\text { TR.RESUS.PT } \\
\text { TR.SEND.AMB } \\
\text { TR.TO.HOME } \\
\text { TR.UNSTACK.ACC }\end{array}$ \\
\hline TMP.ACCS & Global variable & Integer & $\begin{array}{l}\text { PREAMBLE } \\
\text { MAIN }\end{array}$ \\
\hline TMP.AMBS & Global variable & Double & $\begin{array}{l}\text { PREAMBLE } \\
\text { MAIN }\end{array}$ \\
\hline TMP.DUR & Global variable & Double & $\begin{array}{l}\text { PREAMBLE } \\
\text { MAIN } \\
\text { RUN.REPORT }\end{array}$ \\
\hline TMP.MN.PEND & Global variable & Double & $\begin{array}{l}\text { PREAMBLE } \\
\text { MAIN }\end{array}$ \\
\hline TMP.MX.PENI & Global variable & Integer & $\begin{array}{l}\text { PREAMBLE } \\
\text { MAIN }\end{array}$ \\
\hline
\end{tabular}




\begin{tabular}{|c|c|c|c|}
\hline TMP.PTS & Global variable & Integer & $\begin{array}{l}\text { PREAMBLE } \\
\text { MAIN }\end{array}$ \\
\hline TO. BASE & Define to mean & & $\begin{array}{l}\text { PREAMBLE } \\
\text { AMBULANCE.RUN } \\
\text { DISPATCHER }\end{array}$ \\
\hline TO.BASE.SET & Set & & $\begin{array}{l}\text { PREAMBLE } \\
\text { DISPATCHER }\end{array}$ \\
\hline TO.HOSP & Define to mean & & $\begin{array}{l}\text { PREAMBLE } \\
\text { AMBULANCE. RUN } \\
\text { DISPATCHER }\end{array}$ \\
\hline TO.HOSP.SET & Set & & $\begin{array}{l}\text { PREAMBLE } \\
\text { DISPATCHER }\end{array}$ \\
\hline TO.SCENE & Define to mean & & PREAMBLE \\
\hline TO.SCENE.SET & Set & & $\begin{array}{l}\text { PREAMBLE } \\
\text { ASSIGN.AMB } \\
\text { DISPATCHER } \\
\text { RECALL }\end{array}$ \\
\hline TOD & Temporary attribute & Double & $\begin{array}{l}\text { PREAMBLE } \\
\text { PASS.TIME } \\
\text { PATIENT } \\
\text { PT.REPORT }\end{array}$ \\
\hline TOT.COUNTER & Global variable & Integer & $\begin{array}{l}\text { PREAMBLE } \\
\text { GENERATOR }\end{array}$ \\
\hline TR.CHECK.IN.ACC & Routine & & $\begin{array}{l}\text { PREAMBLE } \\
\text { INIT.ACCIDENT } \\
\text { TR.CHECK.IN.ACC }\end{array}$ \\
\hline TR.CHECK. IN. AMB & Routine & & $\begin{array}{l}\text { PREAMBLE } \\
\text { DISPATCHER } \\
\text { GET.EMS } \\
\text { TR.CHECK.IN.AMB }\end{array}$ \\
\hline TR.CHECK.IN.PT & Routine & & $\begin{array}{l}\text { PREAMBLE } \\
\text { INIT.ACCIDENT } \\
\text { TR.CHECK.IN.PT }\end{array}$ \\
\hline TR.CHECK. OUT.ACC & Routine & & $\begin{array}{l}\text { PREAMBLE } \\
\text { ACCIDENT } \\
\text { TR.CHECK.OUT.ACC }\end{array}$ \\
\hline TR.CHECK.OUT.PT & Routine & & $\begin{array}{l}\text { PREAMBLE } \\
\text { PATIENT } \\
\text { TR.CHECK.OUT.PT }\end{array}$ \\
\hline TR.DELIVER.PT & Routine & & $\begin{array}{l}\text { PREAMBLE } \\
\text { DISPATCHER } \\
\text { TR.DELIVER.PT }\end{array}$ \\
\hline TR.ENROUTE. HOSP & Routine & & $\begin{array}{l}\text { PREAMBLE } \\
\text { DISPATCHER } \\
\text { TR.ENROUTE.HOSP }\end{array}$ \\
\hline TR.GO.GREEN & Routine & & $\begin{array}{l}\text { PREAMBLE } \\
\text { CHECK.RED }\end{array}$ \\
\hline
\end{tabular}




\begin{tabular}{|c|c|c|c|}
\hline TR.GO.RED & Routine & & $\begin{array}{l}\text { PREAMBLE } \\
\text { CHECK.RED } \\
\text { TR.GO.RED }\end{array}$ \\
\hline TR.ON.SCENE & Routine & & $\begin{array}{l}\text { PREAMBLE } \\
\text { DISPATCHER } \\
\text { TR.ON.SCENE }\end{array}$ \\
\hline TR.PICKUP.PT & Routine & & $\begin{array}{l}\text { PREAMBLE } \\
\text { AMBULANCE.RUN } \\
\text { GET.PATIENT } \\
\text { TR.PICKUP.PT }\end{array}$ \\
\hline TR.PROP & Global variable & Double & $\begin{array}{l}\text { PREAMBLE } \\
\text { GET.SIM } \\
\text { INIT.ACCIDENT }\end{array}$ \\
\hline TR.PVT.TR.PT & Routine & & $\begin{array}{l}\text { PREAMBLE } \\
\text { PVT.TRAVEL } \\
\text { TR.PVT.TR.PT }\end{array}$ \\
\hline TR.RESUS.PT & Routine & & $\begin{array}{l}\text { PREAMBLE } \\
\text { AMBULANCE.RUN } \\
\text { PATIENT } \\
\text { TR.RESUS.PT }\end{array}$ \\
\hline TR.SEND.AMB & Routine & & $\begin{array}{l}\text { PREAMBLE } \\
\text { ASSIGN.AMB } \\
\text { TR.SEND.AMB }\end{array}$ \\
\hline TR.STACK.ACC & Routine & & $\begin{array}{l}\text { PREAMBLE } \\
\text { GET.AMB } \\
\text { TR.STACK.ACC }\end{array}$ \\
\hline TR.TO.HOME & Routine & & $\begin{array}{l}\text { PREAMBLE } \\
\text { DISPATCHER } \\
\text { TR.TO.HOME }\end{array}$ \\
\hline TR.UNSTACK.ACC & Routine & & $\begin{array}{l}\text { PREAMBLE } \\
\text { DISPATCHER } \\
\text { TR.UNSTACK.ACC }\end{array}$ \\
\hline TRANSIT.TIME & Permanent attribute & Double & $\begin{array}{l}\text { PREAMBLE } \\
\text { BUILD.CALL.LIST } \\
\text { BUILD.HOSP.LIST } \\
\text { GET.NET } \\
\text { GET.PATIIENT } \\
\text { GET.TRAVEL.TIME } \\
\text { PRINT.NET } \\
\text { PVT.TRAVEL }\end{array}$ \\
\hline TRANSP.MODE & Temporary attribute & Integer & $\begin{array}{l}\text { PREAMBLE } \\
\text { AMBULANCE. RUN } \\
\text { GET.PATIENT } \\
\text { PT.REPORT } \\
\text { PVT.TRAVEL }\end{array}$ \\
\hline TRANSP.TIME & Temporary attribute & Double & PREAMBLE \\
\hline
\end{tabular}

$\begin{array}{ll}\text { CLEAR.REDS } & 1 \\ \text { GET.HOSP } & 1 \\ \text { GO.OFF.RED } & 1 \\ \text { TR.GO.GREEN } & 1\end{array}$ AMBULANCE. RUN

PREMBLE $1=$ 1

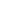
1

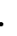

PREAMBLE 1

DISPATCHER

PREAMBLE

PREAMBLE 2

BUILD.CALL.LIST

PREAMBLE

AMBULANCE. RUN

PT. REPORT

PVT.TRAVEL

$=$

$=$ 


\begin{tabular}{|c|c|c|c|}
\hline & & & $\begin{array}{l}\text { DONE } \\
\text { PASS.TIME } \\
\text { PATIENT } \\
\text { PT.REPORT }\end{array}$ \\
\hline TRAUMA & Define to mean & & $\begin{array}{l}\text { PREAMBLE } \\
\text { AMBULANCE. RUN } \\
\text { INIT.ACCIDENT } \\
\text { TR.CHECK.IN.ACC } \\
\text { TR.CHECK.OUT.ACC } \\
\text { TR.ENROUTE.HOSP } \\
\text { TR.ON.SCENE } \\
\text { TR.PICKUP.PT } \\
\text { TR.SEND.AMB } \\
\text { TR.STACK.ACC } \\
\text { TR.UNSTACK.ACC }\end{array}$ \\
\hline TRAVEL & Routine & & $\begin{array}{l}\text { AMBULANCE.RUN } \\
\text { TRAVEL }\end{array}$ \\
\hline TRAVEL.TIME & Permanent attribute & Double & $\begin{array}{l}\text { PREAMBLE } \\
\text { DISPATCHER } \\
\text { FIND.LOC } \\
\text { GET.AMB } \\
\text { TRAVEL }\end{array}$ \\
\hline TRF.RATE & Temporary attribute & Double & $\begin{array}{l}\text { PREAMBLE } \\
\text { PATIENT }\end{array}$ \\
\hline TRF.START.TIME & Temporary attribute & Double & $\begin{array}{l}\text { PREAMBLE } \\
\text { PATIENT }\end{array}$ \\
\hline TRUE & Define to mean & & $\begin{array}{l}\text { PREAMBLE } \\
\text { ACCIDENT } \\
\text { AMBULANCE.RUN } \\
\text { BUILD.HOSP.LIST } \\
\text { CHECK.RED } \\
\text { DISPATCHER } \\
\text { DONE } \\
\text { FIND. HOSP } \\
\text { GET.AMB } \\
\text { GET.PATIENT } \\
\text { GO.GREEN } \\
\text { GO.RED } \\
\text { INIT.ACCIDENT } \\
\text { LIVING } \\
\text { LEFT NO.PTS } \\
\text { PATIENT } \\
\text { PVT.TRAVEL }\end{array}$ \\
\hline TRUNC.F & Library routine & & NSP.F \\
\hline TX.TIME & Temporary attribute & Double & $\begin{array}{l}\text { PREAMBLE } \\
\text { PATIENT } \\
\text { PT.REPORT }\end{array}$ \\
\hline TYPE & Permanent attribute & Integer & $\begin{array}{l}\text { PREAMBLE } \\
\text { AMBULANCE.RUN } \\
\text { ASSIGN.AMB } \\
\text { BUILD.CALL.LIST } \\
\text { DISPATCHER } \\
\text { GET.AMB } \\
\text { GET.EMS }\end{array}$ \\
\hline
\end{tabular}




\begin{tabular}{|c|c|c|c|}
\hline & & & $\begin{array}{l}\text { GET.PATIENT } \\
\text { PRINT.NET } \\
\text { RECALL }\end{array}$ \\
\hline UIB.R & Implied subscript & & GET.LIST \\
\hline UIB.W & Implied subscript & & $\begin{array}{l}\text { MAIN } \\
\text { PRINT.NET } \\
\text { RUN.REPORT }\end{array}$ \\
\hline UNIFORM. $F$ & Library routine & & DISPATCHER \\
\hline UPDATE & Routine & & $\begin{array}{l}\text { PASS.TIME } \\
\text { PATIENT } \\
\text { UPDATE }\end{array}$ \\
\hline UPDATE.TIME & Permanent attribute & Double & $\begin{array}{l}\text { PREAMBLE } \\
\text { LEFT NO.PTS }\end{array}$ \\
\hline UPDATED & Temporary attribute & Integer & $\begin{array}{l}\text { PREAMBLE } \\
\text { ACCIDENT } \\
\text { DISPATCHER }\end{array}$ \\
\hline V.SET & Set & & $\begin{array}{l}\text { PREAMBLE } \\
\text { BEST.ROUTE }\end{array}$ \\
\hline WAIT.TIME & Temporary attribute & Double & $\begin{array}{l}\text { PREAMBLE } \\
\text { DONE } \\
\text { PASS.TIME } \\
\text { PATIENT } \\
\text { PT.REPORT }\end{array}$ \\
\hline WAITING & Define to mean & & $\begin{array}{l}\text { PREAMBLE } \\
\text { INIT.PT }\end{array}$ \\
\hline WEEKDAY. $F$ & Library routine & & $\begin{array}{l}\text { GENERATOR } \\
\text { TR.RESUS.PT }\end{array}$ \\
\hline WEIGHT & Temporary attribute & Double & $\begin{array}{l}\text { PREAMBLE } \\
\text { BEST.ROUTE } \\
\text { BUILD.ROUTE } \\
\text { FIND.LOC } \\
\text { GET.NET } \\
\text { PRINT.NET }\end{array}$ \\
\hline WORKING & Define to mean & & $\begin{array}{l}\text { PREAMBLE } \\
\text { AMBULANCE. RUN }\end{array}$ \\
\hline WRITE.CALL.LIST & Routine & & $\begin{array}{l}\text { INITIIALIZE } \\
\text { WRITE.CALL.LIST }\end{array}$ \\
\hline WRITE.HOSP.LIST & Routine & & $\begin{array}{l}\text { INITIALIZE } \\
\text { WRITE.HOSP.LIST }\end{array}$ \\
\hline WRK & Define to mean & & $\begin{array}{l}\text { PREAMBLE } \\
\text { AMBULANCE. RUN }\end{array}$ \\
\hline
\end{tabular}




\section{Appendix 3}

\section{Data Files}

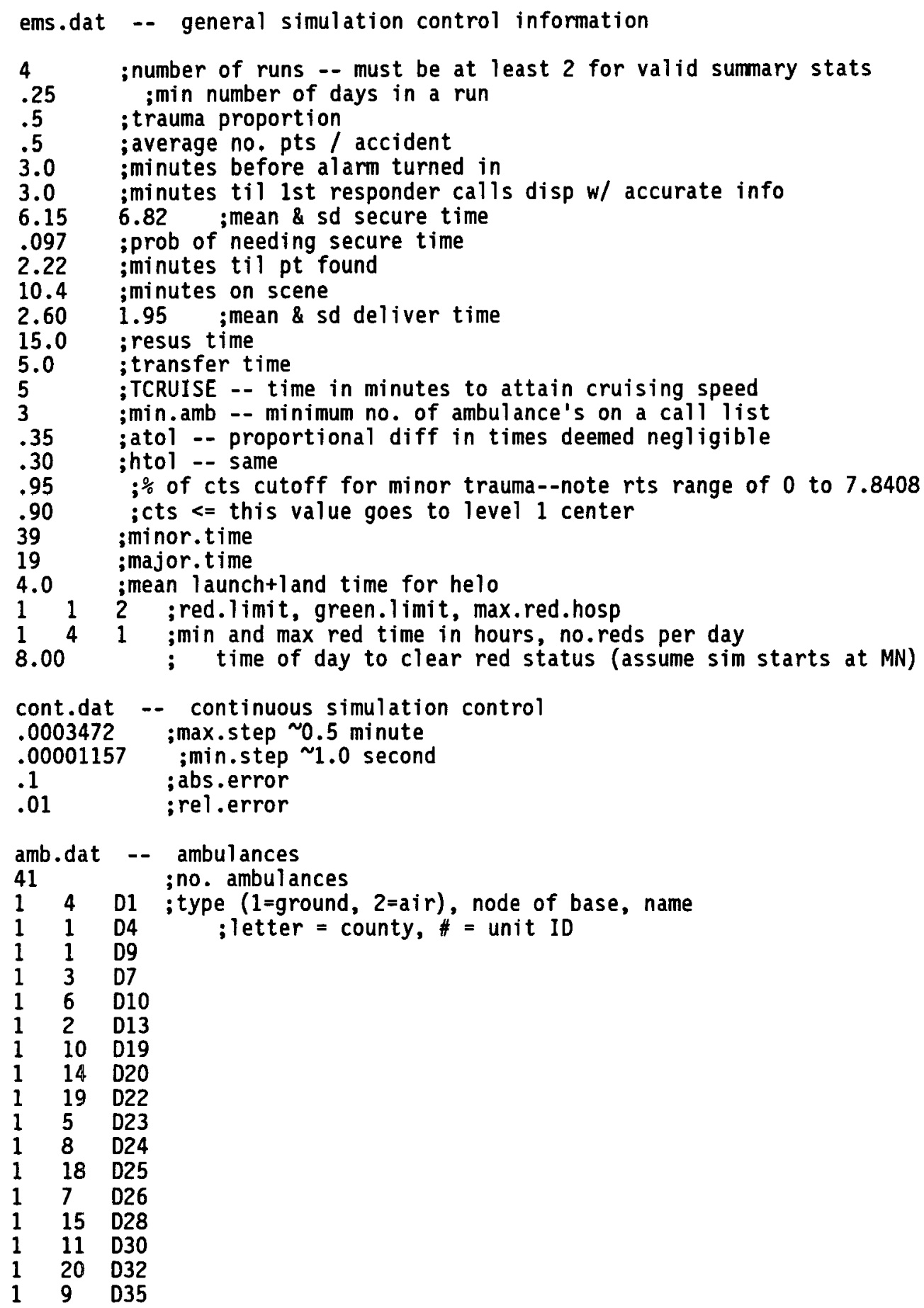




$\begin{array}{llll}1 & 12 & \mathrm{D} 41 & \\ 1 & 17 & \mathrm{D} 42 & \\ 1 & 16 & \mathrm{D} 50 & \\ 1 & & 13 & \mathrm{D} 1 \\ 1 & & 26 & \mathrm{~N} 1 \\ 1 & & 26 & \mathrm{~N} 2 \\ 1 & & 25 & \mathrm{~N} 3 \\ 1 & & 24 & \mathrm{~N} 4 \\ 1 & & 23 & \mathrm{~N} 5 \\ 1 & & 22 & \mathrm{~N} 6 \\ 1 & & 21 & \mathrm{~B} 32 \\ 1 & & 29 & \mathrm{C70} \\ 1 & & 27 & \mathrm{C72} \\ 1 & & 30 & \mathrm{C74} \\ 1 & & 28 & \mathrm{C76} \\ 1 & & 31 & \mathrm{P} 1 \\ 1 & & 34 & \mathrm{~S} 80 \\ 1 & & 34 & 583 \\ 1 & & 32 & 581 \\ 1 & & 33 & 582 \\ 1 & & 36 & \mathrm{~S} 88 \\ 1 & 37 & \mathrm{G} 1 & \\ 2 & 1 & \mathrm{H} 1 & \\ 2 & 2 & \mathrm{H} 2 & \end{array}$

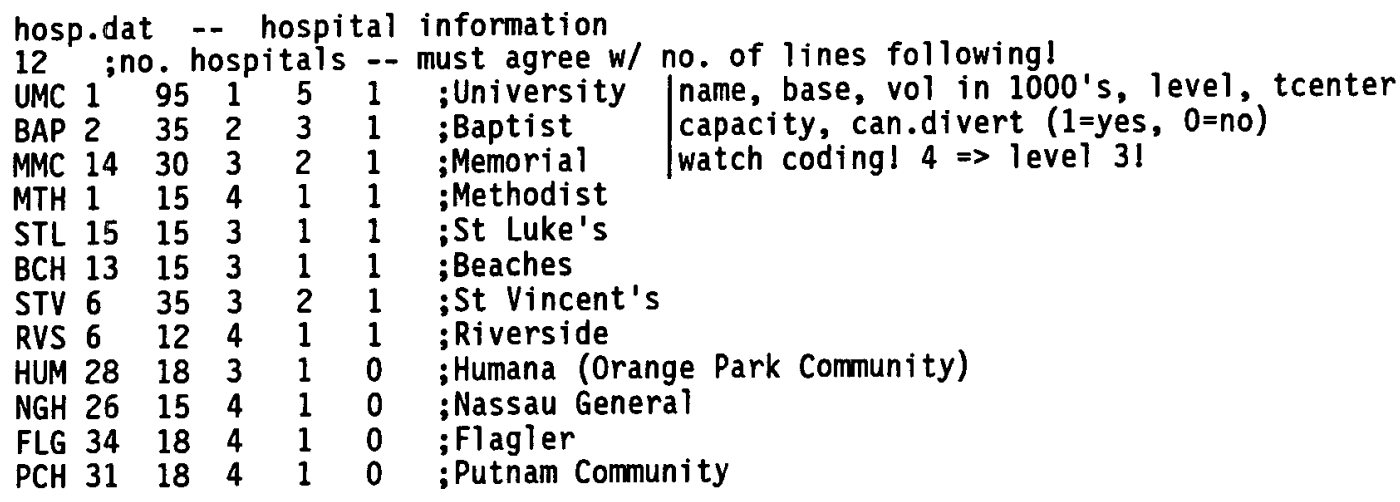

net.dat -- nodes and arcs

37

1 SPF

2 SBK

3 WJX

4 EJX

5 AVD

6 RVS

7 PKV

8 LMT

9 OWY

10 ARL

11 RGY

12 ATB

13 JXB

14 SSD

15 JTB

$16 \mathrm{SPL}$

17 MND

18 TMQ

19 WSD

$20 \mathrm{MWH}$

$21 \mathrm{MCL}$
30.347

30.317

30.347

30.347

30.319

30.308

30.364

30.415

30.466

30.338

30.323

30.33

30.289

30.29

30.25

30.289

30.17

30.25

30.25

30.321

30.289
; n.node -- centered around Rescue stations

81.639 ;Springfield /node, name, lat, long

81.623 ;Southbank

81.665 ;West Jacksonville

81.623 ;East Jacksonville

81.672 ;Avondale

81.663 ;Riverside

81.718 ;Pickettville

81.67 ;Lem Turner

81.619 ;0ceanway

81.585 ;Arlington

81.551 ; Regency

81.408 ;Atlantic Beach

81.405 ;Jacksonville Beach

81.579 ;Southside

81.575 ;J Turner Butler

81.449 ;San Pablo

81.609 ;Mandarin

81.704 ;Timuquana

81.734 ; Westside

81.773 ;Marietta-Whitehouse

82.148 ;McClenny 


\begin{tabular}{|c|c|c|c|}
\hline 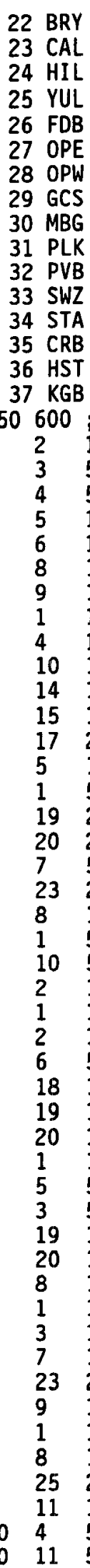 & 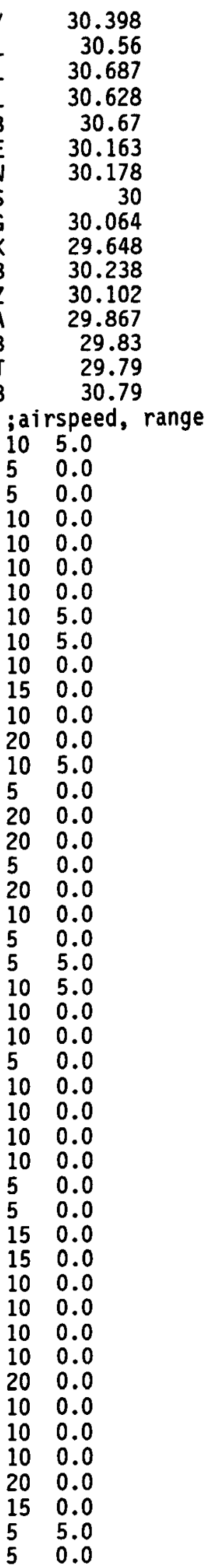 & $\begin{array}{r}81.985 \\
81.889 \\
81.966 \\
81.569 \\
81.443 \\
81.685 \\
81.7 \\
81.587 \\
81.875 \\
81.636 \\
81.398 \\
81.5 \\
81.347 \\
81.219 \\
81.5 \\
81.545\end{array}$ & $\begin{array}{l}\text {;Bryceville } \\
\text {;Callahan } \\
\text {;Hilliard } \\
\text {;Yulee } \\
\text {; Fernandina Beach } \\
\text {;Orange Park East } \\
\text {;Orange Park West } \\
\text {;Green Cove Springs } \\
\text {;Middleburg } \\
\text {;Palatka } \\
\text {;Ponte Vedra Beach } \\
\text {;Switzerland } \\
\text {;St Augustine } \\
\text {;Crescent Beach } \\
\text {;Hastings } \\
\text {;King's Bay }\end{array}$ \\
\hline
\end{tabular}




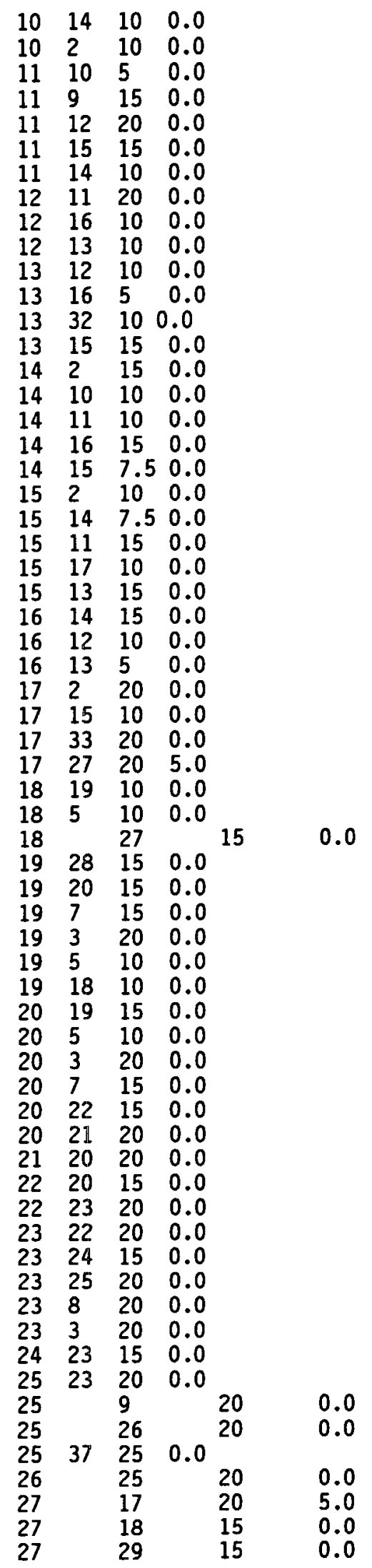




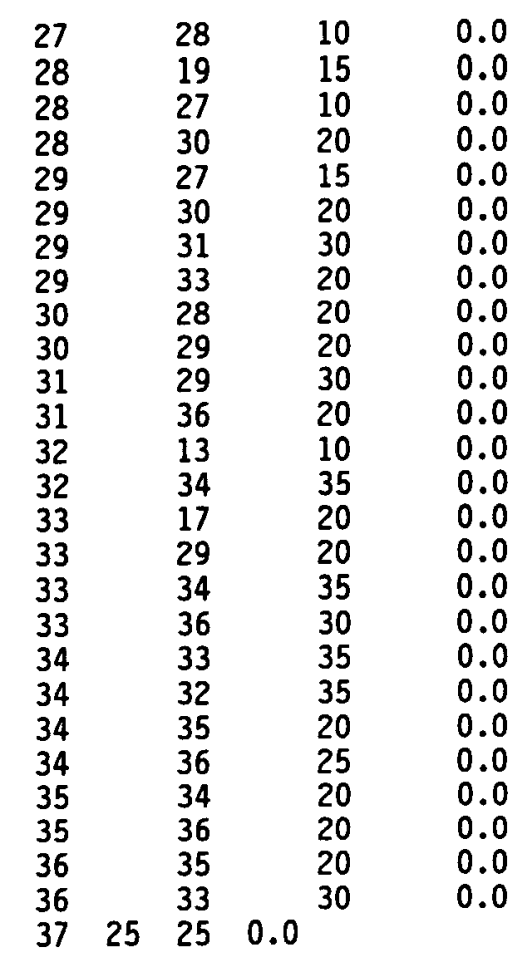

space.dat -- relative incidents per node in node order

5

5

5

5

2

2

4

3

2

2

4

2

3

3

2

1

1

1

4

4

3

4

3

4 
2
1
1

wkrate.dat -- time distribution of incidents

84 ;number of entries

$0 \quad 0$; first number is time

$\begin{array}{lll}2 & 4.77 & \\ 4 & 3.81 \quad \text { second is number of events }\end{array}$

$82.07^{1.14}$;in that time period

10 3.18 2.55 ; assumed to "wrap around" after reaching the last

$14 \quad 3.86$

$16 \quad 4.55$

$18 \quad 5.66$

$20 \quad 5.34$

$22 \quad 5.28$

$24 \quad 5.78$

$\begin{array}{ll}26 & 3.88\end{array}$

$28 \quad 3.09$

$30 \quad .93$

$32 \quad 1.68$

$34 \quad 2.07$

$\begin{array}{ll}36 & 2.59\end{array}$

$38 \quad 3.14$

$\begin{array}{ll}40 & 3.69\end{array}$

$42 \quad 4.60$

$\begin{array}{ll}44 & 4.34\end{array}$

$\begin{array}{ll}46 & 4.29\end{array}$

$48 \quad 4.70$

$\begin{array}{ll}50 & 3.88\end{array}$

$52 \quad 3.09$

$54 \quad .93$

$56 \quad 1.68$

$58 \quad 2.07$

$\begin{array}{ll}60 & 2.59\end{array}$

$62 \quad 3.14$

$\begin{array}{ll}64 & 3.69\end{array}$

$\begin{array}{ll}66 & 4.60\end{array}$

$68 \quad 4.34$

$\begin{array}{ll}70 & 4.29\end{array}$

$72 \quad 4.70$

$74 \quad 4.03$

$76 \quad 3.21$

$78 \quad .96$

$80 \quad 1.75$

$82 \quad 2.15$

$84 \quad 2.68$

$86 \quad 3.26$

$88 \quad 3.83$

$90 \quad 4.78$

$92 \quad 4.51$

$94 \quad 4.46$

$96 \quad 4.88$

$98 \quad 4.03$

$100 \quad 3.21$

$102 \quad .96$

$104 \quad 1.75$

$106 \quad 2.15$

$108 \quad 2.68$

$110 \quad 3.26$

$112 \quad 3.83$ 


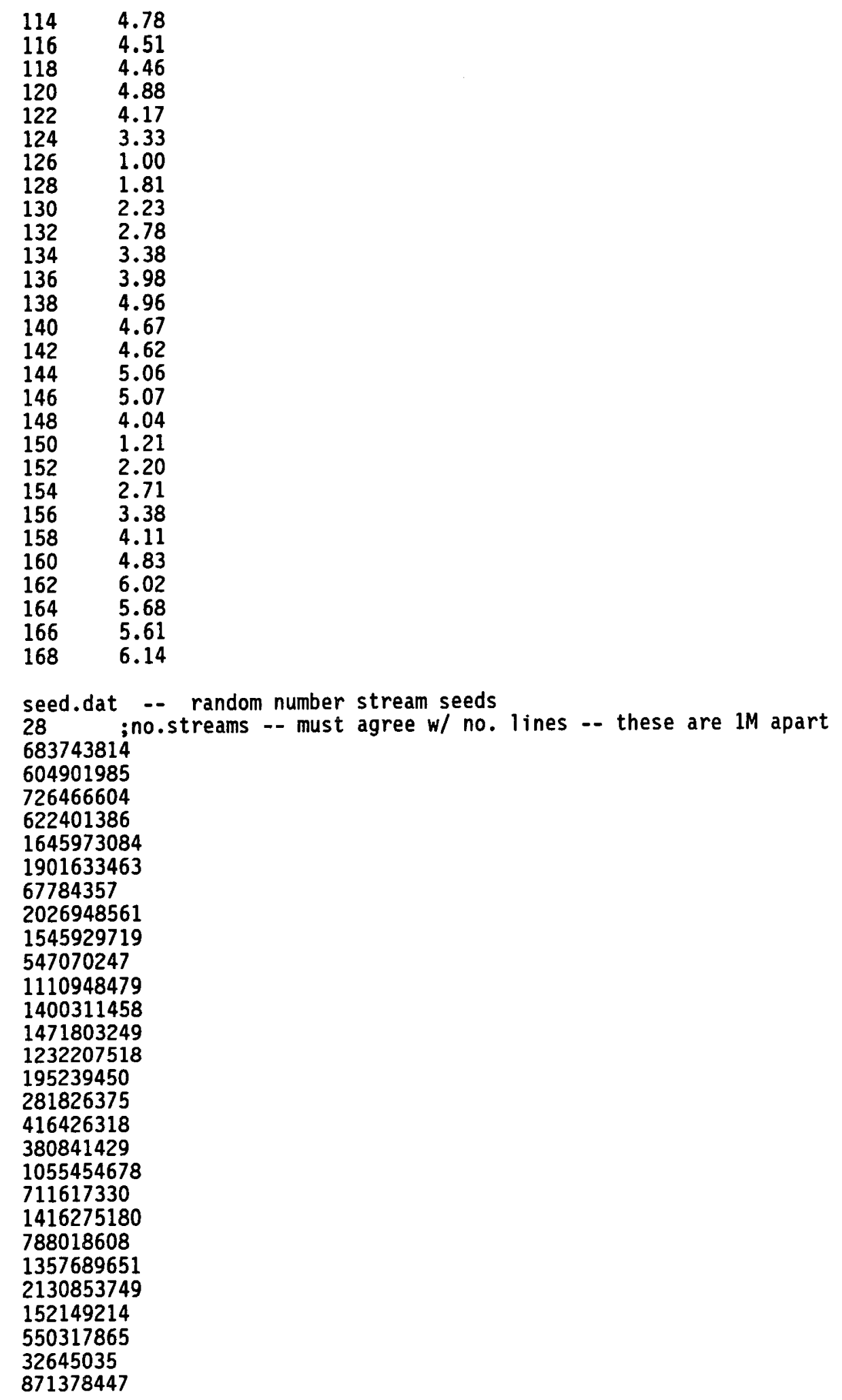


The following two files are produced by the best. route routine

\begin{tabular}{rrrrrrrrrrrr}
\multicolumn{1}{c}{ call.dat } & \multicolumn{1}{c}{- node, } & \multicolumn{1}{c}{ ambulances to be called in order } \\
1 & 3 & 2 & 4 & 1 & 40 & 41 & & & & \\
2 & 6 & 2 & 3 & 1 & 10 & 7 & 14 & 40 & 41 & \\
3 & 4 & 2 & 3 & 13 & 40 & 41 & & & & \\
4 & 1 & 2 & 3 & 7 & 40 & 41 & & & \\
5 & 10 & 5 & 2 & 3 & 6 & 12 & 9 & 16 & 40 & 41 \\
6 & 5 & 10 & 2 & 3 & 40 & 41 & & & & \\
7 & 13 & 4 & 2 & 3 & 11 & 40 & 41 & & & \\
8 & 11 & 2 & 3 & 4 & 13 & 17 & 40 & 41 & \\
9 & 17 & 2 & 3 & 11 & 40 & 41 & & & \\
10 & 7 & 1 & 15 & 40 & 41 & & & & \\
11 & 15 & 7 & 1 & 8 & 40 & 41 & & & \\
12 & 18 & 21 & 20 & 40 & 41 & & & & \\
13 & 21 & 20 & 18 & 36 & 40 & 41 & & & \\
14 & 8 & 14 & 7 & 15 & 40 & 41 & & & \\
15 & 14 & 8 & 6 & 19 & 40 & 41 & & & \\
16 & 20 & 21 & 18 & 40 & 41 & & & & \\
17 & 19 & 14 & 8 & 40 & 41 & & & & \\
18 & 12 & 10 & 9 & 40 & 41 & & & & \\
19 & 9 & 10 & 12 & 40 & 41 & & & & \\
20 & 16 & 10 & 5 & 13 & 9 & 27 & 40 & 41 & \\
21 & 28 & 16 & 10 & 40 & 41 & & & & \\
22 & 27 & 16 & 26 & 40 & 41 & & & & \\
23 & 26 & 25 & 4 & 11 & 27 & 24 & 40 & 41 & \\
24 & 25 & 26 & 4 & 11 & 27 & 24 & 40 & 41 & \\
25 & 24 & 17 & 26 & 22 & 23 & 40 & 41 & & \\
26 & 23 & 22 & 24 & 40 & 41 & & & & \\
27 & 30 & 32 & 12 & 29 & 40 & 41 & & & \\
28 & 32 & 30 & 9 & 40 & 41 & & & & \\
29 & 29 & 30 & 31 & 37 & 40 & 41 & & & \\
30 & 31 & 32 & 29 & 40 & 41 & & & & \\
31 & 33 & 38 & 29 & 40 & 41 & & & & \\
32 & 36 & 21 & 20 & 40 & 41 & & & & \\
33 & 37 & 19 & 29 & 40 & 41 & & & & \\
34 & 35 & 34 & 38 & 40 & 41 & & & & \\
35 & 34 & 35 & 38 & 40 & 41 & & & & \\
36 & 38 & 37 & 34 & 35 & 40 & 41 & & & \\
37 & 39 & 24 & 17 & 26 & 22 & 23 & 40 & 41 &
\end{tabular}

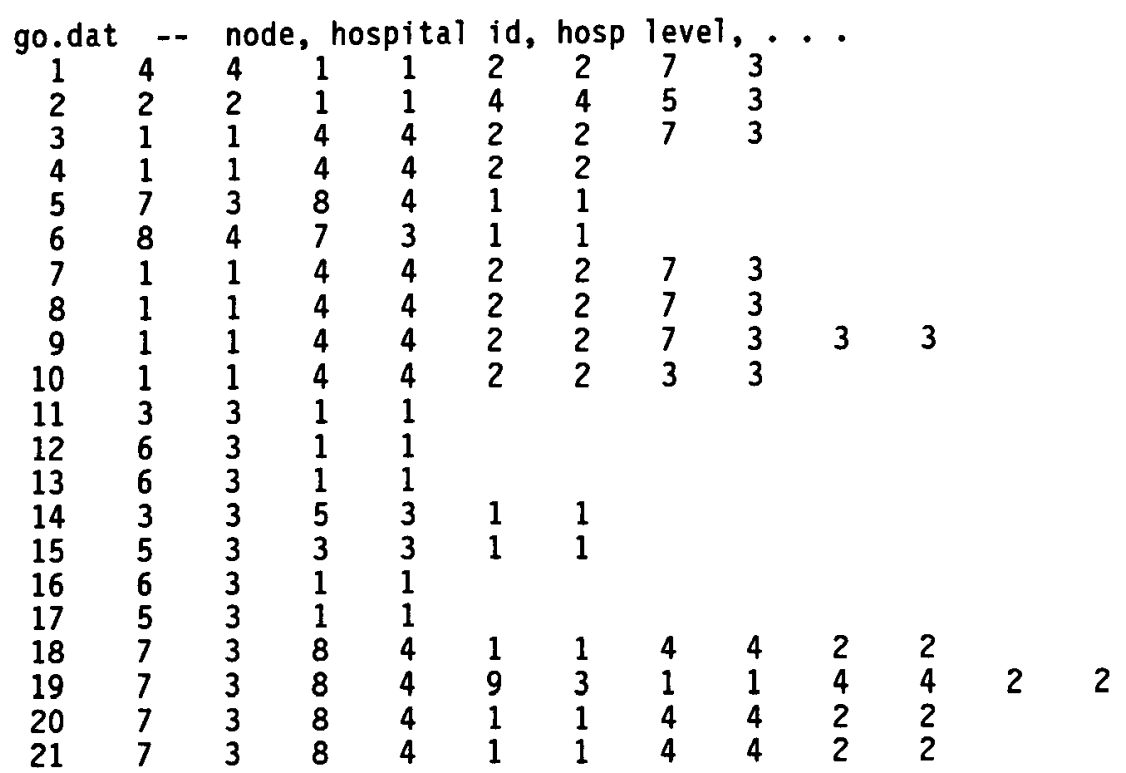




$$
\begin{aligned}
& \begin{array}{rrrrrrrrrrrrrrr}
22 & 7 & 3 & 8 & 4 & 1 & 1 & 4 & 4 & 2 & 2 & & \\
23 & 1 & 1 & 4 & 4 & 2 & 2 & 7 & 3 & 3 & 3 & 5 & 3 & & \\
24 & 1 & 1 & 4 & 4 & 2 & 2 & 7 & 3 & 8 & 4 & 3 & 3 & 5 & 3 \\
25 & 10 & 4 & 1 & 1 & 2 & 2 & 7 & 3 & 3 & 3 & 5 & 3 & & \\
26 & 10 & 4 & 1 & 1 & 2 & 2 & 7 & 3 & 3 & 3 & 5 & 3 &
\end{array} \\
& \begin{array}{lllllll}
27 & 9 & 3 & 1 & 1 & \\
28 & 9 & 3 & 1 & 1 & 1
\end{array} \\
& \begin{array}{lllllll}
29 & 9 & 3 & 12 & 4 & 1 & 1
\end{array} \\
& \begin{array}{rrrrrrr}
30 & 9 & 3 & 1 & 1 & 1 & 1 \\
31 & 12 & 4 & 9 & 3 & 1 & 1
\end{array} \\
& \begin{array}{rrrrrrrrrrr}
33 & 5 & 3 & 11 & 4 & 3 & 3 & 2 & 2 & 1 & 1
\end{array} \\
& \begin{array}{lllllllllllllll}
35 & 11 & 4 & 6 & 3 & 5 & 3 & 3 & 3 & 1 & 1 & & & \\
36 & 11 & 4 & 5 & 3 & 3 & 3 & 2 & 2 & 6 & 3 & 9 & 3 & 1 & 1 \\
37 & 10 & 4 & 1 & 1 & 4 & 4 & 2 & 2 & 7 & 3 & 3 & 3 & 5 & 3
\end{array}
\end{aligned}
$$




\section{Appendix 4}

\section{Sample output}

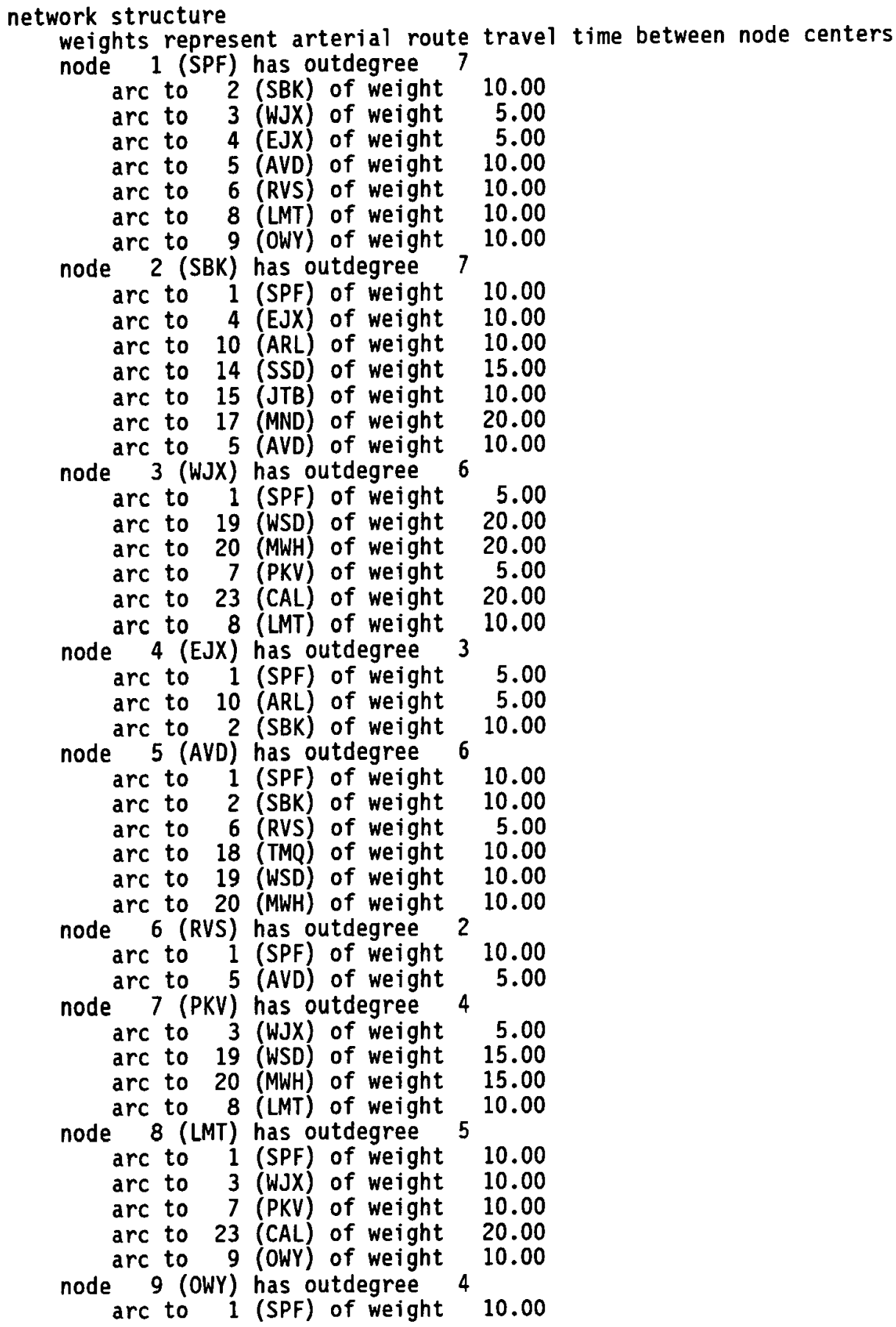




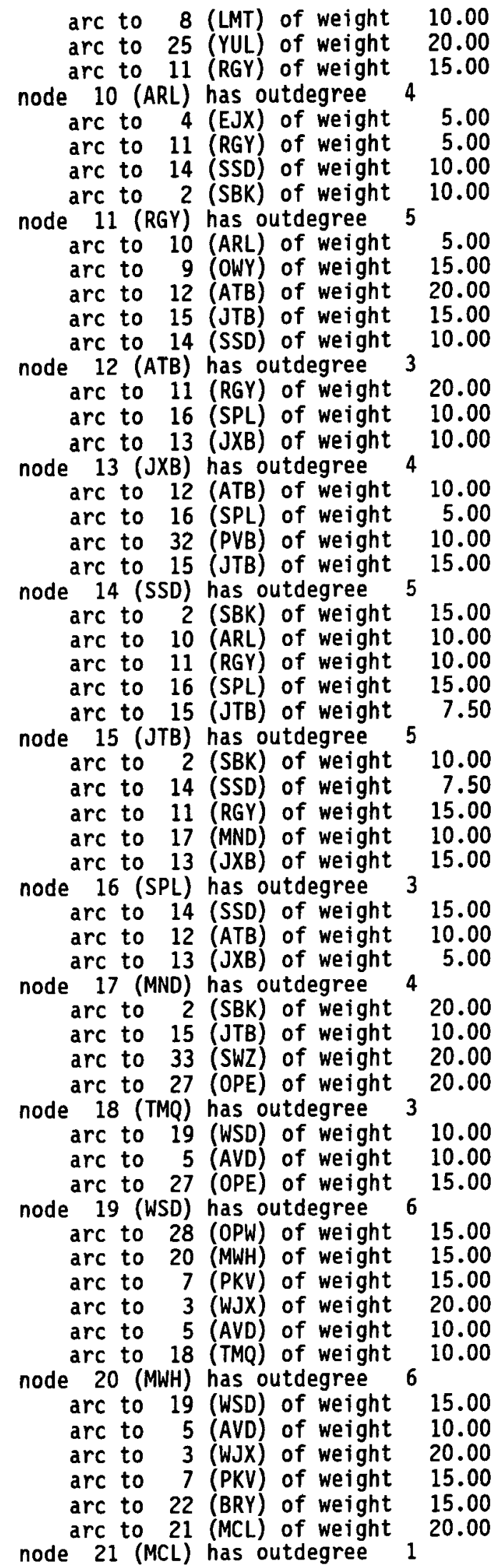


arc to 20 (MWH) of weight 20.00

node 22 (BRY) has outdegree 2 arc to 20 (MWH) of weight 15.00 arc to 23 (CAL) of weight 20.00 node 23 (CAL) has outdegree 5 arc to 22 (BRY) of weight 20.00 arc to 24 (HIL) of weight 15.00 arc to 25 (YUL) of weight 20.00 arc to 8 (LMT) of weight 20.00 arc to 3 (WJX) of weight 20.00 node 24 (HIL) has outdegree 1 arc to 23 (CAL) of weight 15.00 node 25 (YUL) has outdegree 4 arc to 23 (CAL) of weight 20.00 arc to 9 (OWY) of weight 20.00 arc to 26 (FDB) of weight 20.00 arc to 37 (KGB) of weight 25.00 node 26 (FDB) has outdegree 1 arc to 25 (YUL) of weight 20.00 node 27 (OPE) has outdegree 4 arc to 17 (MND) of weight 20.00 arc to 18 (TMQ) of weight 15.00 arc to 29 (GCS) of weight 15.00 arc to 28 (OPW) of weight 10.00 node 28 (OPW) has outtdegree 3 arc to 19 (WSD) of weight 15.00 arc to 27 (OPE) of weight 10.00 arc to 30 (MBG) of weight 20.00

node 29 (GCS) has outdegree 4 arc to 27 (OPE) of weight 15.00 arc to 30 (MBG) of weight 20.00 arc to 31 (PLK) of weight 30.00 arc to 33 (SWZ) of weight 20.00 node 30 (MBG) has outdegree 2 arc to 28 (OPW) of weight 20.00 arc to 29 (GCS) of weight 20.00 node 31 (PLK) has outdegree 2 arc to 29 (GCS) of weight 30.00 arc to 36 (HST) of weight 20.00 node 32 (PVB) has outdegree 2 arc to 13 (JXB) of weight 10.00 arc to 34 (STA) of weight 35.00

node 33 (SWZ) has outdegree 4 arc to 17 (MND) of weight 20.00 arc to 29 (GCS) of weight 20.00 arc to 34 (STA) of weight 35.00 arc to 36 (HST) of weight 30.00

node 34 (STA) has outdegree 4 arc to 33 (SWZ) of weight 35.00 arc to 32 (PVB) of weight 35.00 arc to 35 (CRB) of weight 20.00 arc to 36 (HST) of weight 25.00

node 35 (CRB) has outdegree 2 arc to 34 (STA) of weight 20.00 arc to 36 (HST) of weight 20.00

node 36 (HST) has outdegree 2 arc to 35 (CRB) of weight 20.00 arc to 33 (SWZ) of weight 30.00 node 37 (KGB) has outdegree 1 arc to 25 (YUL) of weight 25.00

hospital locations

UMC, level 1 , 5 beds, in SPF 

BAP, level 2 ,
3 beds, in SBK
MMC, level 2a,
2 beds, in SSD
MTH, level 3 ,
1 beds, in SPF
1 beds, in JTB
$\mathrm{BCH}$, level $2 \mathrm{a}, \quad 1$ beds, in JXB
STV, level $2 \mathrm{a}, \quad 2$ beds, in RVS
RVS, level 3,1 beds, in RVS
HUM, level 2a, 1 beds, in OPW
NGH, level 3 , 1 beds, in FDB
FLG, level 3,1 beds, in STA
PCH, level $3 ; 1$ beds, in PLK

ambulance call list

SPF will request these ambulances

D9 from SPF with mean travel time

D4 from SPF with mean travel time

D7 from WJX with mean travel time

D1 from EJX with mean travel time

H1 from SPF with mean travel time

H2 from SBK with mean travel time

SBK will request these ambulances

D13 from SBK with mean travel time

D4 from SPF with mean travel time

D9 from SPF with mean travel time

D1 from EJX with mean travel time

D23 from AVD with mean travel time

D19 from ARL with mean travel time

D28 from JTB with mean travel time

H1 from SPF with mean travel time

H2 from SBK with mean travel time

WJX will request these ambulances

D7 from WJX with mean travel time

D4 from SPF with mean travel time

D9 from SPF with mean travel time

D26 from PKV with mean travel time

H1 from SPF with mean travel time

H2 from SBK with mean travel time

EJX will request these ambulances

D1 from EJX with mean travel time

D4 from SPF with mean travel time

D9 from SPF with mean travel time

D19 from ARL with mean travel time

H1 from SPF with mean travel time

H2 from SBK with mean travel time

AVD will request these ambulances

D23 from AVD with mean travel time

D10 from RVS with mean travel time

D4 from SPF with mean travel time

D9 from SPF with mean travel time

D13 from SBK with mean travel time

D25 from TMQ with mean travel time

D22 from WSD with mean travel time

D32 from MWH with mean travel time

H1 from SPF with mean travel time

H2 from SBK with mean travel time

RVS will request these ambulances

D10 from RVS with mean travel time

D23 from AVD with mean travel time

D4 from SPF with mean travel time

D9 from SPF with mean travel time

H1 from SPF with mean travel time

H2 from SBK with mean travel time

PKV will request these ambulances
$9.26 \mathrm{~min}$

$9.26 \mathrm{~min}$

$10.00 \mathrm{~min}$

$10.00 \mathrm{~min}$

$5.71 \mathrm{~min}$

$4.74 \mathrm{~min}$

$11.02 \mathrm{~min}$

$14.14 \mathrm{~min}$

$14.14 \mathrm{~min}$

$14.14 \mathrm{~min}$

$14.14 \mathrm{~min}$

$14.14 \mathrm{~min}$

$14.14 \mathrm{~min}$

$4.74 \mathrm{~min}$

$6.43 \mathrm{~min}$

$11.55 \mathrm{~min}$ $10.00 \mathrm{~min}$

$10.00 \mathrm{~min}$

$10.00 \mathrm{~min}$

$4.30 \mathrm{~min}$

$4.85 \mathrm{~min}$

$8.16 \mathrm{~min}$ $10.00 \mathrm{~min}$ $10.00 \mathrm{~min}$ $10.00 \mathrm{~min}$

$4.18 \mathrm{~min}$

$4.72 \mathrm{~min}$

$9.57 \mathrm{~min}$ $10.00 \mathrm{~min}$

$14.14 \mathrm{~min}$ $14.14 \mathrm{~min}$ $14.14 \mathrm{~min}$

$14.14 \mathrm{~min}$

$14.14 \mathrm{~min}$

$14.14 \mathrm{~min}$

$4.77 \mathrm{~min}$

$4.54 \mathrm{~min}$

$8.66 \mathrm{~min}$

$10.00 \mathrm{~min}$

$14.14 \mathrm{~min}$

$14.14 \mathrm{~min}$

$4.98 \mathrm{~min}$

$4.49 \mathrm{~min}$ 
D26 from PKV with mean travel time

D7 from WJX with mean travel time

D4 from SPF with mean travel time

D9 from SPF with mean travel time

D24 from LMT with mean travel time

H1 from SPF with mean travel time

H2 from SBK with mean travel time

LMT will request these ambulances

D24 from LMT with mean travel time

D4 from SPF with mean travel time

D9 from SPF with mean travel time

D7 from WJX with mean travel time

D26 from PKV with mean travel time

035 from OWY with mean travel time

HI from SPF with mean travel time

H2 from SBK with mean travel time

OWY will request these ambulances

D35 from OWY with mean travel time

D4 from SPF with mean travel time

D9 from SPF with mean travel time

D24 from LMT with mean travel time

H1 from SPF with mean travel time

H2 from SBK with mean travel time

ARL will request these ambulances

D19 from ARL with mean travel time

D1 from $E J X$ with mean travel time

D30 from RGY with mean travel time

H1 from SPF with mean travel time

H2 from SBK with mean travel time

RGY will request these ambulances

D30 from RGY with mean travel time

D19 from ARL with mean travel time

D1 from EJX with mean travel time

D20 from SSD with mean travel time

H1 from SPF with mean travel time

H2 from SBK with mean travel time

ATB will request these ambulances

D41 from ATB with mean travel time

D71 from JXB with mean travel time

D50 from SPL with mean travel time

H1 from SPF with mean travel time

H2 from SBK with mean travel time

JXB will request these ambulances

D71 from JXB with mean travel time D50 from SPL with mean travel time D41 from ATB with mean travel time S81 from PVB with mean travel time HI from SPF with mean travel time H2 from SBK with mean travel time

SSD will request these ambulances

D20 from SSD with mean travel time

D28 from JTB with mean travel time

D19 from ARL with mean travel time

D30 from RGY with mean travel time

H1 from SPF with mean travel time

H2 from SBK with mean travel time

JTB will request these ambulances

D28 from JTB with mean travel time

D20 from SSD with mean travel time

D13 from SBK with mean travel time

D42 from MND with mean travel time

H1 from SPF with mean travel time

H2 from SBK with mean travel time
$10.61 \mathrm{~min}$

$10.00 \mathrm{~min}$

$14.14 \mathrm{~min}$

$14.14 \mathrm{~min}$

$14.14 \mathrm{~min}$

$5.00 \mathrm{~min}$

$5.53 \mathrm{~min}$

$10.95 \mathrm{~min}$

$14.14 \mathrm{~min}$

$14.14 \mathrm{~min}$

$14.14 \mathrm{~min}$

$14.14 \mathrm{~min}$

$14.14 \mathrm{~min}$

$5.67 \mathrm{~min}$

$6.41 \mathrm{~min}$

$11.73 \mathrm{~min}$

$14.14 \mathrm{~min}$

14.14 min

$14.14 \mathrm{~min}$

$6.87 \mathrm{~min}$

$7.58 \mathrm{~min}$

$8.66 \mathrm{~min}$

$10.00 \mathrm{~min}$

$10.00 \mathrm{~min}$

$4.66 \mathrm{~min}$

$4.65 \mathrm{~min}$

$11.40 \mathrm{~min}$

$10.00 \mathrm{~min}$

$14.14 \mathrm{~min}$

$14.14 \mathrm{~min}$

$5.17 \mathrm{~min}$

$4.80 \mathrm{~min}$

11.55 min

$14.14 \mathrm{~min}$

$14.14 \mathrm{~min}$

$6.70 \mathrm{~min}$

$6.37 \mathrm{~min}$

$10.00 \mathrm{~min}$

$10.00 \mathrm{~min}$

$14.14 \mathrm{~min}$

$14.14 \mathrm{~min}$

$7.04 \mathrm{~min}$

$6.47 \mathrm{~min}$

$10.72 \mathrm{~min}$

$12.25 \mathrm{~min}$

$14.14 \mathrm{~min}$

$14.14 \mathrm{~min}$

$5.53 \mathrm{~min}$

$4.81 \mathrm{~min}$

$10.72 \mathrm{~min}$

$12.25 \mathrm{~min}$

$14.14 \mathrm{~min}$

$14.14 \mathrm{~min}$

$6.44 \mathrm{~min}$

$5.69 \mathrm{~min}$ 
SPL will request these ambulances

D50 from SPL with mean travel time

D71 from JXB with mean travel time

D41 from ATB with mean travel time

H1 from SPF with mean travel time

H2 from SBK with mean travel time

$10.00 \mathrm{~min}$

$10.00 \mathrm{~min}$

$14.14 \mathrm{~min}$

$6.60 \mathrm{~min}$

$6.01 \mathrm{~min}$

MND will request these ambulances

D42 from MND with mean travel time

D28 from JTB with mean travel time

D20 from SSD with mean travel time

H1 from SPF with mean travel time

H2 from SBK with mean travel time

$13.23 \mathrm{~min}$

$14.14 \mathrm{~min}$

$22.50 \mathrm{~min}$

$8.26 \mathrm{~min}$

$7.53 \mathrm{~min}$

TMQ Will request these ambulances

D25 from TMQ with mean travel time

D23 from AVD with mean travel time

D22 from WSD with mean travel time

H1 from SPF with mean travel time

H2 from SBK with mean travel time

$10.80 \mathrm{~min}$

$14.14 \mathrm{~min}$

$14.14 \mathrm{~min}$

$6.45 \mathrm{~min}$

$5.83 \mathrm{~min}$

WSD will request these ambulances

D22 from WSD with mean travel time

D23 from AVD with mean travel time

D25 from TMQ with mean travel time

$\mathrm{H} 1$ from SPF with mean travel time

H2 from SBK with mean travel time

$11.90 \mathrm{~min}$

$14.14 \mathrm{~min}$

$14.14 \mathrm{~min}$

$6.57 \mathrm{~min}$

$6.01 \mathrm{~min}$

MWH will request these ambulances

D32 from MWH with mean travel time

D23 from AVD with mean travel time

D10 from RVS with mean travel time

D26 from PKV with mean travel time

D22 from WSD with mean travel time

N6 from BRY with mean travel time

H1 from SPF with mean travel time

$\mathrm{H} 2$ from SBK with mean travel time

$12.58 \mathrm{~min}$

$14.14 \mathrm{~min}$

$20.00 \mathrm{~min}$

$20.00 \mathrm{~min}$

$20.00 \mathrm{~min}$

$20.00 \mathrm{~min}$

$5.67 \mathrm{~min}$

$5.64 \mathrm{~min}$

$M C L$ will request these ambulances

B32 from MCL with mean travel time

D32 from MWH with mean travel time

D23 from AVD with mean travel time

$\mathrm{H} 1$ from SPF with mean travel time

H2 from SBK with mean travel time

BRY will request these ambulances

N6 from BRY with mean travel time

D32 from MWH with mean travel time

N5 from CAL with mean travel time

H1 from SPF with mean travel time

H2 from SBK with mean travel time

$14.14 \mathrm{~min}$

$25.00 \mathrm{~min}$

$35.00 \mathrm{~min}$

$10.04 \mathrm{~min}$

$9.77 \mathrm{~min}$

$13.23 \mathrm{~min}$ $20.00 \mathrm{~min}$

$25.00 \mathrm{~min}$

$8.18 \mathrm{~min}$

$8.40 \mathrm{~min}$

CAL will request these ambulances

N5 from CAL with mean travel time

N4 from HIL with mean travel time

D7 from WJX with mean travel time

D24 from LMT with mean travel time

N6 from BRY with mean travel time

N3 from YUL with mean travel time

H1 from SPF with mean travel time

H2 from SBK with mean travel time

HIL will request these ambulances

N4 from HIL with mean travel time

N5 from CAL with mean travel time

D7 from WJX with mean travel time

D24 from LMT with mean travel time

N6 from BRY with mean travel time

N3 from YUL with mean travel time

H1 from SPF with mean travel time

H2 from SBK with mean travel time

$13.78 \mathrm{~min}$

$20.00 \mathrm{~min}$

$25.00 \mathrm{~min}$

$25.00 \mathrm{~min}$

$25.00 \mathrm{~min}$

$25.00 \mathrm{~min}$

$9.87 \mathrm{~min}$

$10.51 \mathrm{~min}$

$12.25 \mathrm{~min}$

$20.00 \mathrm{~min}$

$40.00 \mathrm{~min}$

$40.00 \mathrm{~min}$

$40.00 \mathrm{~min}$

$40.00 \mathrm{~min}$

$12.99 \mathrm{~min}$

$13.64 \mathrm{~min}$ 
YUL will request these ambulances

N3 from YUL with mean travel time

D35 from OWY with mean travel time

N5 from CAL with mean travel time

N1 from FDB with mean travel time

N2 from FDB with mean travel time

H1 from SPF with mean travel time

H2 from SBK with mean travel time

FDB will request these ambulances

N2 from FDB with mean travel time

N1 from FDB with mean travel time

N3 from YUL with mean travel time

H1 from SPF with mean travel time

H2 from SBK with mean travel time

OPE will request these ambulances

C72 from OPE with mean travel time

C76 from OPW with mean travel time

D25 from TMQ with mean travel time

C70 from GCS with mean travel time

H1 from SPF with mean travel time

H2 from SBK with mean travel time

OPW will request these ambulances

C76 from OPW with mean travel time

C72 from OPE with mean travel time

D22 from WSD with mean travel time

HI from SPF with mean travel time

H2 from SBK with mean travel time

GCS will request these ambulances

C70 from GCS with mean travel time

C72 from OPE with mean travel time

C74 from MBG with mean travel time

S82 from SWZ with mean travel time

H1 from SPF with mean travel time

H2 from SBK with mean travel time

$15.62 \mathrm{~min}$

$25.00 \mathrm{~min}$

$25.00 \mathrm{~min}$

$25.00 \mathrm{~min}$

$25.00 \mathrm{~min}$

$10.79 \mathrm{~min}$

$11.49 \mathrm{~min}$

$14.14 \mathrm{~min}$

$14.14 \mathrm{~min}$

$25.00 \mathrm{~min}$

$12.08 \mathrm{~min}$

$12.70 \mathrm{~min}$

$12.25 \mathrm{~min}$

$14.14 \mathrm{~min}$

$20.00 \mathrm{~min}$

$20.00 \mathrm{~min}$

$8.45 \mathrm{~min}$

$7.76 \mathrm{~min}$

$12.25 \mathrm{~min}$

$14.14 \mathrm{~min}$

$20.00 \mathrm{~min}$

$8.12 \mathrm{~min}$

$7.44 \mathrm{~min}$

$15.62 \mathrm{~min}$

$20.00 \mathrm{~min}$

$25.00 \mathrm{~min}$

$25.00 \mathrm{~min}$

$12.35 \mathrm{~min}$

$11.62 \mathrm{~min}$

MBG will request these ambulances

C74 from MBG with mean travel time

C76 from OPW with mean travel time

C70 from GCS with mean travel time

H1 from SPF with mean travel time

H2 from SBK with mean travel time

$14.14 \mathrm{~min}$

$25.00 \mathrm{~min}$

$25.00 \mathrm{~min}$

$11.32 \mathrm{~min}$

$10.67 \mathrm{~min}$

PLK will request these ambulances

P1 from PLK with mean travel time

S88 from HST with mean travel time

C70 from GCS with mean travel time

H1 from SPF with mean travel time

H2 from SBK with mean travel time

$17.50 \mathrm{~min}$

$85.00 \mathrm{~min}$

$35.00 \mathrm{~min}$

$20.78 \mathrm{~min}$

20.06 min

PVB will request these ambulances

S81 from PVB with mean travel time

D71 from JXB with mean travel time

D50 from SPL with mean travel time

H1 from SPF with mean travel time

H2 from SBK with mean travel time

$16.25 \mathrm{~min}$

$14.14 \mathrm{~min}$

$20.00 \mathrm{~min}$

$7.82 \mathrm{~min}$

$7.10 \mathrm{~min}$

SWZ will request these ambulances

S82 from SWZ with mean travel time

D42 from MND with mean travel time

C70 from GCS with mean travel time

H1 from SPF with mean travel time

$\mathrm{H} 2$ from SBK with mean travel time

$18.12 \mathrm{~min}$

$25.00 \mathrm{~min}$

$25.00 \mathrm{~min}$

$10.10 \mathrm{~min}$

$9.33 \mathrm{~min}$

STA will request these ambulances

S83 from STA with mean travel time

S80 from STA with mean travel time

S88 from HST with mean travel time

$19.37 \mathrm{~min}$

$19.37 \mathrm{~min}$

$45.00 \mathrm{~min}$

HI from SPF with mean travel time

$16.00 \mathrm{~min}$ 
H2 from SBK with mean travel time

CRB will request these ambulances

S80 from STA with mean travel time

S83 from STA with mean travel time

S88 from HST with mean travel time

HI from SPF with mean travel time

H2 from SBK with mean travel time

HST will request these ambulances

S88 from HST with mean travel time

$S 82$ from SWZ with mean travel time

S80 from STA with mean travel time

S83 from STA with mean travel time

H1 from SPF with mean travel time

H2 from SBK with mean travel time

$K G B$ will request these ambulances

G1 from KGB with mean travel time

N3 from YUL with mean travel time

D35 from OWY with mean travel time

N5 from CAL with mean travel time

N1 from FDB with mean travel time

N2 from FDB with mean travel time

H1 from SPF with mean travel time

H2 from SBK with mean travel time
$15.21 \mathrm{~min}$

$25.00 \mathrm{~min}$

$25.00 \mathrm{~min}$

$25.00 \mathrm{~min}$

$17.32 \mathrm{~min}$

$16.49 \mathrm{~min}$

$17.50 \mathrm{~min}$

$35.00 \mathrm{~min}$

$30.00 \mathrm{~min}$

$30.00 \mathrm{~min}$

$17.46 \mathrm{~min}$

16.72 min

$17.50 \mathrm{~min}$

$30.00 \mathrm{~min}$

$50.00 \mathrm{~min}$

$50.00 \mathrm{~min}$

$50.00 \mathrm{~min}$

$50.00 \mathrm{~min}$

$14.69 \mathrm{~min}$

$15.38 \mathrm{~min}$

hospital dispatch list

SPF victims will go to these hospitals

$M T H$, level 3 , in SPF, with mean travel time UMC, level 1 , in SPF, with mean travel time BAP, level 2 , in SBK, with mean travel time STV, level $2 \mathrm{a}$, in RVS, with mean travel time

$9.26 \mathrm{~min}$ $9.26 \mathrm{~min}$ $14.14 \mathrm{~min}$ $14.14 \mathrm{~min}$

$11.02 \mathrm{~min}$ $14.14 \mathrm{~min}$ $14.14 \mathrm{~min}$ $14.14 \mathrm{~min}$

$10.00 \mathrm{~min}$ $10.00 \mathrm{~min}$ $20.00 \mathrm{~min}$ $20.00 \mathrm{~min}$

$10.00 \mathrm{~min}$ $10.00 \mathrm{~min}$ $14.14 \mathrm{~min}$ $10.00 \mathrm{~min}$ $10.00 \mathrm{~min}$ $14.14 \mathrm{~min}$

$8.66 \mathrm{~min}$ $8.66 \mathrm{~min}$ $14.14 \mathrm{~min}$ UMC, level 1 , in SPF, with mean travel time

PKV victims will go to these hospitals UMC, level 1 , in SPF, with mean travel time MTH, level 3 , in SPF, with mean travel time BAP, level 2 , in SBK, with mean travel time STV, level 2a, in RVS, with mean travel time

LMT victims will go to these hospitals UMC, level 1 , in SPF, with mean travel time $M T H$, level 3 , in SPF, with mean travel time BAP, level 2 , in SBK, with mean travel time STV, level 2a, in RVS, with mean travel time OWY victims will go to these hospitals
$14.14 \mathrm{~min}$ $14.14 \mathrm{~min}$ $25.00 \mathrm{~min}$ $25.00 \mathrm{~min}$

14.14 min $14.14 \mathrm{~min}$ $25.00 \mathrm{~min}$ $25.00 \mathrm{~min}$ 
UMC, level 1 , in SPF, with mean travel time MTH, level 3 , in SPF, with mean travel time BAP, level 2 , in SBK, with mean travel time STV, level $2 a$, in RVS, with mean travel time $M M C$, level $2 a$, in SSD, with mean travel time ARL victims will go to these hospitals

UMC, level 1 , in SPF, with mean travel time MTH, level 3 , in SPF, with mean travel time BAP, level 2, in SBK, with mean travel time MMC, level $2 a$, in SSD, with mean travel time RGY victims will go to these hospitals

MMC, level 2a, in SSD, with mean travel time UMC, level 1 , in SPF, with mean travel time

ATB victims will go to these hospitals

$\mathrm{BCH}$, level $2 \mathrm{a}$, in $\mathrm{JXB}$, with mean travel time UMC, level 1 , in SPF, with mean travel time

JXB victims will go to these hospitals

$\mathrm{BCH}$, level $2 \mathrm{a}$, in $\mathrm{JXB}$, with mean travel time UMC, level 1 , in SPF, with mean travel time

SSD victims will go to these hospitals

MMC, level $2 a$, in SSD, with mean travel time STL, level 2a, in JTB, with mean travel time UMC, level 1, in SPF, with mean travel time

JTB victims will go to these hospitals

$S T L$, level $2 a$, in JTB, with mean travel time MMC, level 2a, in SSD, with mean travel time UMC, level 1 , in SPF, with mean travel time

$S P L$ victims will go to these hospitals

$B C H$, level $2 a$, in $J X B$, with mean travel time UMC, level 1, in SPF, with mean travel time

MND victims will go to these hospitals

STL, level $2 a$, in JTB, with mean travel time UMC, level 1, in SPF, with mean travel time

TMQ victims will go to these hospitals

STV, level $2 a$, in RVS, with mean travel time RVS, level 3 , in RVS, with mean travel time UMC, level 1 , in SPF, with mean travel time MTH, level 3 , in SPF, with mean travel time BAP, level 2 , in SBK, with mean travel time

WSD victims will go to these hospitals STV, level $2 a$, in RVS, with mean travel time RVS, level 3 , in RVS, with mean travel time HUM, level 2a, in OPW, with mean travel time UMC, level 1 , in SPF, with mean travel time $M T H$, level 3 , in SPF, with mean travel time BAP, level 2 , in SBK, with mean travel time

MWH victims will go to these hospitals

STV, level $2 \mathrm{a}$, in RVS, with mean travel time RVS, level 3 , in RVS, with mean travel time UMC, level 1 , in SPF, with mean travel time MTH, level 3, in SPF, with mean travel time BAP, level 2 , in SBK, with mean travel time

$M C L$ victims will go to these hospitals

STV, level $2 a$, in RVS, with mean travel time RVS, level 3 , in RVS, with mean travel time UMC, level 1 , in SPF, with mean travel time $M T H$, level 3 , in SPF, with mean travel time BAP, level 2 , in SBK, with mean travel time

BRY victims will go to these hospitals

STV, level $2 a$, in RVS, with mean travel time RVS, level 3 , in RVS, with mean travel time UMC, level 1 , in SPF, with mean travel time $M T H$, level 3 , in SPF, with mean travel time
$14.14 \mathrm{~min}$

$14.14 \mathrm{~min}$

$25.00 \mathrm{~min}$

$25.00 \mathrm{~min}$

$30.00 \mathrm{~min}$

$14.14 \mathrm{~min}$

$14.14 \mathrm{~min}$

$14.14 \mathrm{~min}$

$14.14 \mathrm{~min}$

14.14 min

$20.00 \mathrm{~min}$

$14.14 \mathrm{~min}$

$40.00 \mathrm{~min}$

$10.00 \mathrm{~min}$ $40.00 \mathrm{~min}$

$10.72 \mathrm{~min}$

$12.25 \mathrm{~min}$

$25.00 \mathrm{~min}$

$10.72 \mathrm{~min}$ $12.25 \mathrm{~min}$

$25.00 \mathrm{~min}$

$10.00 \mathrm{~min}$ $40.00 \mathrm{~min}$

$14.14 \mathrm{~min}$ $35.00 \mathrm{~min}$

$20.00 \mathrm{~min}$ $20.00 \mathrm{~min}$ $25.00 \mathrm{~min}$ $25.00 \mathrm{~min}$ $25.00 \mathrm{~min}$

$20.00 \mathrm{~min}$ $20.00 \mathrm{~min}$ $20.00 \mathrm{~min}$ $25.00 \mathrm{~min}$ $25.00 \mathrm{~min}$ $25.00 \mathrm{~min}$

$20.00 \mathrm{~min}$ $20.00 \mathrm{~min}$ $25.00 \mathrm{~min}$ $25.00 \mathrm{~min}$ $25.00 \mathrm{~min}$

$40.00 \mathrm{~min}$ $40.00 \mathrm{~min}$ $45.00 \mathrm{~min}$ $45.00 \mathrm{~min}$ $45.00 \mathrm{~min}$

$35.00 \mathrm{~min}$ $35.00 \mathrm{~min}$ $40.00 \mathrm{~min}$ $40.00 \mathrm{~min}$ 
BAP, level 2 , in SBK, with mean travel time

CAL victims will go to these hospitals

UMC, level 1 , in SPF, with mean travel time

MTH, level 3 , in SPF, with mean travel time

BAP, level 2 , in SBK, with mean travel time

STV, level 2a, in RVS, with mean travel time

MMC, level 2a, in SSD, with mean travel time

STL, level $2 a$, in JTB, with mean travel time

HIL victims will go to these hospitals

UMC, level 1, in SPF, with mean travel time

MTH, level 3 , in SPF, with mean travel time

BAP, level 2 , in SBK, with mean travel time

STV, level $2 \mathrm{a}$, in RVS, with mean travel time

RVS, level 3 , in RVS, with mean travel time

MMC, level 2a, in SSD, with mean travel time

$S T L$, level $2 a$, in JTB, with mean travel time

YUL victims will go to these hospitals

NGH, level 3 , in FDB, with mean travel time

UMC, level 1, in SPF, with mean travel time

BAP, level 2 , in SBK, with mean travel time

STV, level $2 a$, in RVS, with mean travel time

MMC, level 2a, in SSD, with mean travel time

STL, level $2 a$, in JTB, with mean travel time

FDB victims will go to these hospitals

NGH, level 3 , in FDB, with mean travel time

UMC, level 1, in SPF, with mean travel time

BAP, level 2 , in SBK, with mean travel time

STV, level $2 a$, in RVS, with mean travel time

MMC, level $2 \mathrm{a}$, in SSD, with mean travel time

$S T L$, level $2 a$, in JTB, with mean travel time

OPE victims will go to these hospitals

HUM, level $2 a$, in OPW, with mean travel time UMC, level 1 , in SPF, with mean travel time

OPW victims will go to these hospitals

HUM, level 2a, in OPW, with mean travel time UMC, level 1, in SPF, with mean travel time

GCS victims will go to these hospitals

HUM, level 2a, in OPW, with mean travel time PCH, level 3 , in PLK, with mean travel time UMC, level 1 , in SPF, with mean travel time

MBG victims will go to these hospitals

HUM, level $2 \mathrm{a}$, in OPW, with mean travel time UMC, level 1, in SPF, with mean travel time

PLK victims will go to these hospitals

$\mathrm{PCH}$, level 3 , in PLK, with mean travel time HUM, level 2a, in OPW, with mean travel time UMC, level 1, in SPF, with mean travel time

PVB victims will go to these hospitals $B C H$, level $2 a$, in $J X B$, with mean travel time UMC, level 1, in SPF, with mean travel time

SWZ victims will go to these hospitals

STL, level $2 a$, in JTB, with mean travel time FLG, level 3 , in STA, with mean travel time MMC, level $2 a$, in SSD, with mean travel time BAP, level 2 , in SBK, with mean travel time UMC, level 1 , in SPF, with mean travel time

STA victims will go to these hospitals

FLG, level 3 , in STA, with mean travel time $B C H$, level $2 a$, in $J X B$, with mean travel time $S T L$, level $2 a$, in JTB, with mean travel time UMC, level 1, in SPF, with mean travel time

CRB victims will go to these hospitals

FLG, level 3 , in STA, with mean travel time
40.00 min

$30.00 \mathrm{~min}$ $30.00 \mathrm{~min}$ $40.00 \mathrm{~min}$ 40.00 min $50.00 \mathrm{~min}$ 50.00 min

$45.00 \mathrm{~min}$ $45.00 \mathrm{~min}$ $55.00 \mathrm{~min}$ $55.00 \mathrm{~min}$ $55.00 \mathrm{~min}$ $65.00 \mathrm{~min}$ $65.00 \mathrm{~min}$

$25.00 \mathrm{~min}$ $35.00 \mathrm{~min}$ $45.00 \mathrm{~min}$ $45.00 \mathrm{~min}$ $50.00 \mathrm{~min}$ $55.00 \mathrm{~min}$

$14.14 \mathrm{~min}$ $55.00 \mathrm{~min}$ $65.00 \mathrm{~min}$ $65.00 \mathrm{~min}$ $70.00 \mathrm{~min}$ $75.00 \mathrm{~min}$

$14.14 \mathrm{~min}$ $40.00 \mathrm{~min}$

$12.25 \mathrm{~min}$ $40.00 \mathrm{~min}$

$30.00 \mathrm{~min}$ $35.00 \mathrm{~min}$ $55.00 \mathrm{~min}$

$25.00 \mathrm{~min}$ $60.00 \mathrm{~min}$

$17.50 \mathrm{~min}$ $60.00 \mathrm{~min}$ $85.00 \mathrm{~min}$

$14.14 \mathrm{~min}$ $50.00 \mathrm{~min}$

$35.00 \mathrm{~min}$ $40.00 \mathrm{~min}$ $42.50 \mathrm{~min}$ $45.00 \mathrm{~min}$ $55.00 \mathrm{~min}$

$19.37 \mathrm{~min}$ $50.00 \mathrm{~min}$ $65.00 \mathrm{~min}$ $85.00 \mathrm{~min}$

$25.00 \mathrm{~min}$ 
$B C H$, level 2a, in JXB, with mean travel time $S T L$, level $2 a$, in JTB, with mean travel time MMC, level $2 a$, in SSD, with mean travel time UMC, level 1 , in SPF, with mean travel time HST victims will go to these hospitals

FLG, level 3 , in STA, with mean travel time STL, level 2a, in JTB, with mean travel time $M M C$, level $2 a$, in SSD, with mean travel time $B A P$, level 2 , in SBK, with mean travel time $B C H$, level $2 a$, in $J X B$, with mean travel time HUM, level 2a, in OPW, with mean travel time UMC, level 1 , in SPF, with mean travel time KGB victims will go to these hospitals

NGH, level 3 , in FDB, with mean travel time UMC, level 1 , in SPF, with mean travel time MTH, level 3 , in SPF, with mean travel time BAP, level 2 , in SBK, with mean travel time STV, level 2a, in RVS, with mean travel time MMC, level 2a, in SSD, with mean travel time $S T L$, level $2 a$, in JTB, with mean travel time
$70.00 \mathrm{~min}$

$85.00 \mathrm{~min}$ $90.00 \mathrm{~min}$ $105.00 \mathrm{~min}$

$45.00 \mathrm{~min}$ $65.00 \mathrm{~min}$ $72.50 \mathrm{~min}$ $75.00 \mathrm{~min}$ $80.00 \mathrm{~min}$ $80.00 \mathrm{~min}$ $85.00 \mathrm{~min}$

$50.00 \mathrm{~min}$ $60.00 \mathrm{~min}$ $60.00 \mathrm{~min}$ $70.00 \mathrm{~min}$ $70.00 \mathrm{~min}$ $75.00 \mathrm{~min}$ $80.00 \mathrm{~min}$

Triage rule:

Champ TS $<=7.1$ goes to level $1,>7.4$ may go to level 3

Travel times exceeding minimum time by less than tolerance included in routine dispatch lists

hospital choice tolerance $30 \%$

ambulance choice tolerance $35 \%$

run 1

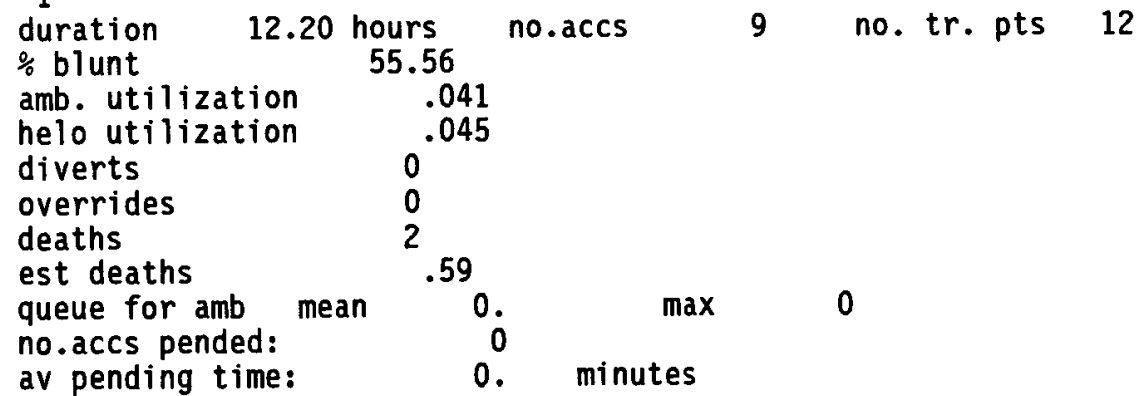

hospital utilization

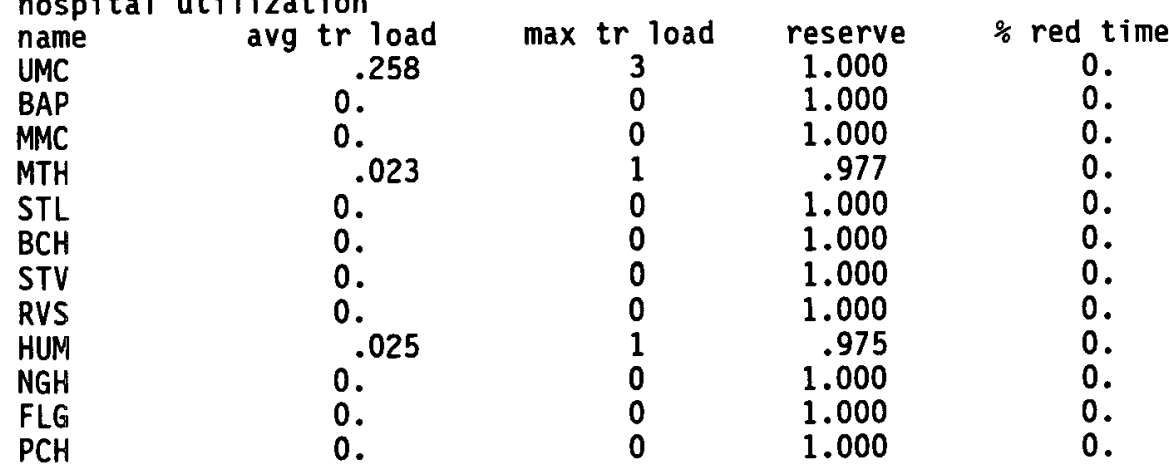

run 2

duration 18.58 hours no.accs 21 no.tr.pts 31

$\%$ blunt

52.38 


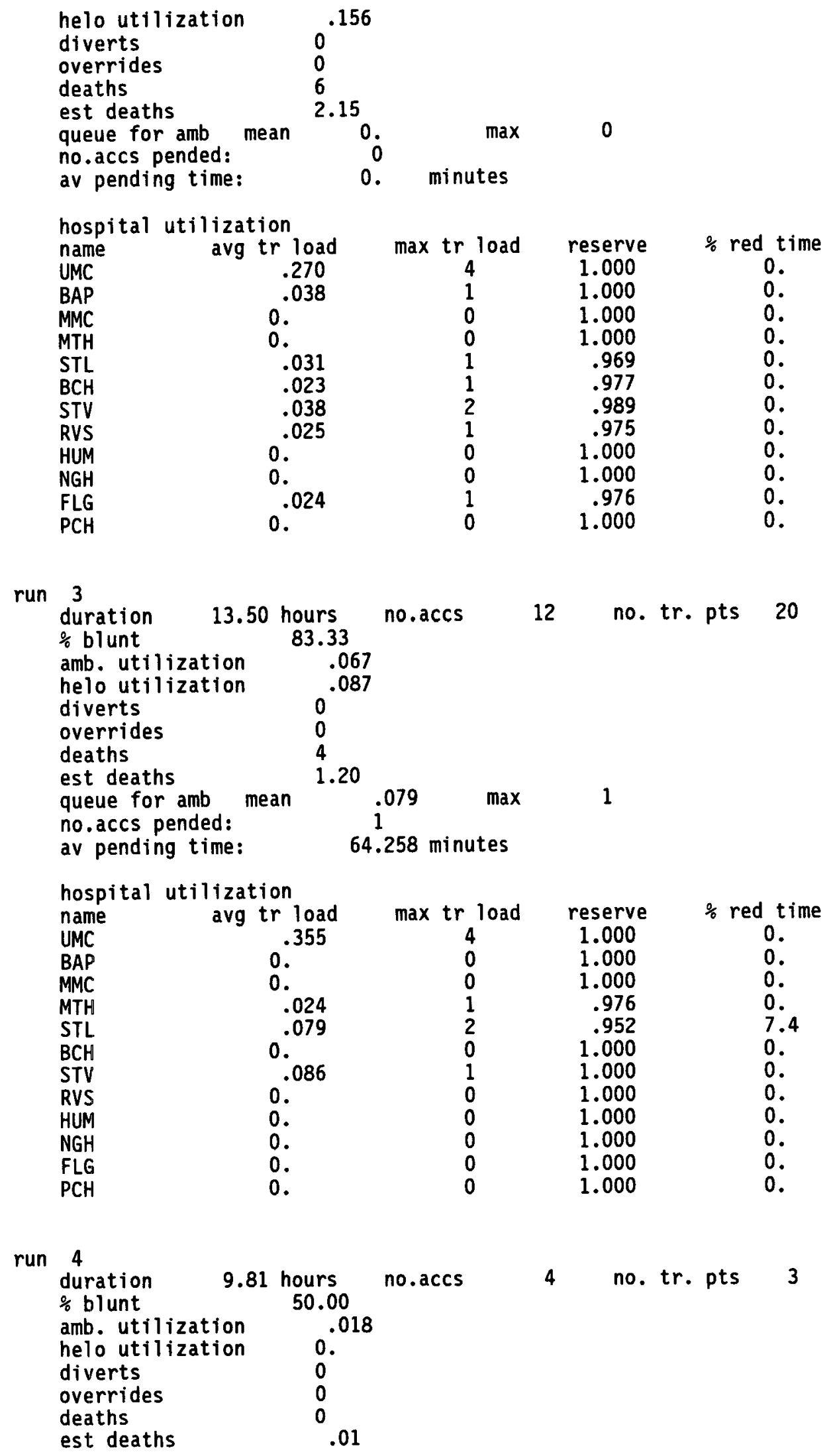




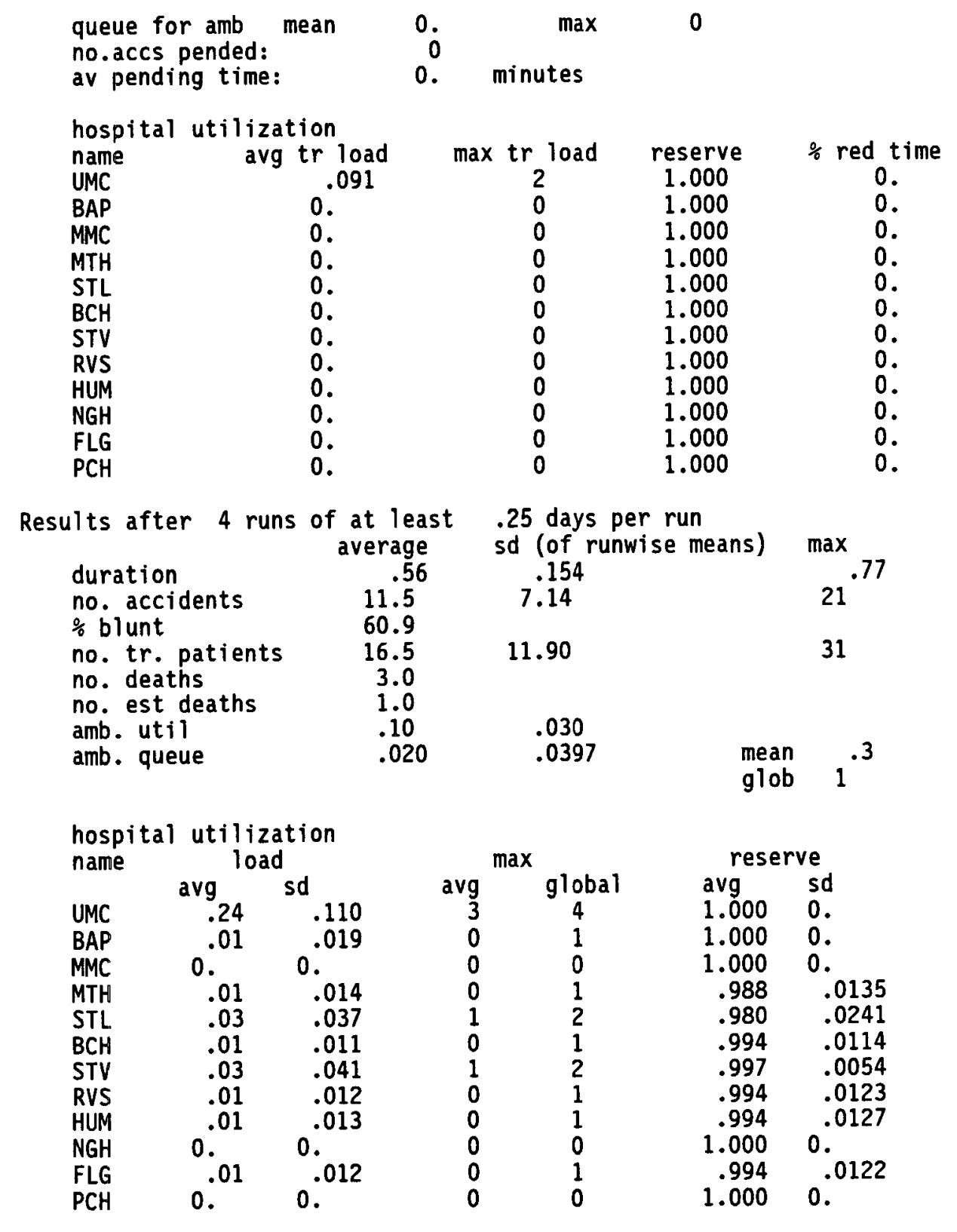




\section{Appendix 5}

Fitting Input Distributions

Time to secure

20 of 215 needed securing: model by beta(21, 196)

\begin{tabular}{lr} 
N OF CASE & \multicolumn{1}{c}{20} \\
MINIMUM & 0.830 \\
MAXIMUM & 32.770 \\
RANGE & 31.940 \\
MEAN & 6.150 \\
VARIANCE & 46.505 \\
STANDARD DEV & 6.819 \\
STD. ERROR & 1.525 \\
SKEWNESS(G1) & 3.141 \\
KURTOSIS(G2) & 9.933 \\
SUM & 123.000 \\
C.V. & 1.109 \\
MEDIAN & 4.230
\end{tabular}

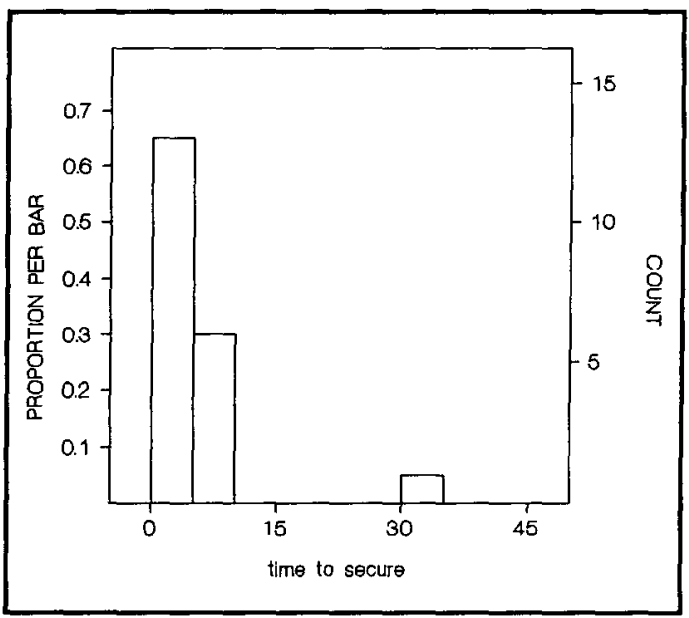

Figure 8. Distribution given need to secure.

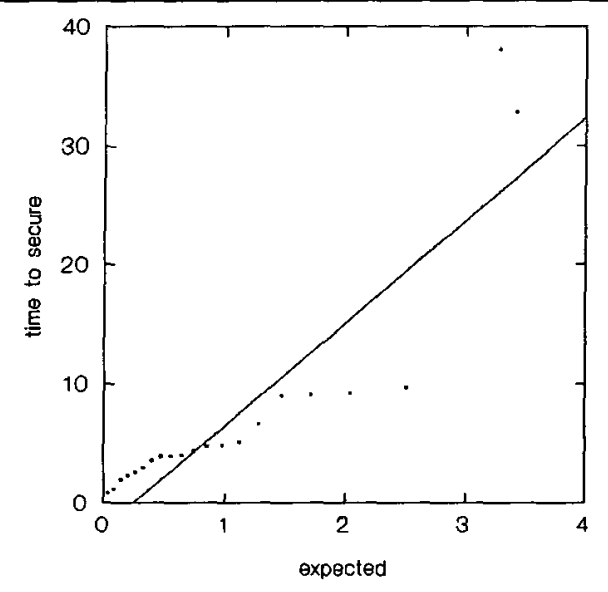

Figure 9. Probability plot: exponential.

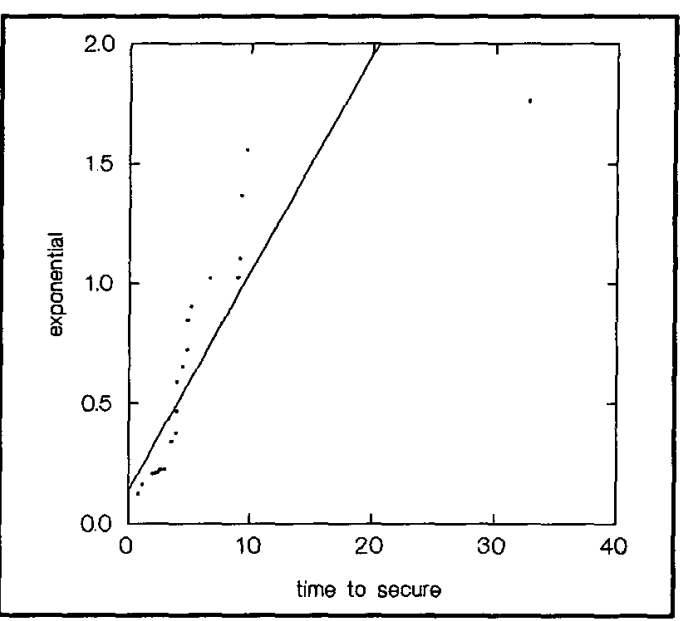

Figure 10. Quantile plot: exponential. 


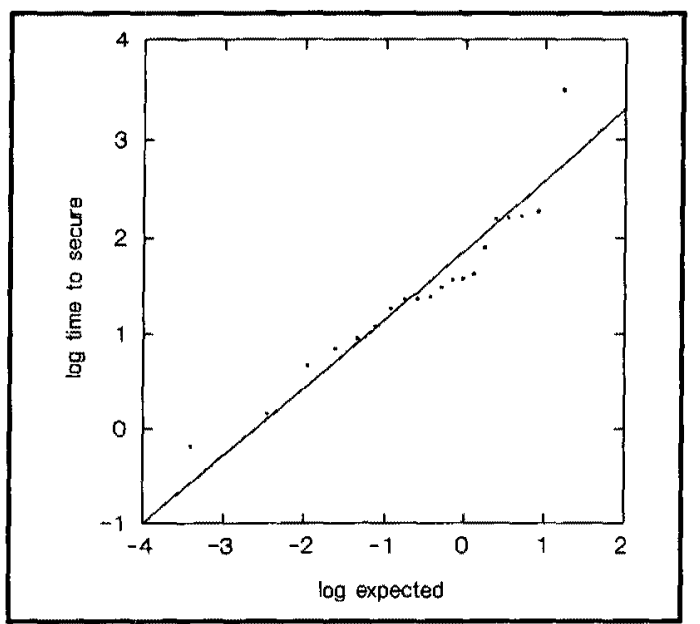

Figure 11. Probability plot: Weibull distribution.

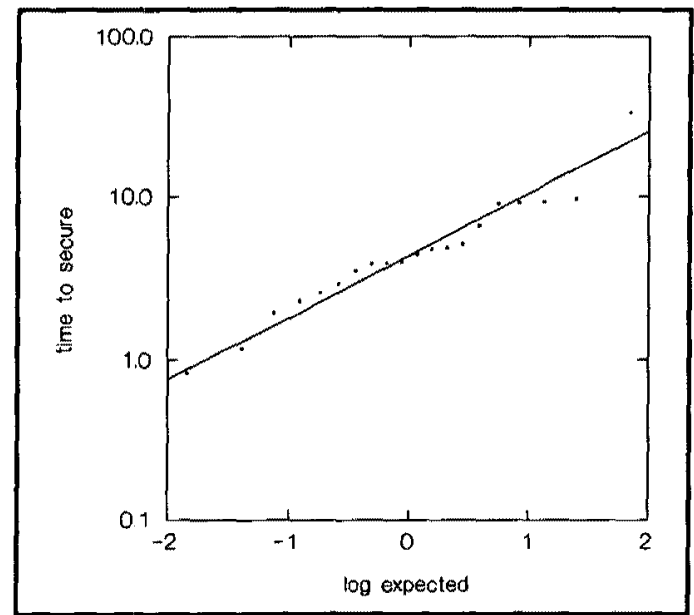

Figure 13. Probability plot: lognormal.

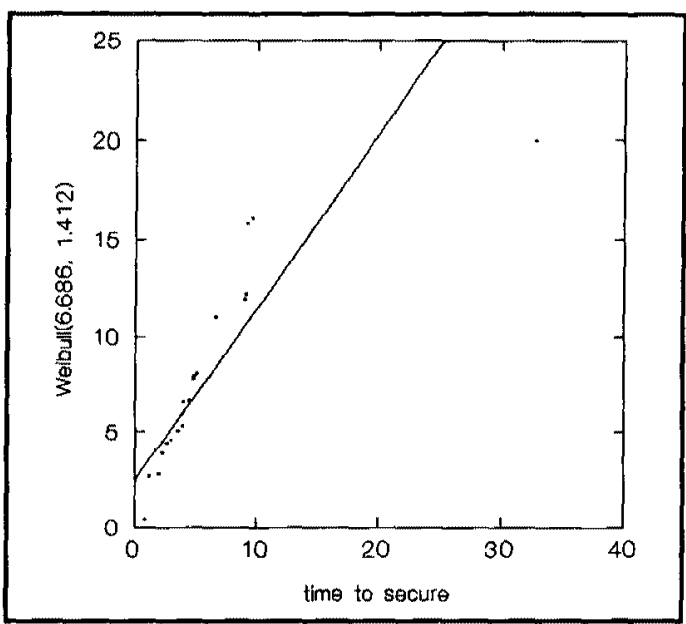

Figure 12. Quantile plot: Weibull (6.686, 1.412).

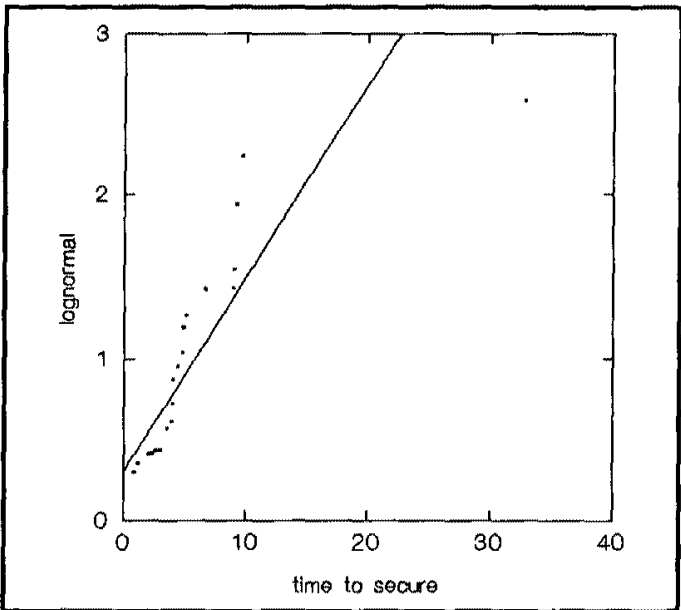

Figure 14. Quantile plot: lognormal. 
Time to patient found

\begin{tabular}{lr} 
N & \multicolumn{1}{r}{215} \\
MINIMUM & 0.050 \\
MAXIMUM & 12.920 \\
RANGE & 12.870 \\
MEAN & 2.220 \\
VARIANCE & 5.818 \\
STANDARD DEV & 2.412 \\
STD. ERROR & 0.165 \\
SKEWNESS (G1) & 1.696 \\
KURTOSIS (G2) & 2.697 \\
SUM & 477.380 \\
C.V. & 1.086 \\
MEDIAN & 1.120
\end{tabular}

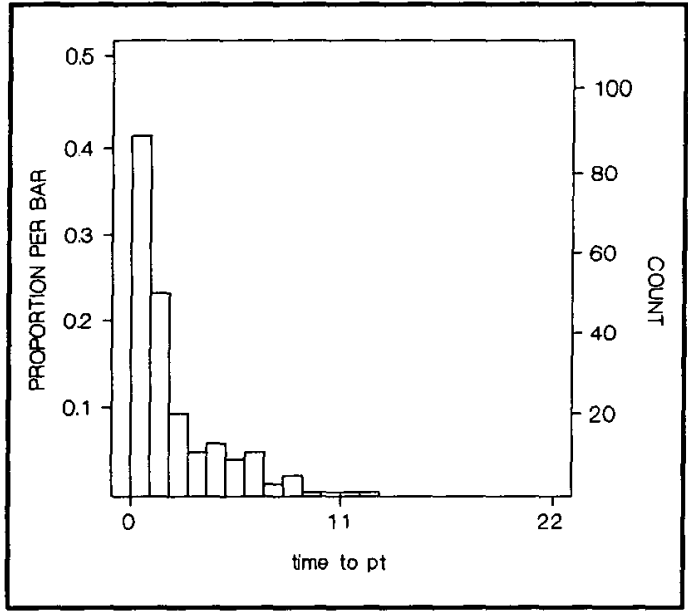

Figure 15. Distribution of time to patient.

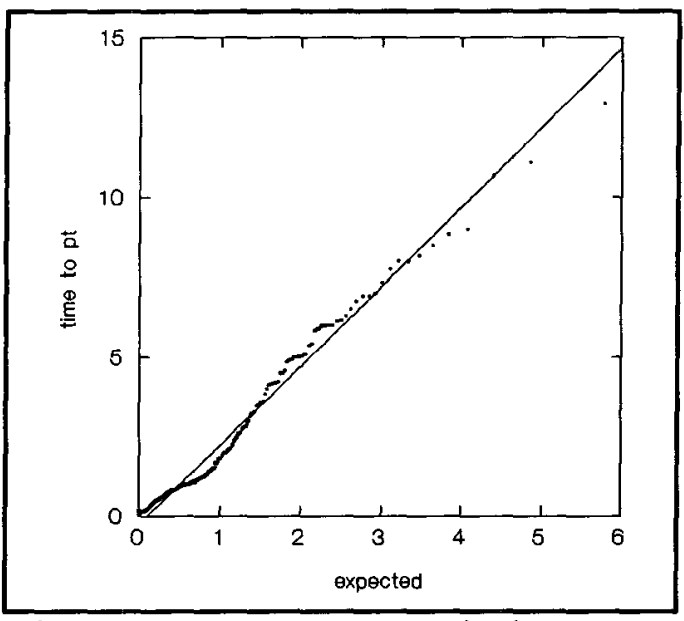

Figure 16. Probability plot: exponential.

Exponential fits very well.

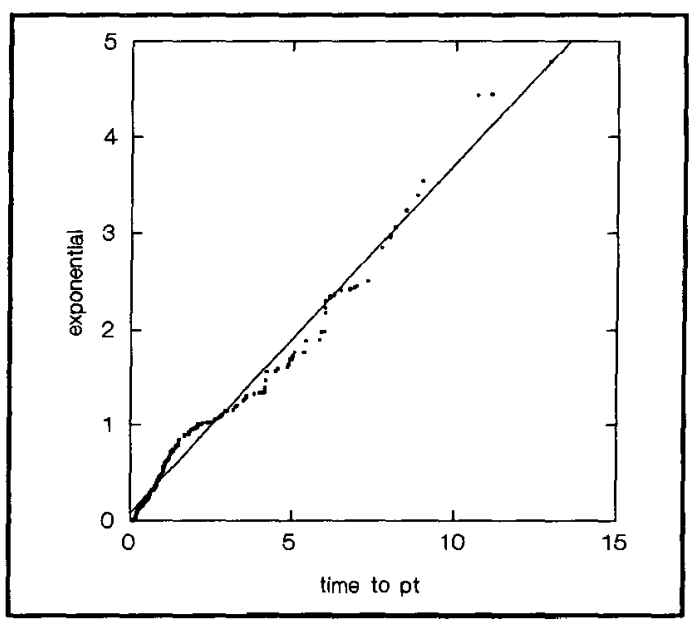

Figure 17. Quantile plot: exponential. 
Time on scene

Total scene time for those needing extrication and those not were not significantly different (Mann-Whitney $P=$ .15, Komolgorov-Smirnov $P=$ $.11)$.

\begin{tabular}{lr} 
N & \multicolumn{1}{c}{185} \\
MINIMUM & 1.000 \\
MAXIMUM & 30.830 \\
RANGE & 29.830 \\
MEAN & 10.404 \\
VARIANCE & 34.368 \\
STANDARD DEV & 5.862 \\
STD. ERROR & 0.431 \\
SKEWNESS(G1) & 1.149 \\
KURTOSIS (G2) & 1.394 \\
SUM & 1924.780 \\
C.V. & 0.563 \\
MEDIAN & 9.070
\end{tabular}

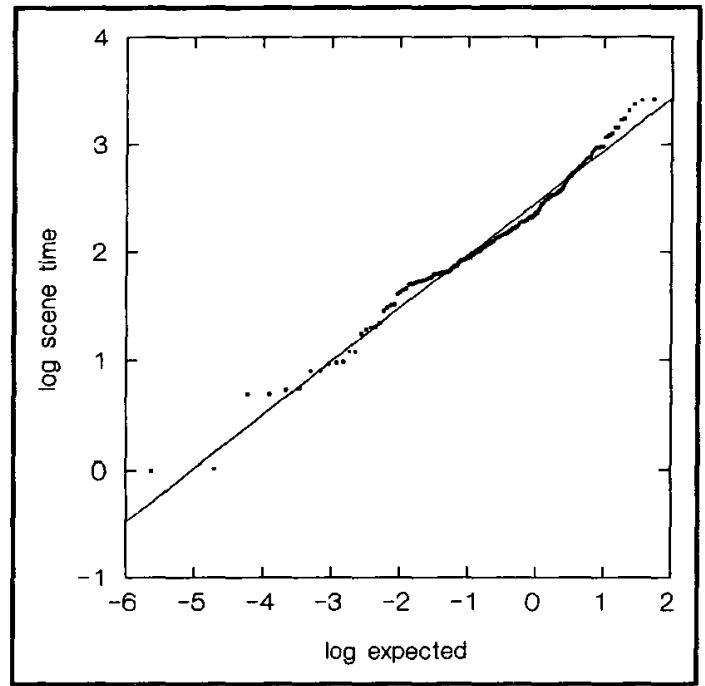

Figure 19. Probability plot: Weibull.

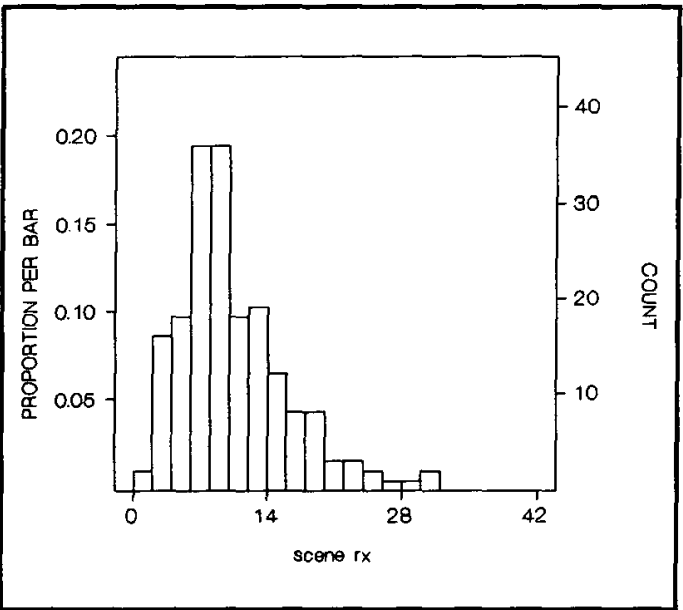

Figure 18. Distribution of scene treatment time (includes extrication if needed).

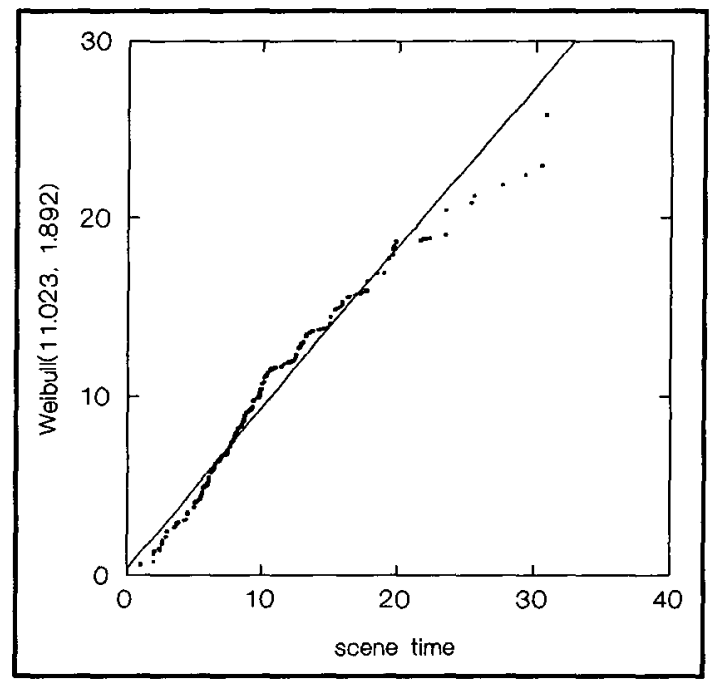

Figure 20. Quantile plot: Weibull(11.023, 1.892). 


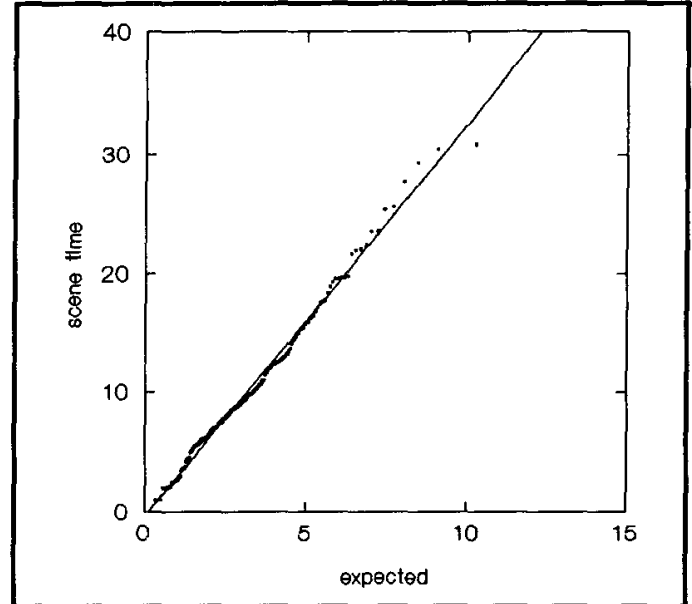

Figure 21. Probability plot: gamma (3).

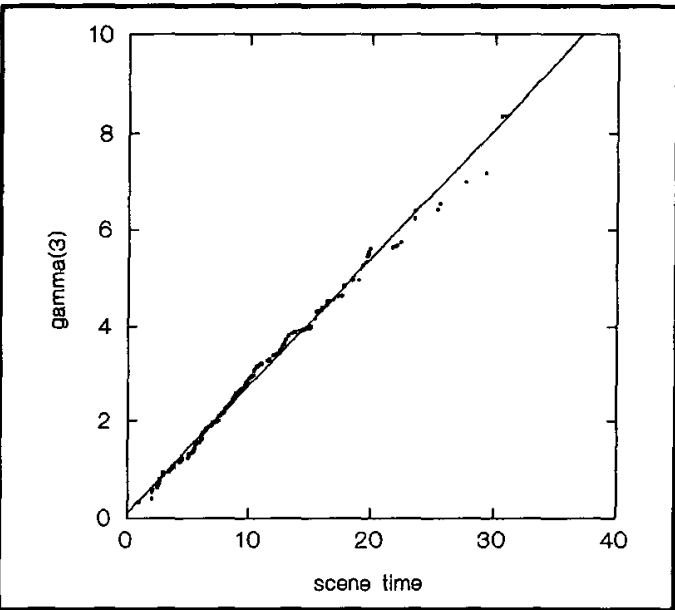

Figure 22. Quantile plot: gamma (3).

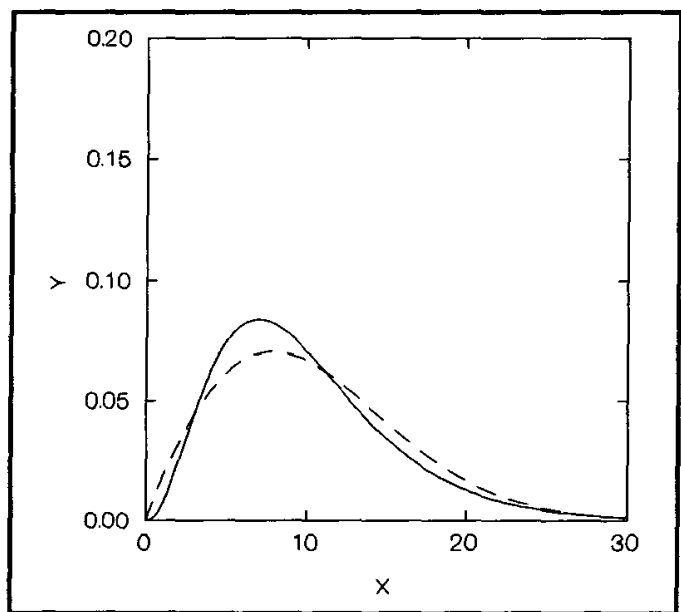

Figure 23. Weibull (dashed

line) and gamma pdf's. 
Time to hospital

\begin{tabular}{lr} 
N & \multicolumn{1}{r}{184} \\
MINIMUM & 1.370 \\
MAXIMUM & 37.230 \\
RANGE & 35.860 \\
MEAN & 10.295 \\
VARIANCE & 29.925 \\
STANDARD DEV & 5.470 \\
STD. ERROR & 0.403 \\
SKEWNESS (G1) & 1.072 \\
KURTOSIS(G2) & 2.268 \\
SUM & 1894.250 \\
C.V. & 0.531 \\
MEDIAN & 9.775
\end{tabular}

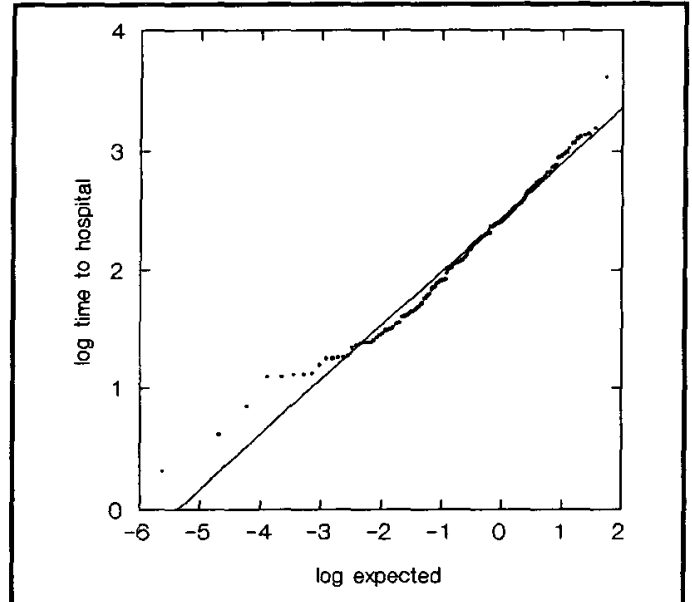

Figure 25. Probability plot: Weibull.

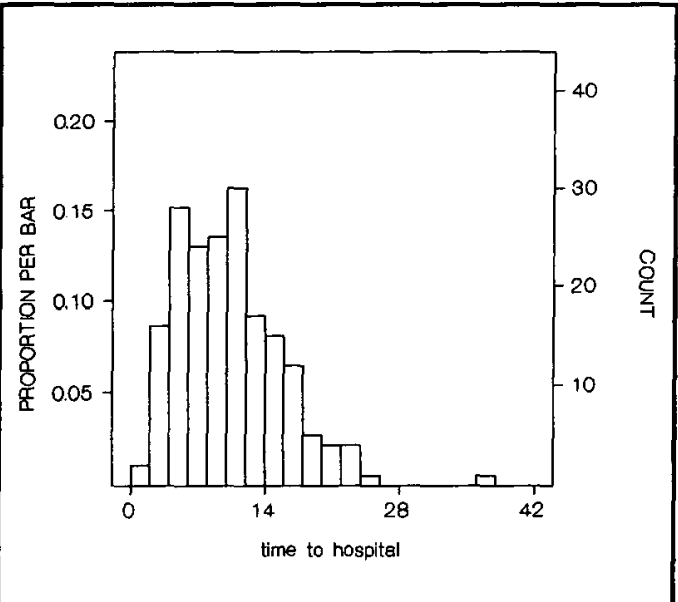

Figure 24. Distribution of time to hospital.

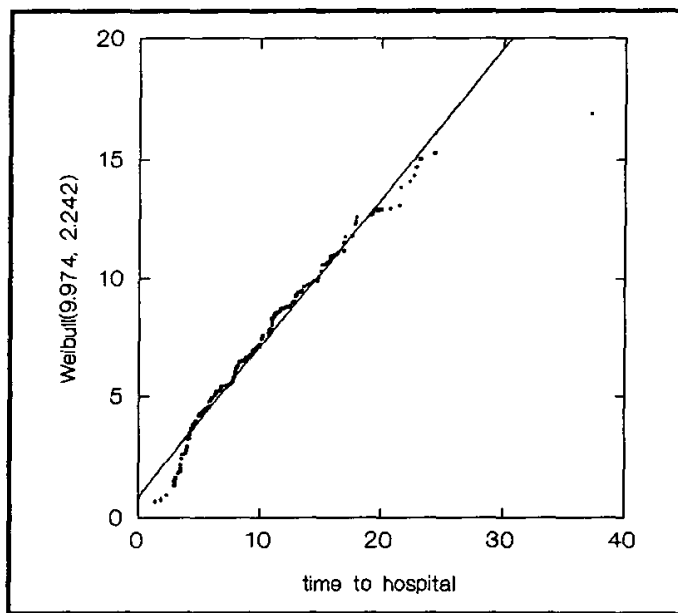

Figure 26. Quantile plot: Weibull $(9.974,2.242)$. 


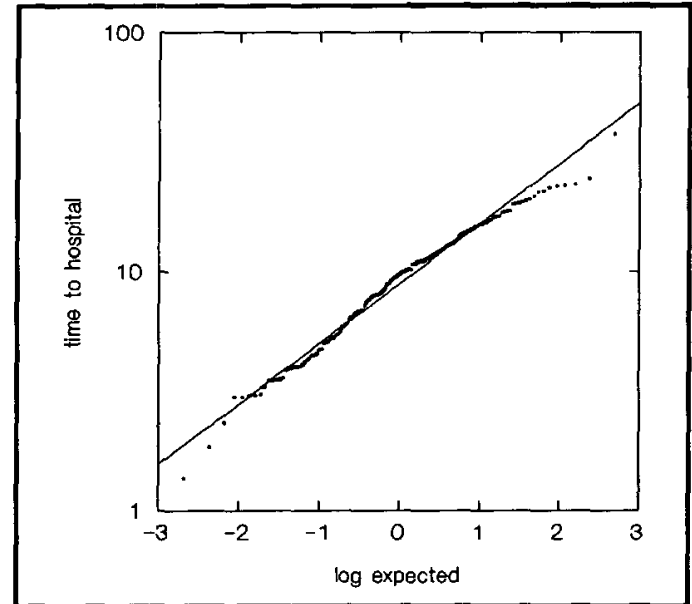

Figure 27. Probability plot: lognormal.

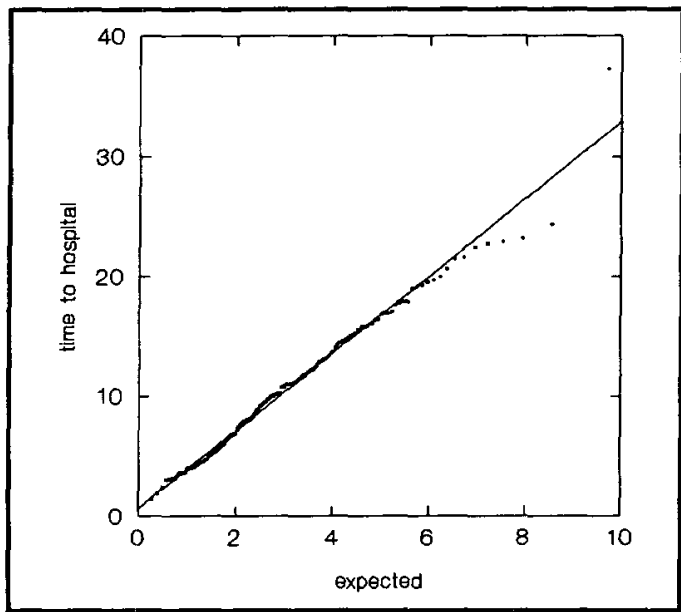

Figure 29. Probability plot: gamma(3).

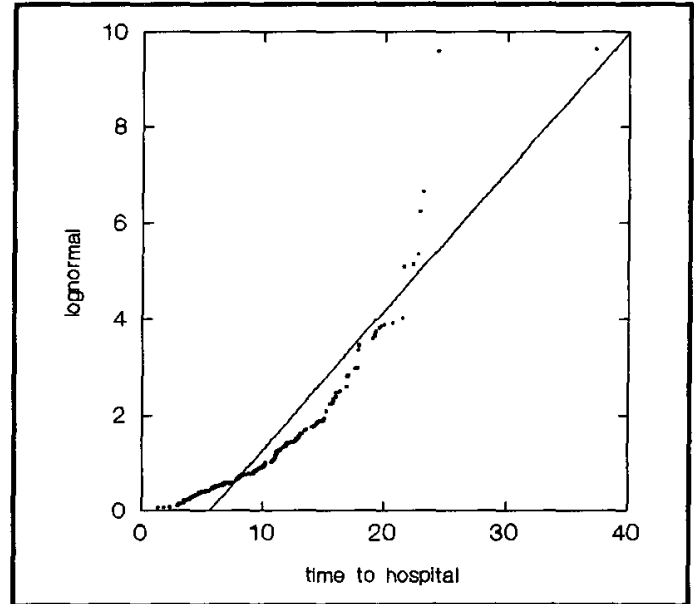

Figure 28. Quantile plot: lognormal.

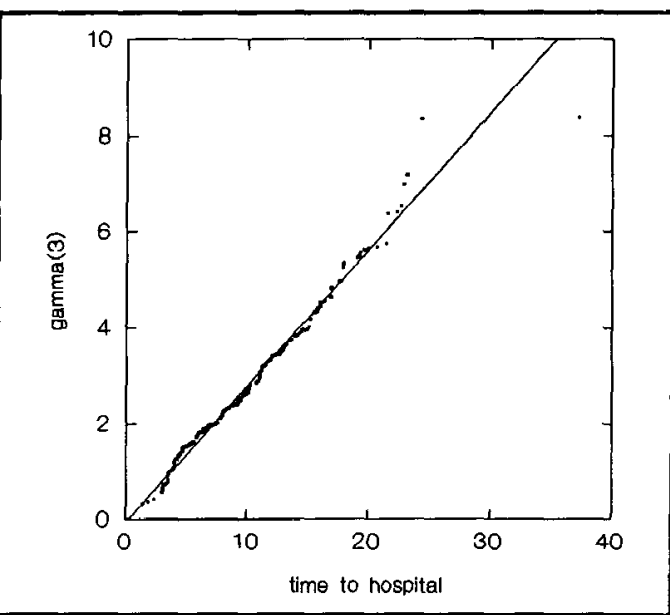

Figure 30. Quantile plot: gamma (3). 
Time to release of pt

\begin{tabular}{lr} 
N & \multicolumn{1}{r}{177} \\
MINIMUM & 0.270 \\
MAXIMUM & 12.000 \\
RANGE & 11.730 \\
MEAN & 2.598 \\
VARIANCE & 3.788 \\
STANDARD DEV & 1.946 \\
STD. ERROR & 0.146 \\
SKEWNESS (G1) & 2.366 \\
KURTOSIS (G2) & 7.257 \\
SUM & 459.880 \\
C.V. & 0.749 \\
MEDIAN & 2.070
\end{tabular}

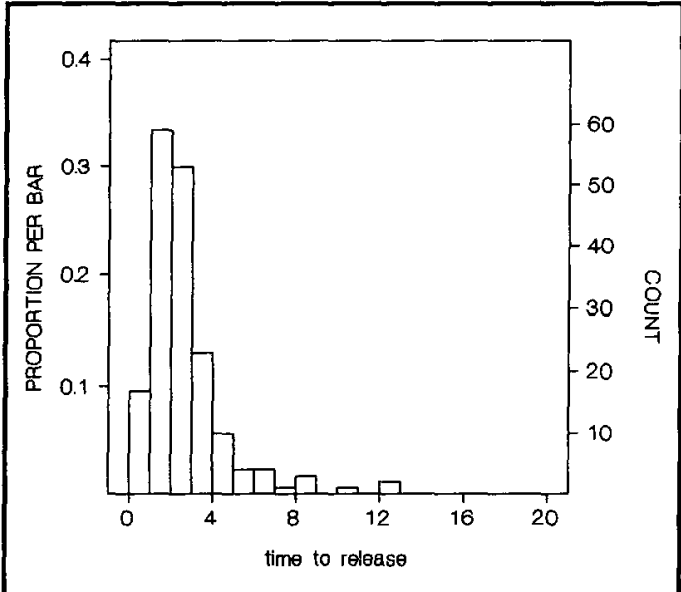

Figure 31. Distribution of time to release of patient.

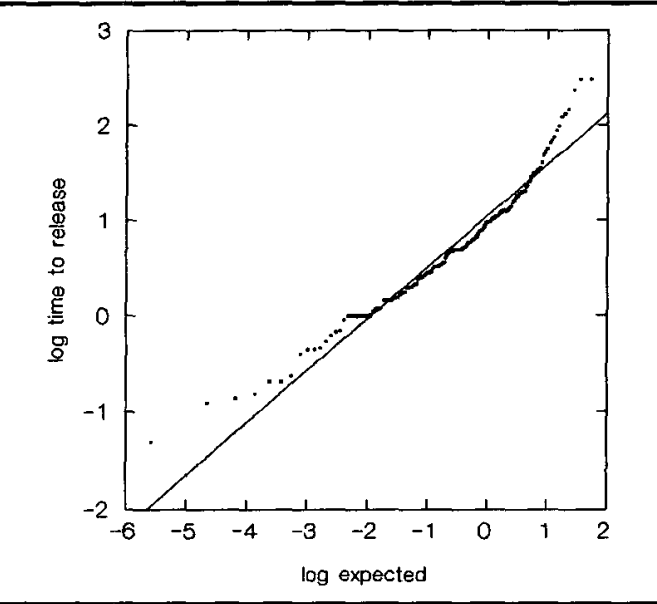

Figure 32. Probability plot: Weibull.

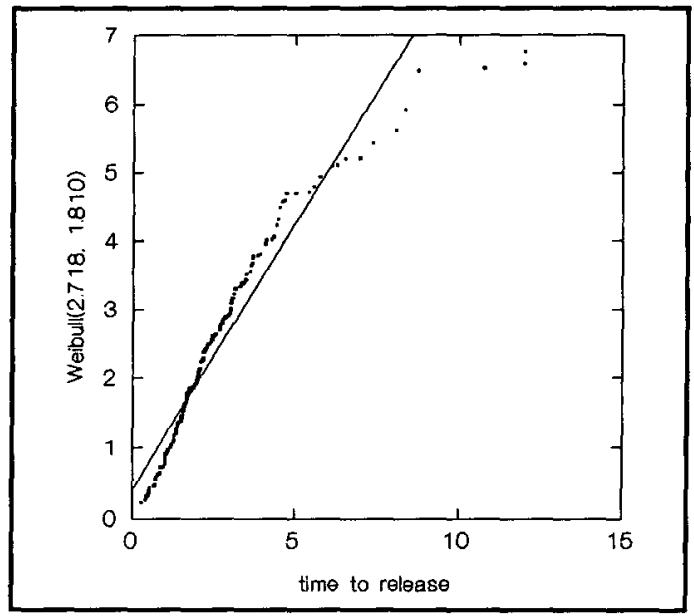

Figure 33. Quantile plot: Weibull $(2.718,1.810)$. 


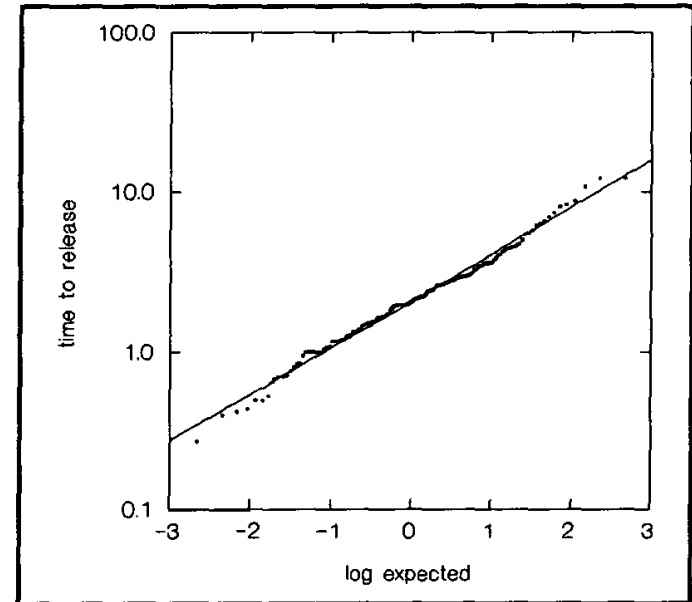

Figure 34. Probability plot: lognormal.

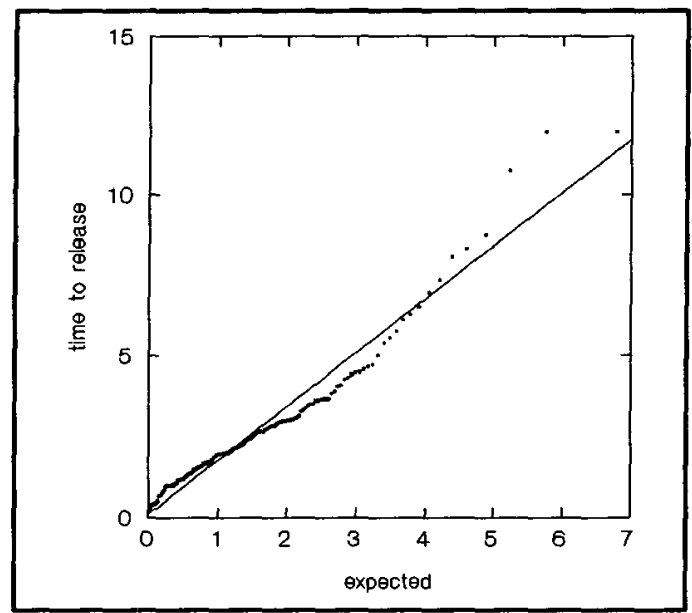

Figure 36. Probability plot: gamma.

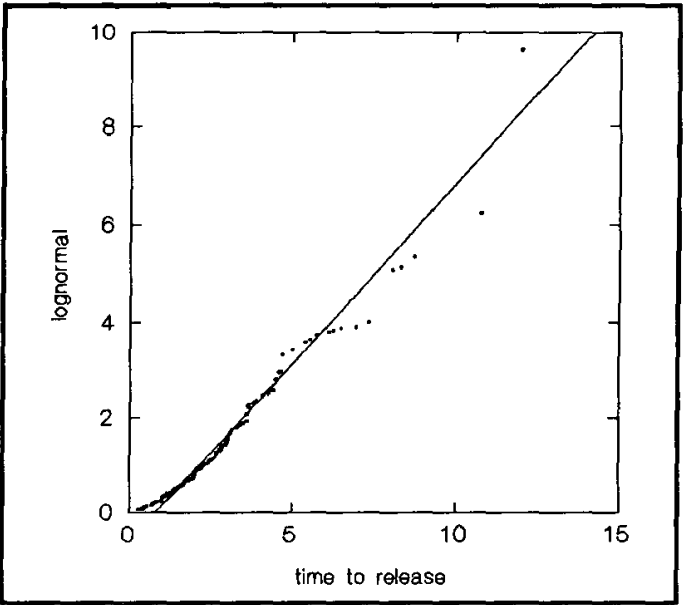

Figure 35. Quantile plot: lognormal.

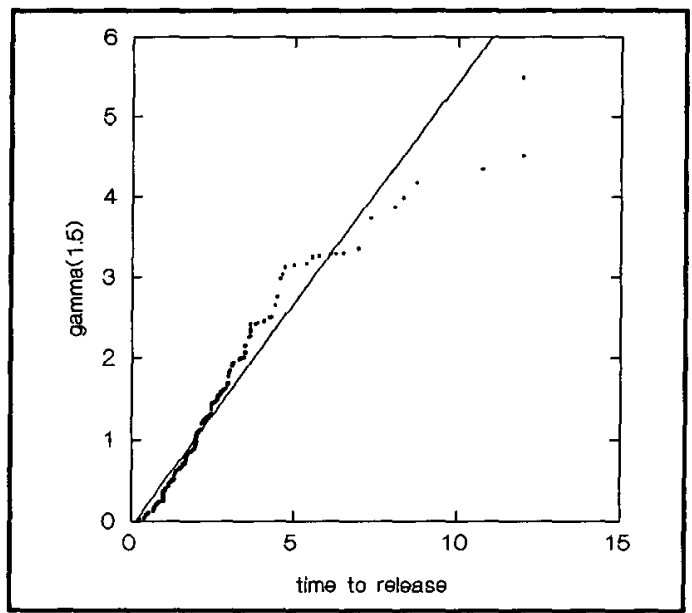

Figure 37. Quantile plot: gamma (1.5). 


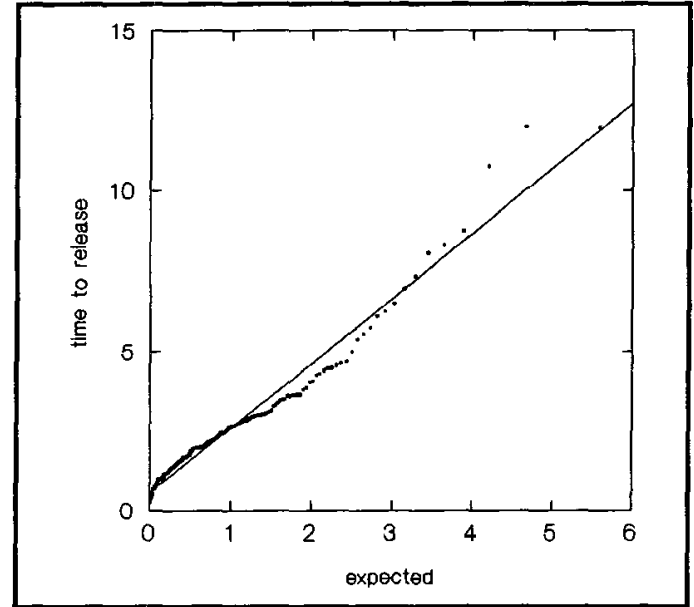

Figure 38. Probability plot: exponential.

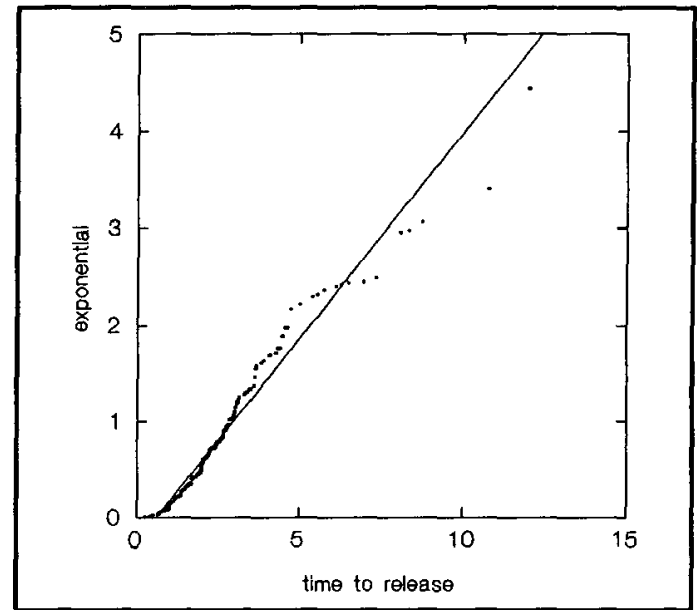

Figure 39. Quantile plot: exponential. 


\section{Appendix 6}

Log of Model Assumptions

\subsection{Distribution of Accidents}

It is assumed that the average number of accidents per unit time is unchanging; i.e., there is no long term growth or decline in the level of demand. Only the number of injuring incidents is assumed to vary with time and location; severity of injury and type of injury are assumed to be independent. Similarly, it is assumed that there is no interaction or synergism between time and location.

\subsection{Definitive Care Survival}

There is no assumption that patients receiving definitive care in a Level 1 center have increased survival compared to those in other centers (after adjusting for severity of injury). There are published reports that this may not be true (that Level 1 patients do better), so this assumption may need to be examined critically.

\subsection{Private Travel}

The function expressing the probability of private travel as inversely proportional to severity and between .30 and .01 is entirely empiric, based on experience, plausibility, and scant data suggesting that overall about one-fifth of non- 
trivial trauma patients find their own way to medical care. In addition, the model currently assumes that all patients involved in an accident make the same decision. This clearly plays a role in the real world model but is not completely valid. Other considerations, including proximity to a hospital and the actual activity producing the injury are also involved in as yet unspecified ways. 


\section{Appendix 7 \\ Log of Improvements and Enhancements}

\subsection{Improvements}

The following items (in no particular order) will enable the existing model to run more efficiently, more realistically, or be more be easily maintained, but do not add additional function.

7.1.1 Transit time. The permanent entity ambulance currently maintains the attribute of transit time. This is more realistically an attribute of an ambulance run process than it is of an ambulance, and in keeping with the second principle of section 4.2 should be moved to the process.

7.1.2 Choke points. Routines for building call and dispatch lists should take better account of the choke point variable than they do presently.

7.1.3 Events. Coding the respiratory support therapeutic interventions as events, rather than inserting them directly into either (or both) of the patient or ambulance run process routines allowed produced much cleaner, more easily maintained code. other critical therapeutic maneuvers such as IV starting or blood transfusion should be recoded into this form. 
7.1.4 End-of-run. The process of cancelling and then rescheduling the clear.reds event if another run follows the current should be changed to leave the event scheduled unless no runs are to follow.

7.1.5 Memory management. The duplicate representation of arcs in the current implementation requires large amounts of memory, leading to disk swapping and poor performance in large models. Since much of this information is redundant, and since it is infrequently referenced once the actual simulation begins, a more efficient representation should produce disproportionate benefits in run times.

\subsection{Enhancements}

The following items are additional (new) capabilities that would increase the utility of the model, but will be deferred at this time as they are not critical to the proof of concept.

7.2.1 Non-trauma patients. Information on medical patients handled by the system should be added to the model. In particular, some method of representing the "walk-in" medical load on emergency departments should be added as this is a major reason for a hospital's going on divert. For example, this could be done quite simply as a random external event, without having to explicitly model large numbers of "walk-in" patients. 
7.2.2 Injury model. Better and more detailed models of injury such as ASCOT [Champion90] are now available. Modification of the model to use ASCOT or a similar measure of injury severity might allow better prediction of outcome and identification of subsets of patients for whom special policies may be beneficial. The use of ASCOT, however, would require far more detailed epidemiologic information about injury patterns than is currently available, although it is being collected in the national Trauma Registry program of the American College of Surgeons (TRACS).

7.2.3 Transfers. While they are only a small fraction of the total volume of trauma patients, inter-hospital transfers are frequently a considerable source of contention. It would be desirable to model the transfer of patients among hospitals as representing an important aspect of the system, but it has proven extremely difficult to obtain reliable information, and what data is available is highly suspect as misleading at best.

7.2.4 Data editor. There is currently no support for creating the data files used to drive the simulation, nor is there any error checking for illogical or impossible conditions, e.g., a node with efferent but no afferent arcs. For complex models, creating the data files with a text can be tedious and prone to error; modification may be even more difficult. A data editor, particularly if it were able to graphically represent the transportation network, would make 
the model much easier to use. Error checking could be provided along with the editing function to ensure that the files finally submitted to the model did not contain logical errors.

7.2.5 Graphical output. Although it may restrict portability somewhat, a graphical display of system activity may be useful in establishing face validity of the model.

7.2.6 Trace control. Currently, the trace output is "all or nothing," making it unwieldy when the region of interest lies deep in a long run or series of runs. The ability to turn the trace on or off from within the program would enhance the usefulness of the trace.

\subsubsection{Interruption. Direct (paired) comparison of} regenerative method simulation data must be done at comparable points in each experimental arm. The number and location of such points is unpredictable, and they become fewer and are spread farther apart as the number of arms in an experiment increases. It would therefore be advantageous to make model runs interruptible, so that if there were not sufficient convergence points for analysis after some period of simulated time, the model could be restarted at that point and run further forward. Since the simulation mechanism is regenerative, this can in principle be done manually simply by preserving the random number seeds (or choosing different random number generators altogether) and 
starting another series of runs with the RNG's reset and time.v set to its value at the end of the previous corresponding run.

7.2.8 Non-regenerative Simulation. The difficulties of statistical analysis of the regenerative method data suggest that it might be advantageous to abandon this method in favor of traditional non-terminating simulation analysis of steady-state cycle parameters. This would require analysis of the startup transients which has not been performed for this model. It is not clear whether this would increase or decrease the required length of the simulation. 


\section{Appendix 8}

Log of Program Bugs

\subsection{Discrete-continuous Interaction}

A variety of hard-to-diagnose problems sometimes appear when the discrete simulation portions of the program interact with the continuous simulation portions. For example, if the minimum step size for the integrator routine in the continuous simulation modules is too large, it is at least theoretically possible for the two sections to become unsynchronized. While it is felt that most of the areas at risk have been protected by a combination of local code and by a policy of keeping the maximum step size small, confidence in the model's reliability would be significantly enhanced by systematically eliminating potential areas of interaction.

\subsection{Pended Accidents}

The dispatcher currently only checks the first accident in the pending set when a new ambulance becomes available; the entire set should be checked. Since, under the conditions modeled for northeast Florida, the pending set virtually never contains more than one accident, this error was not initially apparent. 


\section{Vita}

Robert L. Wears has BA and MD degrees from the Johns Hopkins University (1969 and 1973, respectively). He is currently Associate Professor in the Department of Surgery, Division of Emergency Medicine at the University of Florida Health Science Center in Jacksonville, and expects to receive an MS in computer and Information Sciences from the University of North Florida on April 30, 1993.

Robert has extensive interests in the application of computer-based modeling and analysis techniques to clinical and health policy problems, and has published several examples of their use in the medical literature with Dr. Charles N. Winton, his thesis advisor. His work includes statistical and connectionist approaches to computer modeling, with extensive experience in $\mathrm{C}$, SYSTAT, and SIMSCRIPT. He has developed a fellowship in medical informatics for graduate physicians, installed the first LAN at UFHSC-Jax, and is active in promoting the application of modern information methods in the clinical setting.

Dr. Wears has been married to his first wife for 21 years, and has two teenage children, a dog, a fish, and is a raving windsurfer. 